\title{
RECEIVED
}

OCT 301996

OSTI

\section{In Situ Rheology and Gas Volume in Hanford Double-Shell Waste Tanks}
C. W. Stewart
R. E. Mendóza
J. M. Alźheimer
H. C. Reid
M. E. Brewster
C. L. Shepard
G. Chen
G. Terrones

September 1996

Prepared for the U.S. Department of Energy under Contract DE-AC06-76RLO 1830

Pacific Northwest National Laboratory Operated for the U.S. Department of Energy by Battelle 


\section{DISCLAIMER}

This report was prepared as an account of work sponsored by an agency of the United States Government. Neither the United States Government nor any agency thereof, nor Battelle Memorial Institute, nor any of their employees, makes any warranty, express or implied, or assumes any legal liability or responsibility for the accuracy, completeness, or usefulness of any information, apparatus, product, or process disclosed, or represents that its use would not infringe privately owned. rights. Reference herein to any specific commercial product, process, or service by . trade name, trademark, manufacturer, or otherwise does not necessarily constitute or imply its endorsement, recommendation, or favoring by the United States Government or any agency thereof, or Battelle Memorial institute. The views and opinions of authors expressed herein do not necessarily state or reflect those of the United States Government or any agency thereof.

\section{$\therefore \quad$ PACIFIC NORTHWEST NATIONAL LABORATORY \\ operated by \\ BATTELLE \\ for the \\ UNITED STATES DEPARTMENT OF ENERGY \\ under Contract DE-AC06-76RLO 1830}

Printed in the United States of America

Available to DOE and DOE contractors from the

Office of Scientific and Technical Information, P.O. Box 62, Oak Ridge, TN 37831; prices available from (615) 576-8401.

Available to the public from the National Technical Information Service, U.S. Department of Commerce, 5285 Port Royal Rd., Springfield; VA 22161 


\section{In Situ Rheology and Gas Volume in Hanford Double-Shell Waste Tanks}
C. W. Stewart
R.E. Mendoza ${ }^{(a)}$
J. M. Alzheimer
H.C. Reid
M. E. Brewster
C. L. Shepard
G. Chen
G. Terrones

September 1996

Prepared for

the U.S. Department of Energy

under Contract DE-AC06-76RLO 1830

Pacific Northwest National Laboratory

Richland, Washington 99352

(a) Westinghouse Hanford Company 


\section{DISCLAIMER}

Portions of this document may be illegible in electronic image products. Images are produced from the best available original document. 


\section{DISCLAIMER}

This report was prepared as an account of work sponsored by an agency of the United States Government. Neither the United States Government not any agency thereof, nor any of their employees, makes any warranty, express or implied, or assumes any legal liability or responsibility for the accuracy, completeness, or usefulness of any information, apparatus, product, or process disclosed, or represents that its use would not infringe privately owned rights. Reference herein to any specific commercial product, process, or service by trade name, trademark, manufacturer, or otherwise does not necessarily constitute or imply its endorsement, recommendation, or favoring by the United States Government or any agency thereof. The views and opinions of authors expressed herein do not necessarily state or reflect those of the United States Government or any agency thereof. 


\section{Summary}

This report presents the results derived from operating the ball theometer and void fraction instrument (VFI) in Hanford waste tanks 241-SY-101, SY-103, AW-101, AN-103, AN-104, and AN-105 from December 1994 through July 1996. The VFI and ball rheometer were designed late in 1993 to show that Tank SY-101 was indeed mitigated by the mixer pump and to determine which of the other tanks on the flammable gas watch list (FGWL) might require similar treatment. Evaluating the flammable gas hazard in a particular tank requires an estimate of the volume of gas retained, the fraction of the retained gas that can be released, and how rapidly it might enter the tank headspace in relation to the ventilation rate. The strength and viscosity of the nonconvective waste in which the gas is stored must also be known to understand the gas release mechanisms and to predict potential release volumes and rates. The ball rheometer and VFI enable us to obtain these data in situ.

The ball rheometer consists of a $71-\mathrm{N}(16 \mathrm{lb}), 9.12$-cm-diameter tungsten alloy ball . tethered to a steel cable that is let out and retrieved from a spool at precise speeds using a computercontrolled drive system. A load cell measures the tension on the cable. The rheology and density of the waste and the waste layering can be estimated directly from the drag force on the ball as it moves through the waste at various speeds. The ball is generally operated before the VFI to confirm the expected waste layering and to prevent surprises from unanticipated waste conditions that would require the VFI test plan to be adjusted.

The VFI measures the volume fraction of free (undissolved) gas, or void, at specific locations in a tank. It does not sense gas composition; and its response is very nearly independent of gas composition. The local void fraction is calculated from the initial and final pressures and temperatures after compressing waste captured in a leak-tight sample chamber with nitrogen gas from a precisely measured supply volume. The sample chamber is mounted on a rotating arm that is inserted vertically into a riser with a crane. Once below the waste surface, the arm is rotated 90 degrees to a horizontal position and lowered, with the sample chamber cover open, to the desired location in the waste. There the cover is closed to capture and compress a sample, after which the cover is opened and the arm lowered to the next sampling location. The VFI can take measurements over a radius of $76 \mathrm{~cm}$ (30 in.) about the riser center about every 30 to $60 \mathrm{~cm}$ (12-24 in.) of elevation.

The VFI and the ball rheometer have been operated in the six FGWL double-shell tanks over the time period from December 1994 to May 1996. The deployment history of both instruments is given in the following table:

\section{Ball Rheometer and VFI Deployment History}

\begin{tabular}{|l|c|c|}
\hline Tank & Ball Rheometer & VFI \\
\hline SY-101 & $3 / 27,4 / 5 / 95$ & $12 / 21 / 94,1 / 17 / 95$ \\
\hline SY-103 & $7 / 14,8 / 8 / 95$ & $7 / 19,8 / 18 / 95$ \\
\hline AW-101 & $9 / 18,9 / 20 / 95$ & $9 / 22,9 / 24 / 95$ \\
\hline AN-105 & $12 / 15,12 / 18 / 95$ & $12 / 20,12 / 22 / 95$ \\
\hline AN-104 & $3 / 27,4 / 1 / 96$ & $4 / 2,4 / 4 / 96$ \\
\hline AN-103 & $5 / 6,5 / 10 / 96$ & $5 / 14,5 / 16 / 96$ \\
\hline
\end{tabular}


The viscosity of the supernatant liquid in the convective layer ranged from $6-50 \mathrm{cP}$ in all tanks except SY-101, where the mixed slurry created by repeated pump operation showed a viscosity of about $1,000 \mathrm{cP}$. The apparent viscosity derived from ball rheometer in the nonconvective layer ranges from $\sim 7\left(10^{6}\right)$ to $\sim 2\left(10^{7}\right) \mathrm{cP}$ (at a ball speed of $0.1 \mathrm{~cm} / \mathrm{s}$ ) with increasing depth in all tanks. The apparent viscosity decreases each time the ball passes through it, reaching about an order of magnitude lower after.4-8 passes. Except for AN-103 and SY-103, the estimated yield stress profiles are equivalent within their uncertainty, increasing from $50 \mathrm{~Pa}$ to $250 \mathrm{~Pa}$ with depth. In AN-103 the yield stress was sufficiently high to support the ball at $200 \mathrm{~cm}$ above the bottom; in SY-103, the ball was supported at $120 \mathrm{~cm}$. A yield stress of about $900 \mathrm{~Pa}$ is required to support the ball.

AN-103 has the highest convective layer density at $1.5 \mathrm{~g} / \mathrm{cm}^{3}$. In the other tanks, liquid density ranges from 1.43 to $1.47 \mathrm{~g} / \mathrm{cm}^{3}$. AN-103 also has the highest nonconvective layer density at $1.8 \mathrm{~g} / \mathrm{cm}^{3}$; other tanks show just under $1.6 \mathrm{~g} / \mathrm{cm}^{3}$. The density of the mixed slurry in SY-101 is about $1.6 \mathrm{~g} / \mathrm{cm}^{3}$. The combination of liquid and nonconvective layer densities gives AN-103 the highest neutral buoyancy void fraction of 0.15 ; the next highest is AN-105 with 0.10 , and the lowest is 0.06 in SY-103.

The gas volume is calculated from the average void fraction, which is computed with the analysis of variance (ANOVA) statistical procedure using a model that captures the major sources of uncertainty. The waste is divided into vertical layers so that the void fraction within each layer under a riser can be assumed uniform. The layers are chosen to be consistent with the overall waste configuration. The entire convective layer is treated as a single layer extending from the estimated base of the crust to the approximate top of the nonconvective layer. The nonconvective layer is split into two or three sublayers with boundaries determined by a visual interpretation of. the variation in void fraction to yield a fairly uniform vertical void distribution in each riser. The gas volume stored in the crust layer is estimated from the crust thickness and the void fraction required to make it float.

The gas volumes (at 1 atmosphere pressure and $15^{\circ} \mathrm{C}$ ) and other data for each tank are summarized in the table below. AN-103 contained by far the most gas, comparable to SY-101 prior to mixing. AW-101 has the least gas in the nonconvective layer (not counting SY-101), but tanks AN-104, AN-105, AW-101, and SY-103 have very similar total gas volumes.

Gas Volume Summary

\begin{tabular}{|c|c|c|c|c|c|c|}
\hline & AN-103 & AN-104 & AN-105 & AW-101 & SY-101 & SY-103 \\
\hline $\begin{array}{l}\text { Waste Level (cm) } \\
\text { Solids Level (cm) } \\
\text { Crust Thickness (cm) }\end{array}$ & $\begin{array}{c}884 \\
378 \\
92\end{array}$ & $\begin{array}{r}979 \\
410 \\
40\end{array}$ & $\begin{array}{c}1041 \\
450 \\
30\end{array}$ & $\begin{array}{c}1040 \\
280 \\
64\end{array}$ & $\begin{array}{l}1019 \\
200 \\
102\end{array}$ & $\begin{array}{c}691 \\
345 \\
20\end{array}$ \\
\hline $\begin{array}{l}\text { Conv. Density }\left(\mathrm{kg} / \mathrm{m}^{3}\right) \\
\text { Nonconv. Density }\left(\mathrm{kg} / \mathrm{m}^{3}\right) \text {, } \\
\text { Mean Void (\%) }\end{array}$ & $\begin{array}{l}1530 \\
1800 \\
12.2 \\
\end{array}$ & $\begin{array}{c}1440 \\
1590 \\
5.9\end{array}$ & $\begin{array}{c}1430 \\
1590 \\
3.8 \\
\end{array}$ & $\begin{array}{c}1430 \\
1570 \\
4.7 \\
\end{array}$ & $\begin{array}{c}1600 \\
1700 \\
\text { n/a }\end{array}$ & $\begin{array}{c}1470 \\
1570 \\
6.2 \\
\end{array}$ \\
\hline $\begin{array}{l}\text { Crust Gas Volume }\left(\mathrm{m}^{3}\right) \\
\text { Conv. Layer Gas Vol. }\left(\mathrm{m}^{3}\right) \\
\text { Nonconv. Layer Gas Vol. }\left(\mathrm{m}^{3}\right)\end{array}$ & $\begin{array}{r}91 \\
10 \\
363 \\
\end{array}$ & $\begin{array}{c}39 \\
11 \\
197 \\
\end{array}$ & $\begin{array}{c}30 \\
7 \\
148 \\
\end{array}$ & $\begin{array}{c}63 \\
32 \\
115 \\
\end{array}$ & $\begin{array}{c}100 \\
33 \\
84 \\
\end{array}$ & $\begin{array}{c}20 \\
6 \\
150 \\
\end{array}$ \\
\hline Total Gas Volume $\left(\mathrm{m}^{3}\right)$ & 464 & 247 & 184 & 209 & 218 & 176 \\
\hline Head Space Volume $\left(\mathrm{m}^{3}\right)$ & 1712 & 1323 & 1066 & 1070 & 1159 & 2503 \\
\hline
\end{tabular}


The gas volumes derived from the VFI measurements are consistent with the void fractions estimated for Tank AW-101 with data from the retained gas sampler (RGS). They also match calculations using the barometric pressure effect (BPE) method within one standard deviation. This consistency among three independent methods serves to validate each of them.

The peak headspace pressure resulting from a range of flammable gas burns was computed to quantify the potential safety consequences of a tank's stored gas inventory. A probabilistic model was used to estimate the burn pressure with the best estimates of the required input available and its associated uncertainty. Plots of the estimated burn pressure versus fraction of gas released from the nonconvective layer portray each tank's 'hazard signature.' The release fractions run the entire range from zero (no release) to 1.0 (entire gas volume in the nonconvective layer released). The maximum allowable gauge pressure in the dome is $3.08 \mathrm{~atm}(45.3 \mathrm{psig}, 312 \mathrm{kPa}$ ). This pressure limit prevents structural failure (i.e., dome collapse), although considerable cracking of the concrete and yielding of rebar is predicted to occur.

The hazard signature estimated for SY-101 prior to mixer pump installation showed it was the only tank for which the peak burn pressure could exceed the maximum internal pressure of $3.08 \mathrm{~atm}$ if the larger historical releases were ignited. In contrast, the signatures of SY-103 and AW-101 show the peak pressure will remain below the $3.08 \mathrm{~atm}$ limit at $99 \%$ confidence, and gas concentrations will remain below the lower flammability limit (LFL) in the mixed dome, even for a $100 \%$ release. SY-103 has a very large headspace, and AW-101 stores a relatively small gas volume.

The AN tanks do not exhibit such a clear distinction. They all possess enough gas relative to their dome volume to exceed the maximum allowable pressure if all the gas stored in the nonconvective layer were burned; however, none of them has ever released enough gas to even approach the pressure limit or the LFL. The peak pressure in AN-103 would remain below $3.08 \mathrm{~atm}$ at $99 \%$ confidence for a $70 \%$ release. The peak pressure remains below the 3.08-atm limit at $99 \%$ confidence for an $85 \%$ release in AN-104 and a 75\% release in AN-105. The larger gas volumes in AN-103 and AN-104 are balanced by the smaller head space of AN-105.

The extrusion photographs available from core sampling reveal some interesting similarities and differences. Both $\mathrm{AN}-103$ and $\mathrm{AN}-105$ tend to show a dryer, stiffer looking waste in the middle of the nonconvective layer, with wetter, more pourable material at the top and at the bottom. The trend for AW-101 is not as obvious. The crust layer samples from AW-101, AN-105 and SY103 appear almost indistinguishable from the upper nonconvective layer material. This is consistent with the theory that the crust is formed by small bubbles lifting attached particles to the waste surface and from 'gobs' of buoyant waste that did not release gas and sink after prior rollovers.

The data obtained with the ball rheometer and VFI have allowed us to characterize the physical properties of the waste in the six FGWL double-shell tanks in detail. When this information is combined with results from the retained gas sampler, core extrusion photos, and some of the laboratory analyses, we have all the data required to quantify the flammable gas hazard and assess consequences and risk. However, attaining a full understanding of all the processes that make up the gas retention and release personalities of the individual tanks and explaining them to the satisfaction of all will require further study.

The following recommendations are made: 
- A few double-shell tanks that do not retain or release a significant amount of gas should be tested to provide baseline data for tanks that do not present a flammable gas hazard. This will improve our understanding of those tanks that do retain and release gas. AN-107 is tentatively scheduled for VFI testing in fiscal year 1997 . We also recommend that AW-104 be tested with the ball rheometer, VFI, and retained gas sampler, if possible.

- A revision of this report should be planned for the second quarter of FY 1997 to include results from the repeat VFI and ball rheometer tests in AN-105 and any additional tanks, as recommended above. RGS data will also be available from tanks AN-103, AN-104, and AN-105 by that time for comparison with VFI results and to supply better waste gas composition data. The GRE histories of several tanks can be re-evaluated using gas monitoring data. This additional information will provide a much more complete summary of flammable gas DSTs than is available now. Surface level fluctuations do not adequately correlate with gas releases from several tanks, notably AN-103 and AW-101.

- The in situ gas volume calculated with barometric pressure response method should be compared with that derived from VFI measurements. Since the BPE method senses all stored gas, such a comparison confirms that the VFI data represent the entire tank and validate the estimate of gas volume held in the crust layer. 


\section{Acknowledgments}

The work presented in this report is the culmination of several years of effort, including the conception, design, fabrication, testing, and deployment of the ball rheometer and VFI in six . Hanford waste tanks. The authors are indebted to the many PNNL, WHC, and LANL staff who. participated in the many supporting tasks or otherwise provided assistance.

First, thanks are due to Jack Lentsch, WHC, who has managed the project from inception to completion, setting the priorities and keeping us on schedule with gentle encouragement. The efforts of Troy Stokes and the WHC team that headed up the initial design, fabrication, and deployment task are recognized. Both the ball rheometer and VFI have performed flawlessly without a single breakdown or design flaw. We are grateful to Kemal Pasamehmetoglu and Cetin Unal at LANL for the many helpful ideas put forth in the conceptual design and for putting together the safety assessment and controls that have allowed us to use the machines. We appreciate Jerry Johnson's (WHC) attention in making sure the results were made useful and used. Thanks also to John Gray, Craig Groendyke, and Gary Rosenwald of DOE-RL for their continuing support of the work.

Now we acknowledge the help of the many individuals who deserve to be co-authors for their assistance with this document. Nancy Wilkins (WHC) supplied background information on tank behavior and instrumentation and always replied cheerfully and promptly to last minute requests for data. Laurie Klevgard (PNNL) worked up the spreadsheets for computing the gas volumes and uncertainties. Les Kirihara (PNNL) has been the faithful custodian and processor of the raw ball rheometer data since day one. Judi Cuta and Lenna Mahoney (PNNL) helped compile several sections of the report from earlier material. Kurt Recknagle (PNNL) located, selected, and scanned in the color photos of core extrusions that help us relate the measurements to real waste. Ray Gallucci (PNNL) persevered through the final weeks of running and rerunning the burn pressure simulations as we kept discovering new data for him to try. Bob White (LANL), besides participating in the initial safety assessment, served as our conscience and forced us to question our assumptions and include all the errors and uncertainties.

Finally a great big thanks to Sheila Bennett (PNNL) who edited this report as well as all the prior formal and letter reports leading up to it.

"Ka hohonu i hiki 'ole ke ana 'ia, akāua 'ike 'ia nō kahi mau papa."

"The depths have not all been fathomed, but a few reefs have been seen."

Elbert and Pukui, 1979 



\section{Contents}

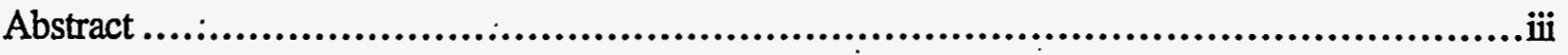

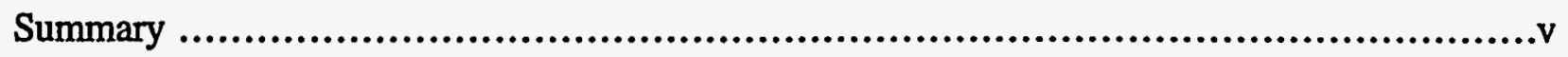

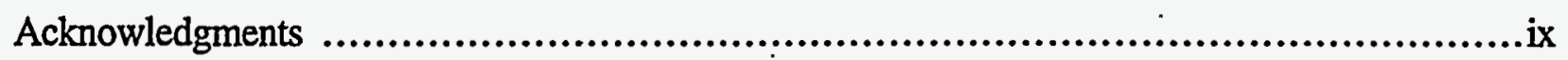

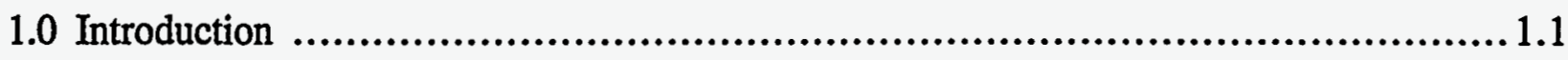

1.1 The Flammable Gas Safety Issue ................................................1.1

1.2 Description of the Ball Rheometer and VFI ..................................... 1.3

1.2.1 Ball Rheometer ...................................................... 1.4



1.2.3 Role of VFI and Ball Rheometer ..................................... 1.8

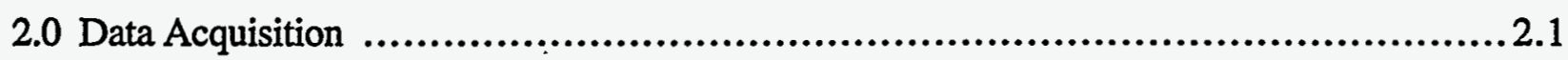

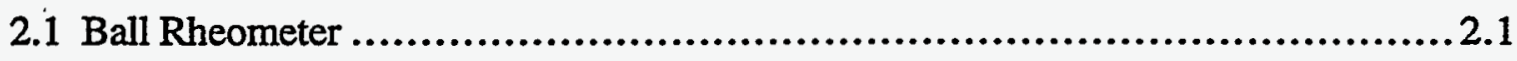

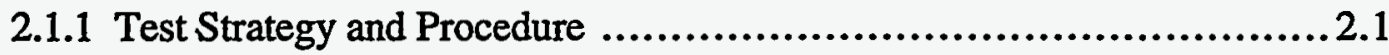



2.1.3 Ball Rheometer Raw Data and Uncertainties .............................2.4

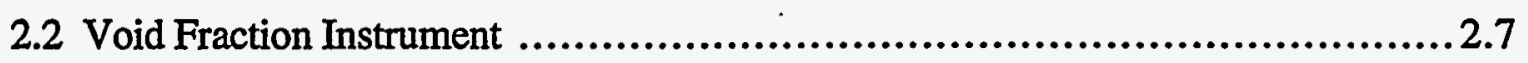

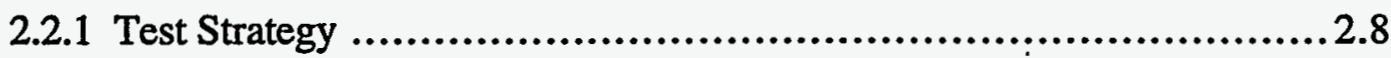

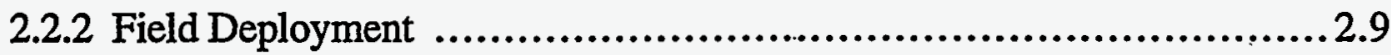

2.2.3 VFI Raw Data and Uncertainties......................................2.11

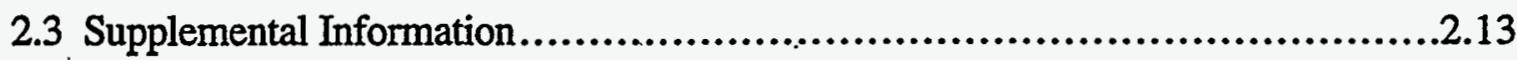

2.3.1 Waste Temperature .....................................................2.13

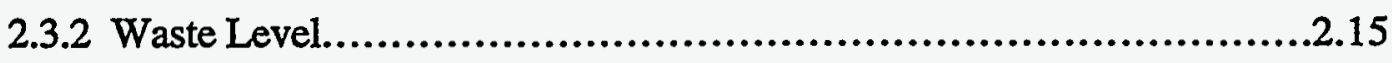

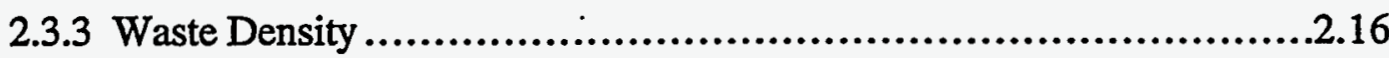

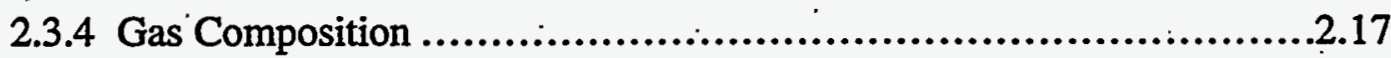



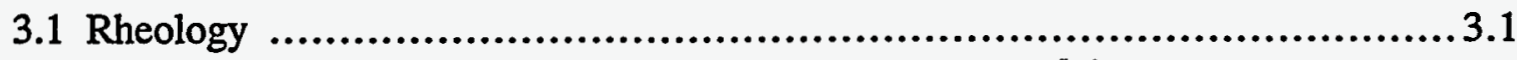


3.1.1 Convective Layer Viscosity................................................ 3.1

3.1.2 Apparent Viscosity of the Nonconvective Layer .............................3.5

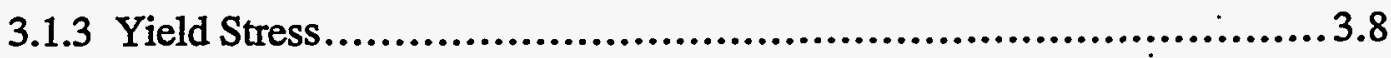

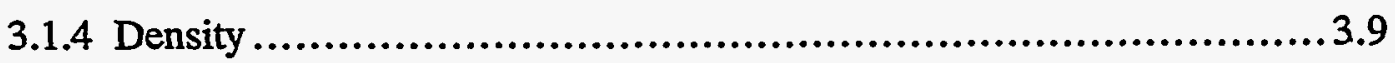

3.2 Void Fraction ................................................................. 3.9

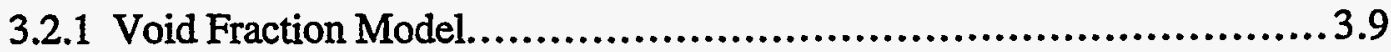

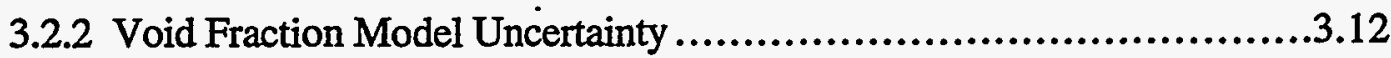

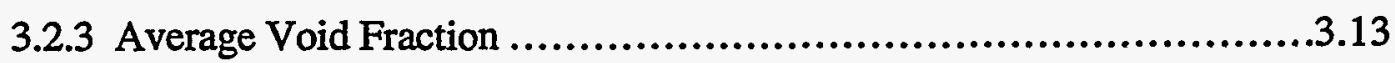

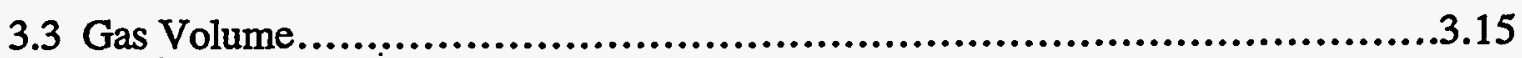



3.3.2 Barometric Pressure Effect ................................................3.17

3.3.3. Uncertainty in Volume Calculations ........................................3.18

3.4 Gas Release Potential and Consequence............................................3.19

3.4.1 Deriving a Tank's GRE History ........................................3.20

3.4.2 Peak Headspace Pressure.................................................3.22

4.0 Tank-By-Tank Test Results......................................................... 4.1

4.1 SY-101 In Situ Rheology and Gas Volume ........................................ 4.2

4.1.1 SY-101 Waste Configuration............................................... 4.3

4.1.2 Rheology and Density ................................................... 4.5

4.1.3 Void Fraction and Gas Volume ......................................... 4.6

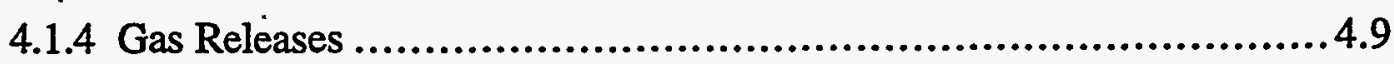

4.2 SY-103 In Situ Rheology and Gas Volume........................................4.10

4.2.1 Waste Configuration........................................................4.11

4.2.2 Rheology. and Density ....................................................4.13

4.2.3 Void Fraction and Gas Volume ...........................................4.15

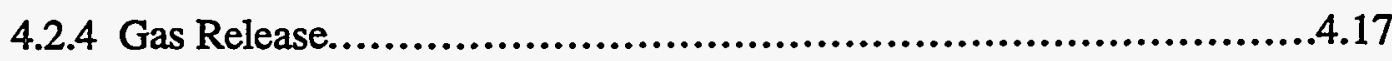

4.3 AW-101 In Situ Rheology and Gas Volume.....................................4.18 


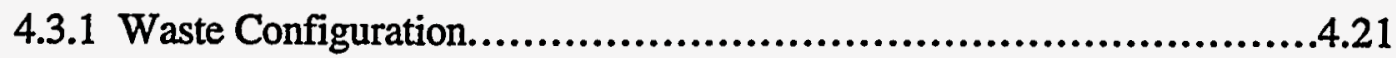

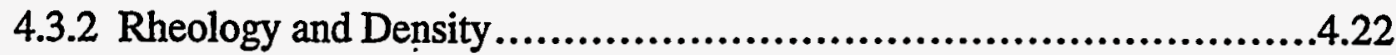

4.3.3 Void Fraction and Gas Volume .........................................4.23

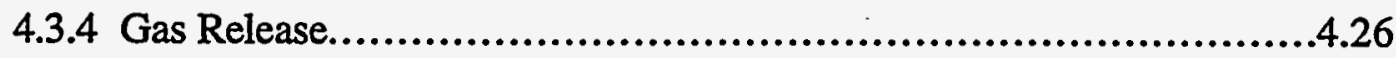

4.4 AN-103 In-Situ Rheology and Gas Volume ....................................27.

4.4.1 Waste Configuration.....................................................29

4.4.2 Rhẹology and Density ....................................................4.30

4.4.3 Void Fraction and Gas Volume ...........................................4.31



4.5 AN-104 In Situ Rheology and Gas Volume ....................................4.34

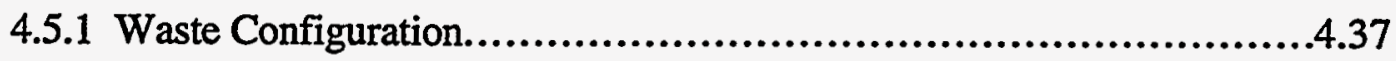

4.5.2 Rheology and Density ....................................................4.37

4.5.3 Void Fraction and Gas Volume ............................................4.40

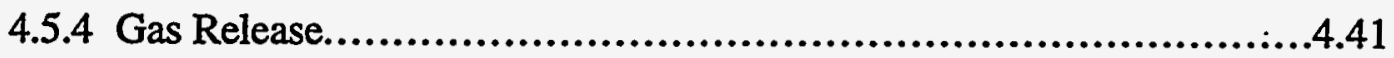

4.6 AN-105 In Situ Rheology and Gas Volume ....................................4.43

4.6.1 Waste Configuration.....................................................4.45

4.6.2 Rheology and Density...................................................4.46

4.6.3 Void Fraction and Gas Volume .........................................4.47

4.6.4 Gas Release...........................................................4.48

5.0 Summary and Conclusions.............................................................. 5.1

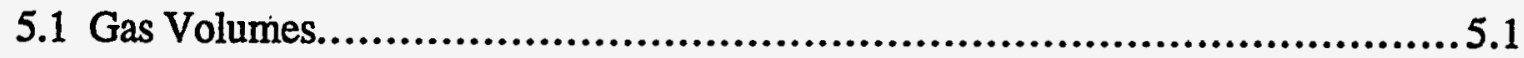

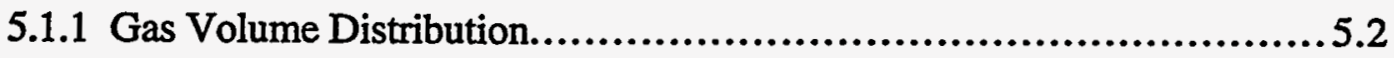

5.1.2 Comparison with Barometric Pressure Effect Method ......................5.3

5.2 Potential Consequences of Stored Gas Volume ................................... 5.4

5.3 Rheology and Waste Configuration.............................................5.12

5.4 The Bottom Line....................................................................16

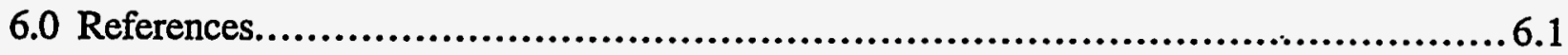


Appendix A: Gas Release Histories

A.1

Appendix B: Core Extrusion Photographs.

B. 1 


\section{Figures}

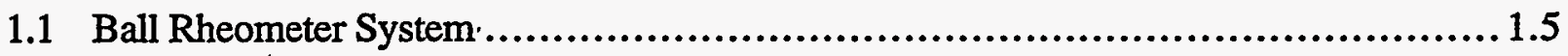

1.2 Void Fraction Instrument Deployed in a Tank ................................... 1.6



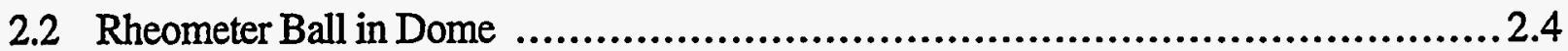

2.3 Rheometer Ball Approaching the Waste Surface in AN-105 ........................... 2.5

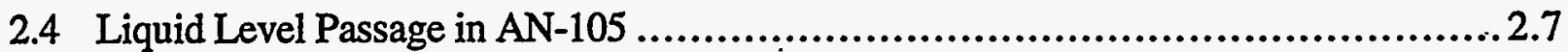

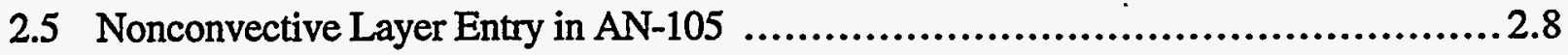

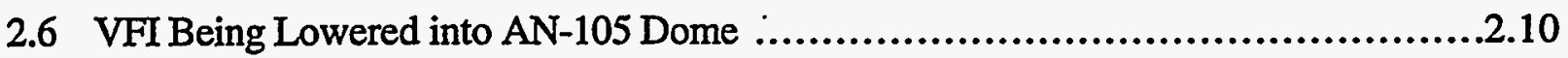

2.7 Closed Sample Chamber Approaching the Waste Surface ..............................2.11

2.8 Open Sample Chamber in Dome During Decontamination................................2.12

2.9 Temperature Profile Segment from SY-103 ..........................................2.14

2.10 SY-101 Waste Level History ...........................................................16

3.1.1 Velocity Field Induced by a Cable Moving Along Its Axis ...............................3.3

3.1.2 Drag Force in Multistep Velocity Function .............................................3.7

3.2.1 Layers for Average Void Calculation in AN-104 ........................................3.14

3.4.1 Gas Release Transient in AN-105, 5/30/96.............................................21

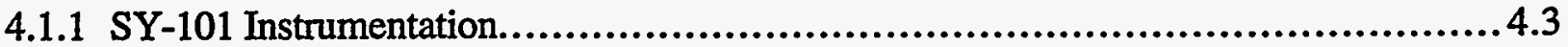

4.1.2 Temperature Profile from the 17C MIT Validation Probe...................................4.4

4.1.3 Temperature Profiles from the 17B MT Validation Probe ................................ 4.5

4.1.4 Apparent Viscosity of SY-101 Mixed Slurry.............................................4.6

4.1.5 Yield Stress of the Loosely Settled Solids in SY-101 Riser 4A..........................4.7

4.1.6 Waste Density Profile in SY-101 ........................................................ 4.7

4.1.7 Void Fraction Measurements in Risers 4A and 11B....................................4.8

4.1.8 - SY-101 GRE Volume Histogram.................................................. 4.9

4.2.1 SY-103 Instrumentation.......................................................11 
4.2.2 Temperature Profiles in Risers 17B and 4A .4 .12

4.2.3 Typical Surface Disturbance from Sample Chamber Opening ...........................12

4.2.4 Apparent Viscosities in Risers 17C and 22A .........................................4.14

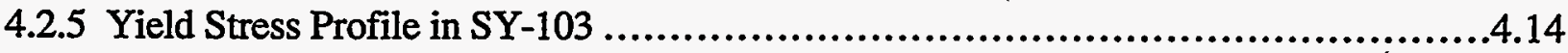

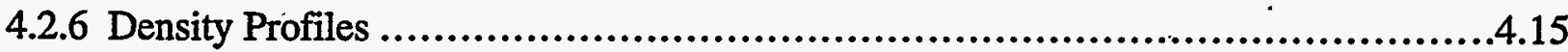

4.2.7 Void Profiles for Each Traverse in SY-103 ..........................................4.16

4.2.8 SY-103 GRE Histogram...........................................................17

4.3.1 Tank 241-AW-101 Instrumentation...................................................19

4.3.2 Waste Level History - October 1994 to October 1995...................................4.20

4.3.3 Hydrogen Concentration History During Deployment .................................20

4.3.4 Sequence of Gas Release Compared with VFI Deployment ..............................21

4.3.5 Temperature Profiles on September 25, 1995 ......................................4.22

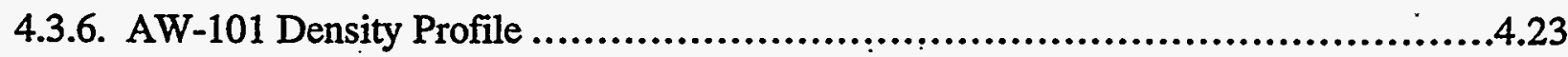

4.3.7 Upper Bound on the Yield Stress .................................................4.24

4.3.8 Apparent Viscosities of the First and Last Passes..........................................4.24

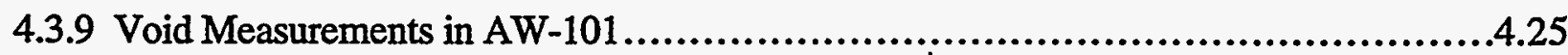

4.3.10 Gas Release Transient in AW-101 May 14, 1996 ....................................26

4.3.11 Hydrogen Release in AW-101 June 4, 1996 .......................................4.27

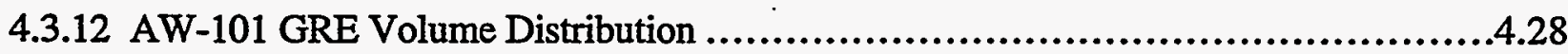

4.4.1 Tank 241-AN-103 Instrumentation ...................................................29

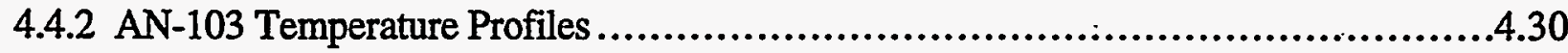

4.4.3 Upper Bound on the Yield Stress .....................................................31

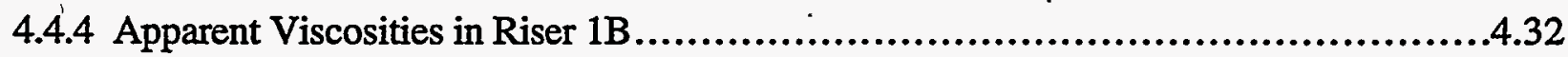

4.4.5 Density as a Function of Elevation ...................................................4.32

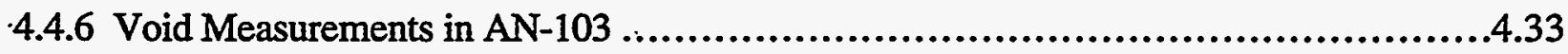

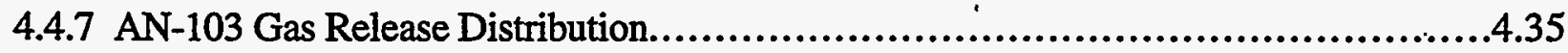

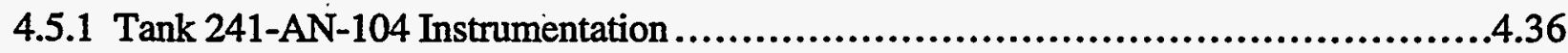


4.5.2 AN-104 Temperature Profiles

4.5.3 AN-104 Density Profile 4.38

4.5.4 Upper Bound on the Yield Stress

4.5.5 Apparent Viscosities at Three Strain Rates

4.5.6 Void Measurements in $\mathrm{AN}-104$

4.5.7 AN-104 GRE Release Rate May 3, 1996.......................................4.42

4.5.8 AN-104 GRE October 2, 1995 ...................................................42

4.5.9 AN-104 GRE Volume Distribution....................................................4.43

4.6.1 Tank 241-AN-105 Instrumentation .................................................4.44

4.6.2. AN-105 Temperature Profiles ..........................................................4.45

4.6.3 AN-105 Density Profile................................................................4.46

4.6.4 Upper Bound on the Yield Stress ....................................................4.47

4.6.5 Apparent Viscosities on the First and Last Passes .......................................4.48

4.6.6 Void Measurements in AN-105 ....................................................4.49

4.6.7 AN-105 Gas Release, May 30, 1996 ...............................................50

4.6.8 AN-105 GRE Volume Distribution ....................................................5.

5.1 Expected Stored Gas Volume by Tank..................................................5.2

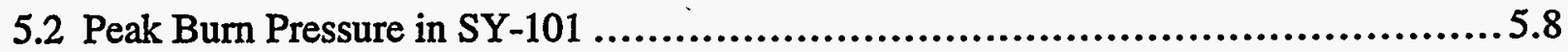

5.3 Peak Burn Pressure in SY-103 ...................................................... 5.9

5.4 Peak Burn Pressure in AW-101 ...................................................... 5.9



5.6 Peak Burn Pressure in AN-104 .....................................................5.11

5.7 Peak Burn Pressure in AN-105 ......................................................5.11

5.8 Yield Stress for Five Tanks .........................................................5.12

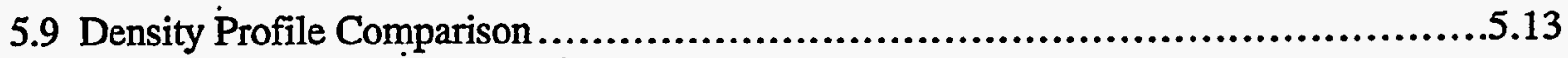

5.10 Temperature Profiles for Five Tanks................................................5.14

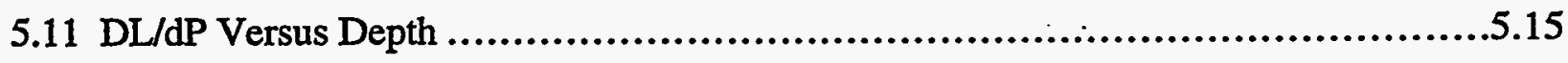




\section{Tables}

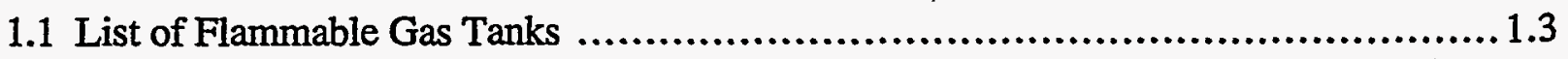

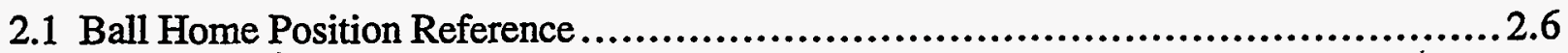

3.1 Correlation Coefficients for the Cable Drag Correlations ................................3.3

3.2 Combustion Energies of Different Fuel-Oxidizer Pairs ...................................3.25

4.1 Summary of Flammable Gas DSTs....................................................4.1

4.2 Ball Rheometer and VFI Deployment History ........................................ 4.2

4.3 Waste Layering in Tank 241-SY-101.................................................. 4.5

4.4 Volume of Gas Stored in Waste Layers ................................................4.8

4.5 Summary of Solids Depth Observations .................................................13

4.6 Estimates of Mean Void Fraction and Uncertainty .......................................4.16

4.7 Summary of Solids Depth Indications....................................................23

4.8 Estimates of Mean Void Fraction and Uncertainty .......................................4.25

4.9 Summary of Sludge Depth Indications ..................................................3.

4.10 Estimates of Mean Void Fraction and Gas Volume .......................................4.34

4.11 Summary of Solids Depth Indications...................................................4.38

4.12 Estimates of Mean Void Fraction and Gas Volume .......................................4.41

4.13 Summary of Solids Depth Observations ................................................4.46

4.14 Estimates of Void Fraction, Gas Volumes, and Effective Pressure........................4.49

5.1 Void Fraction and Volume Summary .................................................. 5.2

5.2 Barometric Response Comparison...................................................5.3

5.3 Waste Gas Composition Distributions................................................. 5.6

5.4 Waste Gas Composition Comparison ................................................. 5.6

5.5 Release Fractions to Achieve LFL .................................................... 5.8

5.6 Neutral Buoyancy Void Fractions Compared with VFI Measurements....................5.14 


\section{Acronyms}

ANOVA analysis of variance

BPE

DST

Enraf $^{\text {(3) }}$

FGWL

FIC

FTIR

GCS

GRE

LANL

LFL

MIT

PNL

barometric pressure effect (method to calculate stored gas volume)

double-shell tank

name of company, not an acronym (type of waste surface level gauge)

Flammable Gas Watch List

Food Instrument Corporation (waste surface level gauge)

Fourier transform infrared (device for measuring gas composition)

gas characterization system

gas release event

Los Alamos National Laboratory

lower flammability limit

multifunction instrument tree (mainly for temperature measurement)

PNNL

Pacific Northwest Laboratory

RGS

RTD

Pacific Northwest National Laboratory

SHMS

SST

TC retained gas sampler

resistance temperature detector

standard hydrogen monitoring system

single-shell tank

thermocouple

USQ . unreviewed safety question

VFI

void fraction instrument

WHC

Westinghouse Hanford Company 


\section{0 .Introduction}

Since 1943, large underground concrete storage tanks (currently numbering 177) have been used at Hanford to store byproducts of uranium and plutonium production. Of these, 151 are single-shell tanks (SSTs), and 26 are double-shell tanks (DSTs). The tanks are up to 75 feet $(23 \mathrm{~m})$ in diameter and 32 feet $(10 \mathrm{~m})$ in height and are capable of holding up to one million gallons $\left(3,800 \mathrm{~m}^{3}\right)$ of waste. The SSTs have a single steel liner on the bottom and sides; they are as much as 50 years old, and some are known to leak. The DSTs were constructed during the late 1970s and have a full steel inner liner with a second steel shell around the bottom and sides; active ventilation and leak detection systems are located in the annulus between the two. The waste in all of these tanks is chemically complex and ranges from mostly liquid to thick, sticky sludge to a crystalline salt cake. The sludge typically has the consistericy of stiff clay to soft mud, and the salt cake ranges in consistency from fine wet silt to 'sno-cone' slush to rock-like crystalline salt.

The waste in these tanks will eventually be retrieved or possibly stabilized in situ for permanent storage. Awaiting permanent disposal, the waste must be stored safely, isolated from the environment. To this end the pumpable liquid part of the waste in the SSTs is being transferred into available space in the DSTs to reduce the possibility of leaks into the groundwater. Core samples are also being obtained on an aggressive schedule to help characterize the waste in support of both retrieval and safe storage.

\subsection{The Flammable Gas Safety Issue}

Discussions of the flammable gas safety issue in Hanford waste tanks are often concerned with the Flammable Gas Watch List (FGWL) and the Unreviewed Saftey Question (USQ). The safety issue is the general concern that the flammable gas hazard may lead to unacceptable consequences. The FGWL is a list of potentially hazardous tanks developed in response to specific legislation. The USQ is an administrative construct for issues that are not covered in existing operations safety documents. This section gives the background and current status of each of these concerns.

Essentially all radioactive waste slowly generates flammable gas by complex chemical reactions and radiolysis of water. In most waste tanks, this gas is released to the head space at about the same rate as it is generated. The generation rate is so low compared with passive or active ventilation flow rates that the flammable gas is diluted to far below the concentration necessary for ignition. However, certain tanks give evidence that they might retain significant volumes of flammable gas (mainly hydrogen with smaller amounts of ammonia, methane, and other hydrocarbons) in the waste.

The flammability hazard associated with these tanks depends on the peak concentration of flammable gases that might occur in the tank head space following a sudden release of a significant fraction of the retained gas. If the peak concentration remains below the lower flammability limit (LFL) the gas cannot be ignited, and there is no flammability hazard. If the concentration exceeds the LFL and a source of ignition is present, the mixture could burn. If a sufficiently large gas volume is burned in the dome space, the resulting pressure increase might be large enough to fail the exhaust filters and even the dome structure, potentially releasing radioactive material to the environment.

The potential for a flammable gas mixture in the dome space and ventilation system of certain Hanford waste tanks was first proposed for DST 241-SY-101 (SY-101). The waste level in this tank began periodically rising and suddenly dropping shortly after it was filled in 1980, but 
the amount of gas released was not well quantified. In January 1990 it was hypothesized that a burn above, within, or even under the crust layer was possible since the waste generated both fuel (hydrogen) and oxidizer (nitrous oxide) (Babad et al. 1992). Some of the releases in SY-101 in fact caused the dome space mixture to exceed the LFL.

Additional SSTs and DSTs were identified in April 1990 as potentially having behavior similar to SY-101. This was the genesis of the Flammable Gas Watch List (FGWL). Because the process was poorly understood and the hydrogen and nitrous oxide releases were not covered by the current facilities safety analysis documents, this was declared to be a USQ in May 1990. Twenty-three tanks were included in the USQ based on evaluations of growth of waste level, changes in waste level, high total organic carbon content, presence of a floating crust layer, and waste received from B Plant.

In January 1991, the same 23 tanks that had been included in the USQ were formally identified on the FGWL in response to Public Law 101-510, Section 3133 (the Wyden Amendment) as having "serious potential for release of high-level waste due to uncontrolled increases in temperature or pressure" from a flammable gas burn. Two more DSTs were added to the FGWL in 1992 and 1993 for a total of 25, six DSTs and 19 SSTs. Separate watch lists were established for other safety issues that could create uncontrolled increases in pressure and temperature, including organics, ferrocyanide, criticality, and high heat. Some FGWL tanks are also on one or two of these other watch lists.

After 1990, relatively high hydrogen concentrations in core sampling equipment, observation of large void spaces in core radiographs, and hydrogen and nitrous oxide measured in the dome space of various tanks all indicated that a number of other tanks were retaining flammable gas in the waste and might present a "serious potential for release." Accordingly, a goal was set to screen all 177 tanks for flammable gas risk and potential addition to the FGWL.

By early 1995, Pacific Northwest National Laboratory (PNNL) completed a screening of all 177 tanks using the barometric pressure response method (Whitney 1995). The results indicated that 58 tanks retained detectable volumes of gas, but the actual volumes were not estimated. Twenty-one of these tanks were already on the FGWL. The Hanford Plant Review Committee issued standing orders to place flammable gas work controls on the remaining 37 suspect tanks.

A more detailed, formal methodology was developed to evaluate tanks for inclusion on the FGWL in late 1995 (Hopkins 1995); it used the barometric pressure response method along with surface level rise to calculate the volume of gas trapped in the waste. All 177 tanks were evaluated in accordance with this methodology by early 1996 (Hodgson et al. 1996). Fifty-three tanks failed the evaluation criteria, and 21 of these were already on the FGWL. Three of the original 25 tanks passed the evaluation and are therefore candidates for removal from the FGWL. The remaining 32 tanks (only three of which are DSTs) were placed under the flammable gas USQ in May 1995 and recommended for the FGWL. Table 1.1 shows the current status of FGWL and USQ tanks. Note that FGWL tanks are also on the USQ.

The recommendation was withdrawn after the Chemical Reactions SubPanel and DOE-HQ raised questions about the assumptions used in the methodology and the data quality on which the evaluation was based (Johnson 1996). However, all of the additional tanks remain under the USQ. Tank SY-101, the tank that initiated flammable gas concerns in 1989, was removed from the USQ in June 1996 after having been mitigated by mixing. 
Table 1.1. List of Flammable Gas Tanks

\begin{tabular}{|c|c|c|c|}
\hline Watch List Tanks & Type & \multirow{32}{*}{$\begin{array}{c}\text { UQ Ianks } \\
\text { A-103 } \\
\text { AN-107 } \\
\text { AW-104 } \\
\text { AY-101 } \\
\text { B-201 } \\
\text { B-202 } \\
\text { BX-107 } \\
\text { BY-101 } \\
\text { BY-102 } \\
\text { BY-10) } \\
\text { BY-105 } \\
\text { BY-106 } \\
\text { BY-109 } \\
\text { C-104 } \\
\text { C-107 } \\
\text { S-10) } \\
\text { S-103 } \\
\text { S-105 } \\
\text { S-106 } \\
\text { S-107 } \\
\text { S-109 } \\
\text { T-201 } \\
\text { T-204 } \\
\text { TX-102 } \\
\text { TX-111 } \\
\text { (c) } \\
\text { TX-112 } \\
\text { TX } \\
\text { TX-113 } \\
\text { TX-115 } \\
\text { U-10) } \\
\text { U-106 } \\
\text { U-111 }\end{array}$} & \multirow{32}{*}{$\begin{array}{c}\text { IST-4 } \\
\text { DST } \\
\text { DST } \\
\text { DST } \\
\text { SST-1 } \\
\text { SST-1 } \\
\text { SST-2 } \\
\text { SST-3 } \\
\text { SST-3 } \\
\text { SST-3 } \\
\text { SST-3 } \\
\text { SST-3 } \\
\text { SST-3 } \\
\text { SST-2 } \\
\text { SST-2 } \\
\text { SST-3 } \\
\text { SST-3 } \\
\text { SST-3 } \\
\text { SST-3 } \\
\text { SST-3 } \\
\text { SST-3 } \\
\text { SST-1 } \\
\text { SST-1 } \\
\text { SST-3 } \\
\text { SST-3 } \\
\text { SST-3 } \\
\text { SST-3 } \\
\text { SST-3 } \\
\text { SST-2 } \\
\text { SST-2 } \\
\text { SST-2 }\end{array}$} \\
\hline$A-101$ & SST-4 & & \\
\hline AN-103 & DST & & \\
\hline AN-104 & DST & & \\
\hline AN-105 & DST & & \\
\hline AW-101 & DST & & \\
\hline$A X-101^{(a)}$ & SST-4 & & \\
\hline$A X-103^{(a)}$ & SST-4 & & \\
\hline S-102 & SST-3 & & \\
\hline S-111 & SST-3 & & \\
\hline S-112 & SST-3 & & \\
\hline SX-101 & SST-4 & & \\
\hline $\mathrm{SX}-102$ & SST-4 & & \\
\hline SX-103 & SST-4 & & \\
\hline$S X-104^{(a)}$ & SST-4 & & \\
\hline SX-105 & SST-4 & & \\
\hline SX-106 & SST-4 & & \\
\hline SX-109 ${ }^{\text {(b) }}$ & SST-4 & & \\
\hline SY-101 & DST & & \\
\hline SY-103 & DST & & \\
\hline$T-110$ & SST-2 & & \\
\hline $\mathrm{U}-103$ & SST-2 & & \\
\hline $\mathrm{U}-105$ & SST-2 & & \\
\hline $\mathrm{U}-107$ & SST-2 & & \\
\hline U-108 & SST-2 & & \\
\hline U-109 & SST-2 & & \\
\hline Tank Capacities & & & \\
\hline SST - 55,000 gal. & SST-1 & & \\
\hline SST - 530,000 gal. & SST-2 & & \\
\hline SST - 758,000 gal. & SST-3 & & \\
\hline SST - $1,000,000 \mathrm{gal}$ & SST-4 & & \\
\hline DST - $1,160,000$ gal. & DST & & \\
\hline \multicolumn{4}{|c|}{$\begin{array}{l}\text { (a) Original FGWL tanks that passed the latest evaluation and are candidates } \\
\text { for removal from the list. } \\
\text { (b) Placed on the FGWL because five other FGWL tanks vent into it. } \\
\text { (c) Tanks whose free liquid was removed by recent salt well pumping. }\end{array}$} \\
\hline
\end{tabular}

\subsection{Description of the Ball Rheometer and VFI}

The VFI and ball rheometer were identified late in FY 1993 as instruments that could be used to prove that SY-101 was indeed mitigated by the mixer pump and to determine which of the other tanks on the FGWL might require similar treatment. Mitigation by mixing was assumed to be required for planning purposes, but its high cost made it imperative to determine which tanks really needed it. Thus the VFI and ball theometer projects were initiated in October 1993. Early discussions at Los Alamos National Laboratory (LANL) and PNNL on how to best obtain rheological information identified a falling ball concept as the front runner for in situ application.

The projects teamed key contributors from Westinghouse Hanford Company (WHC), PNNL, and LANL to install and operate.full-scale devices in SY-101 in one year. WHC led the 
overall project; LANL staff prepared the formal safety assessment (Sullivan 1995) and assisted with the technology development and its application to these two instruments. PNNL staff led prototype testing, assisted in the technology development and application, wrote the test plans, and performed all data reduction.

The VFI and ball rheometer have now been used in two risers each in tanks SY-101, SY103, AW-101, AN-105, AN-104, and AN-103. They have performed as designed in all tests and had no significant problems. The initial testing program in SY-101 and SY-103 is documented in Stewart et al. (1995), Brewster et al. (1995), and Shepard et al. (1995).

\subsubsection{Ball Rheometer}

The ball rheometer concept originated from the need to measure in situ rheological properties in Hanford waste tanks in a relatively short period of time. Laboratory rotational rheometers were impractical, not only because of the difficulty in retrieving and handling the radioactive waste samples but also because large particles in the waste affect the measurements. In addition, preparing the sample for measurements in a conventional rotational rheometer often changes its rheological characteristics, as can the temperature changes that occur after the sample is removed from tank. In contrast, the rheology of the waste material can be estimated directly from the drag force on a ball as it moves through the waste at various speeds.

The ball rheometer system was designed to measure the properties of waste typical of the nonconvective layer in SY-101 prior to mixing. The Ball Rheometer System Design Description, WHC-SD-WM-SDD-043, discusses in detail all design information and references all other design documents pertaining to the ball rheometer (also see Stewart et al. 1995). The ball rheometer system, shown in Figure 1.1, consists of a 71-N (16 lb), 9.12-cm-diameter tungsten alloy ball tethered to a steel cable that is wound onto a spool or drum. The cable runs through a guide that distributes the line across the width of the spool, so only a single layer of cable is needed on the spool. Cable deployment and retrieval are performed with electric motors, clutches, reduction gears, and a driveline. The pulley rests on a load cell that measures the tension in the cable plus the pulley weight and any friction in the pulley when it is in motion.

Two motors are used to operate the spool, one for high speed $(3$ to $100 \mathrm{~cm} / \mathrm{s}$ ) and another for low speed $(0.1$ to $3.0 \mathrm{~cm} / \mathrm{s})$. A data acquisition system controls the ball and records the data. The ball position, velocity, and force as measured by the load cell are recorded as a function of time, typically at a rate of $15 \mathrm{~Hz}$. The ball speed, direction, and distance and the data collection rate are all adjustable. In addition to rising- and falling-ball tests, static measurements can also be made.

The ball rheometer project plan was issued in October 1993, and the project was fully under way in November of that year. Acceptance testing of the ball rheometer in the WHC $306 \mathrm{E}$ facility concluded successfully in August 1994. It was bolted to riser 4A in SY-101 later in the month and was first operated in September 1994, although problems with the water lance delayed actual testing in waste until March 1995. 


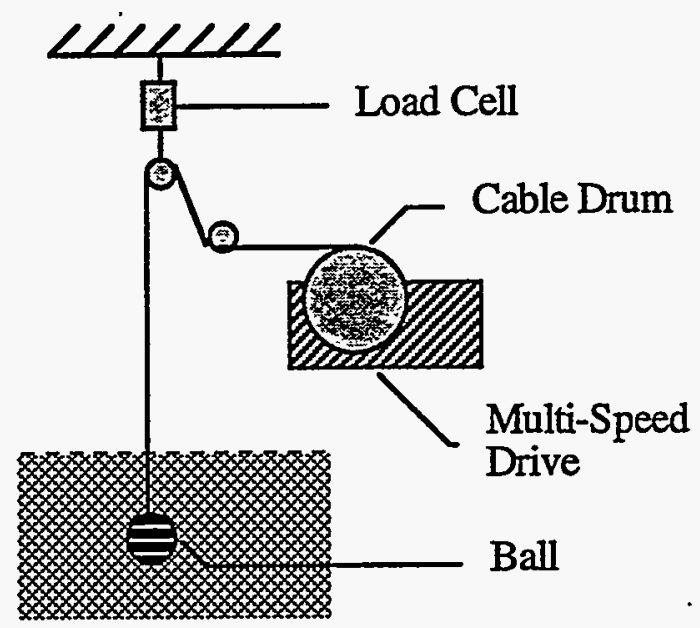

Figure 1.1. Ball Rheometer System

The test plan for deploying the ball rheometer in the various tanks was incrementally modified and refined after measurements in SY-101 and SY-103 were completed and the reduced data were analyzed (Stewart et al. 1995; Shepard et al. 1995). The ball speed range was increased to provide a measurable force in the liquid. It was initially believed that most of the waste had a high apparent viscosity (greater than $500 \mathrm{cP}$ ), and therefore measurements taken at low ball velocities $(0.1$ to $10 \mathrm{~cm} / \mathrm{s}$ ) would provide a detectable drag force. This assumption holds in the nonconvective waste but not in the liquid. Most of the drag data collected in SY-101 at speeds ranging from 1 to $10 \mathrm{~cm} / \mathrm{s}$ yielded barely detectable forces in the mixed fluid region. Accordingly, the ball velocity range in the liquid layer was increased to 10 to $100 \mathrm{~cm} / \mathrm{s}$ in SY-103 and subsequent tanks.

In the nonconvective layer, the ball was programmed to traverse at three different speeds to resolve the rheology on the first as well as on subsequent passes. In the first two tanks, SY-101 and SY-103, the ball was raised and lowered at a constant speed from just below the crust until it became supported by the waste or the tank bottom. This "first pass" test was intended to accurately determine the layering and to measure the properties of waste undisturbed by ball passage. However, we found that a single speed did not provide sufficient data to fully characterize the rheology of the material. Therefore, a range of speeds was used during the first and subsequent passes through AW-101 and the AN tanks. Each speed was held for $20 \mathrm{~cm}$; then the ball was stopped and started again at a different speed. With this method we were able to obtain the rheology of the nonconvective layer in both the undisturbed and fully sheared condition.

\subsubsection{VFI Description}

The VFI is designed to measure the volume fraction of free (undissolved) gas, or void, at specific locations in a tank. The VFI does not determine gas composition, and its response is very nearly independent of gas composition. The measurement is made by compressing the waste captured in a sample chamber of known size with nitrogen gas. The sample chamber is mounted on a rotating arm that is deployed vertically through a riser by means of a crane. Figure 1.2 is a sketch of the VFI deployed in a tank.

Once below the waste surface and any crust layer, the arm is rotated 90 degrees to become horizontal and is lowered to the desired depth in the tank with the cover of the sample chamber 


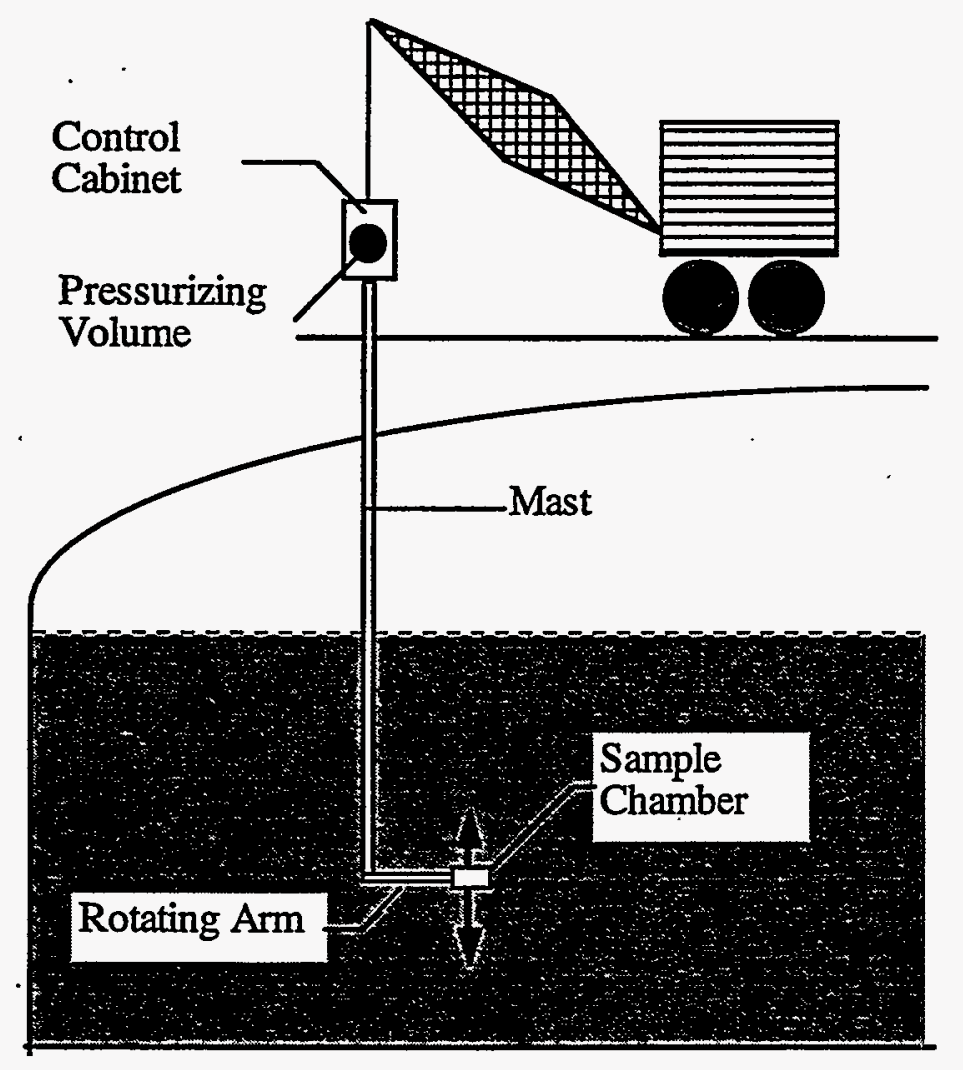

Figure 1.2. Void Fraction Instrument Deployed in a Tank

open. At the measurement location the cover.is closed to capture a sample, and the waste is compressed with nitrogen gas by opening a valve between the connecting line and the source volume. Lowering the chamber with the cover open replaces the previous sample with fresh waste. The void fraction is calculated from the initial and final pressures and temperatures and known system volumes. The VFI can make measurements at a radius of $76 \mathrm{~cm}$ ( $30 \mathrm{in}$.) about the riser center about every 30 to $60 \mathrm{~cm}$ (12-24 in.) of elevation.

The project plan for the VFI was issued in December 1993 and was fully under way by early February 1994. Initial investigations indicated that a compressibility technique was the simplest and quickest way to get direct in situ void measurements. Pressurizing with nitrogen gas was finally selected for accomplishing compression. A scale model of the concept was built and tested at PNNL, and testing showed that stainless-on-stainless galling was a problem, which guided WHC to use hard-chrome plate sliding surfaces. The scale model also helped to refine optimal volumes and thermodynamic equilibration times.

Questions about potential errors due to non-ideal behavior of the gases trapped in the sample and dissolution of ammonia with increasing pressure were solved by simply compressing the gas to a sufficiently small volume to eliminate the effect of these errors. LANL performed tests 
with waste simulant and neutrally buoyant particles of various sizes to discover the fraction of the gas present in the undisturbed material that was actually captured in the sample chamber. The results showed approximately $90 \%$ capture efficiency. (a)

During acceptance testing of the VFI in the WHC 306E facility, it was a challenge to keep the O-ring seals in place while the sample chamber opened under high positive gauge pressure. High-speed video showed the O-rings were being blown out of their grooves when the cover retracted. Additional vent holes were drilled in the sample chamber cover to release the internal pressure before the $\mathrm{O}$-rings were uncovered. This modification prevented $\mathrm{O}$-ring loss under worst-case conditions of $3.45 \mathrm{MPa}(500 \mathrm{psi})$ at $100 \%$ void. Final system testing concluded successfully in September 1994 (Stewart et al. 1995).

With testing completed, the equipment was shipped to the SY tank farm in November 1994. A comprehensive engineering document, Void Fraction Instrument System Design Description, WHC-SD-WM-SDD-043, discusses all design information in detail and references all other design documents pertaining to the VFI. The VFI was first operated in riser 11B in SY-101 on December 19,1994, and in riser 4A on January 17,1995 . No significant in-tank problems occurred, and the VFI has been a very reliable and effective instrument, providing direct measurement of retained gas volumes.

During the early deployments, slightly negative void fractions were calculated in the convective layer of each tank. While these negative measurements were very small (less than $1 \%$ void), they were disturbing because negative values are not physically possible. Careful analysis of the data and reevaluation of the initial system calibration uncovered no errors; however, in an attempt to explain these negative void fractions, all of the basic assumptions of the VFI model were reexamined. Careful analysis of the assumption of ideal gas behavior of the nitrogen used for pressurizing the sample uncovered the discrepancy.

The ideal gas assumption was adequate to ensure that the accuracy of the VFI was within $2 \%$ void fraction, in compliance with the design requirement, and it gave very good results during calibration in the laboratory. However, nitrogen is not exactly an ideal gas at the $-35 \mathrm{~atm}$ of the pressurization chamber, where its compressibility can vary 1 to $2 \%$ from ideal gas behavior. Accordingly, real gas effects were included in the VFI model by using the Beattie-Bridgeman equation of state. Since the data from the VFI are stored as temperatures and pressures versus time, it was possible to calculate new void fractions using the real gas model with the data from the original calibration runs and prior tank deployments without collecting any additional data. Implementing the real gas model for the nitrogen virtually eliminated the negative void fractions. Additional changes included adding the slight gravity head of nitrogen in the $18-\mathrm{m}(60-\mathrm{ft})$ connecting line and accounting for the expansion of the sample chamber as it is pressurized. The effect of these changes was small.

The initial tests in SY-101 used double pressurizations extensively under the assumption that they provided better data. However, without exception, the void fractions from each pressurization were essentially identical to within the measurement uncertainty (and the real gas model and the other improvements made them even closer), and double pressurizations required so much extra time that only one pass was possible in the first riser. Thereafter, double pressurizations were performed very sparingly. The value of the additional data from more sample locations is far higher than that originally expected from double pressurizations.

(a) Abbott, JR, and C Unal. November 16, 1994. "Sampling Ability of the In-Situ Voidmeter Instrument." LANL letter report TSA-6-94-316 (M110), Los Alamos National Laboratory, Los Alamos, New Mexico. 


\subsubsection{Role of VFI and Ball Rheometer}

Evaluation of the flammable gas hazard in a particular tank in view of closing the USQ and resolving the safety issue requires an estimate of the volume of gas retained, the fraction of the retained gas that can be released, and how rapidly it might enter the tank headspace in relation to the ventilation rate. Changes in waste level indicate variation in the stored gas volume (in the absence of evaporation, leaks, or waste additions). Therefore, knowledge of the gas volume and its vertical distribution at a given waste level allows us to use waste level history and future trends to represent the gas volume as it varies over time. It is then possible to calculate the fraction of total gas released in a gas release event (GRE).

The stored gas volume can be determined most accurately from local void fraction measurements. Where it can be used, the VFI resolves the void profile in detail with measurements about every. $30 \mathrm{~cm}$ (12 in.). The gas volume stored in the nonconvective layer can be calculated from the void profiles in two risers to well within $25 \%$ uncertainty when confirmed by a global barometric pressure response calculation. The void fraction of two or three $48-\mathrm{cm}$ (19-in.) segments in a push-mode core can be obtained with the retained gas sampler (RGS); however, the uncertainty in the void profile is higher with only two or three measurements.

The retained gas volume can also be estimated from the correlation of waste level measurements with barometric pressure fluctuations, given sufficiently accurate and frequent level data. The accumulated surface level rise also provides an indication of trapped gas volume, provided the initial gas volume, liquid evaporation, leaks, or additions are known. Both of these indirect methods require an estimate of the effective pressure at which the gas is stored; this requires data on the vertical distribution of the stored gas, which can be provided by VFI measurements. The difference between the total gas volume calculated from the barometric pressure method and the total volume from the VFI data is an estimate of the gas stored in the crust layer, if present.

The potential gas release fraction and rate rely mainly on historical observations and continuous monitoring data in tanks that exhibit spontaneous GREs. Gas release predictions in tanks that do not show evidence of GREs, or in those with large stored gas volumes but only small and occasional historic GREs, must rely on analytical models based on theory, experimental data, and indirect observations. Such models must also account for potential gas releases resulting from external disturbances such as a major seismic event, core sampling, or a waste transfer into or out of the tank.

The strength and viscosity of the nonconvective waste where the gas is stored must be known in order to understand these gas release mechanisms and to predict potential release volumes and rates using empirical or analytical models developed from that understanding. The ball rheometer is the only method currently available that can obtain these data in situ. In addition to the material strength and viscosity, ball rheometer data also yield convective layer density and the precise locations of the free liquid level and the top of the nonconvective layer as well as differences in strength or density within the nonconvective layer.

All of the details of operation of the ball rheometer and VFI during deployment are given in Section 2. The analytical methods for reducing the data and deriving gas volumes and other information are presented in Section 3. The results for each of the six tanks tested are described in Section 4 , and the conclusions drawn from the entire campaign are discussed in Section 5 . Section 6 lists all the references cited in the report. Supporting information can be found in the appendixes. 


\subsection{Data Acquisition}

This section describes how the raw data are obtained when the instruments are operated in the tanks. The test strategy, operating procedure, and field deployment activities are discussed in turn. An assessment of the uncertainty in the raw data is also given as is a description of how various supplemental information is obtained.

The ball rheometer and the VFI are operated in at least two risers on each tank. Ideally, the two risers are at different radii and separated in azimuth by at least a quadrant. Because each set of measurements provides the density, rheology, and void fraction only along an essentially single vertical line, measurements at two risers in different parts of the tank help to account for any nonuniformity in the waste. However, riser selection is sometimes quite limited because of previously installed equipment, because crane access is limited, or because of other conditions peculiar to a specific tank. In SY-101, for example, the two risers were both at the same azimuth because of interest in mixer pump efficacy as a function of radius. Sludge weights have often been removed to gain access to specific risers, if they are especially desirable.

Other factors that influence riser choice are the availability of other instrumentation in the vicinity, such as multifunction instrument trees (MITs), thermocouple trees, and level gauges. It is generally considered beneficial to obtain ball rheometer and VFI data near a location where a temperature profile measurement is available so that waste temperature, rheology, density, and void fraction can be correlated. A core sample from a nearby riser would also be advantageous in interpreting the data.

Other operations must also be considered. Ball rheometer data under a riser from which a recent core sample was taken would be of doubtful value. Likewise, disturbing the waste by operating the ball or VFI makes it impossible to obtain a representative core sample in that riser. Thus core sampling, ball rheometer, and VFI schedules need to be coordinated carefully. Because the VFI extends radially about $76 \mathrm{~cm}$ ( $30 \mathrm{in}$.) from the riser center line, it is not affected by ball operation or core sampling.

\subsection{Ball Rheometer}

The ball rheometer system must accommodate the widely differing properties of each waste layer while determining its dimensions and its rheology. Except for SY-101, all of the tanks have the same general waste configuration, a crust layer floating on the surface of a convective liquid layer. Beneath the liquid.layer is a nonconvective layer of settled solids that extends to the tank bottom. The crust is assumed to be strong enough to prevent ball penetration unless a hole is made with the water lance. The convective layer has a relatively low apparent viscosity, and high ball speeds are necessary to create a measurable drag force. The nonconvective layer has a wide range of strengths, and the lower portion may support the ball.

\subsubsection{Test Strategy and Procedure}

The ball rheometer is generally run prior to using the VFI. The majority of VFI measurement locations are selected below the top of the nonconvective layer where the gas is stored. The ball rheometer confirms the expected elevation of the transition or locates the actual one. It also prevents surprises by revealing unanticipated sublayering or waste properties for which the VFI test plan may need to be adjusted. 
The data collection procedure is the same for ail risers, but we treat the convective and nonconvective layers differently. The convective layer is expected to have no yield stress and a low viscosity. Thus ball speeds in this layer are relatively high, with pull and drop distances of several meters to obtain measurable drag on the ball. Tests are completed in the convective layer before the ball is lowered into the nonconvective layer.

In the nonconvective layer, the data collected with the falling ball on the first pass through the waste represent the rheology of the undisturbed fluid, while subsequent data collected with the ball rising and falling are representative of a disturbed fluid. To get the most detailed rheology information in this layer, short pull and drop distances (around $20 \mathrm{~cm}$ ) are used at only three speeds. Once the fluid no longer changes with continued shearing by the ball, longer distances are used to determine the rheology of the fully sheared fluid.

When the ball rheometer system is in place on the selected tank riser and ready for deployment, the ball is verified to be fully retracted in the "home position" at distance zero, our reference position. Then the ball is lowered through the riser to near the waste surface. Static measurements are made along the way at about $100-\mathrm{cm}$ intervals to establish the apparent weight of the ball and cable at the waste surface, which is important to static density measurements. Starting with the ball near the waste surface, we then perform tests in the dome space at all velocities to be used in the waste to determine pulley friction as a function of velocity. After completion of pulley friction measurements, the ball is prepared for measurements in the waste.

The free liquid surface elevation is established from the change in apparent ball weight as it passes from the dome space and into the liquid. Experiments are performed at ball velocities of 10, $30,50,70$, and $100 \mathrm{~cm} / \mathrm{s}$ in the convective layer. Relatively high velocities are required to produce a measurable drag force on the ball in this region, and data are acquired with both a rising ball and a falling ball. After completing the falling/rising ball experiments, the second series of static ball (zero velocity) tests are conducted at about $50-\mathrm{cm}$ intervals to find the convective layer density profile.

During the first tests in the nonconvective region we locate the top of the nonconvective layer by slowly dropping the ball from the convective region and observing the apparent weight of the ball. At the boundary the apparent weight begins to drop as the ball becomes increasingly supported by the fluid. Testing in the nonconvective layer begins just above this boundary. This layer must be tested differently than the convective layer, since its apparent rheology changes with each pass of the ball through it until several passes have been made.

The rheology of the undisturbed fluid and of the fully disturbed fluid are important to users of these data, and our testing attempts to obtain both. To do this we measure drag at several velocities over as small a distance as possible to resolve the waste rheology profile. Experience has shown that the rheology of the undisturbed waste can change measurably in less than a meter.

The first pass is the only opportunity available to determine the rheology of the undisturbed waste. The ball is dropped into the nonconvective region at $0.1 \mathrm{~cm} / \mathrm{s}$ for $20 \mathrm{~cm}$. The ball speed is then increased to $1 \mathrm{~cm} / \mathrm{s}$ for the rext $20 \mathrm{~cm}$ and to $10 \mathrm{~cm} / \mathrm{s}$ for the third $20-\mathrm{cm}$ segment. In addition, the data rate at $10 \mathrm{~cm} / \mathrm{s}$ velocity is increased to $100 \mathrm{samples} / \mathrm{second}$. This entire procedure is repeated every $60 \mathrm{~cm}$ until the ball stops, either reaching the tank bottom or waste with sufficient strength to fully support the ball.

The same procedure is repeated on the second pass as the ball is raised through the nonconvective layer. A third and fourth pass are also made through the nonconvective layer following the same procedure. Prior testing has shown that in most cases the fluid behavior does not change measurably after about four passes. Following these tests, falling and rising ball tests are performed over the entire depth of the nonconvective region. These tests are performed at 0.1 , 
1.0 , and $10.0 \mathrm{~cm} / \mathrm{s}$. Since the fluid is well sheared at this stage, the rheology does not change with additional passes, and the results from all velocities can be combined to determine the fluid rheology of the entire layer. Finally, static measurements are obtained at $50-\mathrm{cm}$ intervals to determine the fluid density. At this point, testing in the waste is completed and the ball is retrieved back into the rheometer enclosure.

\subsubsection{Field Deployment}

Before installing the ball rheometer assembly onto a tank, we water lance a passage through the crust for the ball. The thickness and hardness of the crust are difficult to estimate, so the crust is lanced in each riser in every tank to ensure that it will not stop the ball from being lowered into the waste. The first tank tested with the ball rheometer, SY-101, had a crust that would not allow the ball to penetrate. The crust was lanced, but ten days later it had reformed and the ball again failed to penetrate. The rheometer is now installed and operated either the same day as lancing or at most within 3-4 days. Because lancing is intended only to create a hole through the crust, the lance is lowered only to $61-91 \mathrm{~cm}(2-3 \mathrm{ft})$ below the crust surface. A collar on the bottom of the lance creates a minimum 9-cm (3.5-in.)-diameter hole through the crust. The water lance, shown in Figure 2.1, uses an average of less than $378 \mathrm{~L}$ (100 gal.) of water.

Once the crust has been lanced, the ball rheometer assembly, with a decontamination spray ring, is mounted directly to the tank riser flange. A crane positions and.lowers the ball rheometer assembly (approximately $700 \mathrm{lb}$ ) into place. The ball rheometer assembly is then bolted to a $25-\mathrm{cm}$ (10-in.) spray ring, which is in turn bolted to the tank riser flange. At this time the rheometer ball is still retracted inside of the assembly, and an isolation valve is closed to provide tank containment.

When ball rheometer testing has been approved by WHC Tank Farm Operations, the test team runs a series of prerequisite checks to verify that tank conditions, weather conditions, and all equipment are acceptable for rheometer operation as defined in the safety analysis (Sullivan 1995). The isolation valve is then opened and the ball is lowered through the riser, as shown in Figure 2.2.

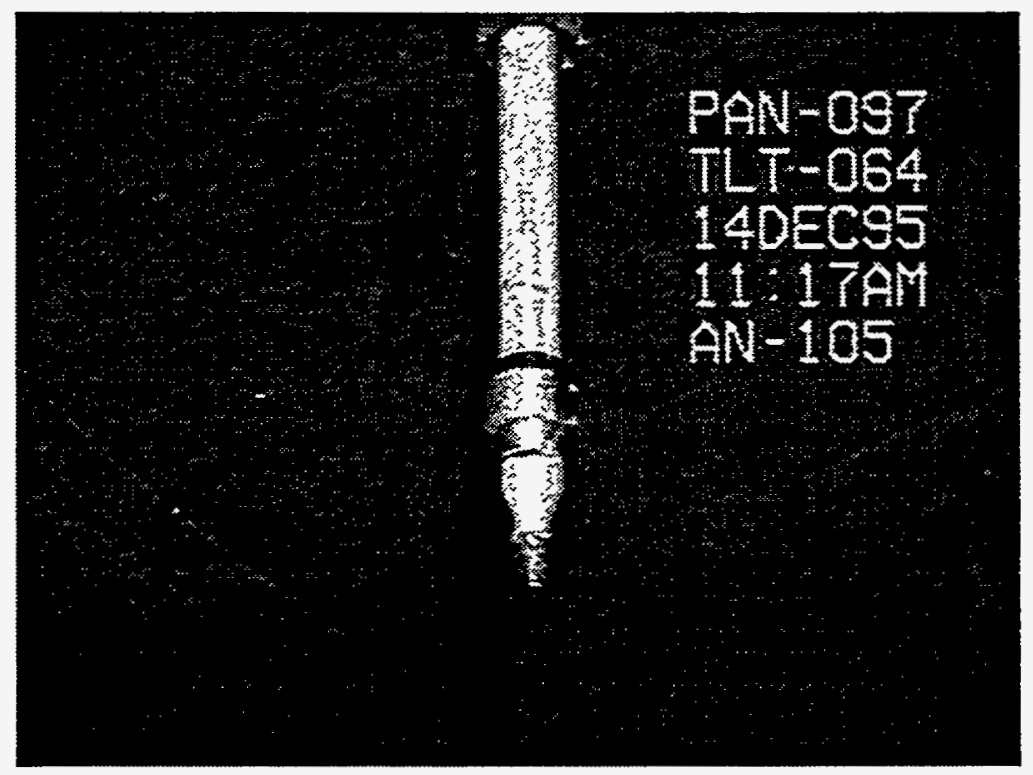

Figure 2.1. Water Lance in Dome 


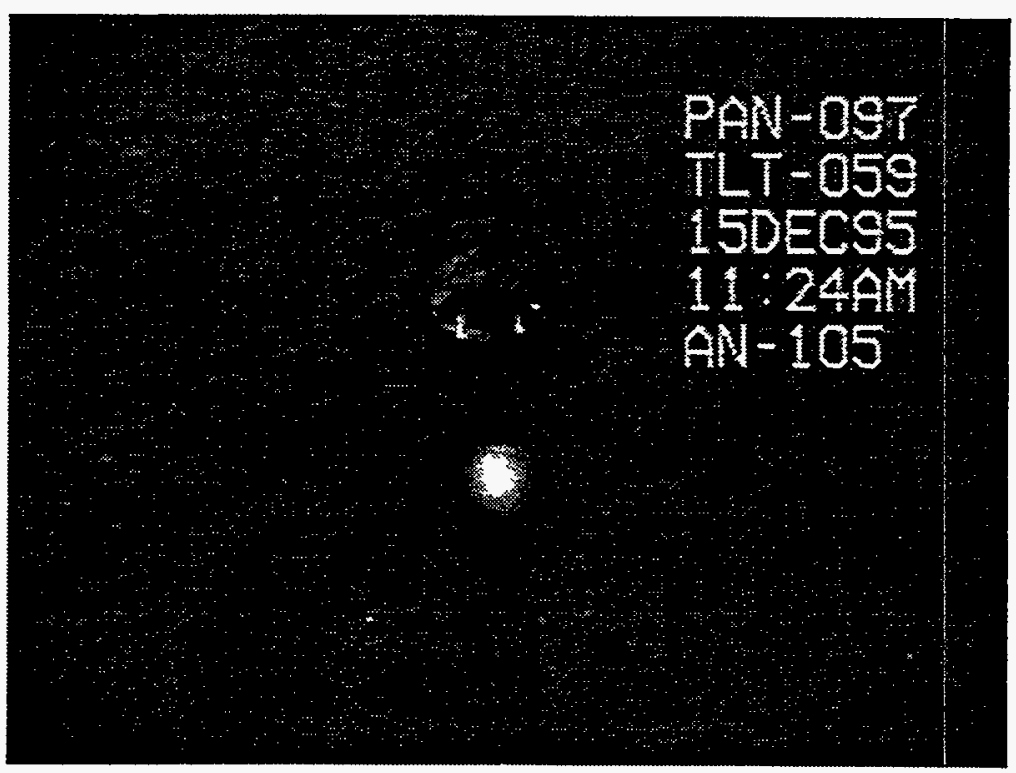

Figure 2.2. Rheometer Ball in Dome

Several strain-gauge-type load cells can be installed in the rheometer assembly as needed. The largest, 2200-N (500-lb)-capacity load cell is used initially when the ball is lowered through the riser to ensure that the ball can be retrieved even if the riser is not true. With the ball through the riser into the dome space, the riser straightness can be evaluated visually with the in-tank video camera. If the riser is true and contact-negligible between the cable or ball on the riser wall, the ball is withdrawn into the rheometer assembly so a lower-capacity, higher-accuracy load cell can be installed. In only one case has the riser not been true enough to allow use of the 445-N (100-lb) load cell. Once the isolation valve is opened, all raising and lowering of the ball theometer is done remotely from a control console located close by. All results are also received and recorded at this console.

The in-tank camera is used to monitor all water lance and rheometer activities in the tank. The video view of the ball approaching the waste surface is shown in Figure 2.3. The operation strategy of the rheometer within the waste is highly dependent on what is found during its use. The rheometer ball is raised and lowered at different speeds over varying distances throughout the waste from the surface to as low as the 76-N (17-lb) ball will sink (usually within 61-91 cm of tank bottom). When measurements have been completed, a high-pressure hot water pump is started to feed the decontamination spray ring while the ball is being retracted. On average, less than $38 \mathrm{~L}$ (100 gal.) is used for decontamination of the ball and cable. Once retracted back into the assembly the isolation valve is closed, restoring tank containment. Water lancing and installation of the rheometer assembly takes approximately 6 to 8 hours, and in situ testing takes from 6 to 10 hours.

\subsubsection{Ball Rheometer Raw Data and Uncertainties}

Four quantities are recorded during the tests: ball position reference to 'home,' ball velocity, force at the load cell, and elapsed time since the start of a test. Ball position is determined by monitoring an encoder attached to the cable spool; ball velocity is measured with a tachometer located on each of the drive's electric motors but is more accurately derived from the position and 


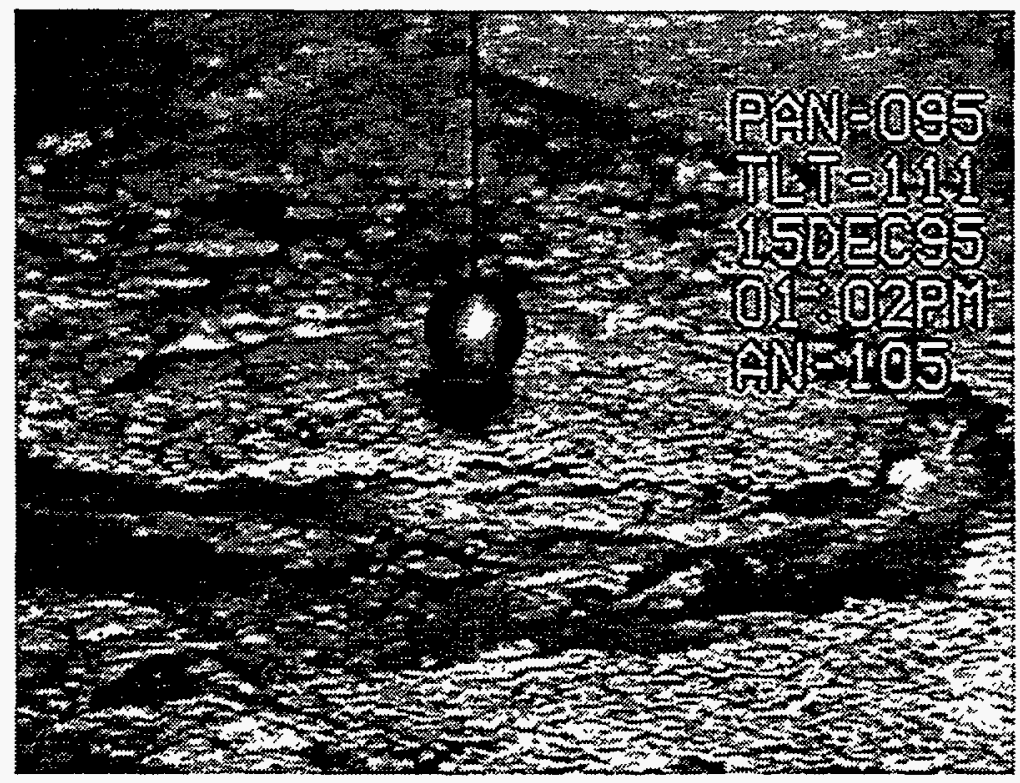

Figure 2.3. Rheometer Ball Approaching the Waste Surface in AN-105

the internal clock. The ball reference elevation, or 'home' position, must also be determined from tank drawings. Changes in the cable force also indicate the elevation of the free liquid level and the top of the nonconvective layer.

Virtually all cable force data obtained to date have been with a nominal 445-N.(100-lb) fullscale load cell. Because the cable runs over a pulley, the effective load limit is actually $222 \mathrm{~N}$ $(50 \mathrm{lb})$, half the load cell value. The advertised error for this load cell is $0.1 \%$ of the full-scâte reading, or $0.2 \mathrm{~N}$, regardless of load. Indeed, our data show that the standard deviation of measurements made under static and dynamic conditions is, in almost all cases, $0.2 \mathrm{~N}$, and we use this measurement error for all of our tests.

The liquid density measurement depends on both ball volume and buoyancy force. The uncertainty in buoyancy force is $0.2 \mathrm{~N}$. To determine density a reference measurement of the ball in air is required, and this value is subtracted in all density determinations. The reference measurement is also uncertain by $0.2 \mathrm{~N}$, but since it is used in all density determinations it represents a systematic error. The ball volume is uncertain by $1 \%$, also a systematic error.

Ball position is determined with a multiturn absolute rotary optical encoder that rotates with the cable spool. The encoder has 4096 steps per revolution; thus the positional accuracy is within $0.01 \mathrm{~cm}$, a negligible error, if the cable spool diameter is known exactly. Uncertainty in the cable spool diameter is the largest source of error in position. The spool diameter, including the cable, was measured to be $16.71 \mathrm{~cm}$ and is believed to be accurate to within $0.03 \mathrm{~cm}$; with $1000 \mathrm{~cm}$ of deployed cable, a positional error of about $2 \mathrm{~cm}$ is possible due to this uncertainty.

Velocity is determined by either of two methods. Tachometers are mounted to each drive motor for a direct velocity measurement. In addition, velocity can be determined from the change in ball position as a function of time. Since data are acquired at a known rate (usually 15 samples per second) and since positional accuracy is very good, ball velocity is most accurately determined by this second method. Errors in velocity are less than $1 \%$ and are negligible with regard to their effect on the determination of rheological parameters, where force measurement errors and corrections to the load cell data dominate the uncertainties. 
Home position is established when the ball approaches an inductive proximity sensor located between the orifice plate and the isolation valve through which the riser is accessed. The volume between these two barriers is the designed resting position for the ball when in storage or transport. At the beginning of a test the sensor will indicate the presence of the ball, and the encoder is zeroed to establish home position. At the completion of a test the ball is retrieved until the proximity sensor is activated, at which time software controls prevent further ball retrieval. Future tests then begin with the ball starting at this location. Home position is believed to be repeatable to well within $1 \mathrm{~cm}$.

There is additional uncertainty in the elevation of home position above the tank bottom. The elevation of the top of the riser and tank bottom are taken from design drawings that represent conditions before the tanks were filled. Attempts have been made to reference the ball position to the indicated waste level, but, because the ball buoyancy transition indicates the free liquid level and the waste level device senses the top of the crust layer, a difference can be expected. For the six tanks tested, the liquid level indicated by the ball averages $2 \mathrm{~cm}$ higher than the surface level, which is opposite what would be expected for a floating crust. In SY-101 the ball indicated the liquid surface to be $2.4 \mathrm{~cm}$ below the level measured by the Enraf gauge. Considering all sources, we ascribe an uncertainty of $\pm 4.5 \mathrm{~cm}$ (1.8 in.), or one ball radius, to elevations indicated by the ball.

The location of the ball in the tank is measured from its center to the 'home' position. To convert the indicated ball position to a height above the tank bottom, we subtract indicated position from the total distance from 'home' to the tank bottom. The height of the ball center above the bottom, $\mathrm{H}_{\mathrm{BALL}}$, is then found by

$$
\mathrm{H}_{\mathrm{BALL}}=\left(\mathrm{Z}_{\text {HOME }}-\mathrm{Z}_{\text {BOTTOM }}\right)-\mathrm{D}_{\text {BALL }}
$$

where $D_{\text {BALL }}$ is the indicated distance of the ball below 'home', $Z_{\text {HOME }}$ is the elevation of the home position, and $Z_{\text {BOTTOM }}$ is the elevation of the tank bottom. Table 2.1 provides values for these elevations for each of the tanks tested.

The ball rheometer locates the liquid level and the top of the nonconvective layer in each riser to within one ball radius $(4.6 \mathrm{~cm})$. Passage of the ball through the liquid surface is taken to be the midpoint of the decrease in tension due to increasing buoyancy as the ball submerges. This always occurs at the same elevation in both risers. Figure 2.4 shows the transition occurred in AN-105 at $705 \pm 5 \mathrm{~cm}(278 \pm 2$ in.) below 'home' position. From Equation (2.1) and Table 2.1, this equates to an elevation of $1746.8-705=1041.8 \pm 5 \mathrm{~cm}$ above the tank bottom, which compares very closely with the waste level of $1041 \pm 5 \mathrm{~cm}(410 \pm 2 \mathrm{in}$.) measured by the Enraf gauge on that day.

Table 2.1. Ball Home Position Reference

\begin{tabular}{|l|c|c|c|}
\hline \multirow{2}{*}{ Tank } & \multicolumn{2}{|c|}{$\begin{array}{c}\text { Tank As-Built Elevations (ft) } \\
\text { (home includes spool pieces) }\end{array}$} & $\begin{array}{c}\text { Calculated Home } \\
\text { Elevation (cm) }\end{array}$ \\
\cline { 2 - 3 } & Bottom & Home & \\
\hline AN-103 & 613.07 & 670.38 & 1746.8 \\
AN-104 & 613.07 & 670.38 & 1746.8 \\
AN-105 & 613.07 & 670.38 & 1746.8 \\
AW-101 & 632.23 & 689.38 & 1741.9 \\
SY-103 & 617.24 & 674.16 & 1734.9 \\
SY-101 & 617.24 & 674.16 & 1734.9 \\
\hline
\end{tabular}






Figure 2.4. Liquid Level Passage in AN-105

The interface between the convective and nonconvective layers is determined in a way similar to determining the liquid level. The tension on the ball decreases when passing downward into material with a higher viscosity, density, and, possibly, yield strength. But the sludge layer interface is not as well defined as that of the liquid level. Interface passage, taken as the point where tension begins to decrease from the constant value observed in the convective layer, is illustrated for AN-105 in Figure 2.5. In this tank, the top of the nonconvective layer is $50 \mathrm{~cm}$ (20 in.) higher below riser 16B than below riser 1B.

\subsection{Void Fraction Instrument}

In contrast to the continuous force and velocity data of the ball rheometer, the VFI makes a series of point measurements. Essentially all of the non-crust-retained gas is stored in the nonconvective layer, so most of test effort is concentrated in that layer. It is important to determine the void fraction at the lowest possible elevation, where the gas is most compressed by the hydrostatic pressure. In all of the tanks tested, the void fraction in the nonconvective layer increases from near zero at the top of the layer to a peak 1-2 meters below, after which it usually decreases slightly. The void fraction in the liquid layer generally measures less than $0.5 \%$ and contains effectively no gas. The VFI cannot be operated in the crust layer. 




Figure 2.5. Nonconvective Layer Entry in AN-105

\subsubsection{Test Strategy}

A test plan describes the locations where VFI measurements will be taken for each of the waste tanks in which the VFI is operated. The test locations are selected based on all available data from the tank and prior ball rheometer testing that indicate the extent of the crust, convective, and nonconvective waste layers. The ball theometer is deployed before the VFI in each riser to 1) describe the waste configuration so the locations for void measurements can be chosen with confidence, and 2) prevent the VFI from disturbing the waste through which the ball moves.

It is important to lower the VFI far enough below the crust layer (if one exists) to avoid damage before extending the lower arm. Therefore, information on waste depth and crust thickness are vital. The thickness of the convective layer is also important for planning the deployments. This information can be inferred from the temperature profiles, core samples, and ball rheometer cable force transitions.

Sample locations are selected to provide the best possible understanding of the void fraction distribution for the available time in the tank. Three parameters describe the sample location in the tank: the selected riser, the angular orientation of the lower arm, and its depth. The risers are selected based on availability and spatial distribution, as described earlier.

Up to four traverses are planned for each riser. In the first traverse the lower arm is normally pointed toward the center of the tank. For the second traverse, the lower arm is rotated 180 degrees to point away from the center. On the third traverse the arm is rotated 90 degrees clockwise from the second, and the fourth is 180 degrees from the third. Because of limits on time and/or nitrogen gas supply, the fourth and sometimes the third traverses are dropped. The 
transition measurement locations can be and usually are varied during VFI deployments based on what is found during the first traverse. All other parameters that can be controlled remain at the values previously determined by analysis or practice to give the best results.

The first VFI measurement in each riser is approximately $2 \mathrm{~m}(6 \mathrm{ft})$ below the waste surface, which ensures that the lower arm is rotated to the sampling position well beneath any crust and allows the system to come to thermal equilibrium with the waste while above the first test location. The minimum distance between VFI measurements is approximately $30 \mathrm{~cm}(1 \mathrm{ft})$. For the first traverse in each riser, at least four VFI readings are planned for the convective layer. A spacing of $30 \mathrm{~cm}(1 \mathrm{ft})$ is used for the nonconvective layer. The VFI is deployed as far into the tank as possible unless the crane load falls below a predetermined value indicating an obstruction. In no case should the VFI be deployed less than $15 \mathrm{~cm}$ (6 in.) from the tank bottom.

Once testing in the tank begins and void fraction data become available, some tests may be dropped from the middle of the matrix in an attempt to maximize the value of each measurement. The intent of modifying the test plan is to select measurement locations that best characterize the void fraction profile. Preliminary void fraction estimates are made during testing using a simplified void fraction model to guide the selection of testing locations. Final void fraction calculations are made after the testing has been completed for a riser. These calculations use the original data files and the complete void fraction model.

Double pressurizations are used for some VFI test locations. A double pressurization is the same as a single pressurization except that a second void fraction measurement is made on the sample before the cover is opened. For the second pressurization, initial pressures of the sample in the sample chamber and connecting line are the final pressures of the first test. The pressurization chamber is repressurized to its standard initial pressure and another pressurization cycle completed.

Double pressurizations were planned in the initial deployment in SY-101 because there was some concern that the O-rings might move slightly when the cover was initially closed, which would introduce an error into the measurement. The first pressurization would seat the $\mathrm{O}$-rings and eliminate this potential error on the second pressurization. It was also thought that double pressurization data might be useful in the future in evaluating the composition of the trapped gases, particularly ammonia. Since ammonia is highly soluble, two pressurizations might yield some information about the amount of ammonia driven back into solution at the higher pressures.

Almost all measurements in SY-101 used double pressurizations, but increasingly fewer have been used as testing progressed to other tanks. Since we have been using the real gas formulation for the pressurizing nitrogen, the difference between the first and second pressurizations has been very small. There is no indication from the testing in the laboratory or in the field that seating of the O-rings is a concern.

Several double pressurizations are still taken in each tank, normally when the void fraction is $2 \%$ greater than previously measured in the current riser. However, the number of double pressurizations is kept to a minimum to make better use of the time available and the nitrogen supply in obtaining data at other locations.

\subsubsection{Field Deployment}

The VFI is normally installed within one to two weeks after the ball rheometer has been installed in that same riser. Although the waste directly below the riser has been altered by multiple passes with the rheometer ball, the sample chamber passes through undisturbed waste approximately $76 \mathrm{~cm}$ (30 in.) away from the mast during operation. Because the VFI weighs about $1500 \mathrm{lb}$, it does not require water lancing to penetrate the crust layer. 
After removing the riser flange (or ball rheometer assembly if still in place), we lower a plug gauge through the length of the riser to ensure that the sample chamber and mast will pass through without interference. A ball valve is then installed directly onto the riser, and a spray ring is installed on top of that. Above the spray ring are two series of impact limiters, a tall set (55 in. high) on top of a short set ( 8 in. high). While the VFI is lying horizontal before installation, a full nitrogen bottle is installed in the instrument enclosure at the top of the mast and instrumentation and grounding cables are connected. A plastic sleeve for contamination control is slipped around the mast and pushed up to the top, where it is compressed as much as possible.

Once the VFI is prepared, two cranes lift it to a vertical orientation. One crane is connected to the top of the assembly and another to two clamps positioned to distribute the vertical forces along the mast. When upright, the crane supporting the lower end is disconnected and the first crane lifts the entire assembly into position over the impact limiters. At this time the ball valve has been opened, allowing access to the tank. While the VFI is slowly lowered into the tank, operators remove the existing plastic sleeving in which the VFI is stored.

An in-tank video camera is required for VFI operation to observe the mast entering the tank dome space (shown in Figure 2.6) to detect any interference of the mast and riser. The video camera is also used to determine the reference height when the arm pivot point (elbow) is at the waste surface. The sample chamber is shown approaching the waste surface in Figure 2.7. When the elbow is beneath the waste surface, its location is measured with a string potentiometer relative to this reference position. With the exception of the lifting and lowering performed by the crane, the VFI is now operated from a nearby control console using pneumatics to move parts of the assembly. All data are received and recorded at this console.

After passing through the waste surface, the VFI is lowered $1 \mathrm{~m}(4 \mathrm{ft})$ and the arm is rotated to the horizontal position. Then the sample chamber cover at the end of the arm is opened, exposing the chamber to the waste. This position is held for approximately 20 minutes to allow the system to come to thermal equilibrium with the waste. To take the sample, the VFI is lowered to the desired depth and the chamber is closed. A single measurement operation requires approximately 15 minutes. When the test is completed, the sample chamber cover is opened and the VFI is lowered to the next location.

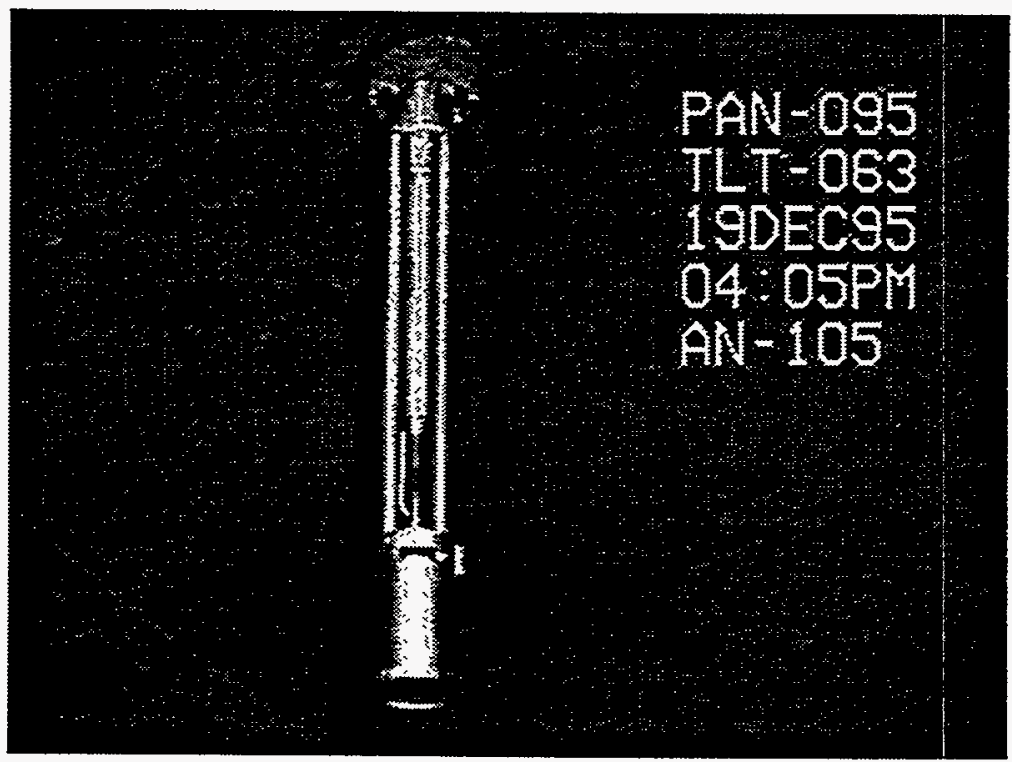

Figure 2.6. VFI Being Lowered into AN-105 Dome 


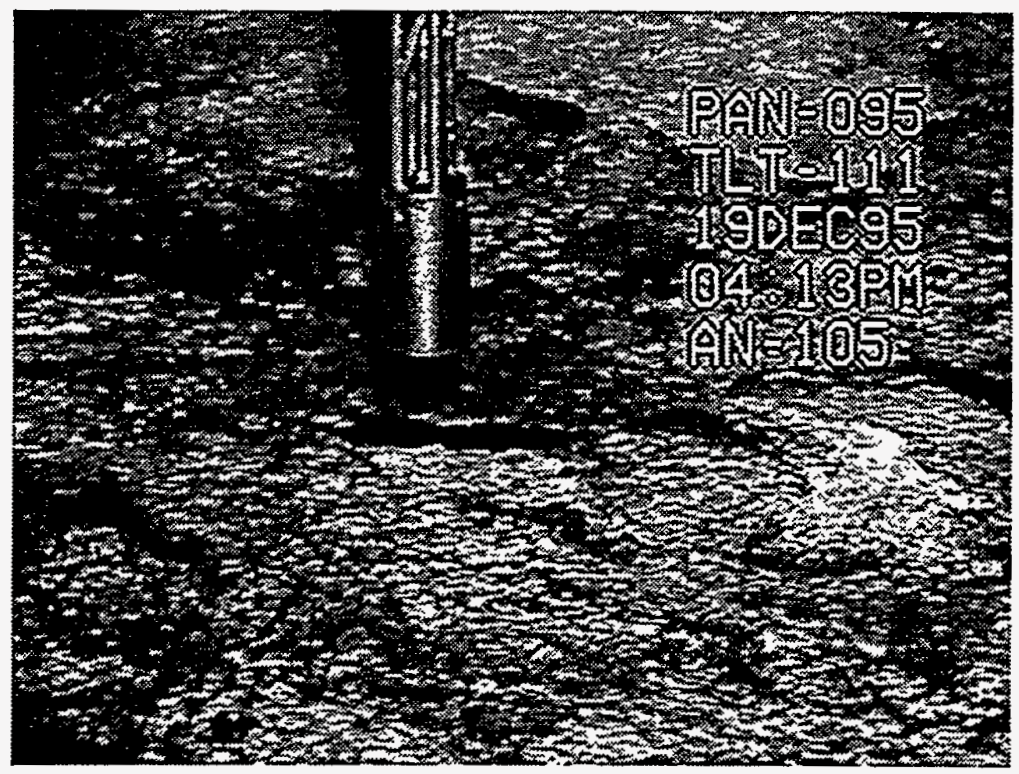

Figure 2.7. Closed Sample Chamber Approaching the Waste Surface

The VFI is lowered as far as possible into the tank. When the new sleeving is within $1 \mathrm{ft}$ of the tall impact limiters they are removed, leaving only the short impact limiters in place. Attainable depth in the tank can be limited by the physical dimensions of the mast, the length of the compressed sleeving, interference with the scaffolding over the riser, and unloading of the crane due to the VFI being partially supported in the waste. When a traverse through the tank is completed, the VFI is lifted to a level where the arm is well within the convective layer. The entire assembly is then rotated to a new orientation and lowered again for testing. By rotating the assembly, several locations can be tested on a $150 \mathrm{~cm}$-diameter circle below the riser centerline.

As with the ball rheometer, test strategy is highly dependent on the results found during testing. The first pass through the waste is the most detailed, with many sample locations, to determine a good profile of the void distribution through the depth of the tank. Subsequent orientations allow for inspection and verification of results in locations several feet away from the first pass.

After testing is completed, the VFI is slowly lifted out of the tank while operators place the sleeve around the mast to prevent the spread of contamination. During this removal, the spray ring is used to clean the mast with high-pressure water from two pumps. Figure 2.8 shows the sample chamber, with its cover open, during this mast decontamination process. When the instrumentation enclosure is high enough to allow installation of the tall impact limiters, they are put back into place on top of the short limiters. Once the bottom of the mast is clear of the spray ring and impact limiters, it is moved away from the riser, and the ball valve is closed to restore tank containment. The VFI is again lowered to the horizontal position with two cranes. The entire process of VFI testing in a specific riser takes from 12 to 16 hours.

\subsubsection{VFI Raw Data and Uncertainties}

The void measuring system consists of three known volumes: 1) a gas source volume initially charged with nitrogen up to $3.5 \mathrm{MPa}(500 \mathrm{psia}), 2)$ the volume of the line connecting the source volume with the sample chamber, and 3) the sample chamber of known size and optimal 




Figure 2.8. Open Sample Chamber in Dome During Decontamination

geometry to capture a waste sample mounted on a moveable arm. Each of these volumes was established precisely in the laboratory, including the effects of vessel expansion under pressure.

The volume of the pressurization chamber is $101.1 \pm 0.4 \mathrm{~cm}^{3}$. The pressurization chamber expands slightly with increasing internal pressure, but the change is insignificant and does not affect system accuracy. The connecting line is a 1.6-mm outside diameter, $18-\mathrm{m}$-long stainless steel tube with 0.5 -mm-thick walls. The volume of the line and fittings is $27.04 \pm 1.16 \mathrm{~cm}^{3}$. The calculated volumetric compliances of the line and fittings and the measured compliance of the pressure transducer show that the volumes of these components do not change significantly over their expected pressure ranges.

The sample chamber, which has a measured volume of $366.7 \mathrm{~cm}^{3}$, is the most compliant component in the system. Its volume increases slightly as it is pressurized. While only a minor contributor to the overall system error if neglected, the compliance of the sample chamber has been included in the void fraction calculation.

Temperatures are measured directly in the source volume and at several locations along the 18-m connecting line. The temperature of the waste in the sample chamber is inferred from temperatures measured about $76 \mathrm{~cm}$ away horizontally, at the base of the rotating arm. This remote temperature measurement is adequate because the void calculation is very insensitive to errors in waste temperature. A temperature error of $5^{\circ} \mathrm{C}$ would change the measurement by about $0.25 \%$ void (see Stewart et al. 1995 for detailed error analysis).

Measurements of pressure and temperature are recorded every two seconds starting before the sample chamber is closed and continuing until the test is completed and the sample chamber opened and ready to move to the next measurement location. While only a very limited amount of the recorded data are used in the calculation of the void fraction, the entire data set for each measurement can be useful in evaluating unusual or unexpected results. For example, the cover did not open quickly enough for one test and an unrealistic void fraction was calculated. It was obvious from the pressure time history of the sample chamber that the cover had not opened. 
The uncertainties in the pressure and temperature measurements are based on the calibration data for the individual sensors. The uncertainty in the initial pressure is $\pm 0.02 \mathrm{~atm}(0.3 \mathrm{psi})$, and the initial pressure of the waste sample has an uncertainty of $\pm 0.07 \mathrm{~atm}(1 \mathrm{psi})$. The reason for the larger error in the initial waste pressure is that it is taken to be the final pressure from the preceding measurement, after the system blows down when the sample chamber is opened. The uncertainty in the difference between initial and final pressures in each volume is $\pm 0.02 \mathrm{~atm}(0.3 \mathrm{psi})$.

The uncertainty in the initial temperature is $\pm 0.1^{\circ} \mathrm{C}\left(0.06^{\circ} \mathrm{F}\right)$, except for the temperature of the connecting line, which was assigned an error of $\pm 0.5^{\circ} \mathrm{C}\left(0.9^{\circ} \mathrm{F}\right)$ due to the potential for large temperature variations along the connecting line. The uncertainty in the differences between initial and final temperatures is $\pm 0.1^{\circ} \mathrm{C}\left(0.06^{\circ} \mathrm{F}\right)$.

The reference for the elevation of the sample chamber is the waste surface. The reference zero position is located by observing the elbow pivot for the lower arm passing into the waste on the in-tank video camera. The uncertainty in this observation is estimated as the radius of the pivot, which is about $4 \mathrm{~cm}$. The same uncertainty in relating the measured waste level elevation and the height of the liquid level penetrated by the VFI is taken to be the same as for the ball rheometer, $\pm 2 \mathrm{~cm}$. The total uncertainty in the level, then, is $\pm 5 \mathrm{~cm}$.

\subsection{Supplemental Information}

To plan ball rheometer and VFI tests and interpret the data they provide, several items of information are required from independent sources, including waste temperature, nonconvective layer density, and waste layer dimensions, which are discussed below. Riser location, availability, and dimensions, and general tank design data are also needed, and gas composition is of interest.

\subsubsection{Waste Temperature}

The waste temperature profile is required to correct the in situ gas volume to standard conditions. The shape of the temperature profile also provides a valuable sounding of the nonconvective layer depth. Changes or lack of changes in the temperature profile sometimes indicate where gas release events (GREs) originate. Each of the tanks tested have temperature profiles in two locations by means of the recently installed MITs and the original thermocouple trees. Tank SY-101 has two MITs.

MITs have 22 thermocouples spaced $30-60 \mathrm{~cm}$ (12-24 in.) apart beginning $10 \mathrm{~cm}$ (4 in.) from the tank bottom. These are usually read manually, except in SY-101, where the readings are made automatically every 12 seconds. A validation probe that measures temperature every $10 \mathrm{~cm}$ (4 in.) with a high-precision resistance temperature detector (RTD) is operated occasionally to confirm thermocouple readings. The higher resolution of the validation probe profile gives a very accurate reading on the nonconvective layer depth and is essentially the only device that can determine the crust thickness.

Readings from the old thermocouple trees are made manually. The thermocouples are spaced approximately every $125 \mathrm{~cm}$ (50 in.), with the first reading near the tank bottom. But, since only half to one-third of the 20 thermocouples may be recorded, there is a large uncertainty in waste layer dimensions derived from these temperature profiles.

Temperature is also recorded on the VFI mast as it penetrates the waste; however, this reading is of limited use because the motion of the mast mixes cool convective liquid with the nonconvective waste and disrupts the temperature profile. In fact, VFI temperature readings show 
exactly the same trend as the new MTT in SY-103 did immediately after it was installed in October 1994. Later readings showed that the waste did not 'heal' and recover the true temperature profile for at least a month.

The uncertainty in the temperature read by a thermocouple, whether on an MIT or thermocouple tree, is estimated at $\pm 1.8^{\circ} \mathrm{C}\left(3^{\circ} \mathrm{F}\right)$ (Brewster et al. 1995). However, experience with SY101 data (Stewart et al. 1994, 1995) has shown that MIT thermocouples are easily able to register temperature changes of $0.06^{\circ} \mathrm{C}\left(0.1^{\circ} \mathrm{F}\right)$. The uncertainty in the absolute temperature reading of the MIT validation probe is $\pm 0.2^{\circ} \mathrm{C}\left(0.3^{\circ} \mathrm{F}\right)$.

The temperature profiles from the MIT and thermocouple trees provide a measurement of the height of the nonconvective layer. Since the temperature gradient in a nonconvective, heatgenerating region is parabolic and that in a convective region is uniform, the boundary is located where the uniform and parabolic temperature profiles intersect. This is usually accomplished by visually interpreting a graph. The uncertainty is assigned as half the distance between temperature measurements.

For example, consider the segment of the temperature profile from SY-103 in Figure 2.9. Profiles from the MIT, the original thermocouple tree, and an MIT validation probe run are given. The plot is interpreted to give nonconvective layer heights of $360 \pm 25 \mathrm{~cm}, 340 \pm 40 \mathrm{~cm}$, and $325 \pm 5 \mathrm{~cm}$, respectively.

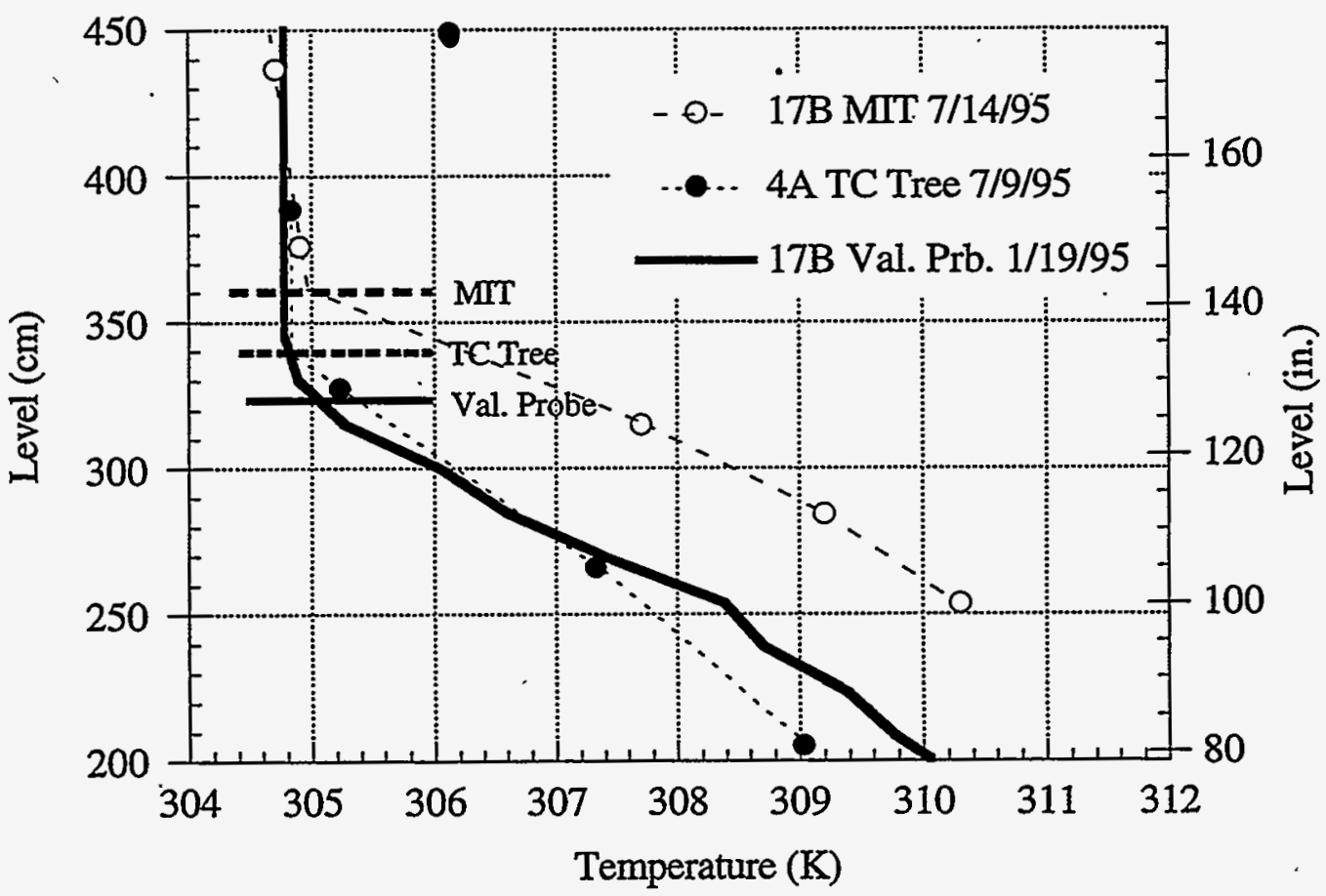

Figure 2.9. Temperature Profile Segment from SY-103 


\subsubsection{Waste Level}

The elevation of the waste surface above the tank bottom is a key indicator of tank status and waste behavior. Tanks with a high waste level are generally more hazardous because they store gas at a higher pressure, and less headspace is available to dilute episodic gas releases. One of the primary objectives of VFI operation is to match an accurate estimate of retained gas volume with waste level at a point in time so that the past and future level measurements also indicate gas volume. The level also serves as a reference for.VFI sample elevation and serves as a consistency check with ball rheometer liquid level passage.

Waste surface level is typically measured with three different devices: the Food Instrument Corporation (FIC) contact probe, a manual tape, and the Enraf ${ }^{\text {buoyancy gauge. }}{ }^{\text {(a) }}$ FIC and manual tape level readings are available in each DST essentially from the time they started operation in the late 1970s. But only the time period since the mid-1980s, from the last fill, is of interest as evidence of current and future gas release behavior. Enraf level gauges have been installed only since 1995, so their history is limited. Level measurements may be either manual or automatic; early data are weekly; daily or once-per-shift readings have been available since the late 1980s.

The various instruments report different values and trends, mainly due to the irregularity of the crust surface but also due to peculiarities of the measurement method. The readings of each level gauge in SY-101 from January 1, 1994, to July 17, 1995, are shown in Figure 2.10 to illustrate the magnitude of the differences.

The FIC and manual tape must be flushed occasionally to remove accumulated deposits called 'wastecicles.' In-tank video in SY-101 showed that repeated flushing eroded the crust near the FIC, and repeated contact with the waste excavated a distinct cavity several centimeters deep. The short-term effect of flushing is not predictable. The flush water is much less dense than the waste liquid and tends to pool at a higher level until it mixes with the waste. This level rise may exceed the length of the wastecicle that was removed, so the FIC actually reads higher for a week or so after the flush than before. The manual tape is also subject to wastecicle buildup but is seldom flushed and thus disturbs the crust less.

The Enraf buoyancy gauge does not depend on electrical contact and merely sits stationary on the waste surface. Thus it is not subject to buildup of waste deposits nor does it disturb the surface on which it rests. This makes the Enraf potentially the most reliable level indicator.

The accuracy of any of the instruments depends on the waste surface irregularity and the uncertainty in the reference position which, in combination, could produce a systematic error of 2 to $10 \mathrm{~cm}$, depending on the tank. Precision in sensing level changes is far more important than absolute accuracy, however. A study of SY-101 data (Brewster et al. 1995) concluded that the Enraf correlated most closely with gas releases and was the most precise level instrument. It records level in $0.025-\mathrm{cm}(0.01-$ in.) increments and is easily able to resolve level changes to within $\pm 0.25 \mathrm{~cm}(0.1 \mathrm{in})$. The FIC usually responded closely with the Enraf and correlated reasonably well with gas release in $S Y-101$. It records level in $0.25 \mathrm{~cm}(0.1$-in.) increments and its sensitivity is estimated at $\pm 0.6 \mathrm{~cm}$ ( 0.25 in) for nearly consecutive readings, but wastecicle growth and periodic flushing adds an uncertainty of $\pm 5 \mathrm{~cm}$ ( 2 in.) in long-term values.

(a) SY-101 measured level by radar from 1993 to 1995, but the radar gauge was erratic at times, especially during gas releases, and it was unclear whether it indicated the actual waste surface or some related quantity sensitive to surface moisture. It eventually succumbed to radiation damage. 


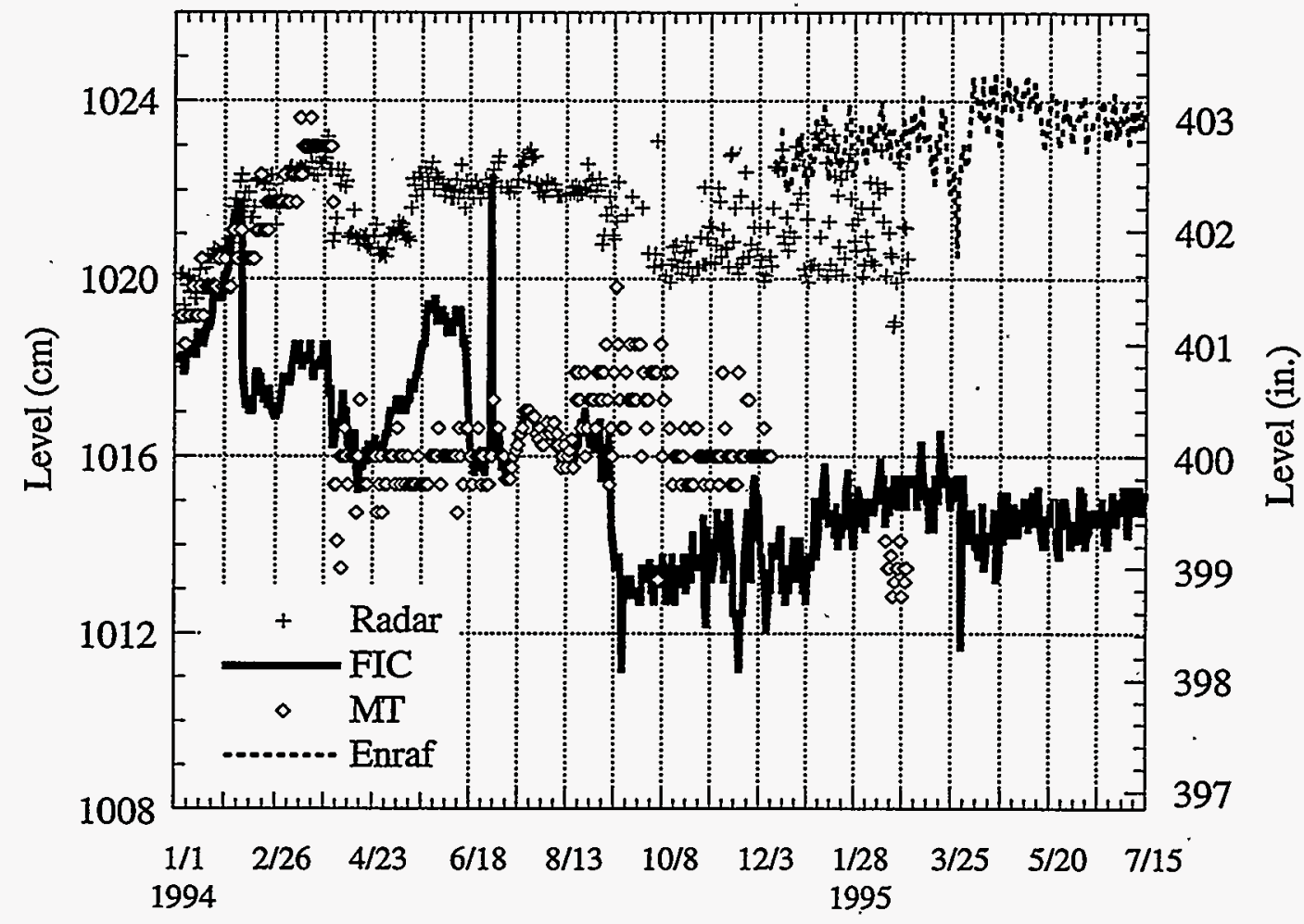

Figure 2.10. SY-101 Waste Level History

The manual tape is typically read in $0.64 \mathrm{~cm}(0.25$-in.) increments, so it senses changes only to within $\pm 2 \mathrm{~cm}(0.75 \mathrm{in}$.) at best. Because of this low sensitivity, the manual tape was uncorrelated with any of the other instruments or with gas release in the SY-101 study. In screening the tanks for trapped gas, Whitney (1995) found that the response of manual tape readings to barometric pressure changes was not as valid an indicator of gas retention as the FIC and Enraf. The manual tape history is generally not used in this study to determine a tank's GRE history.

\subsubsection{Waste Density}

The waste density is required to compute the hydrostatic pressure at which the gas is stored. In the tanks tested, the hydrostatic pressure ranges from 1.8 to $2.5 \mathrm{~atm}$. This means the stored gas volume, expanded to standard pressure, is about twice the volume it occupies in situ. The convective layer density ranges from just over 1.4 to $1.6 \mathrm{~g} / \mathrm{cm}^{3}$, while the nonconvective layer density ranges from just under 1.6 to $1.8 \mathrm{~g} / \mathrm{cm}^{3}$.

The ball rheometer provides density measurements in the liquid region but does not measure density accurately in the nonconvective layer, where the waste strength may partially support the ball. An accurate nonconvective layer density would be available from prior core sample analysis, if a core was taken recently. If not, density must be estimated based on densities measured in other tanks with similar waste. In this report, core sample data were available for SY-101, SY-103, AN-103, AN-105 and AW-101. The nonconvective layer density in AN-104 was assumed to be the same as that in AN-105. 


\subsubsection{Gas Composition}

The waste gas composition is one of the most important quantities in evaluating the flammable gas hazard of a specific tank. The gas composition determines both the LFL of the gas mixture and the energy it would release if burned. The peak pressure calculations presented to compare the potential consequences of the stored gas volumes measured by the VFI require an estimate of the gas composition.

The background headspace concentration of flammable gas species that are not present in air give indirect evidence of the waste gas composition. The composition of the headspace atmosphere in DSTs on the FGWL is continuously monitored with a variety of instruments including gas chromatographs, Fourier transform infrared (FTIR) spectrometers, and flammable gas monitors. Grab samples are periodically collected and analyzed in PNNL's high-resolution gas mass spectrometer. But the headspace composition will not correctly reflect the contribution of dissolved gas that may evolve during a release. The GREs in SY-101 before the mixer pump was installed were large enough to fill the dome and provide a direct measure of the gas release composition. Thankfully, the waste gas composition does not need to be determined this way in any other tank.

A rough estimate of the waste gas composition can be derived from the ratios of the background concentrations of the most prevalent flammable species in the headspace that are not present in air. Ratios of hydrogen-to-nitrous oxide and hydrogen-to-methane are typically used. This assumes that the same gas concentration ratios exist in the waste as in the head space. The concentrations of diluent and soluble gases (e.g., nitrogen, oxygen, ammonia, and water vapor) must be estimated to complete the composition. Unfortunately, a high degree of scatter typically exists in the headspace concentrations, and the assumed concentrations of unmeasured components have high uncertainty and may not include all important species present in the waste gas.

The retained gas sampler (RGS) is the only instrument currently available to actually measure the waste gas composition in situ. The RGS is a modified version of the universal core sampler designed to be absolutely leak-tight (Cannon and Knight 1995). RGSs are loaded into the drill string during a normal push-mode core sampling event. After capturing a waste sample and recovering it from the drill string, the sampler is X-rayed to determine whether a full sample was captured and then carried to the 222-S laboratory. In the laboratory, the sample is extruded into an extraction vessel, where the waste gas is removed for analysis by a combination of stirring, vacuum pumping, and heating. Samples of the gas are taken at each stage of the extraction process and sent to PNNL for mass spectrometry.

Not only does the RGS provide gas composition, but the void fraction can be derived from the extraction results. In addition, the X-rays provide surprising details about the size, number, and shape of the gas bubbles in the waste.

The preliminary RGS composition data available for $\mathrm{AW}-101^{(\mathrm{a})}$ and $\mathrm{AN}-105^{(\mathrm{b})}$ were used in this report. Though these data are still under review, we believe they are the best available estimates of the waste gas composition in these tanks. The RGS void fractions from AW-101 are

(a) Shekarriz, A, DR Rector, MA Chieda, M White, and JM Bates. 1996. Retained Gas Sampler Measurement Results for Hanford Waste Tank 241-AW-101. Letter report TWS-MIT-071996, Pacific Northwest National Laboratory, Richland, Washington.

(b) Preliminary data supplied by JM Bates, PNNL, August 1996. 
also compared with those measured with the VFI in Section 4. The gas composition for SY-101 and SY-103 are taken from the SY-101 mixer pump safety analysis (Sullivan 1995); those for AN104 are assumed to be the same as measured in AN-105; and the AN-103 composition was assumed the same as the RGS results from AW-101 because of their similar low headspace nitrous oxide-to-hydrogen ratios. 


\subsection{Analytical Methods}

\subsection{Rheology}

This section describes how the viscosity, apparent viscosity, and yield stress of the waste are derived from the ball rheometer drag data. The data analysis strategy was developed to accommodate variations in theology between waste layers within the limitations of the ball rheometer operation. Each major waste layer's rheology may differ considerably from its neighbors and may consist of sublayers less than a meter thick with distinct rheology of their own. Since drag measurements from at least three speeds are required to derive the layer's rheology, the precision of the ball/cable drive system is pushed to the limit.

Each major waste layer requires different analysis strategies. The convective layer behaves as an essentially Newtonian fluid, and the nonconvective settled solids layer is non-Newtonian. The apparent viscosities of the two layers differ by several orders of magnitude, and the nonconvective layer is a stratified shear-dependent material with yield stress that usually exhibits timedependent behavior. A high traverse speed is necessary to produce a detectable force on the ball rheometer when it is moving through the convective layer. Very slow speeds are used in the nonconvective layer to resolve its varying properties over as short a distance as possible. Accordingly, the ball rheometer operates in the turbulent flow regime in the convective layer and in the creeping flow regime in the nonconvective layer. An exception is the waste in Tank 241-SY-101, where the waste was found to be non-Newtonian throughout due to mixing (Stewart et al. 1995).

A Newtonian fluid, in which the shear stress is linearly dependent on strain rate, is characterized by a fixed viscosity. The viscosity is derived from ball rheometer tension and velocity data accounting for the additional drag on the cable. A non-Newtonian fluid is characterized in terms of the apparent viscosity and yield stress. The apparent viscosity depends on the particular rheological model used. The Herschel-Bulkley model is adopted in this study because it captures shear-thinning/thickening behavior and accommodates a yield stress. The flow field around the ball/cable system moving through a non-Newtonian fluid is very complicated and involves a wide range of strain rates around the ball. Nevertheless, the apparent viscosity and yield stress can be derived from ball rheometer data using experimental correlations for the drag on a sphere in a viscoplastic fluid.

\subsubsection{Convective Layer Viscosity}

The viscosity of the convective layer is calculated from cable tension measurements obtained by lowering and raising the ball/cable system at a constant velocity over distances of 1 to $3 \mathrm{~m}$. The contributions to the tension force include the following effects:

$\begin{array}{ll}\text { pulley friction } & \mathbf{f} \\ \text { ball weight } & \mathrm{Wb}_{\mathrm{b}} \\ \text { ball buoyancy } & \mathrm{B}_{\mathrm{b}} \\ \text { cable weight } & \mathrm{W}_{\mathrm{c}} \\ \text { cable buoyancy } & \mathrm{B}_{\mathrm{c}} \\ \text { drag on the ball } & \mathrm{D}_{\mathrm{b}} \\ \text { drag on the cable } & \mathrm{D}_{\mathrm{c}}\end{array}$


The magnitude of the tension depends on whether the ball/cable system moves up or down. The load cell tensions, $T_{u}$ and $T_{d}$, indicate upward and downward motion, respectively, and can be expressed in terms of the above components as

$$
\begin{aligned}
& T_{u}=W_{b}+W_{c}-B_{b}-B_{c}+D_{b}+D_{c}+f \\
& T_{d}=W_{b}+W_{c}-B_{b}-B_{c}-D_{b}-D_{c}-f
\end{aligned}
$$

The combined force increases with depth because of the increasing contribution of the cable. From Equation (3.1.1a-b), the combined ball and cable drag is

$$
D_{b}+D_{c}=\frac{T_{u}-T_{d}}{2}-f
$$

The time for flow field around the cable to reach a steady state is much greater than the ball traverse time during a measurement. Therefore, the shear stress on the cable, $\tau$, as a function of. time is obtained by solving the equations of motion for an impulsively started cable of infinite extent moving along its axis in an unbounded viscous fluid. The momentum equation and the initial and boundary conditions are

$$
\begin{aligned}
& \frac{\partial v}{\partial t}=\frac{\mu}{\rho} \frac{1}{r} \frac{\partial}{\partial r}\left(r \frac{\partial v}{\partial r}\right) \\
& v(r, t=0)=0 \\
& v(r=R, t)=U \\
& v(r \rightarrow \infty, t)=0
\end{aligned}
$$

where $\mathrm{v}$ is the axial velocity in the fluid, $\mathrm{t}$ is time, $\mathrm{r}$ is the radial coordinate (perpendicular to the cable axis, see Figure 3.1.1), $\mu$ is the fluid viscosity, $\rho$ is the fluid density, $U$ is the speed at which the ball and cable system moves, and $R$ is the cable radius. The closed form solution of Equation (3.1.3a-d) can be obtained using the Laplace transform method (Carslaw and Jaeger 1973). The instantaneous shear stress at the cable surface is found from the derivative of the. velocity with respect to $r$. Thus

$$
\tau(\mathrm{t})=-\left.\mu \frac{\partial \mathrm{v}}{\partial \mathrm{r}}\right|_{\mathrm{r}=\mathrm{R}}=\frac{2 \mu \mathrm{U}}{\pi \mathrm{R}} \int_{0}^{\infty} \exp \left(-\frac{\mu \mathrm{ty}^{2}}{\rho \mathrm{R}^{2}}\right) \frac{\mathrm{J}_{1}(\mathrm{y}) \mathrm{Y}_{0}(\mathrm{y})-\mathrm{J}_{0}(\mathrm{y}) \mathrm{Y}_{1}(\mathrm{y})}{\mathrm{J}_{0}^{2}(\mathrm{y})+\mathrm{Y}_{0}^{2}(\mathrm{y})} \mathrm{dy}
$$

where $\mathrm{J}_{0}, \mathrm{Y}_{0}, \mathrm{~J}_{1}, \mathrm{Y}_{1}$ are Bessel functions.

The total cable drag is the sum of the drag on the cable as it moves through the region between the liquid surface and the position of the top of the ball at the time when measurements begin and the drag on the section of cable extending downward from the initial position as the measurement proceeds. 




Figure 3.1.1. Velocity Field Induced by a Cable Moving Along Its Axis

If a drag measurement is made from initial position $\mathrm{L}_{1}$ to a final position $\mathrm{L}_{2}$ below the surface, the average drag force on the cable due to contributions $\mathrm{D}_{\mathrm{c} 1}$ and $\mathrm{D}_{\mathrm{c} 2}$ are, respectively,

$$
\begin{aligned}
& D_{\mathrm{cl}}=\frac{2 \pi R L_{1} \mathrm{U}}{\mathrm{L}_{2}} \int_{0}^{\mathrm{L}_{2} / \mathrm{U}} \tau(\mathrm{t}) \mathrm{dt} \\
& \mathrm{D}_{\mathrm{c} 2}=\frac{2 \pi R \mathrm{U}^{2}}{\mathrm{~L}_{2}} \int_{0}^{\mathrm{L}_{2} / \mathrm{U}}\left[\int_{0}^{\mathrm{t}} \tau\left(\mathrm{t}-\mathrm{t}^{\prime}\right) \mathrm{dt} \mathrm{t}^{\prime}\right] \mathrm{dt}
\end{aligned}
$$

A general relationship between cable drag and velocity can be conveniently written as a correlation between cable drag coefficients, $C_{D c i}$, and cable Reynolds number, $R_{c}$, defined by

$$
\begin{aligned}
& C_{D c i}=\frac{D_{c i}}{\pi R L_{i} \rho U^{2}} . \quad i=1,2 \\
& \operatorname{Re}_{c}=\frac{\rho U R}{\mu}
\end{aligned}
$$


Upon substitution of Equation (3.1.4), numerical integration of Equations (3.1.5) and (3.1.6) and application of Equations (3.1.7) and (3.1.8) leads to correlations that have the functional form

$$
C_{D c i}=\frac{\alpha_{i}}{\operatorname{Re}_{c}^{\beta_{i}}}
$$

where the coefficients $\alpha_{i}$ and $\beta_{i}$ are given in Table 3.1. Note that the cable drag correlations used are based on a time-averaged shear stress.

The drag force on the ball can be calculated from correlations between drag coefficient, $C_{D b}$, and ball Reynolds number, $\operatorname{Re}_{b}$, which are defined by

$$
C_{D b}=\frac{8 D_{b}}{\pi d^{2} \rho U^{2}}
$$

and

$$
\mathrm{Re}_{\mathrm{b}}=\frac{\rho U \mathrm{~d}}{\mu}
$$

where $d$ is the ball diameter. The following experimental correlation proposed by Khan and Richardson (1987) has an uncertainty of no more than $5 \%$.

$$
C_{D b}=\left(2.25 \operatorname{Re}_{b}^{-0.31}+0.36 \operatorname{Re}_{b}^{0.06}\right)^{3.45}
$$

Substituting Equations (3.1.7) and (3.1.10) into (3.1.2), we obtain a nonlinear equation for the viscosity, which must be solved numerically. The functional form is

$$
F(\mu)=H
$$

where

and

$$
F(\mu)=R L_{1} C_{D 1}(\mu)+R L_{2} C_{D 2}(\mu)+\frac{d^{2}}{8} C_{D b}(\mu)
$$

Table 3.1. Correlation Coefficients for the Cable Drag Correlations

\begin{tabular}{|c|c|c|c|c|}
\hline Range of $\mathrm{Re}_{\mathrm{c}}$ & $\alpha_{1}$ & $\beta_{1}$ & $\alpha_{2}$ & $\beta_{2}$ \\
\hline $0.05-500$ & 0.580 & 0.826 & 0.315 & 0.811 \\
\hline $10^{-1}-10^{-4}$ & 0.433 & 0.940 & 0.120 & 0.984 \\
\hline
\end{tabular}




$$
\mathrm{H}=\frac{1}{\pi \rho \mathrm{U}^{2}}\left(\frac{\mathrm{T}_{\mathrm{u}}-\mathrm{T}_{\mathrm{d}}}{2}-\mathrm{f}\right)
$$

The value of $H$ is obtained experimentally. For low-viscosity fluids (such as water), there is a great deal of scatter in the determination of the tensions, $T_{\mathfrak{u}}$ and $T_{d}$, with the load cells that can be used in the ball rheometer. In addition, high-velocity measurements are needed when the ball rheometer is testing low-viscosity fluids so that the forces are detectable with the load cells. This situation produces oscillations in the measurements, which increases the level of uncertainty. In this case, Equation (3.1.13a-c) can be used to determine an upper bound for the viscosity rather than a precise value.

\subsubsection{Apparent Viscosity of the Nonconvective Layer}

The apparent viscosity is defined for viscometric flows as the ratio of the shear stress function $\tau_{\mathrm{s}}(\dot{\gamma})$ divided by the strain rate $\dot{\gamma}$ (Skelland 1967). For the Herschel-Bulkley constitutive equation (Skelland 1967), the apparent viscosity $\mu_{\mathrm{a}}(\dot{\gamma})$ in pure shear is

$$
\mu_{\mathrm{a}}(\dot{\gamma})=\frac{\tau_{\mathrm{o}}}{\dot{\gamma}}+\mathrm{K} \dot{\gamma}^{\mathrm{n}-1}
$$

where $\tau_{\mathrm{o}}$ is the yield stress (in $\mathrm{Pa}$ ), $\mathrm{K}$ is the consistency factor in ( $\mathrm{Pa}-\sec ^{\mathrm{n}}$ ), and $\mathrm{n}$ is the behavior index. This model is adopted here because of its versatility in describing a viscoplastic material.

The ball and cable velocities are much smaller $(0.1-10 \mathrm{~cm} / \mathrm{s})$ in the nonconvective layer than in the convective layer. The high apparent viscosities in the nonconvective layer and the low velocities of the ball are indicative of creeping flow. The drag force on a ball traversing in a viscoplastic material in the creeping flow regime can be estimated from an experimental correlation for the ball drag coefficient, $C_{D b}$ (Atapattu et al. 1995). By defining a generalized ball Reynolds number for viscoplastic fluids, $\mathrm{Re}_{\mathrm{Gb}}$,

$$
\operatorname{Re}_{G b}=\frac{\rho U^{2}}{\tau_{o}+K\left(\frac{U}{d}\right)^{n}}
$$

Atapattu's correlation can be written as

$$
\mathrm{C}_{\mathrm{Db}}=\frac{24}{\operatorname{Re}_{\mathrm{Gb}}}
$$

which indicates that the same functional relationship holds in both Newtonian and purely viscous non-Newtonian fluids, provided a generalized Reynolds number is introduced (Chhabra 1993).

The flow field generated when the ball/cable system traverses through the waste is very complicated and involves a wide range of strain rates in the fluid around the ball. Therefore we define a strain rate measure, $\dot{\gamma}_{\mathrm{m}}$, as the ratio of the ball velocity divided by the ball diameter 


$$
\dot{\gamma}_{\mathrm{m}}=\frac{\mathrm{U}}{\mathrm{d}}
$$

The choice of this measure is consistent with the definition of the generalized ball Reynolds number. By analogy with Equation (3.1.14), the apparent viscosity obtained with the ball rheometer, $\mu_{\text {app }}$, is

$$
\mu_{\mathrm{app}}=\frac{\tau_{\mathrm{o}}}{\dot{\gamma}_{\mathrm{m}}}+\mathrm{K} \dot{\gamma}_{\mathrm{m}}^{\mathrm{n}-1}
$$

A generalized cable Reynolds number, $\mathrm{Re}_{\mathrm{Gc}}$, for a Herschel-Bulkley fluid can be defined in terms of the apparent viscosity

$$
\mathrm{Re}_{\mathrm{Gc}}=\frac{\rho \mathrm{UR}}{\mu_{\mathrm{app}}}
$$

It is assumed that the cable drag in a viscoplastic fluid can be calculated from Equation (3.1.9) with $\operatorname{Re}_{\mathrm{Gc}}$ instead of $\mathrm{Re}_{\mathrm{c}}$.

In the case of time-independent fluids, the apparent viscosity for a given value of $\dot{\gamma}_{\mathrm{m}}$ is obtained by solving an equation similar to Equation (3.1.13), in which the appropriate correlations (for the ball and the cable) and the generalized Reynolds numbers have been used. In general, the nonconvective layer is stratified and its rheological behavior is a function of elevation, $z$. Therefore, the equation for the apparent viscosity has the form

$$
\mathrm{F}\left(\mu_{\mathrm{app}} ; \mathrm{z}, \dot{\gamma}_{\mathrm{m}}\right)=\mathrm{H}\left(\mathrm{z}, \dot{\gamma}_{\mathrm{m}}\right)
$$

with $\mathrm{F}$ and $\mathrm{H}$ defined by Equation (3.1.13a-b).

When a stratified layer exhibits time-dependent behavior (thixotropic or rheopectic), the apparent viscosity is a function of elevation, strain rate, and strain history. The drag force that the ball/cable system experiences is also a function of these three independent variables. In a timedependent fluid, both the measuring and analysis procedures must be modified to derive the apparent viscosity. Because the ball can only traverse along a vertical line, there is only one opportunity (within the duration of the tests) to measure drag force in the undisturbed waste. Subse- . quent measurements will reflect the changes in the waste microstructure wrought in previous ball passes. To obtain a functional relationship of the apparent viscosity as a function of the independent variables, the ball and cable system must be moved at several alternating velocities along each upward or downward traverse through the nonconvective layer. A typical multistep velocity function with drag force measurements is shown in Figure 3.1.2.

For each pass, the tension data is sorted out by speed to isolate the variation of tension as a function of position for each pass. After the data from all the passes have been rearranged, the locally weighted least squares error method is applied to obtain a fit for the total tension as a function of the elevation. During each pass in the nonconvective layer, the ball/cable system traverses until the ball is fully supported by the material or by the tank floor. Weighted fits are required for these data because overshoots, recorded every time the speed changes, are not used in the analysis. Fitting the rearranged tension data also allows us to obtain interpolating tension functions of the elevation. 


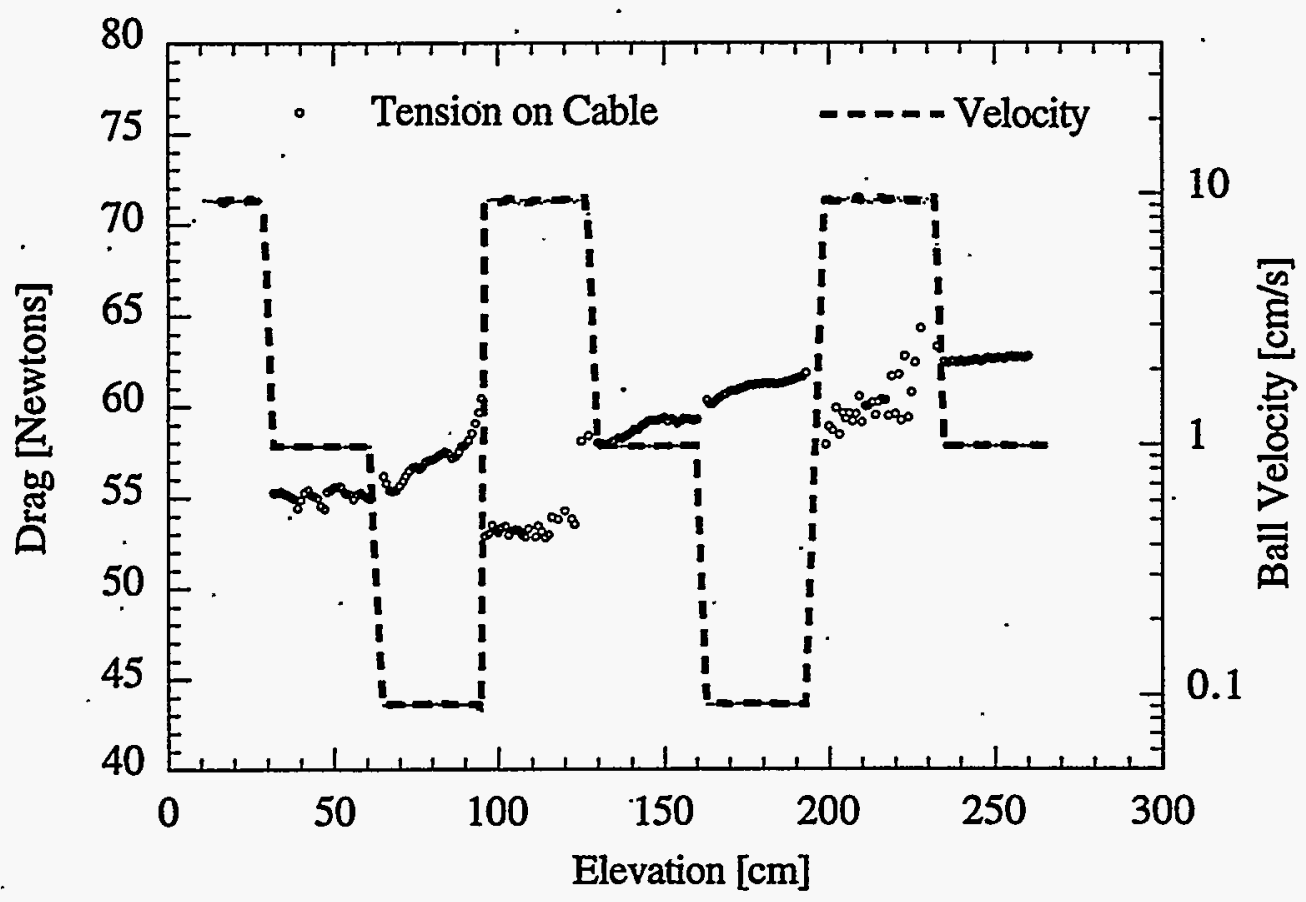

Figure 3.1.2. Drag Force in Multistep Velocity Function (fourth downward pass in AW-101)

Having obtained a functional form for the tension curves for each velocity (strain rate measure), the ball/cable drag functions can be constructed. The variation of the apparent viscosity with position, strain rate, and shear history is calculated for the down and up passes by numerically solving for $\mu_{\text {app }}$ from

$$
F\left(\mu_{\text {app }} ; z, \dot{\gamma}_{m}, \dot{j}\right)=H_{x}\left(z, \dot{\gamma}_{m}, j\right)
$$

where $j$ refers to the pass number, and the subindex $x$ denotes either a pass up (u) or a pass down (d). The functions $\mathrm{H}_{x}$ are given by

$$
\begin{aligned}
& H_{u}=\frac{T_{u}\left(z, \dot{\gamma}_{m} j\right)-\dot{W}_{b}+W_{c}-B_{b}-B_{c}-f}{\pi \rho U^{2}} \\
& H_{d}=\frac{W_{b}+W_{c}-B_{b}-B_{c}-T_{d}\left(z, \dot{\gamma}_{m} j\right)-f}{\pi \rho U^{2}}
\end{aligned}
$$

Since the nonconvective material is time-dependent fluid, the tension curves for the upward traverses (up-curves) are not a reflection of the downward traverses (down-curves) about the line given by the weight minus the buoyancy of the ball. The weight and buoyancy of the cable are much smaller than other contributions to the tension and can be neglected in the analysis. For each up and down tension curve, the combined ball and cable drag is obtained from Equation (3.1.1a, b). 
Regardless of time-dependent effects, when the ball/cable system traverses downward (upward) through a rheologically stratified nonconvective layer, the combined drag of the system increases (decreases) monotonically due to two contributing factors. First, the drag increases (decreases) because the ball encounters fluid with higher (lower) apparent viscosity as it moves down (up). Second, the cable experiences an increasingly larger (smaller) force not only because the cable is in contact with more (less) fluid but also because the apparent viscosity increases (decreases) as the cable moves down (up).

When multistep velocity measurements are not used in a thixotropic nonconvective layer, an integrated measure of the apparent viscosity can be calculated over the range of experimental strain rate measures. This average apparent viscosity was used in the characterization of the waste in Tank 241-SY-103 (Shepard et al. 1995) when the multistep velocity approach was not available. The apparent average viscosity, $\langle\mu\rangle$, is

$$
\langle\mu\rangle=\frac{\sum_{\mathrm{i}=1}^{N} \mu_{\mathrm{i}}\left(z, \dot{\gamma}_{\mathrm{mi}}\right)}{\sum_{\mathrm{i}=1}^{N} \dot{\gamma}_{\mathrm{mi}}}
$$

\subsubsection{Yield Stress}

Once the apparent viscosities have been calculated, the yield stress of the waste is obtained as a function of position by solving Equation (3.1.18) for three different values of $\dot{\gamma}_{\mathrm{m}}$. For each pass and at each elevation, the yield stress is given by

$$
\tau_{\mathrm{o}}=\dot{\gamma}_{\mathrm{m} 1} \mu_{\mathrm{app} 1}-\dot{\gamma}_{\mathrm{m} 1}^{\mathrm{n}} \frac{\dot{\gamma}_{\mathrm{m} 2} \mu_{\mathrm{app} 2}-\dot{\gamma}_{\mathrm{m} 1} \mu_{\mathrm{app} 1}}{\dot{\gamma}_{\mathrm{m} 2}^{\mathrm{n}}-\dot{\gamma}_{\mathrm{m} 1}^{\mathrm{n}}}
$$

and the behavior index, $\mathrm{n}$, is calculated by solving

$$
\frac{\dot{\gamma}_{\mathrm{m} 3}^{\mathrm{n}}-\dot{\gamma}_{\mathrm{m} 1}^{\mathrm{n}}}{\dot{\gamma}_{\mathrm{m} 2}^{\mathrm{n}}-\dot{\gamma}_{\mathrm{m} 1}^{\mathrm{n}}}=\frac{\dot{\gamma}_{\mathrm{m} 3} \mu_{\mathrm{app} 3}-\dot{\gamma}_{\mathrm{m} 1} \mu_{\mathrm{app} 1}}{\dot{\gamma}_{\mathrm{m} 2} \mu_{\mathrm{app} 2}-\dot{\gamma}_{\mathrm{m} 1} \mu_{\mathrm{app} 1}} .
$$

However, an upper bound on the yield stress $t_{u b}$ is easily calculated from the apparent viscosity function obtained with data collected during the first pass at the lowest traversing velocity (or smallest $\dot{\gamma}_{\mathrm{m}}$ ), then

$$
\tau_{\mathrm{ub}}=\frac{\mathrm{U}_{\mathrm{MN}} \mu_{\mathrm{app}}}{\mathrm{d}}
$$

This bound is inferred from the drag measurements for the region where the ball can traverse freely. If we were to calculate the "precise" yield stress we would obtain a smaller value than that of Equation (3.1.26). The yield stress required to support the ball used in the field measurements $(900 \mathrm{~Pa})$ should not be confused with the upper bound on the yield stress in the region in which the ball can traverse freely. 


\subsubsection{Density}

The fluid density, $\rho_{\mathrm{f}}$, is obtained from

$$
\rho_{\mathrm{f}}=\frac{B_{b}}{V_{b} g}
$$

where $B_{b}$ is the buoyancy force on the ball, $V_{b}$ is the ball volume, and $g$ is the gravitational constant.

Total tension in the cable is measured with the ball at rest in the fluid; this value is subtracted from the reference tension measurement with the ball just above the waste surface to obtain the buoyancy force. Small corrections are applied to account for the weight of additional cable and the buoyancy force acting on this cable. Uncertainty in density values in a liquid is about $3 \%$. The ball cannot measure density in material with a yield strength. The strength of the material unpredictably supports the ball and makes the buoyancy term inaccurate.

\subsection{Void Fraction}

The VFI is designed to determine the volume fraction of free gas, or void, at specific locations in the waste. The VFI does not determine, and its response is nearly independent of, gas composition. The void fraction is not measured directly. Once the waste sample is isolated in the sample chamber, the chamber is pressurized with nitrogen gas. The void fraction is calculated from the initial and final pressures, temperatures, and known system volumes. The void fraction model discussed below comprises the assumptions and equations of this procedure.

\subsubsection{Void Fraction Model}

The void fraction is determined using the basic concept that the number of moles of gas in the system is conserved during pressurization. The initial amount of gas includes the gas in the pressurization chamber and the connecting line plus the free gas existing as bubbles or pockets in the waste sample. The total amount of gas in the system after a sample has been pressurized includes the gas in the pressurization chamber and the connecting line, the free gas remaining in the waste, a small amount that may have condensed or dissolved in the waste, and the nitrogen 'injected' into the sample chamber during pressurization.

The pressurizing chamber, connecting line, and sample chamber each have a measured temperature and pressure and a known volume. All of the pressure measurements are made inside the equipment enclosure, which is outside of the tank; the only instruments inside the tank are temperature sensors. The pressure transducers are connected to the pressurizing chamber and to the connecting line near its upper end. The initial and final pressures and temperatures of the nitrogen gas charge in the pressurizing chamber are measured for each test. The pressures in the connecting lines, which extend from inside the equipment enclosures through the support masts to the sample chamber, are measured with a pressure transducer in the equipment enclosure. The temperature of the gas in the connecting line varies along its length. The gas inside the connecting lines and fittings is at essentially the same temperature as the tube walls at equilibrium. Tube wall temperatures are measured at several locations along the lines and averaged to calculate the line temperature. 
The temperature of the waste in the sample chamber is measured by an RTD located $76 \mathrm{~cm}$ from the sample chamber, near the lower arm pivot and at the same elevation as the sample chamber. The initial pressure in the sample chamber is assumed to be equal to the ambient hydrostatic pressure of the waste. At the end of each test, after the sample chamber is opened, the gas in the connecting line escapes through the check valve until equilibrium is reached. The line pressure, measured by a pressure transducer in the equipment enclosure, is then recorded as the initial waste pressure.

The following nomenclature is used to describe the volumes and properties in the model:

$$
\begin{aligned}
& T=\text { temperature } \\
& P=\text { pressure } \\
& V=\text { volume } \\
& N=\text { number of moles of gas }
\end{aligned}
$$

Subscripts:

$$
\begin{array}{ll}
0 & =\text { gas bubbles in the waste } \\
1 & =\text { pressurization chamber } \\
2 & =\text { sample chamber } \\
3 & =\text { connecting line } \\
\text { i } & =\text { initial conditions } \\
\mathrm{f} & =\text { final conditions }
\end{array}
$$

The pressurization chamber and the connecting line are rigid; their volumes are essentially constant and do not change with pressure. The sample chamber, however, is less rigid; the cover undergoes hoop expansion, and the sample chamber length increases because the side ligaments stretch when pressurized. These effects have been included in the model by computing a change in sample chamber volume proportional to the pressure change:

$$
\Delta V_{2}=\beta \cdot\left(P_{2 f}-P_{2 i}\right) \cdot V_{2}
$$

where $\beta$ is the volumetric compliance of the sample chamber. The elevation head is added to the line and sample chamber pressures. . At $35 \mathrm{~atm}$, the 18-m height of the VFI mast produced a head of about $1 / 30 \mathrm{~atm}$, or $0.1 \%$ of the maximum pressure.

The pressurizing gas in the system is nitrogen and is treated as a real rather than an ideal gas. If the volume, pressure, and temperature of the gas in each volume are all known, the number of moles of gas can be calculated using appropriate relationships. For real gases it can be shown that the number of moles of gas held within a volume is directly proportional to the volume, to very good approximation. The relation is given by

$$
\mathrm{N}=\mathrm{V} \cdot \mathrm{f}(\mathrm{T}, \mathrm{P})
$$

where

$$
f(T, P)=\frac{P \cdot Z(T, P)}{R T}
$$

In Equation (3.2.3), $R$ is the universal gas constant, and $Z(T, P)$ is the compressibility of nitrogen, which can be obtained from published gas properties tables. The Beattie-Bridgeman equation of state is used to model the behavior of nitrogen. The Beattie-Bridgeman equation of state is expressed as (Moran and Shapiro 1988) 
where

$$
P=\frac{R T(1-\varepsilon)}{v^{2}}(v+B)-\frac{A}{v^{2}}
$$

$$
\begin{aligned}
& A=A_{0}(1-a / v) \\
& B=B_{0}(1-b / v) \\
& \varepsilon=\frac{c}{v T^{3}}
\end{aligned}
$$

and $A_{0}, a, B_{0}, b$ and $c$ are constants, $P$ is the pressure, $T$ is the temperature, $v$ is the molar specific volume, and $R$ is the universal gas constant. In application, the standard Beattie-Bridgeman constants were changed slightly to obtain a more accurate correlation over the pressure range of 1 to $40 \hat{E}$ atm and temperatures of 250 to $350 \mathrm{~K}$, the ranges over which the VFI is expected to operate. The model is accurate to well within $0.1 \%$ of published gas tables (Keenan and Kaye 1965) over this range of operating conditions.

The gas in the waste sample may depart from ideal gas behavior for a number of reasons. Some of the species present, specifically ammonia, dissolve in the liquid as pressure increases. This effect is included in the calculation by allowing a small fraction of the gas in the sample chamber to be removed from the system.

Equating the initial and final amount of gas in the system results in the following:

$$
N_{1 i}+N_{2 i}+N_{3 i}=N_{1 f}+N_{2 f}+N_{3 f}+N_{z}
$$

where $\mathrm{N}_{\mathrm{z}}$ is the number of moles of gas, originally in the sample chamber, that condenses or otherwise disappears. We define $\mathrm{N}_{2}$ as a simple fraction, $\mathrm{k}$, of the initial number of moles in the sample chamber so that

$$
\mathrm{N}_{\mathrm{z}}=\mathrm{kN}_{2 \mathrm{i}}
$$

Substituting Equations (3.2.3) and (3.2.6) ịto Equation (3.2.5) yields

$$
\begin{aligned}
& V_{1} \cdot f\left(T_{1 i}, P_{1 i}\right)+V_{0} \cdot f\left(T_{2 i}, P_{2 i}\right)+V_{3} \cdot f\left(T_{3 i}, P_{3 i}\right)= \\
& V_{1} \cdot f\left(T_{1 f}, P_{1 f}\right)+V_{0} \cdot f\left(T_{2 f}, P_{2 f}\right)+\Delta V_{2} \cdot f\left(T_{2 f}, P_{2 f}\right) \\
& +V_{3} \cdot f\left(T_{3 f}, P_{3 f}\right)+k \cdot V_{0} \cdot f\left(T_{2 i}, P_{2 i}\right)
\end{aligned}
$$

Now define the volume ratios, $\mathrm{K}_{1}=\mathrm{V}_{1} / \mathrm{V}_{2}$ and $\mathrm{K}_{3}=\mathrm{V}_{3} / \mathrm{V}_{2}$, and the void fraction, $\alpha=\mathrm{V}_{0} / \mathrm{V}_{2}$. Substituting these definitions for the volume ratios in Equation (3.2.7), applying the definition of pressure and temperature differentials, and solving for the void fraction yields

$$
\begin{aligned}
& \alpha=K_{1}\left[f\left(T_{1 f}, P_{1 f}\right)-f\left(T_{1 i}, P_{1 i}\right)\right]+K_{3}\left[f\left(T_{3 f}, P_{3 f}\right)-f\left(T_{3 i}, P_{i 3}\right)\right] \\
& +\frac{\beta \cdot\left(P_{2 f}-P_{2 i}\right) \cdot f\left(T_{2 f}, P_{2 f}\right)}{f\left(T_{2 i}, P_{2 i}\right) \cdot(1-k)-f\left(T_{2 f}, P_{2 f}\right)}
\end{aligned}
$$


Equation (3.2.8) can be used to calculate void fraction from the initial and final pressures and temperatures, system volumes, compliance of the sample chamber, and assumed properties of the trapped gas.

\subsubsection{Void Fraction Model Uncertainty}

Uncertainties in the void fraction measurements are of two types: errors associated with the uncertainties in the individual parameters used in calculating the void fractions and errors due to some of the trapped gases in the sample escaping from the waste before the sample chamber.is closed. An analytic evaluation of the uncertainty due to parameter errors was performed, and the errors due to the sampling process were examined experimentally. The results of both of these investigations are described below.

The linear combination of uncertainties in the calculated void fraction due to errors in the individual parameters of Equation (3.2.8) yields an uncertainty of $\pm 0.5 \%$ void fraction. The estimates of the individual errors are based on sensor calibration data, calculated values based on the physical system, and estimates of the waste properties. The main contributing parameters to the overall error were the connecting line volume, the parameter ' $\mathrm{k}$ ' that models the real gas behavior of the trapped gases in the waste, and the compliance of the sample chamber.

The pressure inside the bubbles in the waste is slightly greater than the 1.5-2.5 atm ambient hydrostatic pressure because of surface tension. 'If the surface tension pressure were significant; the VFI would under-predict the void fraction; however, calculations show that the pressure added by surface tension is significant only for bubbles less than one micron in diameter. Studies of gas release signatures and photomicrographs of core samples from SY-101 (Brewster et al. 1995) indicate that the volume-average bubble size is on the order of a few hundred microns. Tanks that are not forcibly mixed (all except SY-101) would be expected to have larger, bubbles.

The waste must have a non-zero yield strength to retain gas bubbles. As the sample is compressed, the pressure inside the bubbles may be slightly less than the pressure measured by the pressure transducer because the surrounding material supports some of the load. The relatively high operating pressure minimizes this effect. The ball rheometer indicates yield strengths less than $1000 \mathrm{~Pa}$, which is insignificant compared with the $3.5 \mathrm{MPa}$ sample chamber pressurization.

The temperatures inside the gas bubbles are not necessarily the same as those measured by the transducers. The bubble temperature will tend to increase temporarily upon compression until heat transfer to the waste reestablishes equilibrium. But bubbles have negligible thermal mass compared with the waste and system hardware, so the transient time is short and the initial and final temperatures are essentially equal. Thermal equilibrium of the sample due to gas compression is not an issue, even for the largest bubbles.

However, thermal equilibrium between the waste and the VFI structure must be considered, particularly for the first void fraction measurement after the VFI enters the waste. Transient heat transfer calculations indicate that a 10-minute wait is sufficient to reduce the maximum temperature difference to below $0.6^{\circ} \mathrm{C}\left(1^{\circ} \mathrm{F}\right)$. A 20 -minute wait is used in actual testing to ensure thermal equilibrium.

There is also a sample capture error that was first quantified approximately in experiments conducted at LANL with both gassed SY-101 chemical simulant and neutrally buoyant spheres to investigate capture of bubbles in non-Newtonian fluids. Although the resemblance of those tests and analyses to actual VFI measurements in general tank waste is questionable, the results showed the void of the sample to be less than that of the undisturbed waste by a factor of around 0.1 with 
an uncertainty of \pm 0.04 . $^{\text {(a) }}$ Analysis of the Retained Gas Sampler also raised the possibility of incomplete capture due to shear stress of the sludge on the container walls. ${ }^{(b)}$ However, a zero error is predicted for shear strength below $1,500 \mathrm{~Pa}(0.2 \mathrm{psi})$, which is the case in all the tanks tested. To account for this very real effect, though its value is unknown, we assume a.10\% sampling error. That is, the indicated void is multiplied by a factor of 1.1 to give the correct value.

Other than the sampling error, the other uncertainties in the system are small compared with the typical scatter in the measurements of $1 / 5$ to $1 / 3$ of the void fraction and are neglected in computing the average void fraction and gas volume.

\subsubsection{Average Void Fraction}

The average void is computed from the VFI measurements with the ANOVA statistical procedure using a model that captures the major sources of uncertainty. The only assumptions behind the ANOVA model are 1) the void fraction varies horizontally in the tank with a certain standard deviation; and 2) the mean void fractions in specified vertical layers may be different, but the void fraction at a riser within each layer is assumed to be uniform.

The model for applying the ANOVA procedure was based on the void measurement process. The model has the form

$$
\alpha_{i j k l}=\bar{\alpha}+R_{i}+T_{j(i)}+D_{k}+R D_{i k}+T_{j(i) k}+\varepsilon_{i j k l}
$$

where

$\bar{\alpha} \quad=$ the mean void fraction in the tank

$\mathrm{R}_{\mathrm{i}} \quad$ = deviation of the void fraction at riser $\mathrm{i}$ from the mean, $i=1$ and 2 (representing the two risers tested)

$T_{i(i)}=$ deviation of the void fraction of traverse $j$ in riser $i$

$D_{k} \quad=$ the effect of $k$ th layer, $k=1,2$, and 3 (see discussion below)

$\mathrm{RD}_{\mathrm{ik}}=$ the void fraction deviation at riser $\mathrm{i}$ and elevation $\mathrm{k}$ from the mean

$\mathrm{TD}_{\mathrm{j}(\mathrm{l}) \mathrm{k}}=$ deviation of the void fraction of traverse $\mathrm{j}$ and elevation $\mathrm{k}$ from the mean

$\varepsilon_{\mathrm{ijkl}} \quad=$ sampling and instrument error.

Each term in the model describes a source of variability in the measurement process. All terms except the mean void itself and the effect of layer, $D$, have a zero mean and represent deviation from the mean. Deviation due to interaction of traverse and elevation and riser and elevation are also included in the terms TD and $\mathrm{RD}$, respectively.

The layers are chosen to be consistent with the overall waste configuration. The entire convective layer is treated as a single layer extending from the estimated base of the crust to the approximate top of the nonconvective layer. The latter elevation is chosen to be just above any significant void fractions (above 0.01 ) measured on the first pass. Higher void fractions in the convective layer from second or third pass measurements are discarded since they are assumed to result from gas released from below on the prior pass. The assignment of layers is illustrated by those chosen for AN-104 in Figure 3.2.1.

(a) Abbott, JR, and C Unal. November 16, 1994. Sampling Ability of the In-Situ Voidmeter Instrument. LANL letter report TSA-6-94-316 (M110), Los Alamos National Laboratory, Los Alamos, New Mexico.

(b) Shekarriz, A, and JD Norton. September 15, 1995. Retained Gas Sampler System Analysis. Letter report PNL-FG-091595, Pacific Northwest Laboratory, Richland, Washington. 




Figure 3.2.1. Layers for Average Void Calculation in AN-104

The nonconvective layer is split into two or three sublayers with boundaries determined by. a visual interpretation of the variation in void fraction. The number and thickness of the sublayers are rather arbitrary, but each is chosen to yield a fairly uniform vertical void distribution. The ANOVA model emphasizes predicting the mean void fraction in each layer of a tank. For estimating the total gas volume stored in a tank, this is more important than predicting the exact void fraction profile.

With this model, the mean void fraction and its uncertainty estimate can be obtained for each of the three layers. The MIXED procedure of SAS, a statistical software package (SAS 1992), is used to estimate the effects and deviations of the model in Equation (3.2.9) from the void data using the layers as defined above.

Although measurements are made in only two risers, it is legitimate to estimate horizontal variation based on the data. There is a potential for missing important horizontal variation, but if the void profile in the two risers is nearly the same, the chance of an unmeasured nonuniformity is small. Likewise, if the two risers show a very different void profile, the uncertainty will.be large compared with any undetected void variation. This procedure has been used to estimate the horizontal variation of tank chemical contents based on core samples from two risers (Hartley et al. 
1995). Also, the gas volume estimated from the VFI measurements can be confirmed by the global volume estimate from the barometric pressure effect method (see Section 3.3 .2 below) which accounts for all horizontal nonuniformities.

\subsection{Gas Volume}

The VFI does not measure gas volume; it must be computed from the average void fractions. Another important aspect of the volume calculation is the pressure at which the gas is stored. The void fraction represents the space occupied by the gas compressed in situ under the local hydrostatic pressure. The total gas volume at standard pressure and temperature that is required to compute headspace gas concentrations and combustion energies from a postulated ignition event is larger than the in situ volume by a factor equal to the local pressure in atmospheres.

\subsubsection{Standard Volume}

Given the void fraction, $\alpha_{i}$, of a given layer, $i$, the in situ volume, $V_{i}$, of the layer is the product of the void fraction, layer height, $\mathrm{H}_{\mathrm{i}}$, and the tank area, $\mathrm{A}$ :

$$
\mathrm{V}_{\mathrm{i}}=\alpha_{\mathrm{i}} \mathrm{AH}_{\mathrm{i}}
$$

The standard volume of each layer, $\hat{V}_{i}$, is the product of the in situ volume and the corrections for standard pressure and temperature conditions $\mathbf{s}^{(\mathfrak{)})}$

$$
\hat{V}_{i}=V_{i} \frac{P_{i}}{\hat{P}} \frac{\hat{T}}{T_{i}}
$$

where $P_{i}$ is the layer effective pressure, $\hat{P}$ is the standard atmospheric pressure at sea level $(101,325 \mathrm{~Pa}), \hat{\mathrm{T}}$ is the standard temperature $(288.15 \mathrm{~K})$ and $\mathrm{T}_{\mathrm{i}}$ is the layer average temperature taken from available temperature profile measurements. The small variations in local ambient pressure due to weather and the $\sim 200 \mathrm{~m}(700 \mathrm{ft})$ elevation of the Hanford tank farms are neglected in the pressure correction.

It is convenient to define an effective pressure ratio that includes both pressure and temperature corrections to standard conditions. The definition is

$$
\text { - } \overline{\mathrm{P}}_{\mathrm{i}}=\left(\mathrm{P}_{\mathrm{i}} / \hat{\mathrm{P}}\right)\left(\hat{\mathrm{T}} / \mathrm{T}_{\mathbf{i}}\right)
$$

For a uniform void distribution, the pressure in Equations (3.3.2) and (3.3.3) is equal to the local pressure at the midpoint of the layer. This is estimated in terms of the average densities of the convective and nonconvective layers, $\rho_{\mathrm{CL}}$ and $\rho_{\mathrm{NC}}$, by

$$
P_{i}=\hat{P}+g\left[\rho_{C L}\left(H_{W}-H_{N C}\right)+\rho_{N C}\left(\sum_{j<i} H_{j}+\frac{1}{2} H_{i}\right)\right] \text {. }
$$

(a) Standard conditions are taken from "U.S. Standard Atmosphere, 1976" as defined in CRC Handbook of Chemistry and Physics, 71st Edition, DR Lide, editor. CRC Press, Boston. 
for sublayers of the nonconvective layer, and

$$
\mathrm{P}_{\mathrm{CL}}=\hat{\mathrm{P}}+\frac{\mathrm{g}}{2} \rho_{\mathrm{CL}}\left(\mathrm{H}_{\mathrm{W}}-\mathrm{H}_{\mathrm{NC}}\right)
$$

for the convective liquid layer, where $\mathrm{H}_{\mathrm{W}}$ is the elevation of the free liquid level above tank bottom, $\mathrm{H}_{\mathrm{Nc}}$ is the total height of the top of the nonconvective layer, and $\mathrm{H}_{\mathrm{i}}$ is the height the tops of individual layers. The weight of the floating crust is included in the pressure implicitly by using the liquid level.

The ball rheometer gives a reliable estimate of density in the convective layer but not in the nonconvective material. There, densities must be obtained from recent core sample analysis or estimated from data from other tanks. The height of the liquid level is indicated by the appropriate level gauge.

The total in situ gas volume in the nonconvective waste is the sum of the gas volumes in the nonconvective sublayers:

$$
\mathrm{V}_{\mathrm{NC}}=\mathrm{A} \sum_{\mathrm{i}=1}^{\mathrm{NC}} \alpha_{\mathrm{i}} \mathrm{H}_{\mathrm{i}}
$$

The total standard volume is similarly computed, making use of Equation (3.3.3), as

$$
\hat{V}_{N C}=A \sum_{i=1}^{N C} \alpha_{i} H_{i} \bar{P}_{i}
$$

The overall average void fraction for the entire nonconvective layer can be determined from

$$
\bar{\alpha}_{\mathrm{NC}}=\frac{\hat{\mathrm{V}}_{\mathrm{NC}}}{\mathrm{AH}_{\mathrm{NC}}}=\frac{1}{\mathrm{H}_{\mathrm{NC}}} \sum_{\mathrm{i}=1}^{\mathrm{NC}} \alpha_{\mathrm{i}} \mathrm{H}_{\mathrm{i}}
$$

For the nonconvective layer, the average pressure ratio is defined as

$$
\overline{\mathrm{P}}_{\mathrm{NC}}=\frac{\hat{\mathrm{V}}_{\mathrm{NC}}}{\mathrm{V}_{\mathrm{NC}}}=\frac{1}{\mathrm{H}_{\mathrm{NC}} \bar{\alpha}_{\mathrm{NC}}} \sum_{\mathrm{i}=1}^{\mathrm{NC}} \alpha_{\mathrm{i}} \mathrm{H}_{\mathrm{i}} \overline{\mathrm{P}}_{\mathrm{i}}
$$

The total in situ and standard gas volumes in the entire waste column are the sum of that in the nonconvective layer from Equations (3.3.5) and (3.3.6) plus the gas in the convective layer ${ }^{(a)}$ and the crust. The in situ and standard volumes are given by

$$
\mathrm{V}_{\mathrm{W}}=\mathrm{V}_{\mathrm{NC}}+\mathrm{V}_{\mathrm{CL}}+\mathrm{V}_{\mathrm{Crust}}
$$

(a) The convective layer void fraction was originally assigned to be zero; however, we later chose to add this very small contribution and its relatively large uncertainty. as a valid feature of the VFI measurement. 


$$
\hat{\mathrm{V}}_{\mathrm{W}}=\hat{\mathrm{V}}_{\mathrm{NC}}+\hat{\mathrm{V}}_{\mathrm{CL}}+\mathrm{V}_{\text {Crust }}\left(\hat{\mathrm{T}} / \mathrm{T}_{\text {Crust }}\right)
$$

The in situ and standard volumes in the convective layer are computed using Equations (3.3.1) and (3.3.2) with the effective pressure from Equation (3.3.4b).

The crust volume is estimated by computing the gas necessary to make it buoyant. The void required to float the crust in SY-101 was found to be $25 \pm 8 \%$ (Brewster et al. 1995) considering the estimated porosity and density of the crust material. This void estimate is assumed to apply to the crust in other tanks as well. The gas volume in the crust is simply the product of the estimated average crust thickness, waste surface area and the crust void fraction.

$$
\mathrm{V}_{\text {Crust }}=\mathrm{A} \alpha_{\text {Crust }} \mathrm{T}_{\text {Crust }}
$$

The crust gas volume is assumed to be stored at standard pressure. The crust thickness can sometimes be estimated very roughly from the temperature profiles or, more precisely, by a validation probe run in an MIT. However, video observation of the ball rheometer and VFI passing into the waste or of water lancing during installation of MITs also can provide some information on crust thickness.

The mean void fraction and average pressure ratio for the entire waste column are calculated using individual contributions from the crust, convective, and nonconvective layers. This becomes

$$
\begin{gathered}
\bar{\alpha}_{w}=\frac{V_{w}}{A H_{w}} \\
\vdots \\
\bar{P}_{w}=\frac{\hat{V}_{w}}{V_{w}}
\end{gathered}
$$

where the subscript ' $w$ ' refers to the entire waste column. $V_{w}$ and $\hat{V}_{w}$ are calculated with Equations (3.3.9a) and (3.3.9b), respectively.

\subsubsection{Barometric Pressure Effect}

The total retained gas volume can also be determined from the waste compressibility. The compressibility is derived from the effect on the waste surface level of changes in barometric pressure. The basic assumption underlying the barometric pressure effect (BPE) method is that the gas stored in the waste is free to expand or compress as the hydrostatic pressure changes, and the bubble internal pressure is equal to the local hydrostatic pressure. Compression and expansion are assumed to be isothermal because of the intimate contact of the bubbles and waste. These are basically the same assumptions applied in the void fraction model in Section 3.2.

For isothermal compression, the ideal gas law (which is appropriate for typical waste gas at pressures under $3 \mathrm{~atm}$ ) states that

$$
\mathrm{PV}=\mathrm{PAL}=\text { constant }
$$

where $\mathrm{V}$ is the in situ volume, $\mathrm{L}$ is the waste surface level, and $\mathrm{A}$ is the tank cross-sectional area. Taking the derivative of Equation (3.3.12) with respect to pressure and rearranging yields 


$$
\frac{\mathrm{dL}}{\mathrm{dP}}=\frac{-\mathrm{V}}{\mathrm{AP}}
$$

The compressibility of the total waste column is the sum of the compressibilities of the individual layers. Hence we have

$$
\left.\frac{\mathrm{dL}}{\mathrm{dP}}\right|_{W}=\frac{-1}{\mathrm{~A}}\left[\frac{\mathrm{V}_{\text {Crust }}}{\hat{\mathrm{P}}}+\frac{\mathrm{V}_{\mathrm{CL}}}{\mathrm{P}_{\mathrm{CL}}}+\sum_{\mathrm{i}=1}^{\mathrm{NC}} \frac{\mathrm{V}_{\mathrm{i}}}{\mathrm{P}_{\mathrm{i}}}\right]
$$

'where $P_{C L}$ and $P_{i}$ are defined via Equations (3.3.4a) and (3.3.4b), respectively. This value can be compared with that obtained by correlating the surface level measurements and barometric pressures.

Notice from Equation (3.3.13) that the effective pressure must be known to determine the volume from the pressure-level response. In the absence of a VFI measurement, the effective pressure must be estimated from an assumed vertical distribution of retained gas. Knowing the distribution of stored gas we can compute the effective pressure for compressibility by combining Equations (3.3.13) and (3.3.14) to yield

$$
P_{E F F}=\frac{V_{w}}{\frac{V_{\text {Crust }}}{\hat{P}}+\frac{V_{C L}}{P_{C L}}+\sum_{i=1}^{N C} \frac{V_{i}}{P_{i}}}
$$

where $\mathrm{V}_{\mathrm{w}}$ is the total waste in situ volume from Equation (3.3.9a). Note that this effective pressure is different from the average pressures defined by Equations (3.3.8) and (3.3.11).

If the compressibility and effective pressure are known, the total in situ retained gas volume and standard volume can be estimated by

and

$$
\mathrm{V}_{\mathrm{w}}=-\mathrm{AP}_{\mathrm{EFF}} \frac{\mathrm{dL}}{\mathrm{dP}}
$$

$$
\hat{\mathrm{V}}_{\mathrm{w}}=\mathrm{V}_{\mathrm{w}} \overline{\mathrm{P}}_{\mathrm{w}}
$$

respectively, where the average pressure ratio $\bar{P}_{w}$ is defined by Equation (3.3.11) from the void profile.

\subsubsection{Uncertainty in Volume Calculations}

In general, uncertainties represent one standard deviation and are estimated by linear propagation through their defining equations, assuming each parameter was independent. If $y$ is a function of $N$ variables, $y=F\left(x_{1}, x_{2}, \ldots x_{N}\right)$, each with uncertainty, $\sigma_{i}$, the standard error is expressed as 


$$
\sigma_{F}=\sqrt{\sum_{i=1}^{N}\left(\frac{\partial F}{\partial x_{i}} \sigma_{i}\right)^{2}}
$$

The uncertainties in the in-situ and standard gas volume in each layer depend mainly on the uncertainty of mean void fraction in that layer. However, the uncertainty of layer height, pressure, and temperature are included for completeness. Based on Equations (3.3.1), (3.3.2), and (3.3.17), these are expressed as

$$
\sigma_{\mathrm{Vi}}=\mathrm{A} \sqrt{\left(\mathrm{H}_{\mathrm{i}} \sigma_{\alpha \mathrm{i}}\right)^{2}+\left(\alpha_{\mathrm{i}} \sigma_{\mathrm{Hi}}\right)^{2}}
$$

and

$$
\sigma_{\hat{\mathrm{V} i}}=\sqrt{\left[\mathrm{P}_{\mathrm{i}} / \hat{\mathrm{P}}\left(\hat{\mathrm{T}} / \mathrm{T}_{\mathrm{i}}\right) \sigma_{\mathrm{Vi}}\right]^{2}+\left[\mathrm{V}_{\mathrm{i}} / \hat{\mathrm{P}}\left(\hat{\mathrm{T}} / \mathrm{T}_{\mathrm{i}}\right) \sigma_{\mathrm{Pi}}\right]^{2}+\left[\mathrm{V}_{\mathrm{i}}\left(\mathrm{P}_{\mathrm{i}} / \hat{\mathrm{P}}\right)\left(\hat{\mathrm{T}} / \mathrm{T}_{\mathrm{i}}^{2}\right) \sigma_{\mathrm{Ti}}\right]^{2}}
$$

where the uncertainty in the void fraction is provided by the statistical model described in Section 3.2.3. Except for the convective layer, the layer heights are assigned and their uncertainty is zero. In the former, the uncertainty of the waste surface level and crust thickness is included.

The uncertainties of total in situ and standard gas volumes in the nonconvective layer include the covariances of the layer void fractions. The covariances exist because the estimates of mean void fraction in each layer are not independent. They share a common deviation due to riser (horizontal variability). The uncertainties are derived from Equations (3.3.18a) and (3.3.18b) and are given by

$$
\sigma_{V_{N C}}=\sqrt{\sum_{i=1}^{N C} \sigma_{V i}^{2}+A^{2} \sum_{i \neq j} 2 H_{i} H_{j} \operatorname{cov}\left(\alpha_{i}, \alpha_{j}\right)}
$$

and

$$
\sigma_{\hat{\mathrm{V}}_{\mathrm{NC}}}=\sqrt{\sum_{\mathrm{i}=1}^{\mathrm{NC}} \sigma_{\hat{\mathrm{V}}_{\mathrm{i}}}^{2}+\mathrm{A}^{2} \sum_{\mathrm{i} \neq \mathrm{j}} 2(\mathrm{HP})_{\mathrm{i}}(\mathrm{HP})_{\mathrm{j}} \operatorname{cov}\left(\alpha_{\mathrm{i}}, \alpha_{\mathrm{j}}\right)}
$$

where $\operatorname{cov}\left(\alpha_{i}, \alpha_{j}\right)$ represents the covariance of mean void fraction between layers $i$ and $j$, calculated from the estimate of riser variability and the structure of the ANOVA model. Covariances of the layer pressures and temperatures are considered to be negligible and are not included.

\subsection{Gas Release Potential and Consequence}

The ultimate objective of measuring stored gas volume is to assess potential gas release volumes and the consequences thereof. All of the FGWL DSTs considered in this report exhibit spontaneous gas releases of varying magnitudes. SY-101 might have released over half the gas stored in its nonconvective layer in a few minutes during one of its historic rollovers before the mixer pump was installed. AN-103, on the other hand, stores the largest volume of the six tanks 
studied but only releases a small fraction of it during any one event. The GRE history, as defined by the behavior of each tank over 6-10 years since it was last filled, indicates the size and frequency of releases that can be expected if the tank continues to behave 'normally.'

However, there are two reasons to consider larger releases that depart from the historical behavior. First, a very conservative calculation estimates that a large earthquake $(0.25 \mathrm{~g}, \sim 100$-year return frequency) could impart as much energy to the waste in a DST as was released in one of the larger, pre-mixer-pump rollovers in SY-101. This implies that over 50\% of the stored gas might be released, even if the tank's historical behavior showed only much smaller natural releases. Second, a tank can be demonstrated as 'safe' with regard to catastrophic dome failure if it can be shown that the peak dome pressure resulting from a burn of $100 \%$ of its stored gas remained under the maximum design pressure.

To address these considerations, the 'safety state' of each tank will be quantified by computing the peak dome pressure as a function of release fraction from 0-100\%. This covers the consequences of all eventualities. Three of most interesting might be 1) the range of expected release from the historical record, 2) a release of up to $50 \%$ of the stored gas that might occur during a severe earthquake, and 3 ) a release of $100 \%$ of the stored gas as a bounding case. We begin by discussing how the GRE history of a tank is determined.

\subsubsection{Deriving a Tank's GRE History}

The most effective and accurate means to characterize gas releases is by headspace gas monitoring; however, gas monitoring has only been available in the last couple of years and can serve only to guide the calculation of release volume from level changes. The GRE history for a typical tank prior to the mid-1990s must be derived from the waste level history, usually as measured by an FIC contact probe or Enraf buoyancy gauge (since about 1995). The manual tape or other devices are suitable for identifying but not quantifying some of the larger releases. GREs are identified by a sudden level drop following a long period of steady level rise. The initial drop is usually followed by a slower decline to a minimum level several days or even a couple of weeks after the main event. Often there is an accelerated or even abrupt level rise just before the event.

Gas releases in DSTs occur by the buoyancy-induced rollover mechanism. The accepted model for a rollover (Allemann 1993) assumes that a region, or 'gob,' of the nonconvective layer accumulates gas until it becomes buoyant under the local hydrostatic pressure and rises to the surface. The expansion of the gas during the rise will produce a level rise if it occurs slowly or if the gas is not released immediately. At the surface, gas is released until the gob returns just to neutral buoyancy at the surface. This causes the sudden level drop that is the signature of a rollover. Then the waste sinks slowly back to the bottom, the gas it still contains being compressed. This final process yields the slower level decline that occurs days or even weeks after the actual release. The model predicts that only the initial level drop is accompanied by an actual release of gas into the headspace. Thus only the initial level drop should be used to compute the release.

Rollovers proceed at widely varying rates depending on the amount and type of waste involved. Large releases that are energetic enough to liquify the rising gobs may take only a few minutes; such behavior was typical of SY-101. A thick crust may reduce the rate of releases that are not able to break through it as in AW-101. The actual gas release rate can be estimated from the hydrogen (or any other waste gas species not present in air) concentration transient in the tank headspace. Assuming the gas in the head space is fully mixed and its concentration is accurately. represented by the gas monitoring equipment, the mass conservation equation is 


$$
\mathrm{V}_{\mathrm{HS}} \frac{\mathrm{d}\left[\mathrm{H}_{2}\right]}{\mathrm{dt}}=\dot{\mathrm{R}}_{\mathrm{H}_{2}}-\left[\mathrm{H}_{2}\right]\left(\dot{\mathrm{R}}_{\mathrm{H}_{2}}+\dot{\mathrm{B}}\right)
$$

where $\left[\mathrm{H}_{2}\right]$ is the hydrogen concentration measured by the monitoring system, $\dot{\mathrm{R}}_{\mathrm{H}_{2}}$ is the release rate of hydrogen from the waste, $\mathrm{V}_{\mathrm{HS}}$ is the headspace volume, and $\dot{\mathrm{B}}$ is the ventilation rate. Solving Equation (3.4.1) for the release rate yields

$$
\dot{\mathrm{R}}_{\mathrm{H}_{2}}=\frac{1}{1-\left[\mathrm{H}_{2}\right]}\left(\mathrm{V}_{\mathrm{HS}} \frac{\mathrm{d}\left[\mathrm{H}_{2}\right]}{\mathrm{dt}}+\dot{\mathrm{B}}\left[\mathrm{H}_{2}\right]\right)
$$

The ventilation rate can be estimated from the slope of the concentration decay curve or determined by trial and error adjustment so that the cumulative release fraction is asymptotic to 1.0. This method cannot be used for very small releases or in tanks such as SY-103 with a very large headspace.

Analysis of several GREs shows that release rates are typically from 1-10 cfm, and the total release requires one to several hours. A plot of the release rate and cumulative release fraction for a typical rollover in AN-105 is shown in Figure 3.4.1. The total release from this calculation is consistent with that calculated from the initial level drop, ignoring the subsequent level decline.

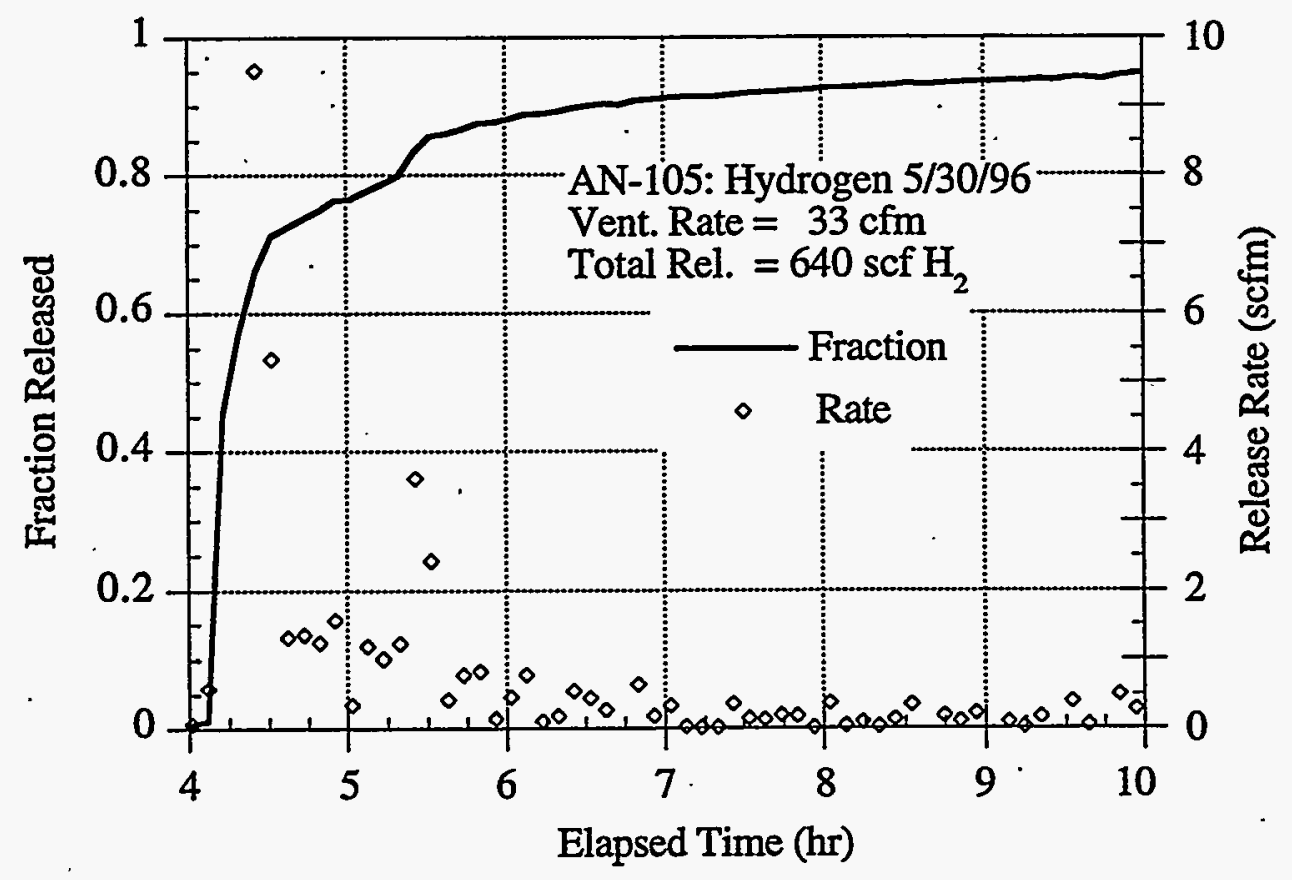

Figure 3.4.1. Gas Release Transient in AN-105, 5/30/96 
Once potential GREs are identified, the waste level history must be screened to weed out false positives resulting from occasional FIC flushes or spurious readings recorded in the operations log. There is a good bit of art in this step. Once a GRE is validated, the level drop is determined as the difference between the peak level immediately before the drop to the level on the next day, even if the level on subsequent days is lower. Then the standard gas release volume is

$$
\hat{\mathrm{V}}_{\mathrm{REL}}=\Delta \mathrm{L}_{\mathrm{GRE}} \mathrm{A} \overline{\mathrm{P}}_{\mathrm{NC}}
$$

where $\Delta \mathrm{L}_{\mathrm{GRE}}$ is the initial level drop, $\mathrm{A}$ is the tank area, and $\overline{\mathrm{P}}_{\mathrm{NC}}$ is the average pressure ratio of the gas stored in the nonconvective layer described by Equation (3.3.8). In some tanks, gas releases occur with no surface level change, or the releases are so small as to challenge the resolution of the level measurement-this is particularly true of AW-101 and AN-103. In these cases waste level fluctuations are simply inadequate to describe gas releases, and gas monitoring data should be used to define the GRE history.

The fraction of the total retained gas volume that escapes from the waste in a major release event represents the product of the fraction of waste participating and the fraction of gas that is released from that volume. This product is estimated from the tank level history as the ratio of preGRE gas volume to the volume released. The VFI data provide good estimates of the gas content at the current waste level, the amount of gas stored in the nonconvective layer before each historical GRE can be calculated from the corresponding waste level. The release fraction is calculated by

$$
\mathrm{F}_{\mathrm{REL}}=\frac{\Delta \mathrm{L}_{\mathrm{GRE}}}{\mathrm{L}_{\mathrm{GRE}}-\mathrm{L}_{\mathrm{NO}-\mathrm{GAS}}}
$$

where $\Delta \mathrm{L}_{\mathrm{GRE}}$ is the level drop, $\mathrm{L}_{\mathrm{GRE}}$ is the pre-GRE waste level, and $\mathrm{L}_{\mathrm{NO}-\mathrm{GAS}}$ is the waste level that would exist if all gas in the nonconvective layer were removed. This is calculated by

$$
\mathrm{L}_{\mathrm{NO}-\mathrm{GAS}}=\mathrm{H}_{\mathrm{NC}}\left(1-\bar{\alpha}_{\mathrm{NC}}\right)
$$

where $\bar{\alpha}_{\mathrm{NC}}$ is the average void fraction in the nonconvective layer defined by Equation (3.3.7). The gas stored in the crust does not participate heavily in a rollover, as evidenced by the quick reestablishment of the crust layer in SY-101 following large rollovers. The small amount of gas that may exist in transit in the convective layer consists of small bubbles that are not subject to release; therefore, only the nonconvective layer gas is calculated to participate in the release. No estimate of the effective pressure of the stored gas is necessary, because the ratio of gas release to-initial inventory is independent of pressure.

The models described in this section are used to derive the GRE history in terms of gas release in Appendix A and to characterize the releases described in Section 4.

\subsubsection{Peak Headspace Pressure}

The peak headspace pressure resulting from a postulated deflagration is determined to assess the potential safety consequences of a tank's stored gas volume. The hazard is evaluated by comparing the predicted peak pressure with the maximum allowable pressure, which is assumed 
tobe 3.08-atm gauge. We don't consider specific gas release mechanisms but vary the release fraction from 0 to 1.0 as a parameter to cover all possible releases. The combustion model is based on LANL's maximum allowable release analysis for SY-103. ${ }^{\text {(a) }}$

Uncertainties in the gas volumes and compositions and other data are specifically included by a probabilistic implementation of the gas release and combustion model. Inputs are described as probability distributions. The distribution of the burn pressure over the full range of the input is computed by the simulations described below. The probability distributions so derived are conditional probabilities that assume ignition of the entire gas release. Dilution or other plume effects that determine the volume of gas that is actually flammable as a function of time are left to an ignition probability calculation. The inputs modeled as probability distributions are as follows:

- species concentration in the waste gas

hydrogen

nitrous oxide

methane

carbon monoxide

ammonia

- ratio of volume of dissolved ammonia evaporated to total volume of free gas released

- void fraction in each subregion of the nonconvective layer

- pressure in each subregion of the nonconvective layer

- waste level.

The void fraction and pressure distributions in each sublevel are assumed normal with statistics based on the actual VFI observations as described in Section 3.2.

Distributions for the major gas components for the equivalent fuel calculation were obtained from the following sources:

- RGS (AW-101, ${ }^{(b)} \mathrm{AN}-105^{(\mathrm{c})}$ - These distributions were input as beta or log-normal distributions in species mole fractions $\left(\mathrm{H}_{2}, \mathrm{~N}_{2} \mathrm{O}, \mathrm{CO}, \mathrm{CH}_{4}, \mathrm{NH}_{3}\right)$ on $[0,1]$.

- Headspace analysis of a large GRE (SY-101) - These distributions were input as lognormal distributions based on the mean and standard deviations reported in Sullivan (1995) but modified to convert release gas concentration to waste gas concentration.

- Extrapolations based on observed similarities to another tank (SY-103 = SY-101, $\mathrm{AN}-103=\mathrm{AN}-104=\mathrm{AN}-105)$.

Some volume of dissolved ammonia evaporates from the waste surface during a GRE in addition to the free gas volume released. If the ratio of dissolved to free gas release volume is denoted as $F_{\text {SOL }}$, the free gas volume released is multiplied by a factor $\left[1+F_{\text {sol }}\right]$ to get the total release volume. At the same time, the waste gas concentrations are reduced by the same factor in computing equivalent fuel values and flammability in the head space.

(a) Pasamehmetoglu, KO. 1996. Maximum Allowable Gas Release Volume Predictions. Letter report TSA-10-96-329, Los Alamos National Laboratory, Los Alamos, New Mexico.

(b) Shekarriz, A, DR Rector, MA Chieda, M White, and JM Bates. 1996. Retained Gas Sampler Measurement Results for Hanford Waste Tank 241-AW-101. Letter report TWS-MIT-071996, Pacific Northwest National Laboratory, Richland, Washington.

(c) Preliminary data supplied by JM Bates, PNNL, August 1996. 


$$
\chi_{i}^{\prime}=\frac{\chi_{i}}{1+F_{\text {SOL }}}
$$

where $\chi_{i}^{\prime}$ is the concentration of component $i$ in the release gas. The ammonia concentration in the headspace after the release is given by

$$
\chi_{\mathrm{A}}^{\prime}=\left(\chi_{\mathrm{A}}+\mathrm{F}_{\mathrm{SOL}}\right) /\left(1+\mathrm{F}_{\mathrm{SOL}}\right)
$$

When the release gas species concentrations are known, as in SY-101, the waste gas concentrations are derived by solving Eq. (3.4.6) for $\chi_{i}$.

Waste level appears in two ways in the calculation. There was a point level observation at the time of the VFI measurement from which the degassed level is calculated which was not modeled as a distribution. Given the degassed level, the waste level at the time of a gas release must be input to define the stored gas volume available. The distribution for the pre-GRE waste level was obtained from actual level data over a long time period; these were processed to produce a piece-wise constant distribution. An 'add-on' uncertainty modeled as a uniform distribution in [$0.025,0.025]$ meters was applied to the base distribution account for FIC flushes and offsets due to changes of level instruments. The SY-101 level was input as a normal distribution with mean and standard deviation derived from the 'before GRE' column of Table A.1.

The peak pressure model begins by calculating the volume-averaged pressure, in atmospheres, of the undissolved gas in the nonconvective layer:

$$
\dddot{\mathrm{P}}_{\mathrm{NC}}=\frac{1}{\mathrm{~V}_{\mathrm{NC}} \hat{\mathrm{P}}} \sum_{\mathrm{i}=1}^{N \mathrm{NC}} \alpha_{\mathrm{i}} \mathrm{H}_{\mathrm{i}} \mathrm{P}_{\mathrm{i}}
$$

where $P_{i}$ are the layer pressures defined by Equation (3.4.4a). This differs from the average pressure ratio defined by Equation (3.3.8) in neglecting the temperature correction factor.

Next, the fraction of the fuel that is oxidized by nitrous oxide (rather than oxygen) is estimated, and the total equivalent fuel value (for all fuels present) is determined. It should be noted that recent flammability tests at California Institute of Technology ${ }^{(c)}$ suggest that nitrous oxide is essentially inert in lean conditions close to the LFL. However, it does apparently participate actively when the flame temperature exceeds $1300 \mathrm{~K}$. Since this is likely to occur in burns of larger volumes that might exceed the maximum pressure we consider nitrous oxide to be as effective as oxygen, recognizing that this may be over-conservative for small releases. Combustion energies with oxygen and nitrous oxide are compared in Table 3.2.

$$
\begin{aligned}
& \eta_{U}=\frac{\chi_{N}}{S_{H} \chi_{H}+S_{A} \chi_{A}+S_{M} \chi_{M}+S_{C} \chi_{C}} \\
& \eta_{D}=\frac{\dot{\chi}_{N}}{S_{A}}
\end{aligned}
$$

(a) Personal communication, August 1996, Dr. M. E. Brewster (PNNL) with Dr. J. Shepard (CIT). 
Table 3.2. Combustion Energies of Different Fuel-Oxidizer Pairs (Sullivan 1995)

\begin{tabular}{|l|c|c|}
\hline \multirow{2}{*}{ Fuel } & \multicolumn{2}{|c|}{$\begin{array}{c}\text { Combustion Energy } \\
(\mathrm{kJ} / \text { mole of fuel) }\end{array}$} \\
\cline { 2 - 3 } & Oxygen & Nitrous oxide \\
\hline Hydrogen & -241 & -324 \\
Ammonia & -317 & -442 \\
Methane & -789 & -1132 \\
Carbon monoxide & -281 & -365 \\
\hline
\end{tabular}

$$
\begin{aligned}
& \eta_{\mathrm{TOT}}=\frac{1}{\left(1 / \eta_{\mathrm{U}}+\mathrm{F}_{\mathrm{SOL}} / \eta_{\mathrm{D}}\right)} \\
& \mathrm{e}_{\mathrm{TOT}}=\left(\frac{1}{1+\mathrm{F}_{\mathrm{SOL}}}\right)\left\{\begin{array}{l}
\chi_{\mathrm{H}}\left(\mathrm{E}_{\mathrm{HN}} \eta_{\mathrm{TOT}}+\left(1-\eta_{\mathrm{TOT}}\right)+\left(\chi_{\mathrm{A}}+\mathrm{F}_{\mathrm{SOL}}\right)\left(\mathrm{E}_{\mathrm{AN}} \eta_{\mathrm{TOT}}+\mathrm{E}_{\mathrm{A}}\left(1-\eta_{\mathrm{TOT}}\right)+\right.\right. \\
\chi_{\mathrm{M}}\left(\mathrm{E}_{\mathrm{MN}} \eta_{\mathrm{TOT}}+\mathrm{E}_{\mathrm{M}}\left(1-\eta_{\mathrm{TOT}}\right)+\chi_{\mathrm{C}}\left(\mathrm{E}_{\mathrm{CNN}} \eta_{\mathrm{TOT}}+\mathrm{E}_{\mathrm{C}}\left(1-\eta_{\mathrm{TOT}}\right)\right.\right.
\end{array}\right\}
\end{aligned}
$$

where $\eta_{U}=$ the fraction of fuel from undissolved gas that is oxidized by $\mathrm{N}_{2} \mathrm{O}$

$\eta_{D}=$ the fraction of fuel from dissolved gas that is oxidized by $\mathrm{N}_{2} \mathrm{O}$

$\eta_{\text {TOT }} \doteq$ the total fraction of fuel oxidized by $\mathrm{N}_{2} \mathrm{O}$

$\chi=$ the concentration (mole fraction) of a component in the undissolved gas; the subscript $H$ is hydrogen, $A$ is ammonia, $M$ is methane, $C$ is carbon

$S \quad=\quad$ monoxide, and $\mathrm{N}$ is nitrous oxide

subscripts are as noted above

$\mathrm{F}_{\mathrm{SOL}}=$ the ratio of gas released from solution to that released from undissolved gas.

$\mathrm{e}_{\mathrm{TOT}}=$ the total equivalent fuel value (in terms of hydrogen)

$\mathrm{E}=$ the equivalent fuel value of gases other than hydrogen when burned in oxygen; subscripts are as noted above.

$\mathrm{E}_{\mathrm{N}}=$ the equivalent fuel value of gases when burned in nitrous oxide; subscripts are as noted above.

The total headspace volume available to absorb the burn energy depends on the depth of the waste immediately after a GRE (and immediately preceding the hypothetical burn). The depth, $\mathrm{L}_{\text {post }}$, is given by

$$
\mathrm{L}_{\text {pOSt }}=\mathrm{L}_{\mathrm{NO}-\mathrm{GAS}}+\left(1-\mathrm{F}_{\mathrm{REL}}\right)\left(\mathrm{L}-\mathrm{L}_{\mathrm{NO}-\mathrm{GAS}}\right)
$$

where $L=$ the waste level $(\mathrm{m})$ at some randomly selected observation time

$\mathrm{F}_{\mathrm{REL}}=$ the ratio of the volume of undissolved gas released to the

$\mathrm{L}_{\text {post }}=\quad \begin{aligned} & \text { total undissolved gas present } \\ & \text { the waste level (m) after a GRE. }\end{aligned}$

The standard volume (STP) of gas released is proportional to the total gas volume before the GRE, the release fraction, the fraction of dissolved gas released with the insoluble gas, and the pressure at which the gas is stored. This is expressed as 


$$
\hat{\mathrm{V}}_{\mathrm{REL}}=\mathrm{F}_{\mathrm{REL}}\left(1+\mathrm{F}_{\mathrm{SOL}}\right)\left(\mathrm{L}-\mathrm{L}_{\mathrm{NO}-\mathrm{GAS}}\right) \mathrm{A}\left(\ddot{\mathrm{P}}_{\mathrm{NC}} \hat{\mathrm{T}} / \mathrm{T}_{\mathrm{NC}}\right)
$$

where A $=$ the cross-sectional area of the tank $\left(\mathrm{m}^{2}\right)$

$\mathrm{T}_{\mathrm{NC}}=$ the estimated nonconvective layer temperature. $(\mathrm{K})$

$\hat{\mathrm{T}} \quad=$ the standard temperature $(\mathrm{K})$

$\hat{\mathrm{V}}_{\mathrm{REL}}=$ the standard volume of gas released $\left(\mathrm{m}^{3}\right)$

$\mathrm{F}_{\mathrm{SOL}}=$ the ratio of dissolved to undissolved gas in the release.

The distribution of the ratio of dissolved to undissolved gas in the release was chosen in an ad hoc manner that attempted to capture the uncertainty of the current state of knowledge regarding this quantity. This quantity contributes greatly to the uncertainty of the result and is dominated . only by the uncertainty in the hydrogen concentration.

Finally, the peak pressure (in atm gauge) that can be achieved by burning the entire release 'is computed by scaling a very detailed coupled combustion and structural calculation of burn pressure performed for SY-101 (Sullivan 1995). The SY-101 calculation predicted a $2.91 \mathrm{~atm}$ (2.95 bar) gauge pressure as a result of burning $245 \mathrm{~m}^{3}(8,650 \mathrm{SCF})$ of gas, equivalent to $62.7 \%$ hydrogen combusted in air, in a head space volume of $1,218 \mathrm{~m}^{3}\left(43,000 \mathrm{ft}^{3}\right)$. Assuming a linear dependence, this result is simply scaled by the release volume, headspace volume, and equivalent fuel value of the release gas to estimate the peak pressure in the tank of interest. The scaling is expressed as

$$
P_{\text {PEAK }}=\frac{\Theta e_{\text {TOT }} \hat{\mathrm{V}}_{\text {REL }}}{\left(\mathrm{V}_{\text {dome }}+A\left(L_{\text {MAX }}-L_{\text {post }}\right)\right.}
$$

. where $\Theta=23.09 \mathrm{~atm}=2.91 \mathrm{~atm} \bullet 1,218 \mathrm{~m}^{3} /\left(245 \mathrm{~m}^{3} \bullet 0.627 \mathrm{H}_{2}\right)$; the pressure increase per concentration of hydrogen-equivalent fuel burned

$\mathrm{V}_{\text {dome }}=$ the volume $\left(\mathrm{m}^{3}\right)$ of the dome space above $\mathrm{L}_{\mathrm{MAX}}$.

$\mathrm{L}_{\mathrm{MAX}}=$ the waste level at maximum capacity (m).

The software Crystal Ball was used to perform the simulations. Five-thousand samples were used to ensure that the simulation had converged in the tail of the distribution. The results of the simulation were output as percentile (cumulative distribution) in increments of 5\%. A sensitivity analysis was performed to validate the use of point estimates for certain parameters. Results are presented for each tank in terms of the peak burn pressure at the 50th, 95th and 99th percentile as a function of the release fraction. These results are presented in context in Section 5.

The results of the Monte Carlo simulation were verified for convergence up to the 99th percentile values, which were the largest values used in the graphs in Section 5. The results are deemed accurate to one significant figure at the 99th percentile value. 


\subsection{Tank-By-Tank Test Results}

This report focuses on the DSTs that are on the FGWL: SY-101, SY-103, AW-101, AN-103, AN-104, and AN-105. Each of these tanks has been assayed with the VFI and ball rheometer, and the results are presented in this section. No tests have yet been performed in the three DSTs recently added to the Flammable Gas USQ: AN-107, AW-104, and AY-101. All of these tanks except SY-103 are relatively full, and all except AN-107 and AY-101 have a significant depth of settled solids that could trap gas.

Only the tanks on the FGWL actually exhibit episodic GREs. SY-101, prior to the mixer pump installation, had by far the most severe GREs, with level drops of over $30 \mathrm{~cm}$. Next in line is AN-105, which has shown level drops as high as $7 \mathrm{~cm}$. Typical level drops in the other tanks are only 1-5 cm. AW-104 and AY-101 do not show GREs, but their barometric pressure response indicates the presence of some stored gas. AN-107 does not show GRE behavior, has only about $2 \mathrm{~m}$ of nonconvective material and no measurable barometric pressure response, and its waste level has been declining. It was recommended for the FGWL solely on the basis of the potential for evaporation to mask level growth due to:gas accumulation. Table 4.1 summarizes this comparison.

The VFI and ball theometer were operated in the six FGWL DSTs from December 1994 to May 1996. A second test is currently planned in AN-105 in September 1996, and the VFI may be run in AN-107 later. After that, no further action is scheduled, though tests in AW-104 are recommended. This report may, therefore, represent essentially the entire history of VFI and ball rheometer testing at Hanford. Table 4.2 summarizes the deployment history of both instruments, including the lowest elevations reached in each tank. The preparatory water lancing through the crust is not included in the table.

Table 4.1. Summary of Flammable Gas DSTs

\begin{tabular}{|c|c|c|c|c|c|}
\hline $\begin{array}{l}\text { Tank } \\
\text { (FGWL } \\
\text { in bold) }\end{array}$ & $\begin{array}{l}\text { Waste and } \\
\text { Solids Level } \\
(\mathrm{cm})\end{array}$ & $\begin{array}{l}\text { Crust } \\
\text { Depth } \\
\text { (cm) }\end{array}$ & $\begin{array}{l}\text { GRE Level Drop } \\
\text { (Mean-Max) } \\
\text { (cm) }\end{array}$ & $\begin{array}{l}\text { Approx. GRE } \\
\text { Period }^{(b)} \\
\text { (days) }\end{array}$ & $\begin{array}{c}\text { Compressibility } \\
(\mathrm{cm} / \mathrm{kPa})\end{array}$ \\
\hline $\begin{array}{l}\text { AN-103 } \\
\text { AN-104 } \\
\text { AN-105 } \\
\text { AN-107 } \\
\text { AW-101 } \\
\text { AW-104 } \\
\text { AY-101 } \\
\text { SY-101 } \\
\text { SY-103 }\end{array}$ & $\begin{array}{c}885 / 380 \\
980 / 415 \\
1040 / 450 \\
975 / 180^{(c)} \\
1040 / 280 \\
1040 / 266^{(c)} \\
870 / 80^{(c)} \\
1060 / 510^{(d)} \\
690 / 345\end{array}$ & $\begin{array}{c}92 \\
40 \\
30 \\
\text { none } \\
64 \\
\text { none } \\
\text { none } \\
100 \\
20\end{array}$ & $\begin{array}{c}2-3 \\
3-7 \\
3-6 \\
\text { none } \\
2-5 \\
\text { none } \\
\text { none } \\
15-22^{(\mathrm{d})} \\
3-5\end{array}$ & $\begin{array}{c}100^{(\mathrm{b})} \\
110 \\
160^{(\mathrm{b})} \\
\mathrm{N} / \mathrm{A} \\
\text { random } \\
\mathrm{N} / \mathrm{A} \\
\mathrm{N} / \mathrm{A} \\
104^{(\mathrm{b}, \mathrm{c})} \\
\text { random }\end{array}$ & $\begin{array}{c}-0.46 \\
-0.13 \\
-0.14 \\
\text { none } \\
-0.25 \\
-0.08^{(c)} \\
-0.02^{(c)} \\
-0.32^{(c)} \\
-0.21\end{array}$ \\
\hline \multicolumn{6}{|c|}{$\begin{array}{l}\text { (a) A tank is 'full' at about } 1070 \mathrm{~cm} \text {. } \\
\text { (b) Trend to increasing period. } \\
\text { (c) From Hodgson et al. (1996). } \\
\text { (d) Typical values in SY-101 before the mixer pump was installed }\end{array}$} \\
\hline
\end{tabular}


Table 4.2. Ball Rheometer and VFI Deployment History

\begin{tabular}{|c|c|c|c|c|c|}
\hline \multirow[b]{2}{*}{ Tank } & \multirow[b]{2}{*}{ Riser } & \multicolumn{2}{|c|}{ Ball Rheometer } & \multicolumn{2}{|r|}{$\overline{\mathrm{VFI}}$} \\
\hline & & Date & Min. Elev. (cm) & Date & Min.Elev. (cm) \\
\hline \multirow[t]{2}{*}{ SY-101 } & $11 \mathrm{~B}$ & $4 / 5 / 95$ & 80 & $12 / 21 / 94$ & 25 \\
\hline & $4 \mathrm{~A}$ & $3 / 27 / 95$ & $\overline{0}$ & $1 / 17 / 95$ & 34 \\
\hline \multirow[t]{2}{*}{ SY-103 } & $17 \mathrm{C}$ & $7 / 14 / 95$ & 120 & $7 / 19 / 95$ & 48 \\
\hline & $22 \mathrm{~A}$ & $8 / 8 / 95$ & 135 & $8 / 18 / 95$ & 42 \\
\hline \multirow{2}{*}{$\overline{A W}-101$} & $13 \mathrm{~A}$ & $9 / 18 / 95$ & 0 & 9/22/95 & 58 \\
\hline & $1 \mathrm{C}$ & $9 / 20 / 95$ & 110 & $9 / 24 / 95$ & 64 \\
\hline \multirow[t]{2}{*}{ AN-105 } & $\overline{1 B}$ & $12 / 15 / 95$ & 110 & $12 / 20 / 95$ & 155 \\
\hline & $16 \mathrm{~B}$ & $12 / 18 / 95$ & $\overline{0}$ & $.12 / 22 / 95$ & 157 \\
\hline \multirow[t]{2}{*}{ AN-104 } & $16 \mathrm{~B}$ & $3 / 27 / 96$ & 65 & $4 / 2 / 96$ & 93 \\
\hline & $1 \mathrm{~B}$ & $4 / 1 / 96$ & 0 & $4 / 4 / 96$ & 79 \\
\hline \multirow[t]{2}{*}{ AN-103 } & $16 \mathrm{~B}$ & $5 / 6 / 96$ & 200 & $5 / 14 / 96$ & 43 \\
\hline & $1 \bar{B}$ & $5 / 10 / 96$ & 150 & $5 / 16 / 96$ & 63 \\
\hline
\end{tabular}

Each subsection that follows summarizes the history, instrumentation, waste configuration, rheology, void fraction, gas volume, and gas release behavior of a specific tank. The major assumptions and calculation procedures were described in Section 3, and the raw data from which the input is derived were given in Section 2. The GRE history derived from the waste level record is detailed in Appendix A. Photographs of the core extrusions for several of the tanks are shown in Appendix B. The gas volumes and other values given here may differ from those previously published because various corrections and revisions have been made to the data analysis procedures over the last two years.

\subsection{SY-101 In Situ Rheology and Gas Volume}

SY-101 initially received about $260 \mathrm{~cm}$ (100 in.) of double-shell slurry, the most concentrated material produced by the evaporators, from the 242-S evaporator between 1977 and 1980. Subsequent additions included complexed concentrate (similar to double-shell slurry but not as concentrated) and more double-shell slurry through 1980; these brought the level up to its nominal reading of $1042 \mathrm{~cm}$ (410 in.) (Sullivan 1995).

Level and temperature profile data plotted by Antoniak (1993) show that the waste level began fluctuating in the typical 'sawtooth' pattern indicative of episodic gas releases shortly after the final fill. Level drops were initially on the order of $8 \mathrm{~cm}$ (5 in.) but increased to $15-25 \mathrm{~cm}$ by 1986. The largest GREs, with level drops over $30 \mathrm{~cm}$ (12 in.), occurred in 1991-92. After that the GRE period, which had decreased from 100 days to 40-80 days, increased abruptly to 140 days. The large GREs ceased after the waste was mixed by the pump from July to December 1993, and the waste level dropped to its current $1019 \mathrm{~cm}$ (400 in.). Babad et al. (1992), Allemann et al. (1993), Allemann et al. (1994), and Stewart et al. (1994) contain the detailed history of the mitigation of Tank SY-101.

SY-101 is the most heavily monitored tank at Hanford; Brewster et al. (1995) contains a complete description of all the instrumentation and typical readings. The locations of the MITs and other important instruments in the tank are shown in Figure 4.1.1, along with the location of the mixing pump. Tank conditions can be inferred from temperature profiles and transient thermocouple response to pump operation indicated by the two MITs in risers 17B and 17C. 


\section{SY-101 Instrument Placement}

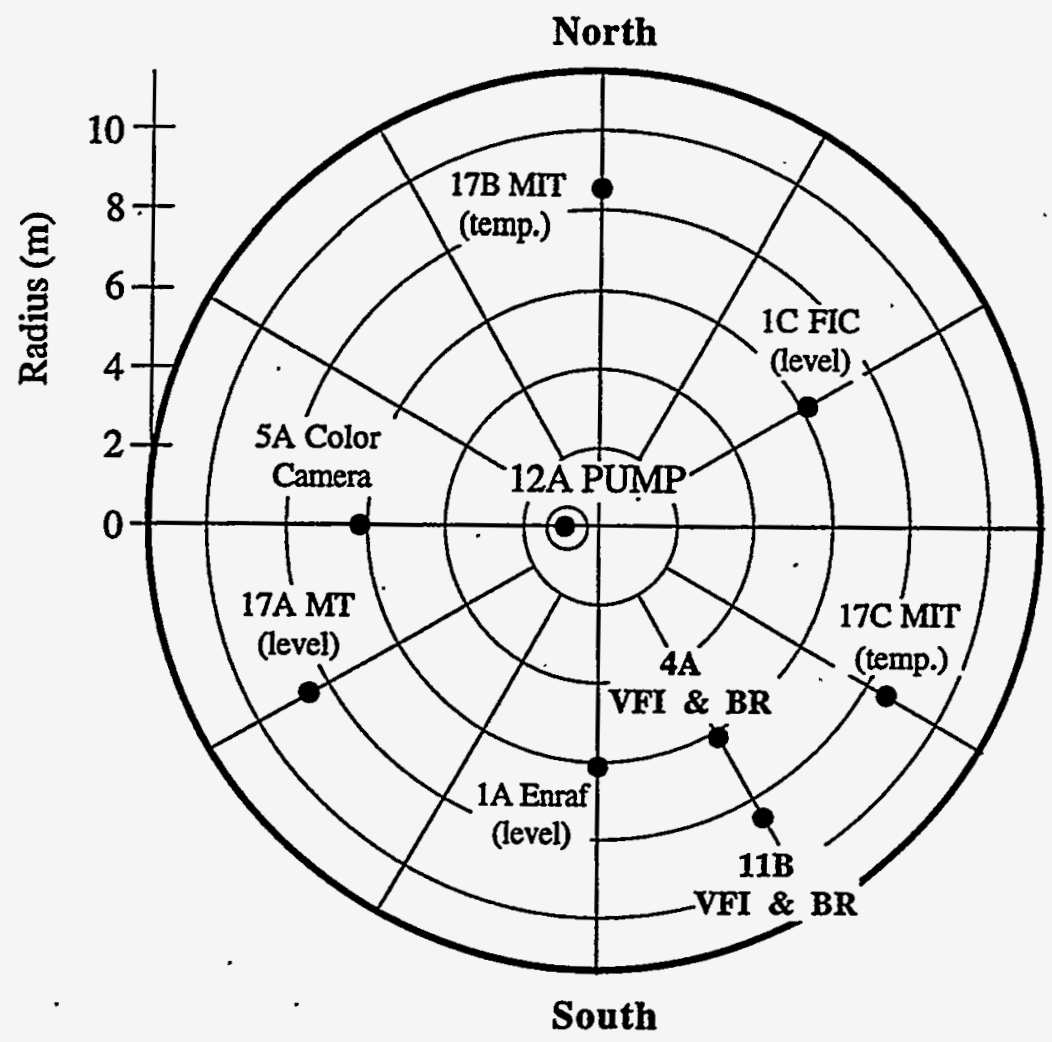

Figure 4.1.1. SY-101 Instrumentation

The VFI was first operated in riser 11B in SY-101 on December 21, 1994, and in riser 4A on January 17, 1995. Two traverses were accomplished in riser 11B and three in riser 4A. A fourth traverse in $4 \mathrm{~A}$ was canceled because of a low battery in the crane dynamometer. The VFI could not penetrate below about $60 \mathrm{~cm}$ in $11 \mathrm{~B}$ due to crane unloading. The ball rheometer was deployed three months after the VFI tests due to difficulty in penetrating the crust. The ball was lowered through riser 4A on March 27, 1995, and through riser 11B on April 5, 1995. It found the bottom in $4 \mathrm{~A}$ but became supported by the waste at about $80 \mathrm{~cm}$ in 11B.

\subsubsection{SY-101 Waste Configuration}

Because of the continued mixing since December 1993, SY-101 waste consists of a wellmixed slurry with a relatively thick crust floating on the surface and a thin layer of undisturbed solids on the bottom of the tank. The mixed slurry contains very little gas and has approximately uniform properties from just below the crust to near the bottom of the tank. The waste remains in a continual flux, however. Solids suspended by each thrice-weekly, 30-minute pump run are continually settling out, and small bubbles freed by the jet are continually rising. Both of these 
processes are at maximum rates immediately after a pump rin and decay exponentially until the next one. This leads to a gradation in the density and gas content of the material with depth and time.

Vertical temperature profiles obtained from several MIT validation probe runs in risers $17 \mathrm{C}$ and 17B are shown in Figures 4.1.2 and 4.1.3. These measurements indicate four distinct waste layers: a heat-generating nonconvective layer on the bottom (evidenced by a half-parabolic temperature profile), two distinct convective layers (indicated by a uniform temperature profile), and a solid crust on top (indicated by a linear temperature profile). Based on the transient response of the temperature profile to the pump jet, the nonconvective layer appears to consist of two separate layers, settled solids and undisturbed sludge. Table 4.3 lists the five layers from top to bottom.

The crust layer has remained almost totally undisturbed and unchanged, except for appearing somewhat 'dryer' since early November 1993, when a gas release caused the most recent surface motion. Comparisons of MIT validation probe temperature profiles from July 1994 through April 1995, shown in Figures 4.1.2 and 4.1.3, indicate that the crust thickness of $102 \pm 10 \mathrm{~cm}$ (40 \pm 4 in.) at $17 \mathrm{~B}$ and $76 \pm 10 \mathrm{~cm}(30 \pm 4$ in.) at $17 \mathrm{C}$ has not changed measurably.

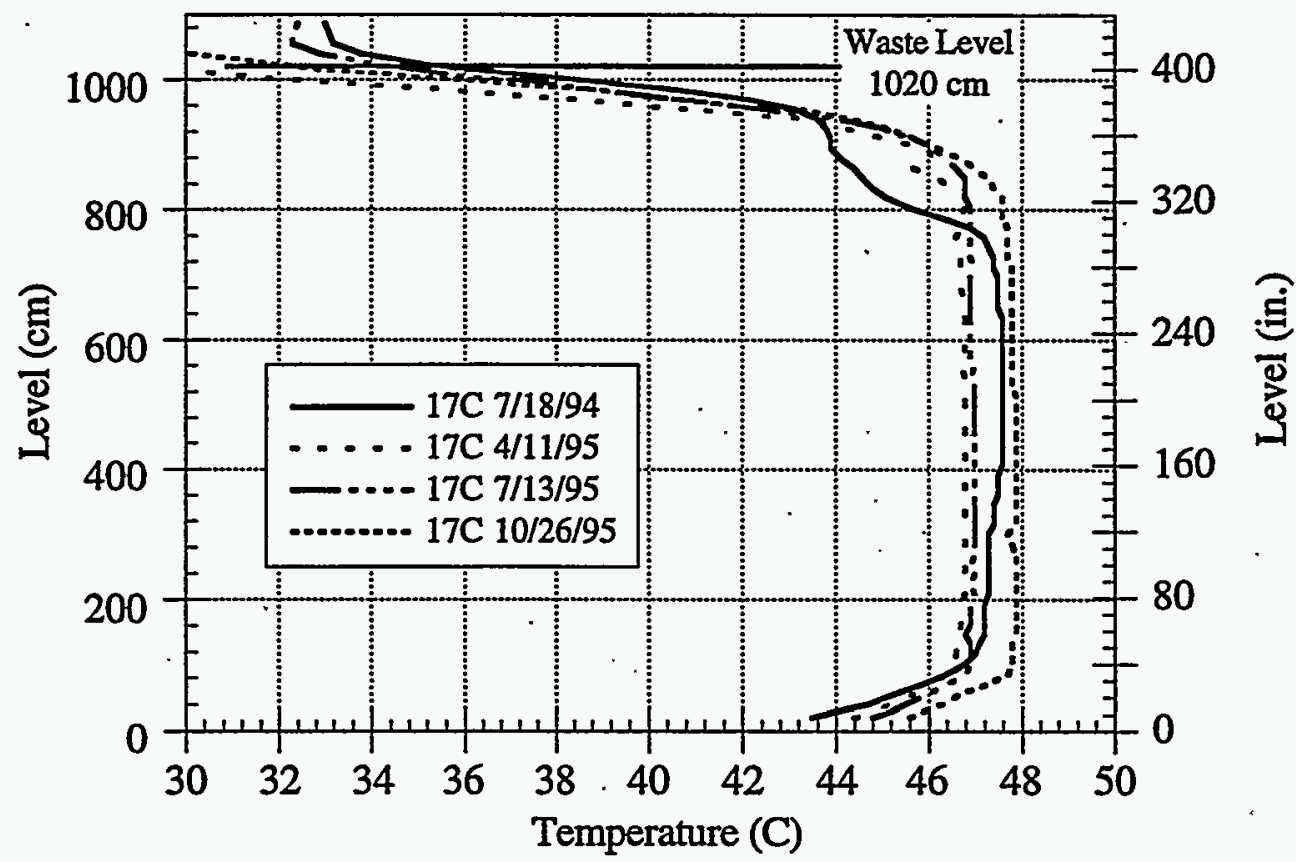

Figure 4.1.2. Temperature Profile from the 17C MIT Validation Probe 


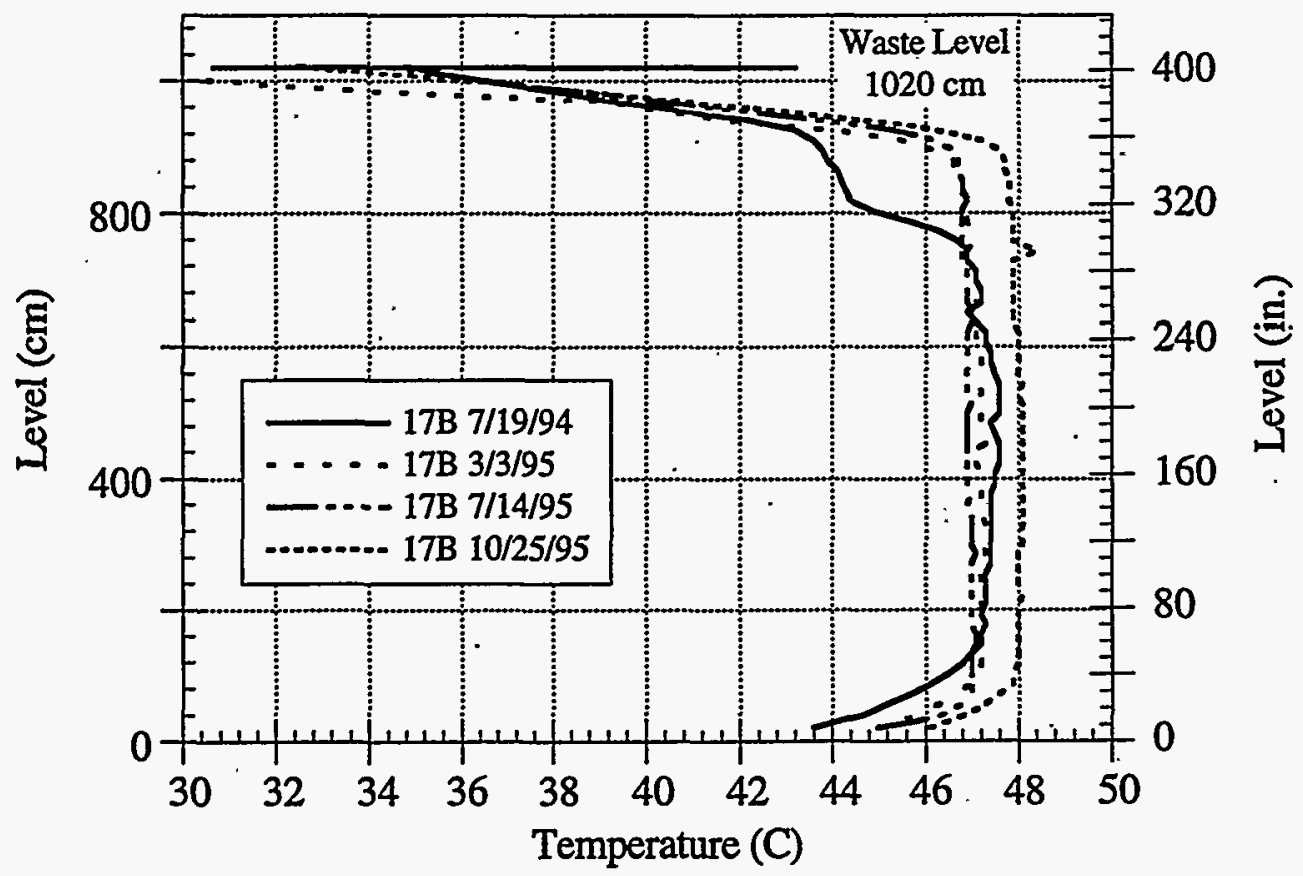

Figure 4.1.3. Temperature Profiles from the 17B MIT Validation Probe

\subsubsection{Rheology and Density}

The viscosity of the mixed slurry was actually lower than the ball theometer was designed to measure. In fact, the cumulative drag on the tether cable was several times greater than the drag on the ball, making it difficult to interpret the measurements. Nevertheless, the data seem to indicate that the mixed slurry is a non-Newtonian, shear-thinning fluid. The best fit to the data gives a viscosity of about $1000 \mathrm{cP}$ with an uncertainty of about a factor of two. These results are plotted in Figure 4.1.4.

Table 4.3. Waste Layering in Tank 241-SY-101

\begin{tabular}{|c|c|l||}
\hline Layer & $\begin{array}{c}\text { Approx. Thickness } \\
(\mathrm{cm})\end{array}$ & \multicolumn{1}{|c|}{ Character } \\
\hline Crust & 100 & $\begin{array}{l}\text { Porous solids floating on the liquid. } \\
\text { No physical changes in over two years. }\end{array}$ \\
\hline Supernatant liquid & $150-0$ & $\begin{array}{l}\text { Forms only during periods of reduced } \\
\text { mixing. }\end{array}$ \\
\hline Mixed slurry & $675-875$ & $\begin{array}{l}\text { High fraction of suspended solids. } \\
\text { Well mixed }\end{array}$ \\
\hline Loosely settled solids & $75-0$ & $\begin{array}{l}\text { Heavier, larger particles settle out of } \\
\text { slurry. Readily dispersed by jet. }\end{array}$ \\
\hline Undisturbed sludge & $15-40$ & Eroding slowly, non-uniform depth \\
\hline
\end{tabular}




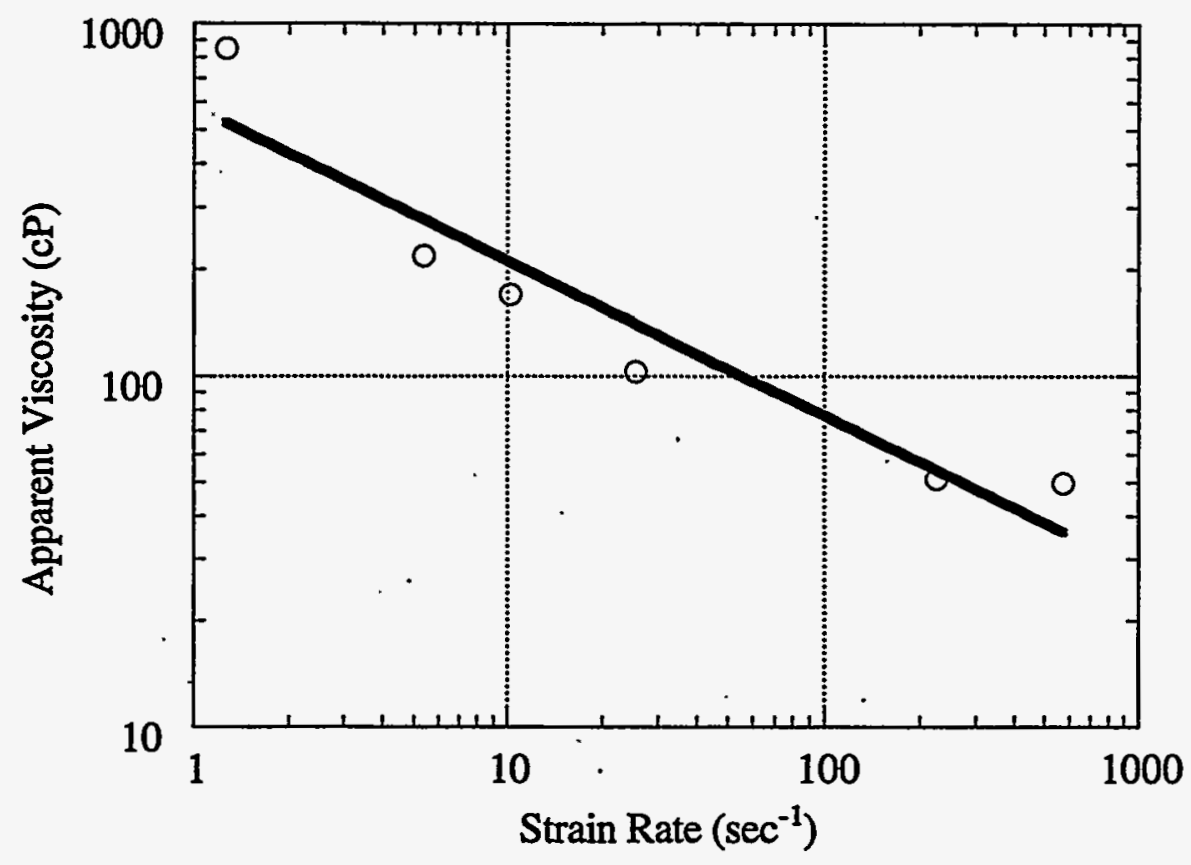

Figure 4.1.4. Apparent Viscosity of SY-101 Mixed Slurry

The ball was able to penetrate to within about $15 \mathrm{~cm}$ (approximately $6 \mathrm{in}$.) of the bottom of the tank in riser $4 \mathrm{~A}$. The material near the bottom showed shear-thickening behavior, with a very small yield stress of about $20 \mathrm{~Pa}(0.004 \mathrm{psi})$ and an average viscosity of about $20,000 \mathrm{cP}$. The yield strength profile is plotted in Figure 4.1.5.

The density of the mixed slurry derived from ball theometer data is $1.60 \pm 0.03 \mathrm{~g} / \mathrm{cm}^{3}$. The profiles of the specific gravity for the runs in $4 \mathrm{~A}$ and 11B are shown in Figure 4.1.6. The data from riser $4 \mathrm{~A}$ were obtained four days after a pump run; those from riser 11B were obtained just one day after a pump run. The difference in the profiles is clearly an effect of the different amounts of time available for solids to settle out in each case. Prior to mixing, Reynolds (1993) recommended a density of $1.57 \pm 0.04 \mathrm{~g} / \mathrm{cm}^{3}$ for the convective layer and $1.70 \pm 0.04 \mathrm{~g} / \mathrm{cm}^{3}$ for the nonconvective layer based on core samples following gas release Event $E$ in December 1991 (Herting et al. 1992).

\subsubsection{Void Fraction and Gas Volume}

All of the void fraction measurements in SY-101 are plotted in Figure 4.1.7 along with the selected layers used to compute the average void fraction. Table 4.4 contains the average void fraction and gas volumes. Adding up the stored gas volumes in each of the three layers yields a total of $218 \pm 53 \mathrm{~m}^{3}(7,700 \pm 1,900 \mathrm{SCF})$ of gas at $1 \mathrm{~atm}$. Given the waste level of $1019 \mathrm{~cm}$ (401 in.) when the VFI measurements were made, the degassed waste level would be $1010 \mathrm{~cm}$ (398 in.), not including the gas in the crust or in the mixed slurry above $200 \mathrm{~cm}$. The computed barometric pressure response of the total in situ gas volume is $-0.32 \mathrm{~cm} / \mathrm{kPa}$, and the effective pressure for compressibility is $1.23 \mathrm{~atm}$. 


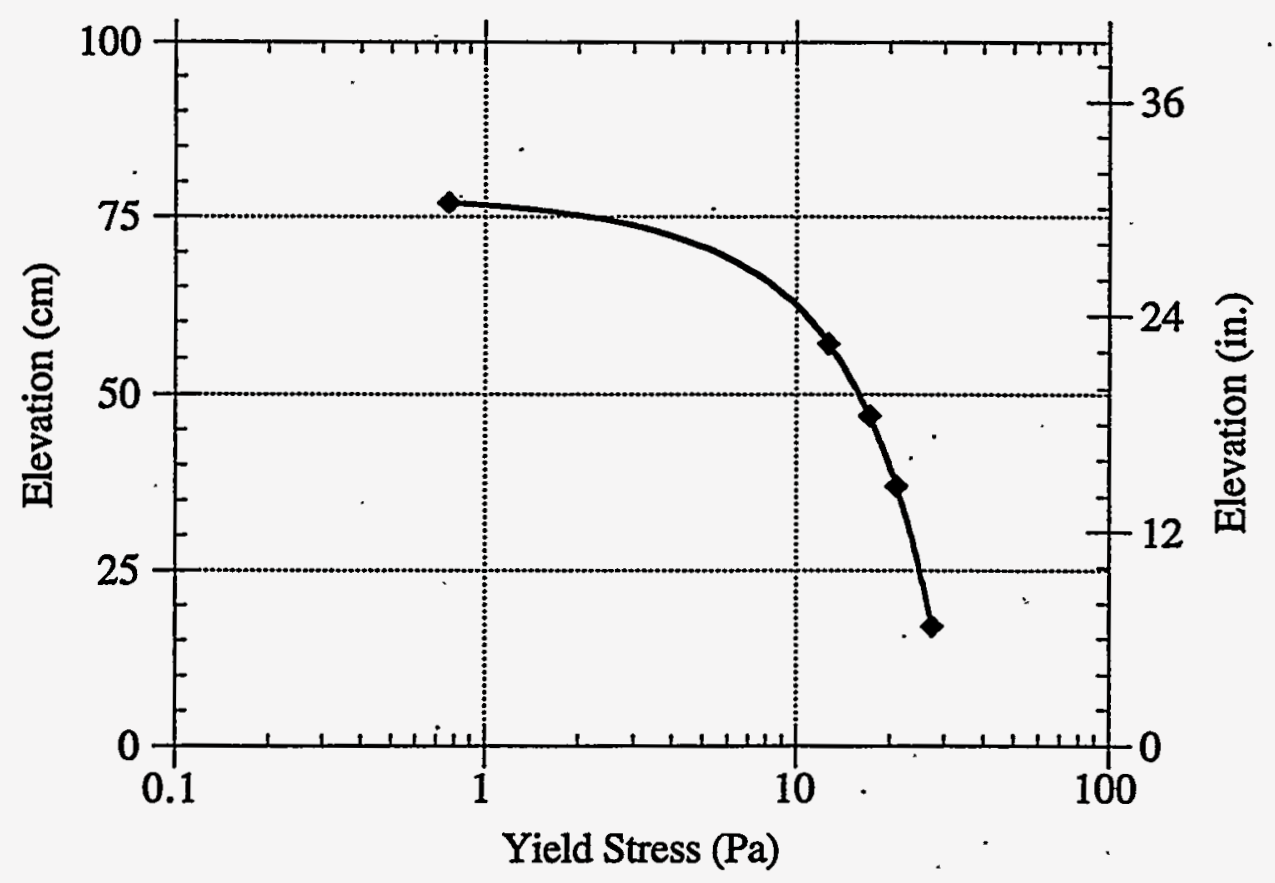

Figure 4.1.5. Yield Stress of the Loosely Settled Solids in SY-101 Riser 4A

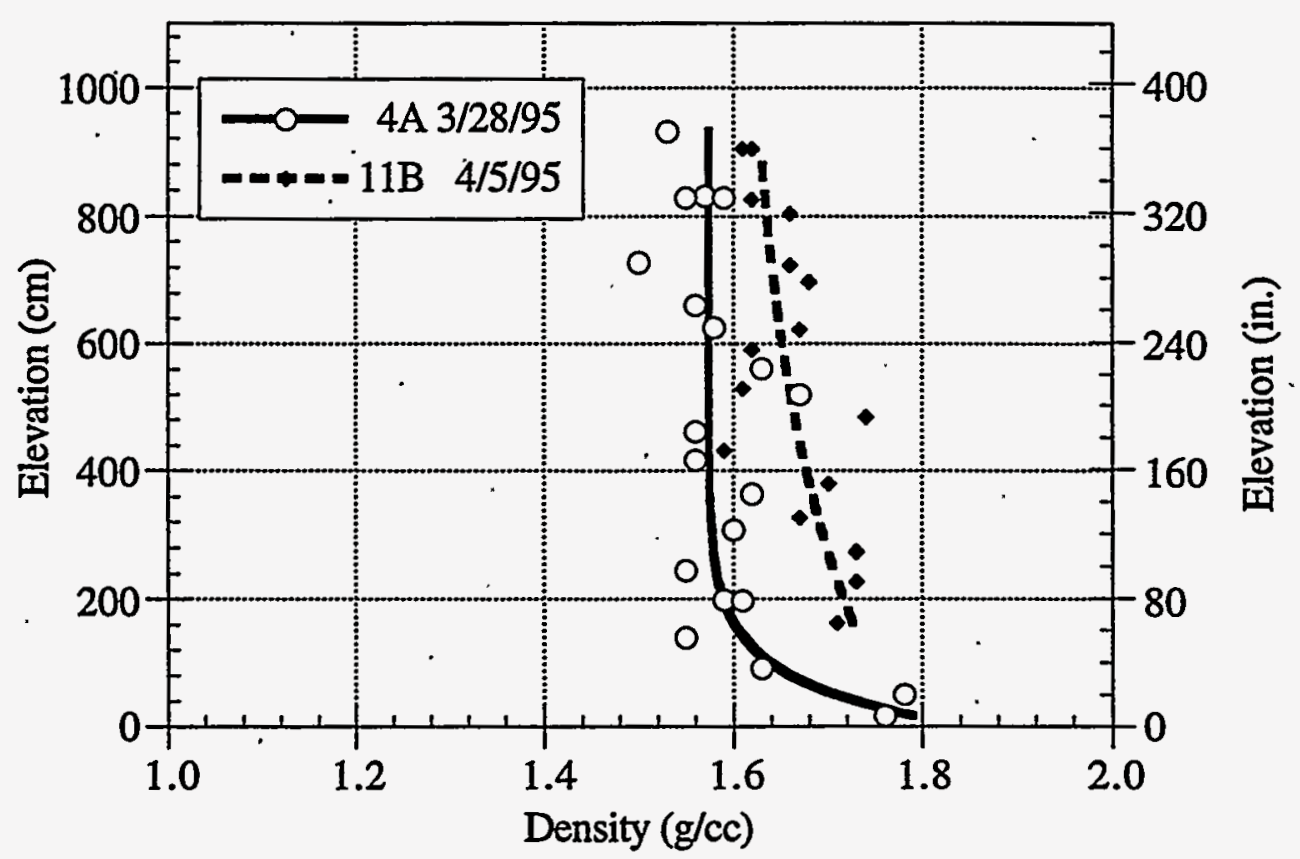

Figure 4.1.6. Waste Density Profile in SY-101 


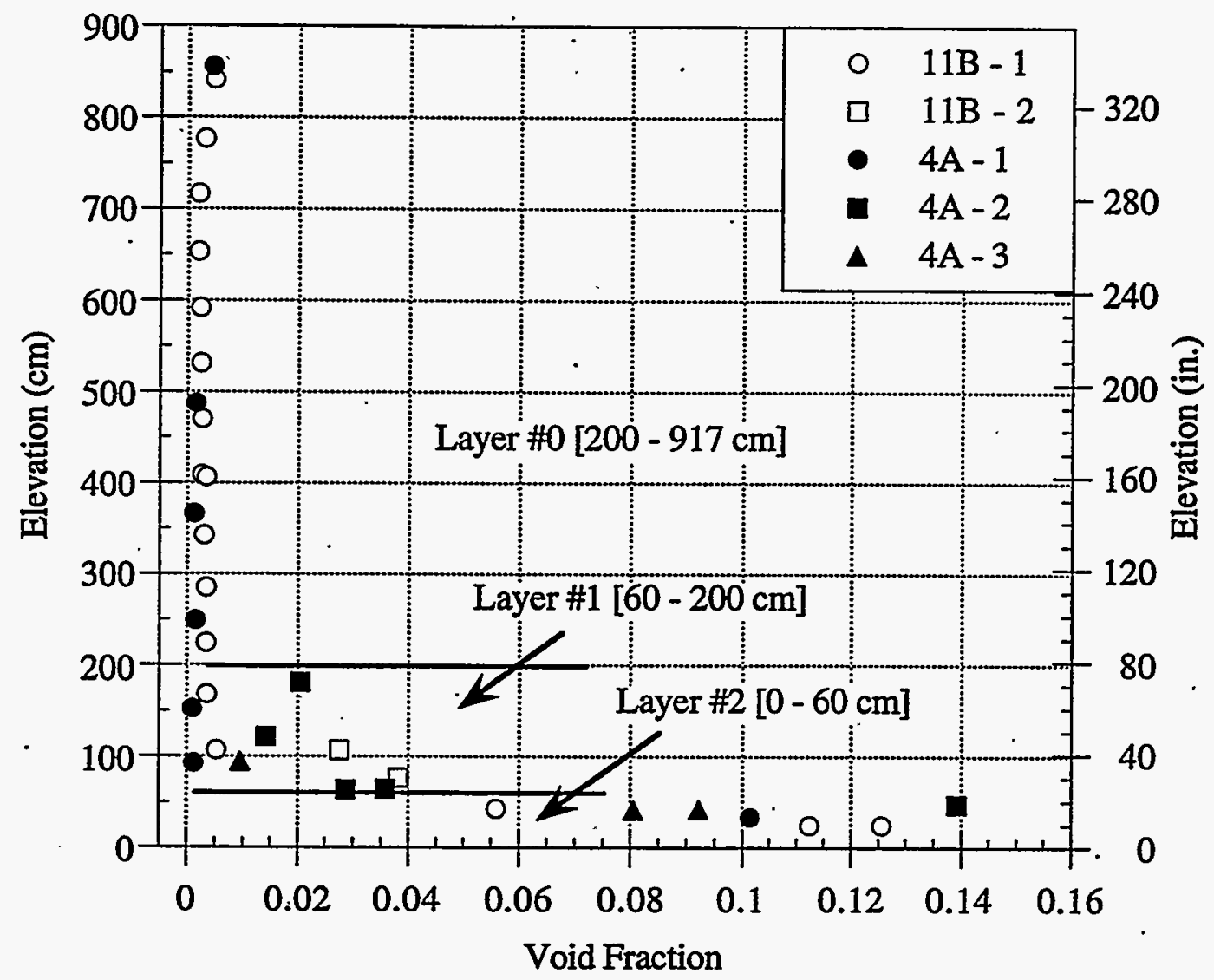

Figure 4.1.7. Void Fraction Measurements in Risers 4A and 11B

Table 4.4. Volume of Gas Stored in Waste Layers

\begin{tabular}{||c|c|c|c|c||}
\hline $\begin{array}{c}\text { Layer } \\
\text { Crust }\end{array}$ & Void (\%) & $\begin{array}{c}\text { In Situ Volume } \\
\left(\mathrm{m}^{3}\right)\end{array}$ & Pressure (atm) & $\begin{array}{c}\text { Standard Volume } \\
\left(\mathrm{m}^{3}\right)\end{array}$ \\
\hline $\begin{array}{c}\text { N/A }-1019 \mathrm{~cm} \\
\# 0\end{array}$ & $105 \pm 35$ & 1.0 & $101 \pm 34$ \\
$200-917 \mathrm{~cm}$ & $0.8 \pm 0.7$ & $23 \pm 21$ & 1.63 & $33 \pm 31$ \\
\hline $\begin{array}{c}\# 1 \\
60-200 \mathrm{~cm}\end{array}$ & $1.5 \pm 0.7$ & $9 \pm 4$ & 2.38 & $18 \pm 9$ \\
\hline $\begin{array}{c}\# 2 \\
0-60 \mathrm{~cm}\end{array}$ & $11.6 \pm 0.8$ & $29 \pm 2$ & 2.55 & $66 \pm 4$ \\
\hline Total (or Avg.) & $4.5 \pm 0.7^{\text {(a) }}$ & $164 \pm 43$ & $1.32^{(0)}$ & $218 \pm 53$ \\
\hline $\begin{array}{l}\text { (a) Layers \#1 and \#2 only. } \\
\text { (b) Includes correction to standard temperature }\end{array}$ \\
\hline
\end{tabular}




\subsubsection{Gas Releases}

The waste level history and observed gas releases in SY-101 prior to mixer pump installation are given in Appendix A. There have been no large rollovers since November 1993. The level drops and release volumes may not match those recorded elsewhere, since we now define the level drop as that occurring in a 24-hour period following the GRE. As stated earlier, this is a better measure of the prompt gas release.

The expected gas release volume is $131 \pm 47 \mathrm{~m}^{3}$ at $1 \mathrm{~atm}(4600 \pm 1700 \mathrm{SCF})$. The average release fraction is $0.34 \pm 0.13$. The maximum recorded release was Event $\mathrm{H}$ with a one-day release of $203 \mathrm{~m}^{3}$ (7200 SCF), which represented almost 70\% of the gas retained in the nonconvective layer. A histogram of the gas release event count is given in Figure 4.1.8. The overall GRE period is $104 \pm 37$ days, although the last four ranged from 136 to 152 days.

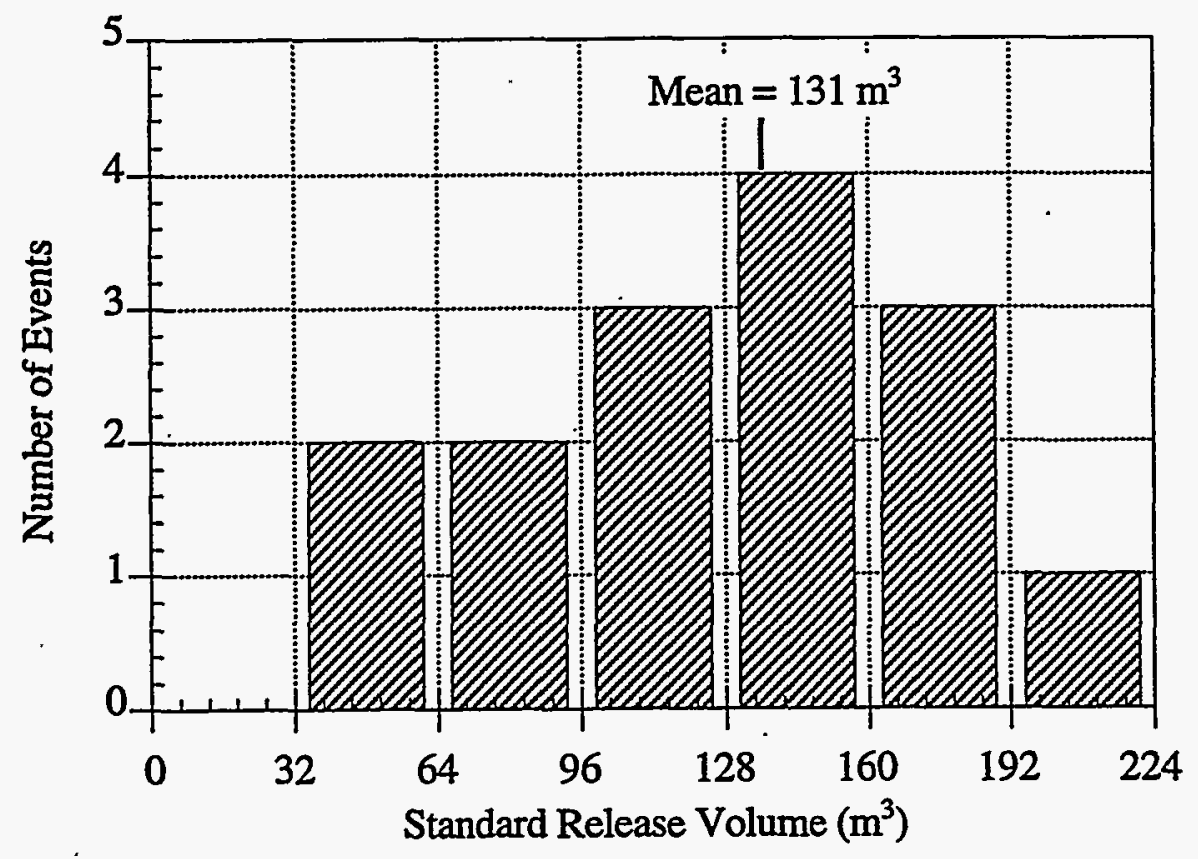

Figure 4.1.8. SY-101 GRE Volume Histogram 


\subsection{SY-103 In Situ Rheology and Gas Volume}

From its initial fill in 1977 until 1980, SY-103 received concentrated complexant (CC) waste from B Plant that was pumped out to the 242-S evaporator on a regular basis. In the third quarter of 1980 , the tank was pumped down to a $120 \mathrm{~cm}$ (46 in.) heel before receiving doubleshell slurry, which filled it to a level of $500 \mathrm{~cm}$ (200 in.) by December 31,1980 . Uranium sludge from ion exchange processing was added in 1985 to $550 \mathrm{~cm}$ (216 in.). Interstitial liquid and water from Tank 241-SX-104 (SX-104) was added in 1988, bringing the level up to $660 \mathrm{~cm}$ (260 in.), and numerous other small additions brought the tank to its current level. SY-103 now contains ? about $691 \mathrm{~cm}$ (272 in.) of waste, of which $356 \mathrm{~cm}$ (140 in.) is supernatant liquid lying over a $335-\mathrm{cm}$ (132-in.) nonconvective layer. The headspace is $2503 \mathrm{~m}^{3}\left(88,400 \mathrm{ft}^{3}\right)$.

Between 1981 and mid-1985, when no large waste transfers occurred, waste surface level measurements with the FIC contact probe show a 1-2-in. level decrease about once a year. Following the addition of uranium ion exchange wastes in 1985, the level decreases began to occur about three times per year. These level decreases were of rather long duration, not the sudden drops typical of a rollover. After the liquid addition from Tank SX-104 in 1988, sudden level. drops of 2-3 cm ( 1 in.), typical of rollover gas releases, began occurring (Shepard et al. 1995). Level drops attained 3-5 cm ( 2 in.) by 1992 . The GRE period in SY-103 varies randomly from 20-200 days.

Locations of various tank instruments are shown in Figure 4.2.1. The waste surface level is measured using an Enraf ${ }^{8} 854$ ATG (advanced technology gauge) buoyancy gauge located in riser 2A. This gauge replaced the FIC contact probe in 1994. A manual tape is located in riser 17A.

A standard hydrogen monitoring system (SHMS) was installed in the vent header in late June 1994. Hydrogen in the exhaust gas is detected with two Whittaker ${ }^{\otimes}$ cells, which rely on the reaction of the gas with an electrode in an electrolyte. One cell has a range of $0-1 \%$, and the other $0-10 \%$ hydrogen. The cells are tested and calibrated quarterly. Baseline hydrogen concentrations are typically $100-200 \mathrm{ppm}$. The highest hydrogen concentration measured during a GRE was $2940 \mathrm{ppm}$ on May 2, 1995. Grab samples were taken from the SHMS cabinets to provide a baseline for the Whittaker cells. These measurements also show baseline nitrous oxide concentrations of 4 to $39 \mathrm{ppm}$, with hydrogen-to-nitrous oxide ratios of 0.3 to 5.5. Ammonia baseline concentrations of 40-180 ppm were measured in the vent header from mid-December 1994 to midJanuary 1995.

Waste temperatures are monitored with a thermocouple tree in riser 4A and an MIT.in riser 17B. A validation probe run was performed in January 1995 to confirm temperature readings from the MIT; profiles from these measurements are shown in Figure 4.2.2.

The ball rheometer was operated in riser $17 \mathrm{C}$ on July 14, 1995, and in riser 22A on August 8,1995 . The ball became supported by the waste about $120 \mathrm{~cm}$ and $135 \mathrm{~cm}$ above the bottom in risers $17 \mathrm{C}$ and $22 \mathrm{~A}$, respectively. The VFI was first deployed on July 19, 1995, in riser 17C, and on August 18, 1995, in riser 22A. Three traverses were conducted in each riser. 


\section{SY-103 Instrument Placement}

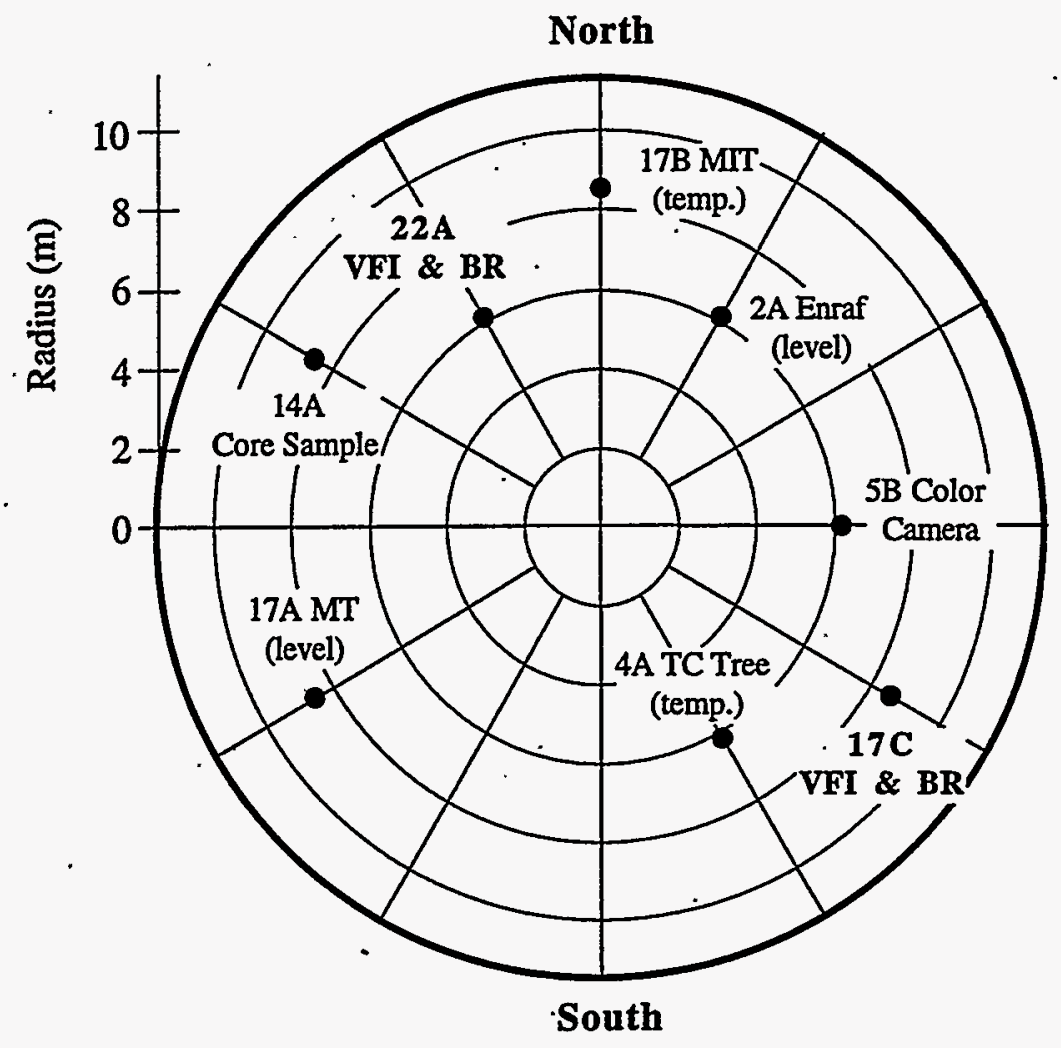

Figure 4.2.1. SY-103 Instrumentation

There was no crust in the immediate vicinity of the VFI in either riser, allowing direct observation of gas releases caused by the VFI disturbing the waste. Although the releases were rather dramatic in appearance, analysis shows that only a very small amount of gas was actually released during these measurements, and this could not have significantly affected the void fraction measurement (Shepard et al. 1995). Most of the surface disturbance arose from opening the sample chamber and dumping the pressurized nitrogen from the prior test. (A video frame of such an event is shown in Figure 4.2.3.)

\subsubsection{Waste Configuration}

Measurements from five different locations in the northwest and southeast quadrants of the tank (see Figure 4.2.1) define the thickness of the nonconvective layer, as summarized in Table 4.5. According to the validation probe measurements, the interface between the nonconvective and convective layers, as indicated by the transition from the isothermal region to the parabolic profile at the bottom of the tank in Figure 4.2.2, is at about $325 \mathrm{~cm}(128 \mathrm{in}$.). This interface was determined to be approximately $335 \mathrm{~cm}$ (132 in.) from the tank bottom by a core 


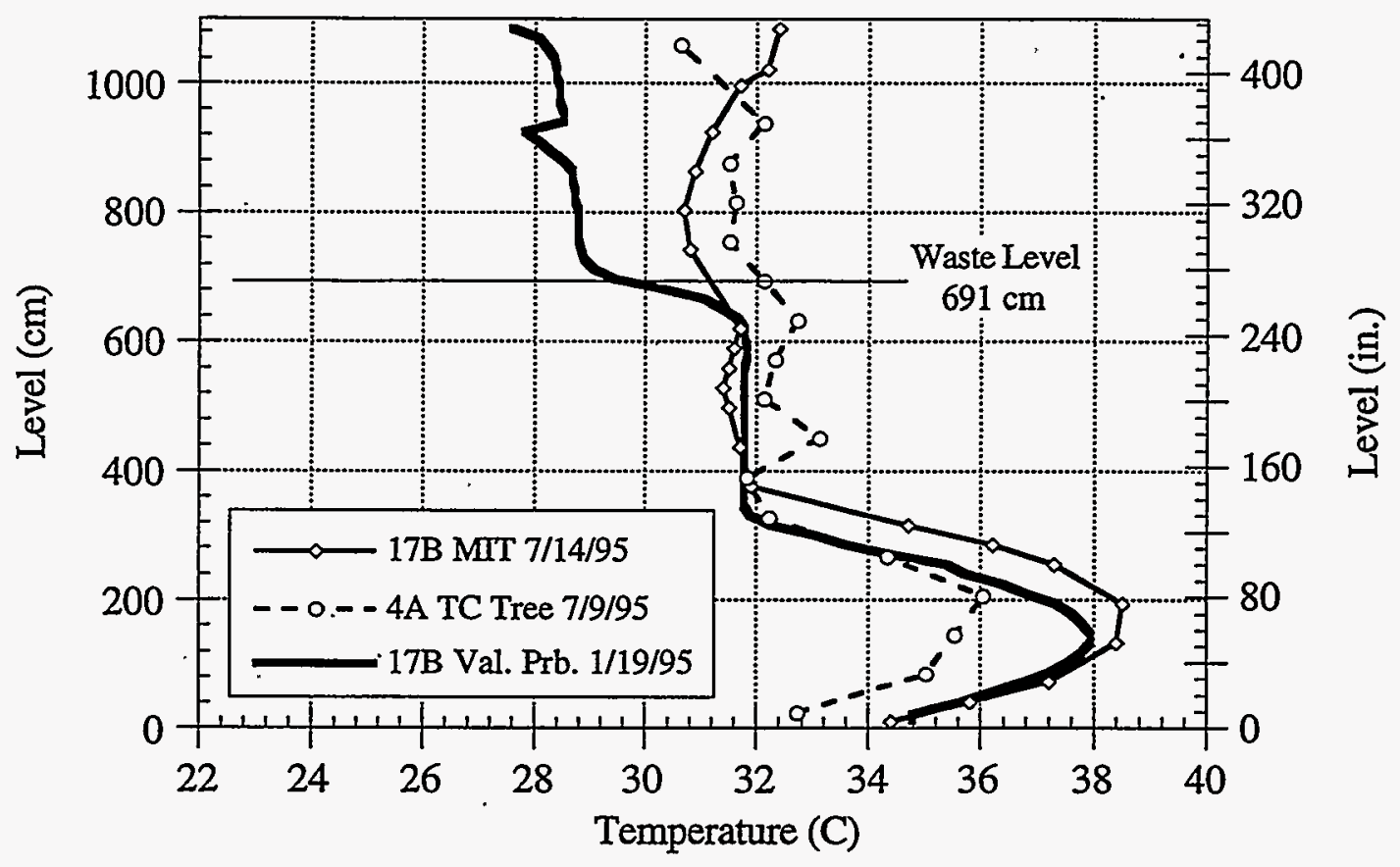

Figure 4.2.2. Temperature Profiles in Risers 17B and 4A

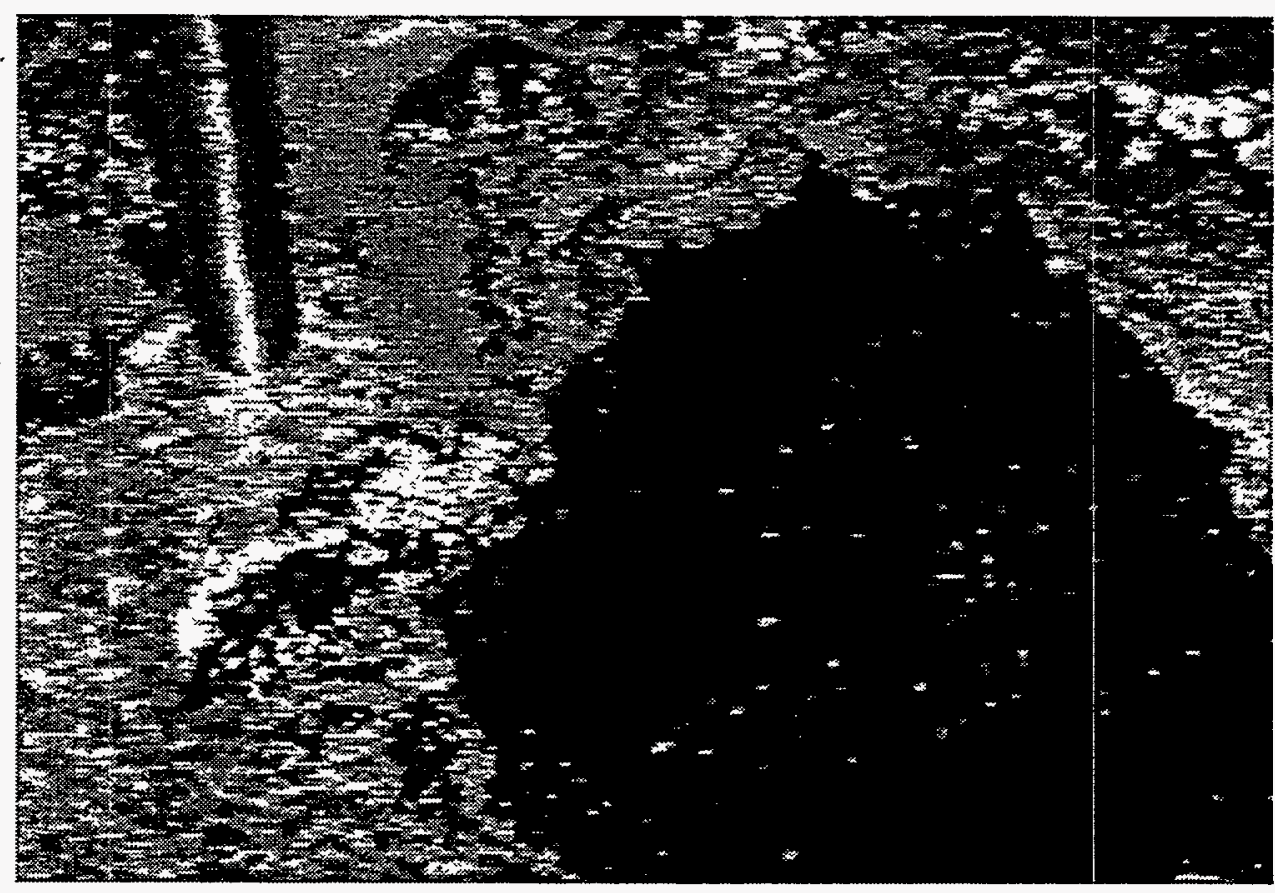

Figure 4.2.3. Typical Surface Disturbance from Sample Chamber Opening 
Table 4.5. Summary of Solids Depth Observations

\begin{tabular}{|c|c|c|}
\hline Riser/Date & Depth $(\mathrm{cm})$ & Method of Estimate \\
\hline 17B 7/14/95 & $350 \pm 25$ & MIT temperature profile \\
\hline 4A 7/9/95 & $340 \pm 40$ & Thermocouple tree temp. profile \\
\hline 17B1/19/95 & $325 \pm 5$ & MIT val. probe temp. profile \\
\hline 22A $8 / 8 / 95$ & $326 \pm 5$ & Ball rheometer \\
\hline 14A 9/94 & $335 \pm 20$ & Core sample \\
\hline Average & $335 \pm 23$ & \\
\hline
\end{tabular}

sample taken from riser 14A during August and September 1994. These data imply a fairly uniform sludge layer with an average height of $335 \mathrm{~cm}$ and standard deviation of $\pm 23 \mathrm{~cm}$. The ball rheometer measurements indicate that there is also a heel layer $120-135 \mathrm{~cm}(47-53$ in.) thick on the tank bottom. Photos of the core extrusions from 1986 and 1994 are shown in Appendix B.

The floating crust layer in SY-103 is much less extensive than that in SY-101. The 17B MIT validation probe temperature profile (see Figure 4.2.2) indicates a $30 \pm 10 \mathrm{~cm}(12 \pm 4 \mathrm{in}$.) crust layer, but in-tank video shows that the crust does not cover the entire surface. Where crust is visible, the sizes of surface features are consistent with the $30-\mathrm{cm}$. thickness inferred from the temperature profile. We estimate that the crust coverage fraction is $0.7 \pm 0.1$. The average crust thickness for gas volume calculations is then taken to be $20 \pm 10 \mathrm{~cm}$.

\subsubsection{Rheology and Density}

Measurements were obtained with the ball rheometer at traverse speeds of 1.0, 3.0, 5.0, $10.0,30.0,50.0$, and $100 \mathrm{~cm} / \mathrm{s}$. Very little drag was observed on the ball in the supernatant liquid at any speed, indicating a relatively low viscosity. The results obtained in the nonconvective layer, however, indicate a somewhat more complicated picture. The variation in drag with respect to elevation in the sludge indicated a marked stratification.

Figure 4.2.4 shows the apparent viscosity as a function of elevation for risers $17 \mathrm{C}$ and 22A. The first pass values were derived for a ball speed of $3 \mathrm{~cm} / \mathrm{s}$. Both the first pass, representative of undisturbed waste, and the strain rate averaged values, indicative of mixed waste, are shown. Note that the material under $22 \mathrm{~A}$ has a much higher apparent viscosity than $17 \mathrm{C}$ and that it decreases more upon mixing.

An upper bound on the yield stress in the nonconvective layer was estimated from the drag measurements in the first pass of the ball through the fluid at $3 \mathrm{~cm} / \mathrm{s}$. In this case, the maximum apparent viscosity is $6.4 \times 10^{5} \mathrm{cP}$, giving an upper bound of $210 \mathrm{~Pa}$ for the yield stress. The upper bound of yield stress is shown as a function of elevation in Figure 4.2.5.

The density of the convective layer is estimated as $1.47 \pm 0.03 \mathrm{~g} / \mathrm{cm}^{3}$ from dynamic density measurements with the ball rheometer in riser 22A. The density of the nonconvective layer is $1.57 \pm 0.05 \mathrm{~g} / \mathrm{cm}^{3}$, as determined from analysis of core samples taken in riser 14A in September 1994 (Wilkins 1995; Bredt and Tingey 1996). The density profiles obtained from the ball rheometer measurements for both risers are shown in Figure 4.2.6. The density of 


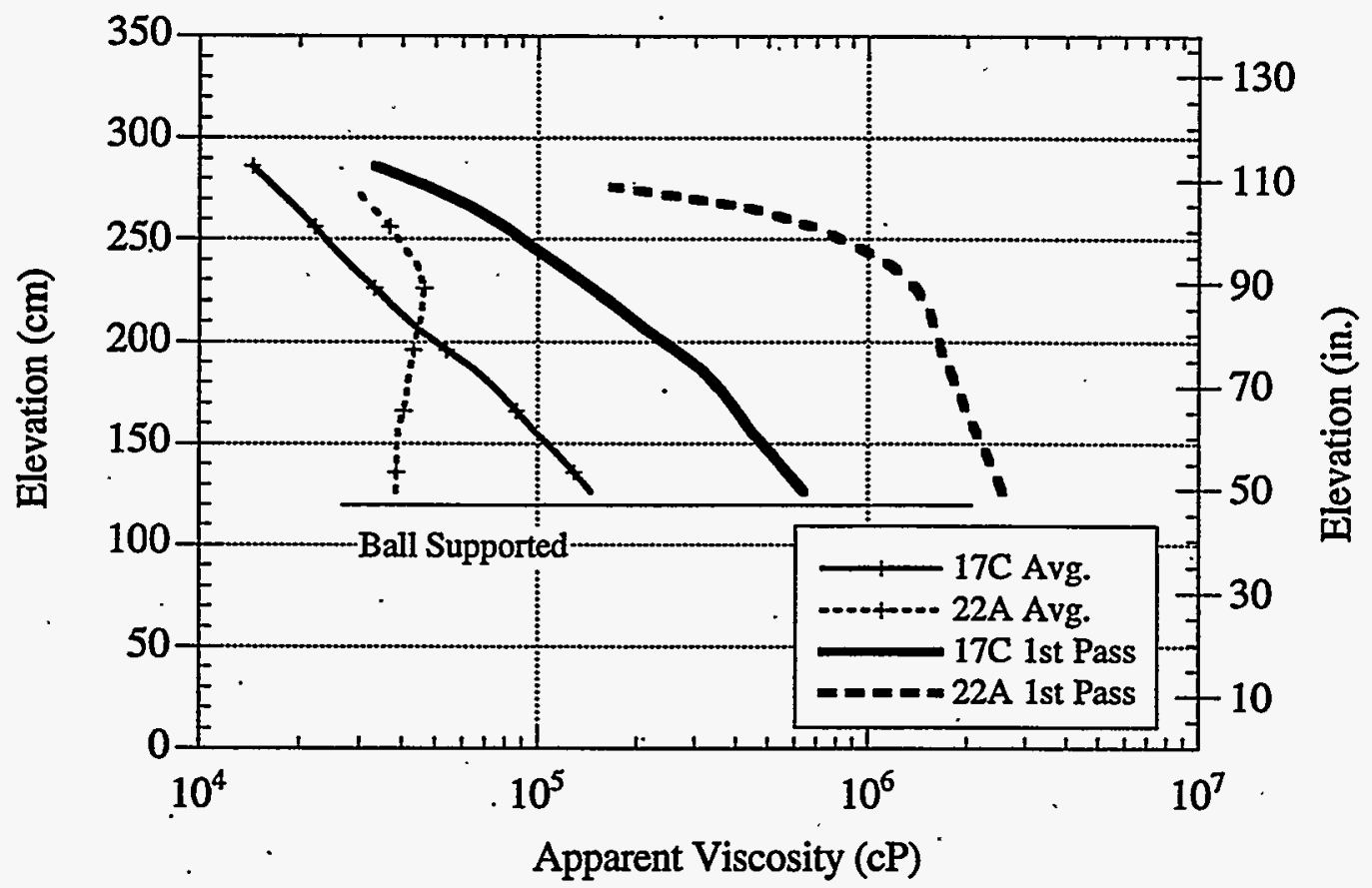

Figure 4.2.4. Apparent Viscosities in Risers $17 \mathrm{C}$ and $22 \mathrm{~A}$

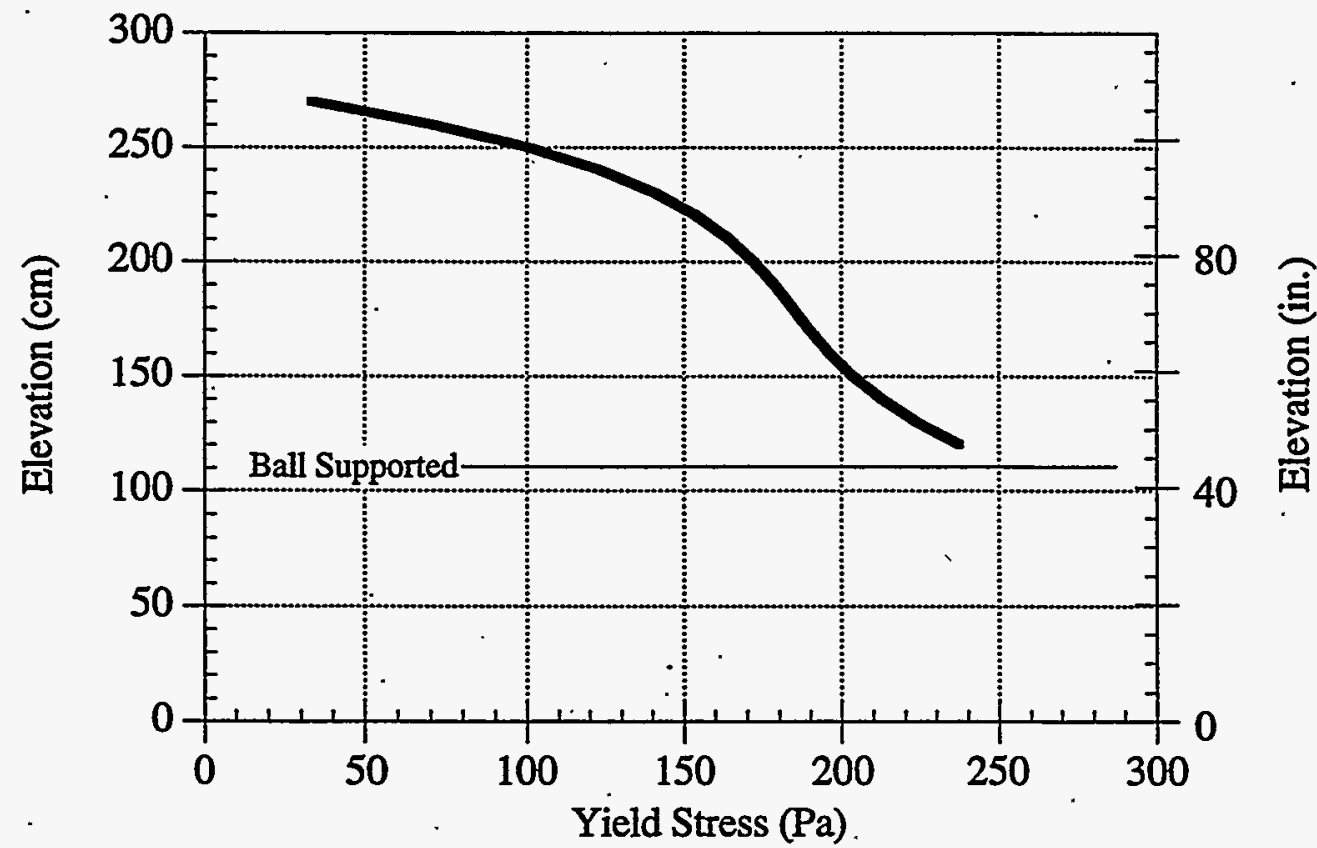

Figure 4.2.5. Yield Stress Profile in SY-103 


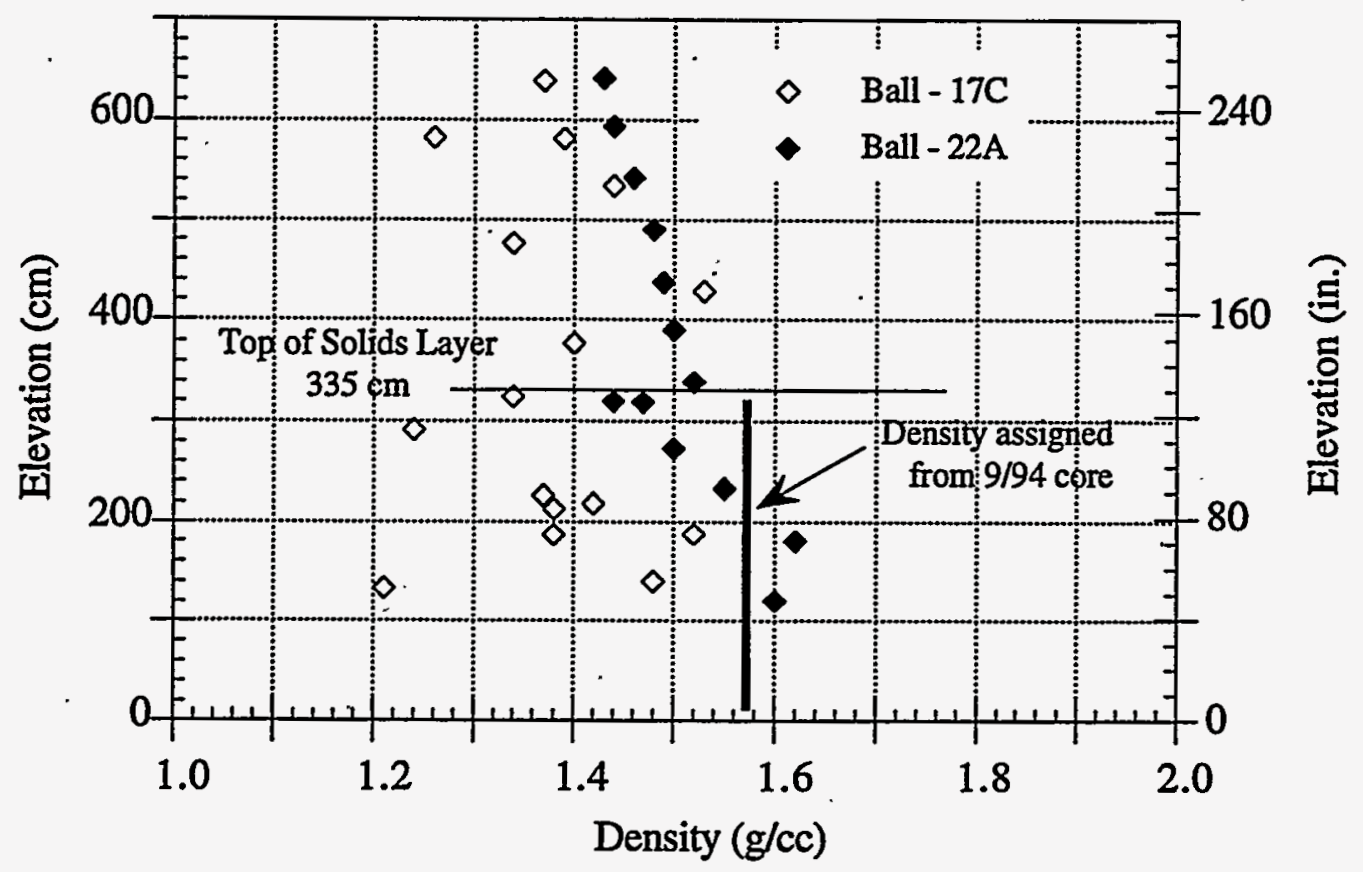

Figure 4.2.6. Density Profiles

$1.40 \pm 0.2 \mathrm{~g} / \mathrm{cm}^{3}$ in riser $17 \mathrm{C}$ does not appear to change with depth. The density near the waste surface in riser $22 \mathrm{~A}$ is also about $1.40 \mathrm{~g} / \mathrm{cm}^{3}$ but increases nearly linearly with depth to approximately $1.54 \mathrm{~g} / \mathrm{cm}^{3}$ near the bottom of the convective layer. The two density measurements in the two risers are consistent within measurement error.

\subsubsection{Void Fraction and Gas Volume}

The void fraction profiles for each traverse in the two risers and the dimensions of the two layers defined to compute the average void fraction are shown in Figure 4.2.7. The estimates of mean void fraction values, gas volumes, and effective pressure ratios for each layer are given in Table 4.6.

The nonconvective layer is estimated to contain a standard gas volume of $150 \pm 46 \mathrm{~m}^{3}$ $(5,300 \pm 1,600 \mathrm{SCF})$. Using a void fraction of $0.25 \pm 0.08$ for the crust yields a standard gas volume of $20 \pm 12 \mathrm{~m}^{3}(7000 \pm 400 \mathrm{SCF})$. Summing up the gas content in the nonconvective layer, supernatant, and crust, the total gas content in SY-103 as of August 1995 was $176 \pm 79 \mathrm{~m}^{3}$ $(6,200 \pm 2,800 \mathrm{SCF})$. The supernatant layer contributes only $5 \mathrm{~m}^{3}$ to the gas volume but $\pm 32 \mathrm{~m}^{3}$ to its uncertainty. Removing the in situ gas in the nonconvective layer reduces the level by $22 \mathrm{~cm}$, making the degassed level $669 \pm 8 \mathrm{~cm}$.

The effective pressure ratio in the nonconvective layer is $1.70 \mathrm{~atm}$; it is $1.55 \mathrm{~atm}$ for the entire tank gas content. The computed barometric pressure effect or compressibility is $-0.18 \pm$ $0.08 \mathrm{~cm} / \mathrm{kPa}$, and the effective pressure for calculating the gas volume from the barometric response correlation is $1.56 \pm 1.0 \mathrm{~atm}$. 


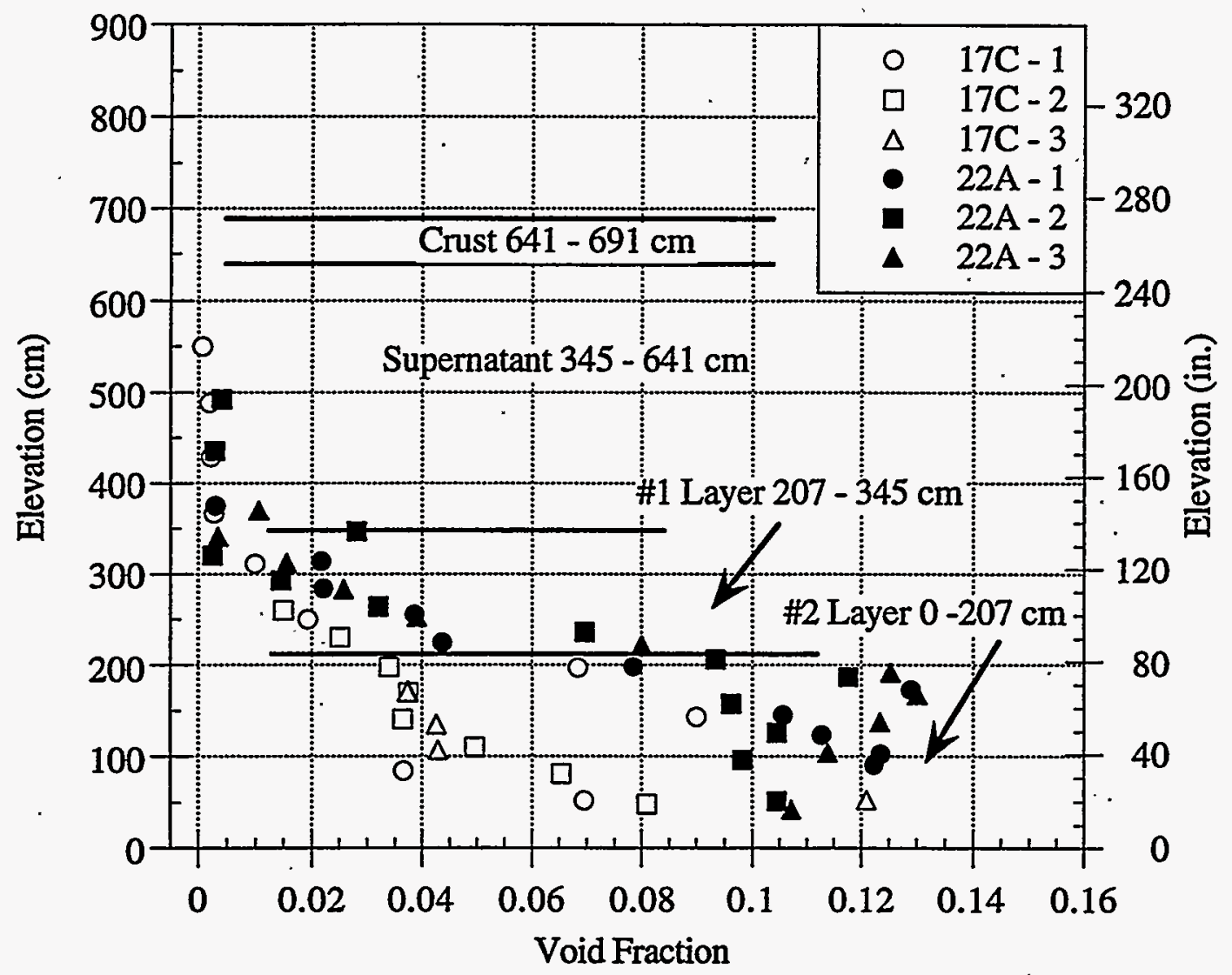

Figure 4.2.7. Void Profiles for Each Traverse in SY-103

Table 4.6. Estimates of Mean Void Fraction and Uncertainty

\begin{tabular}{||l|c|c|c|c||}
\hline $\begin{array}{c}\text { Layer ID, } \\
\text { Dim. }(\mathrm{cm})\end{array}$ & $\begin{array}{c}\text { Mean Void } \\
(\%)\end{array}$ & $\begin{array}{c}\text { In-Situ Volume } \\
\left(\mathrm{m}^{3}\right)\end{array}$ & $\begin{array}{c}\text { Ptandard } \\
\text { Polume }\left(\mathrm{m}^{3}\right)\end{array}$ \\
\hline$\# 2 \quad 0-207$ & $9.2 \pm 2$ & $78 \pm 17$ & $1.74 \pm 0.02$ & $135 \pm 29$ \\
\hline$\# 1 \quad 207-345$ & $1.8 \pm 2$ & $10 \pm 12$ & $1.51 \pm 0.01$ & $15 \pm 17$ \\
\hline $\begin{array}{l}\text { Supernate } \\
345-641\end{array}$ & $0.4 \pm 2$ & $5 \pm 28$ & $1.20 \pm 0.01$ & $5 \pm 32$ \\
\hline Crust & N/A & $21 \pm 12$ & 1.0 & $35 \pm 18$ \\
\hline Tot. Nonconv. & $6.2 \pm 2$ & $88 \pm 28$ & $1.70 \pm 0.03$ & $150 \pm 46$ \\
\hline Tot. Tank & N/A & $114 \pm 57$ & $1.55 \pm 0.10$ & $176 \pm 79$ \\
\hline
\end{tabular}




\subsubsection{Gas Release}

Figure 4.2.8 shows the histogram of SY-103 GRE volumes based on FIC level data from December 7, 1989 (see Appendix A). For a no-gas level of $669 \mathrm{~cm}$ (264 in.) and an effective pressure of $1.70 \mathrm{~atm}$, the average release fraction is $0.09 \pm 0.04$. The maximum release fraction was 0.18 for the November 21,1992 , event. The expected release standard volume is $14 \pm 6 \mathrm{~m}^{3}$, and the maximum release was just under $30 \mathrm{~m}^{3}$ in November 1992 and March 1990.

The histogram indicates that most of the releases are smaller than the mean and that the two largest ones are not part of the same distribution. The GRE period averages $87 \pm 67$ days with a range of 222 to 20 days. This indicates essentially random behavior.

SY-103 gas releases are quite rapid initially, but much of the gas is released over the 12-24 hours after the main event. Elevated ammonia concentrations typically persist at the SY farm exhaust stack for many days following a release in SY-103. ${ }^{(a)}$ This indicates that the GREs create a significant surface disturbance and expose fresh liquid to the dome atmosphere.

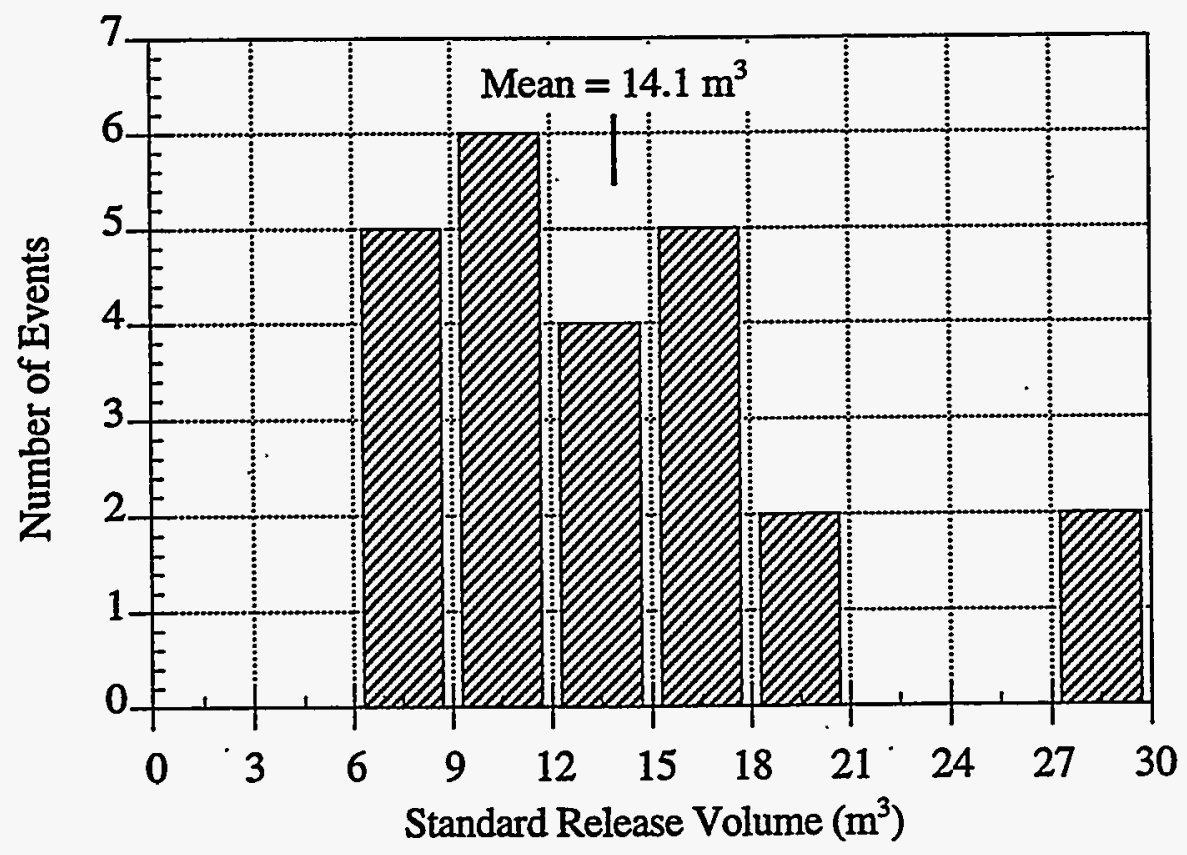

Figure 4.2.8. SY-103 GRE Histogram

(a) Wilkins, NE. March 21, 1995. Ammonia in SY Farm.. Letter to GD Johnson. 71310-95018, Westinghouse Hanford Company, Richland, Washington. 


\subsection{AW-101 In Situ Rheology and Gas Volume}

Major additions to AW-101 began in late 1981 with transfers from the 242-A evaporator. The tank was essentially emptied and refilled several times during evaporator campaigns until 1984. From mid-1984 to mid-1986, various process wastes from the PUREX plant were collected in AW-101 and periodically transferred to the evaporator. In mid-1986 the tank was pumped out to about a 50-cm (20-in.) heel before being filled to its current level.with double-shell slurry feed from the 242-A evaporator. The waste level is currently around $1040 \mathrm{~cm}$ (410 in.) and consists of a nonconvective layer, $250-320 \mathrm{~cm}$ (100-125 in.) in depth; 660-730 cm (260-290 in.) of supernatant liquid; and a floating crust layer about $60 \mathrm{~cm}$ (24 in.) thick. The head space volume in $A W-101$ is $1,070 \mathrm{~m}^{3}\left(37,800 \mathrm{ft}^{3}\right)$.

Level fluctuations began immediately after the last fill and reached their current $2-5 \mathrm{~cm}$ ( 2 in.) range by mid-1987. The GRE period in AW-101 is almost random, ranging from 40 to 750 days. Level drops typically require several days, and the drop is typically less than $5 \mathrm{~cm}$. The largest drop, $10.8 \mathrm{~cm}$, was indicated by the manual tape between November 29 and December 27, $1993 ; 7 \mathrm{~cm}$ occurred in one day. ${ }^{(a)}$

The placement of important in-tank instrumentation is shown in Figure 4.3.1. Waste surface level is currently measured by both a manual tape (MT) in riser 1A and an Enraf ${ }^{\circ}$ buoyancy gauge in riser 2A on the opposite side of the tank. The Enraf gauge replaced a Food Instrument Corporation (FIC) contact probe in the same riser on August 18, 1995. Vertical temperature profiles are measured in two locations: 1) an MIT installed in riser. 15A in 1995 that is currently being read manually and 2) an older thermocouple tree mounted in riser 4A. Six of its thermocouples are recorded manually; readings are spaced approximately every $125 \mathrm{~cm}$ (50 in.), with the first near the tank bottom.

An SHMS was installed in September 1994 to measure hydrogen concentration with two Whittaker ${ }^{\otimes}$ cells, one with a range of $0-1 \%$ and the other $0-10 \%$. A gas characterization system (GCS) was installed in April 1996. A GCS comprises three instruments, two gas chromatographs (GCs) and a Fourier transform infrared spectrometer (FTIR). One GC measures hydrogen, the other measures nitrous oxide and methane, and the FTIR measures ammonia concentrations. Hydrogen concentrations in AW-101 typically rise to $0.2-0.5 \%(2000-5000 \mathrm{ppm})$ during GREs. In the GRE that occurred during October 1994, the hydrogen concentration peaked at $0.88 \%$. The background hydrogen concentration is typically below $10 \mathrm{ppm}$, nitrous oxide and methane are $0 \mathrm{ppm}$, and ammonia is $10-20 \mathrm{ppm}$.

The gas monitoring data show small releases every few months, sharply increasing the hydrogen concentration to several thousand $\mathrm{ppm}$. But there is no abrupt waste level drop such as would be expected of a gas release in a DST. Instead, AW-101 releases usually show a sharp increase in waste level of about $1 \mathrm{~cm}$, after which both level and concentration slowly return to their initial values. The waste level history for a one-year period from October 1994 to October 1995 is shown in Figure 4.3.2.

Hydrogen concentration spikes can also occur without affecting level, and waste level spikes and drops sometimes occur without any corresponding change in hydrogen (as on December 12, 1994, and April 23, 1995). The recent release, September 15-25, 1995, was actually accompanied by a $2-\mathrm{cm}$ (1-in.) level rise. Apparently, gas escapes from a relatively high

(a) See also Wilkins, NE. October 19, 1994. "Tank 241-AW-101 Data Review." Internal memo TE310-94-053, Westinghouse Hanford Company, Richland, Washington. 


\section{AW-101 Instrument Placement}

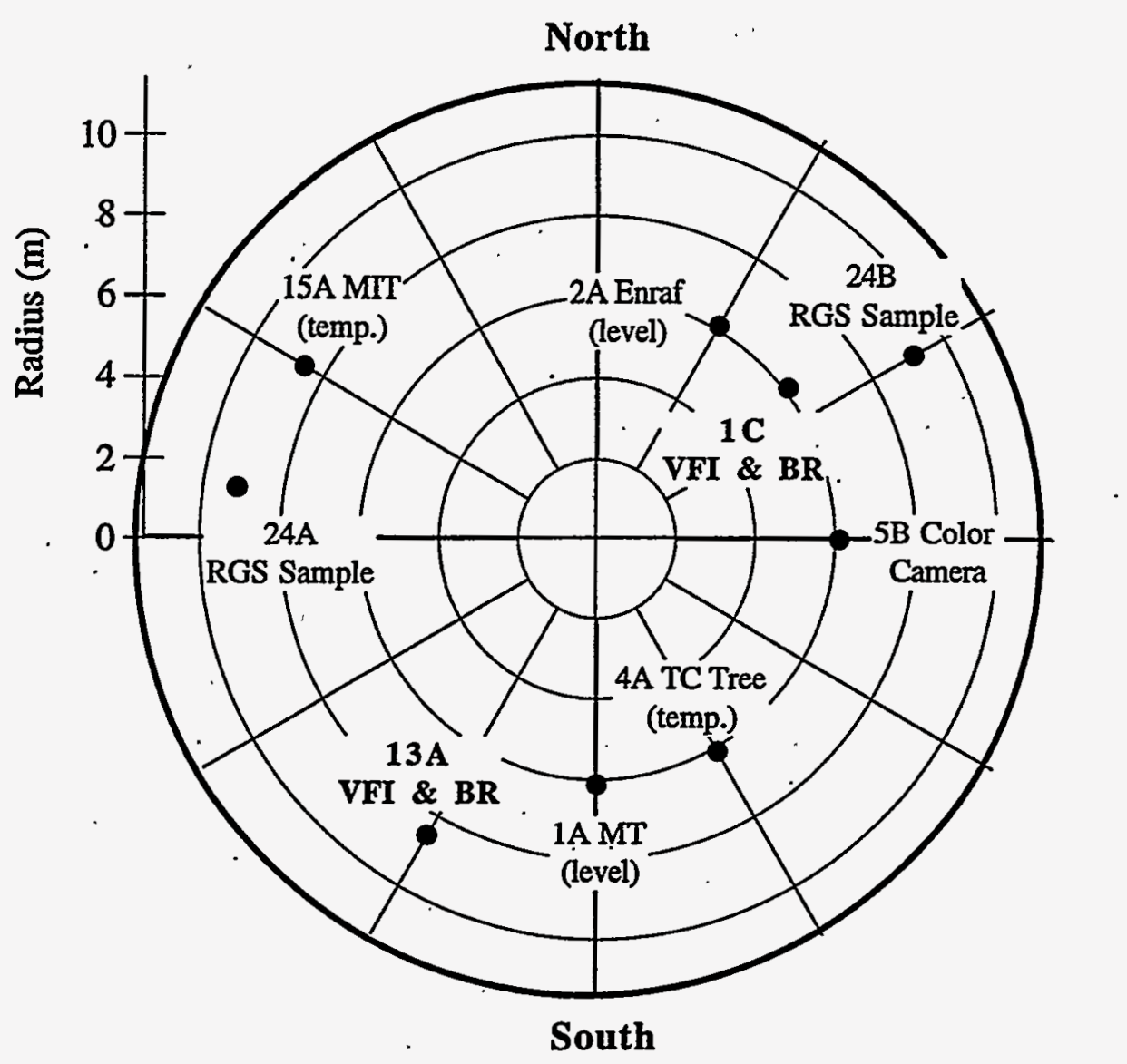

Figure 4.3.1. Tank 241-AW-101 Instrumentation

pressure near the bottom but is not immediately released. The expansion of the gas as it rises causes a level rise, and the release of part of the gas through the crust allows the level to fall back.

The ball rheometer and VFI were each run in risers 13A and 1C; the ball rheometer was run in $13 \mathrm{~A}$ on September 18,1995, and in 1C on September 20. The VFI was deployed in 13A on September 22 and in $1 \mathrm{C}$ September 24 . Water lancing was performed to penetrate the crust layer for the ball in 13A on September 15 and in 1C on September 18, 1995.

The testing activity apparently disturbed the waste sufficiently to trigger small gas releases. The hydrogen concentration history during this period is given in Figure 4.3.3. The first release occurred immediately after lancing through the crust in riser 13A and must have come from the crust since the lance did not penetrate the nonconvective layer. The ball rheometer did not release any more gas in 13A; neither did the subsequent lancing and testing in riser 1C. The VFI also released gas. Looking closely at the timing of the gas release and VFI operation in Figure 4.3.4, the entire test series was completed in $13 \mathrm{~A}$, and the first pass was completed in $1 \mathrm{C}$ before the hydrogen concentration began to increase. 




Figure 4.3.2. Waste Level History - October 1994 to October 1995



Figure 4.3.3. Hydrogen Concentration History During Deployment 


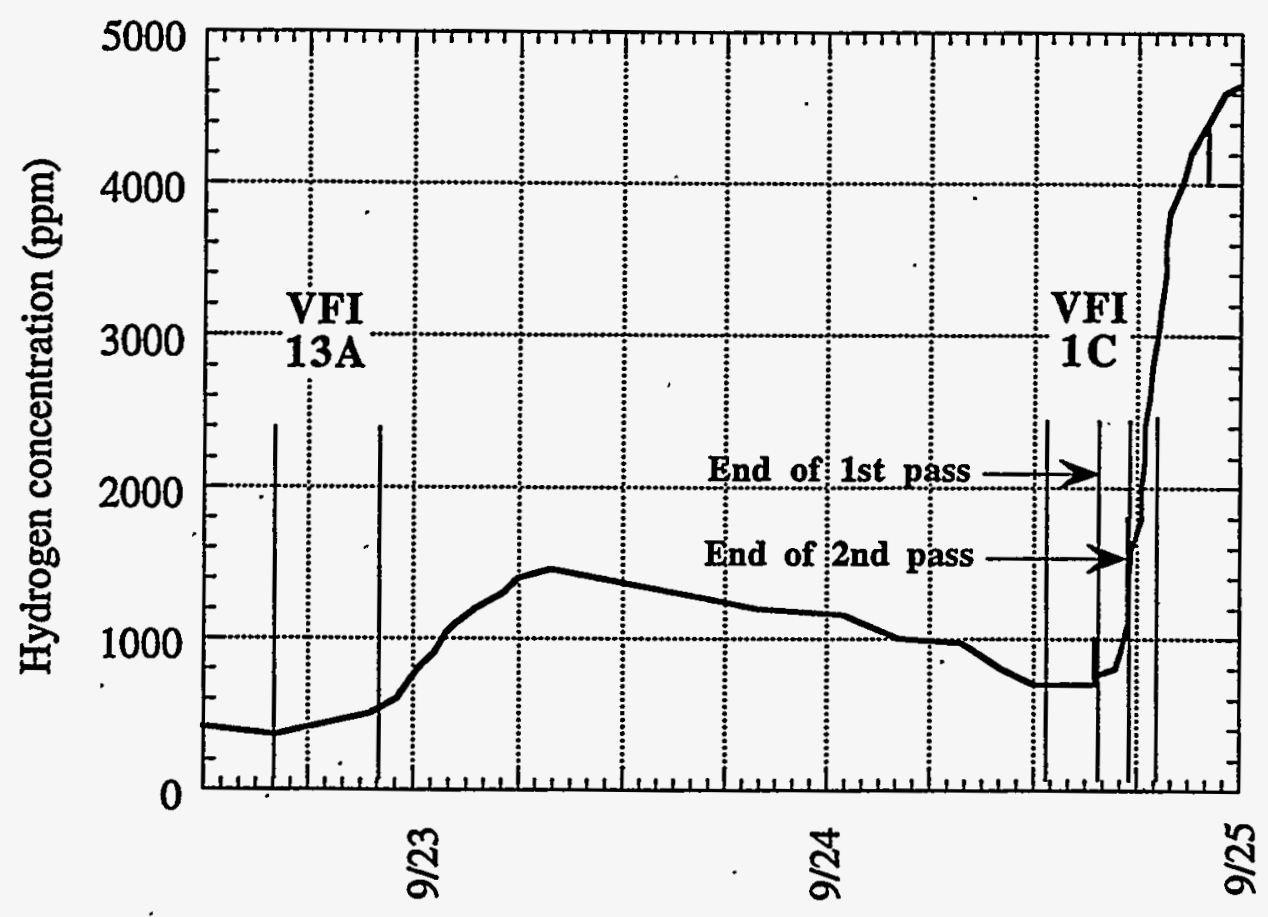

Figure 4.3.4. Sequence of Gas Release Compared with VFI Deployment

The computed release rate matching the dome concentration transient from September 22 through September 29 indicated that about $14.3 \mathrm{~m}^{3}(503 \mathrm{SCF})$ of hydrogen was released.

Assuming 30\% hydrogen concentration, the total gas release may have been as high as $47.7 \mathrm{~m}^{3}$ (1670 SCF). Additional gas may have been stored in the crust layer, as evidenced by the $2.5-\mathrm{cm}$ (1-in.) waste level increase over this period.

AW-101 was the first tank sampled with the RGS; segments 8, 17, 19, and 21 were taken from riser $24 \mathrm{~A}$ and segments 18 and 22 from riser 24B. Segment 8 is in the convective layer, and the rest are in the nonconvective layer. Laboratory analysis showed that the insoluble fraction of the stored gas contained about $25 \%$ hydrogen and $60 \%$ nitrogen, with the remaining $15 \%$ composed of oxygen, nitrous oxide, methane, argon, and small amounts or other hydrocarbons. ${ }^{\text {(a) }}$

\subsubsection{Waste Configuration}

Passage of the ball through the liquid surface occurred in both risers at an elevation of $1044 \pm 5 \mathrm{~cm}$ (411 \pm 2 in.) in both risers on September 18 and 20, 1995. The Enraf gauge in riser $2 \mathrm{~A}$ indicated a level of $1040 \pm 5 \mathrm{~cm}$ (409.5 in) during that same week.

The crust occupied all of segment 1 and about $1 / 3$ of segment 2 of the core in 24A. Since a segment is $48 \mathrm{~cm}$ (19 in) in length, the crust thickness is $64 \pm 10 \mathrm{~cm}$ (25 \pm 4 in.). Video scans

(a) Shekarriz, R, DR Rector, MA Chieda, M White, and JM Bates. July 1996. Retained Gas Sampler Measurement Results for Hanford Waste Tank 241-AW-101. Letter Report TWS-MIT071996, PNNL, Richland, Washington. 
indicate the crust covers the entire waste surface. The MIT profile in riser $15 \mathrm{~A}$ indicates a crust thickness of $50 \pm 20 \mathrm{~cm}$; however, the core sample is the most direct measurement.

The nonconvective layer depth in AW-101 apparently varies considerably over the tank. The ball rheometer indicated 259 and $280 \mathrm{~cm}$ in risers $1 \mathrm{C}$ and $13 \mathrm{~A}$, respectively. Temperature profiles in risers 4A and 15A imply sludge depths of 280 and $310 \mathrm{~cm}$, as shown in Figure 4.3.5. Table 4.7 summarizes the indications available at four different risers. The average of the four yields a depth of $282 \pm 40 \mathrm{~cm}(111 \pm 15 \mathrm{in}$.).

\subsubsection{Rheology and Density}

The average density in the convective layer is $1.42 \pm 0.03 \mathrm{~g} / \mathrm{cm}^{3}$ as determined with the ball rheometer. The density profile is shown in Figure 4.3.6. X-ray images calibrated to water density indicated a specific gravity of $1.42 \pm 0.07$, which is in close agreement with that indicated by the ball rheometer. The reported density of core segments 18,20, and 22 from riser $24 \mathrm{~A}$ give an average density of $1.57 \pm 0.03 \mathrm{~g} / \mathrm{cm}^{3}$ for the nonconvective layer.

The average viscosity of the convective layer was calculated at $18 \mathrm{cP}$ from the drag force on the ball and cable at speeds varying from 10 to $100 \mathrm{~cm} / \mathrm{s}$. However, because of load cell sensitivity and the experimental error, the actual value could range from 7 to $46 \mathrm{cP}$. The yield strength and viscosity of the nonconvective layer increase monotonically with depth. Figure 4.3.6 shows upper bounds on the yield stress as a function of elevation for the first pass of the ball through the

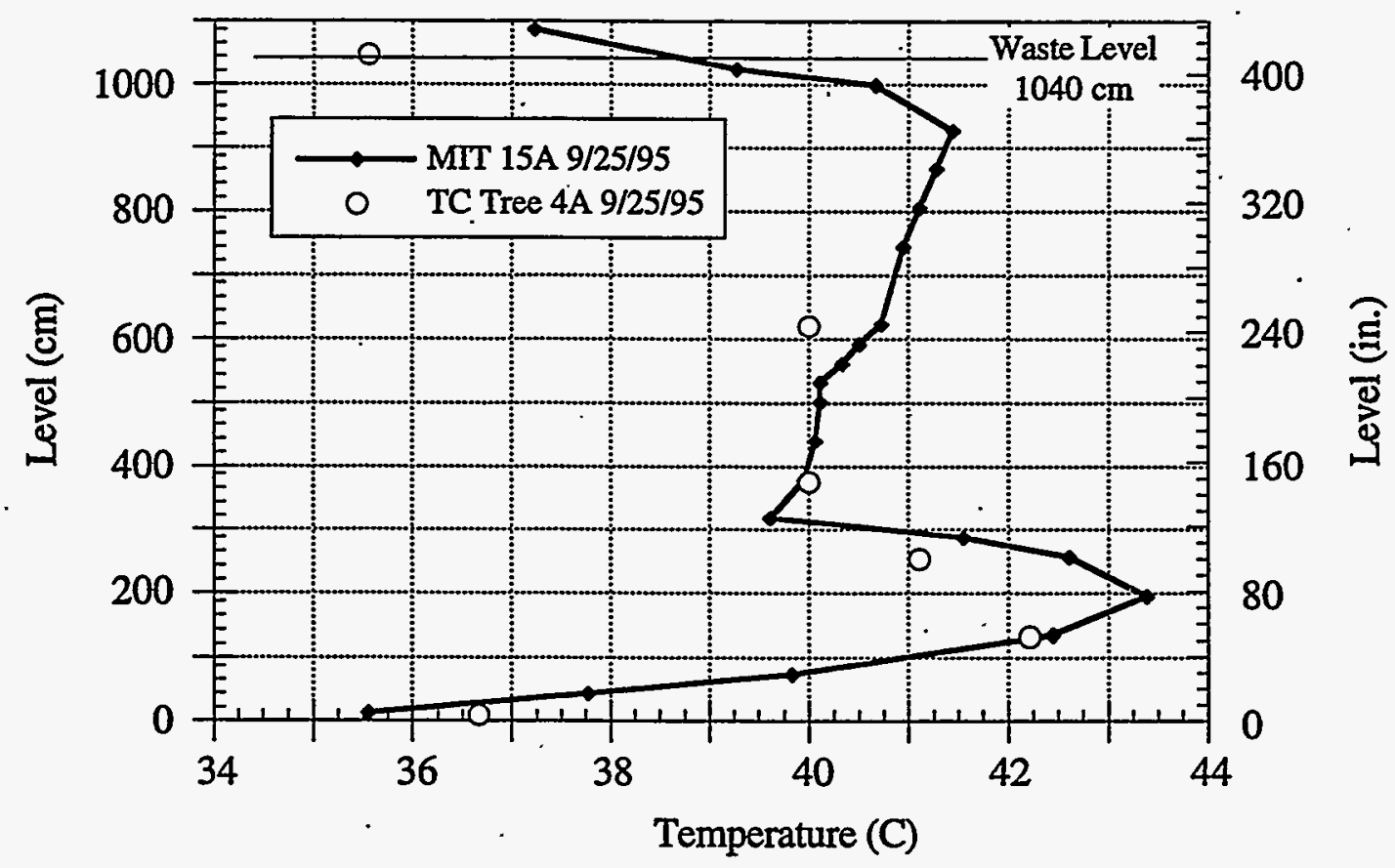

Figure 4.3.5. Temperature Profiles on September 25, 1995

(a) Electronic mail message, C Benar, AW-101 Tank Coordinator, WHC Characterization Project, to CW Stewart, PNNL, July 19, 1996. 
Table 4.7. Summary of Solids Depth Indications

\begin{tabular}{||c|c|c|}
\hline Riser/Date & Depth $(\mathrm{cm})$ & Method of Estimate \\
\hline 15A 9/25/95 & $310 \pm 30$ & MIT temperature profile \\
\hline 4A $9 / 25 / 95$ & $280 \pm 60$ & Thermocouple tree temperature profile \\
\hline 13A $9 / 18 / 95$ & $280 \pm 7$ & Ball rheometer \\
\hline 1C $9 / 20 / 95$ & $259 \pm 7$ & Ball rheometer \\
\hline Average & $282 \pm 40$ & \\
\hline
\end{tabular}

sludge layer. After the ball has traversed through the sludge layer eight times, the apparent viscosity and the yield strength decreased considerably. Figure 4.3.7 shows a comparison between the apparent viscosities for the first and eighth passes through the sludge layer at $0.1 \mathrm{~cm} / \mathrm{s}$.

\subsubsection{Void Fraction and Gas Volume}

The void measurements for each traverse in each riser are shown in Figure 4.3.9 with the selected averaging layers. The estimates of mean void fraction and its uncertainty as well as the gas volume calculations for each defined layer are given in Table 4.8.

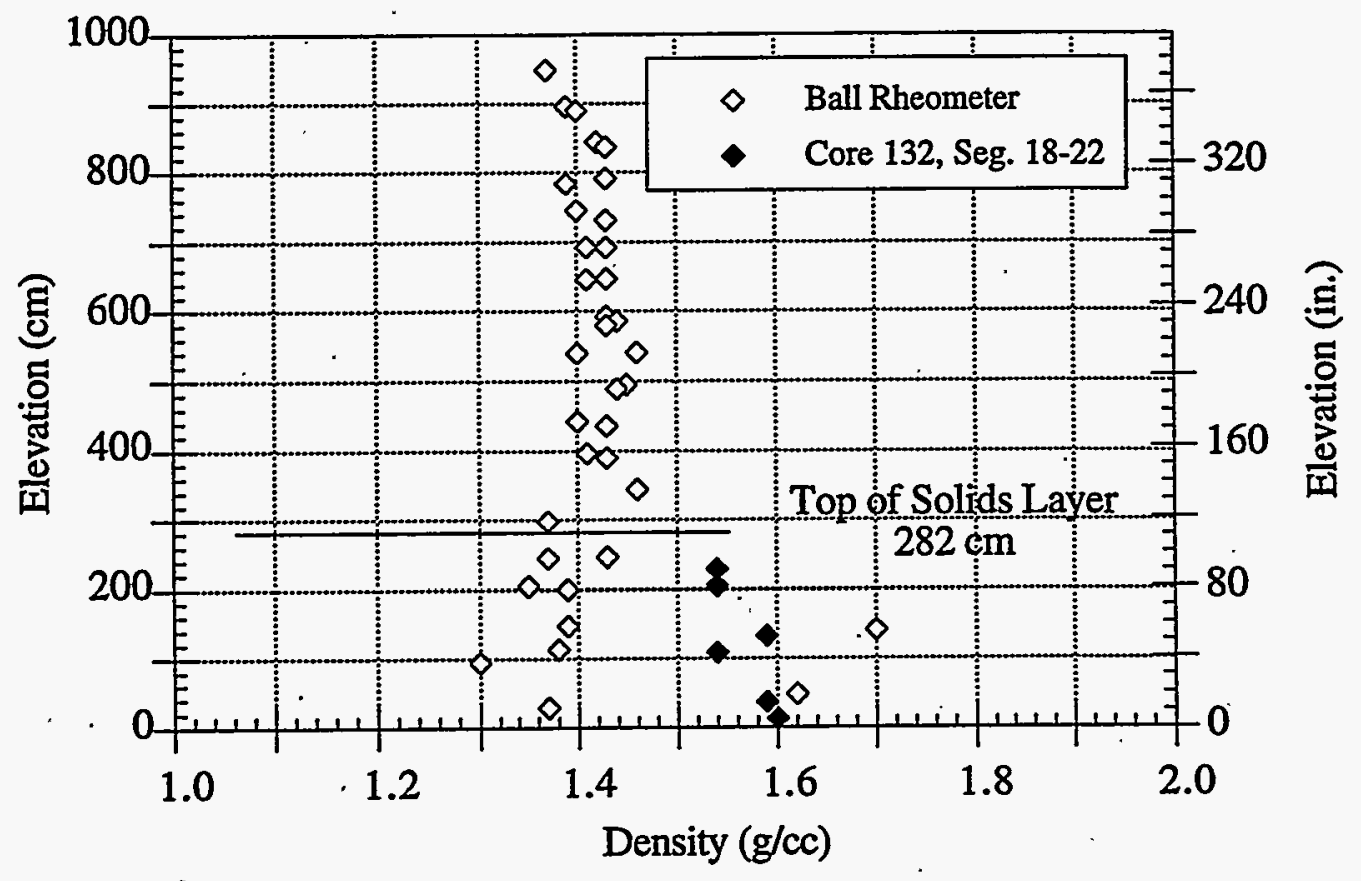

Figure 4.3.6. AW-101 Density Profile 


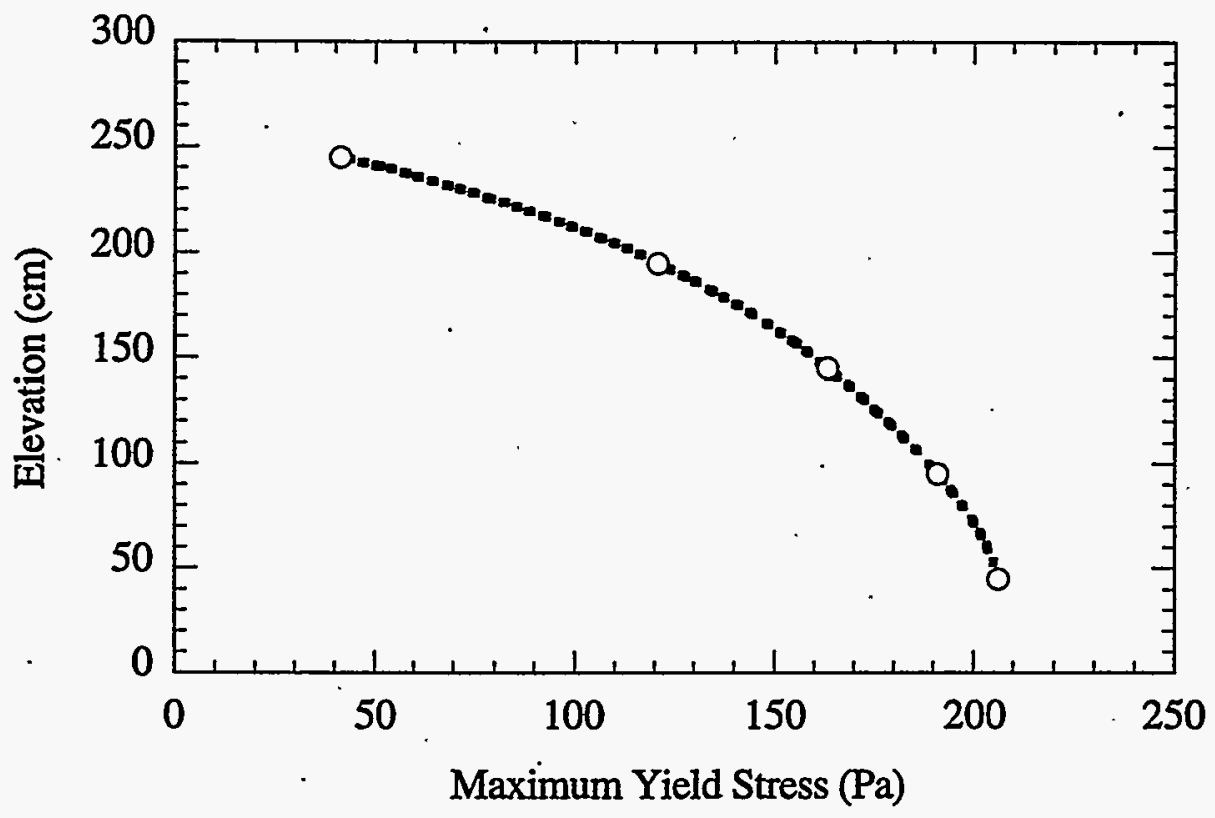

Figure 4.3.7. Upper Bound on the Yield Stress



Figure 4.3.8. Apparent Viscosities of the First and Last Passes 


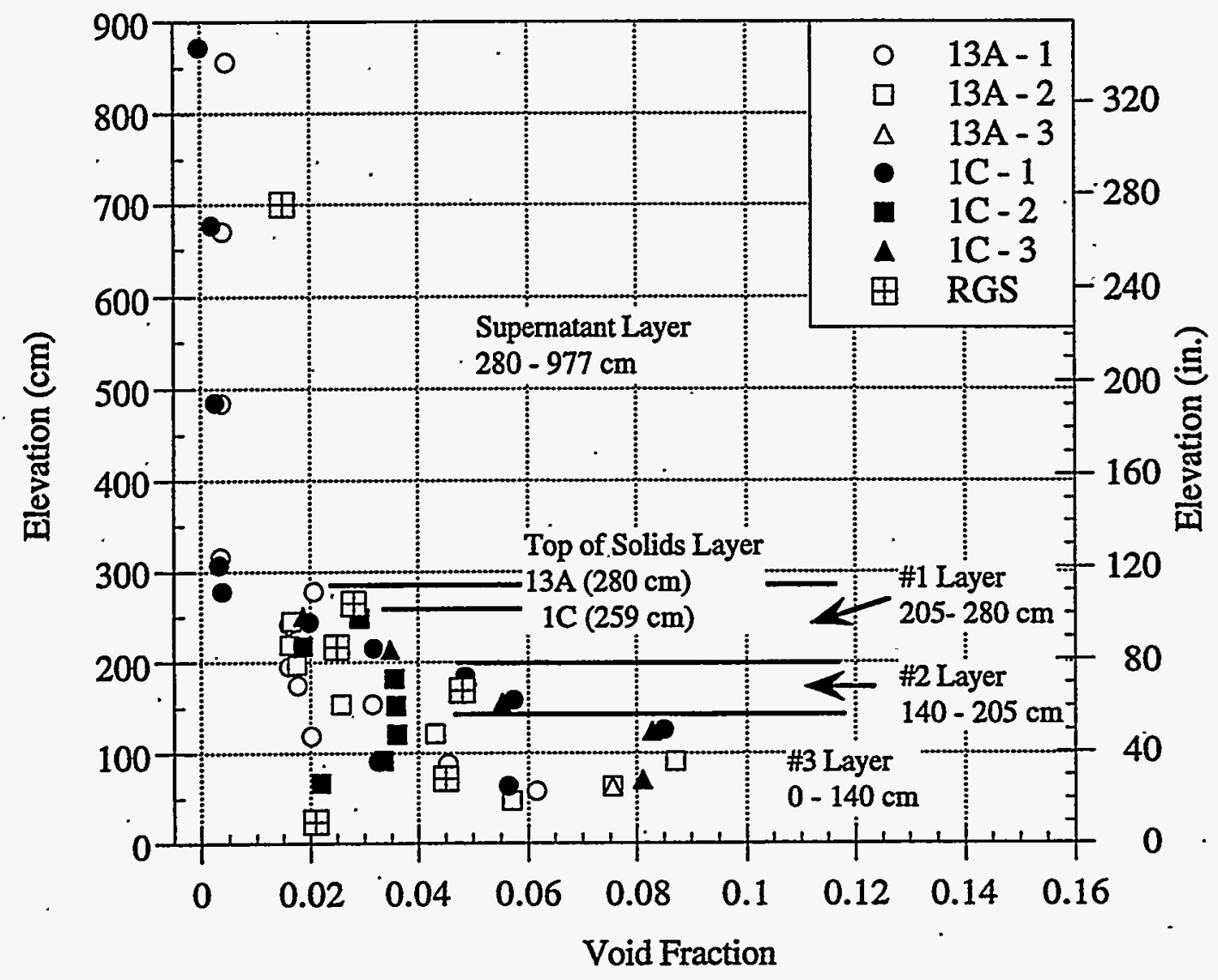

Figure 4.3.9. Void Measurements in AW-101

The mean void fractions of the three layers differ significantly, ranging from 2.2 to $6.2 \%$ with uncertainties of $0.6-0.7 \%$. The void measurements in the convective layer averaged $0.8 \%$ with an uncertainty of $0.8 \%$. The uncertainty in void due to traverse was estimated to be $0.88 \%$. The deviation due to riser and to the interaction of riser and elevation were very close to zero. The interaction of traverse and elevation gave a deviation of $0.7 \%$, and the deviation due to sampling

Table 4.8. Estimates of Mean Void Fraction and Uncertainty

\begin{tabular}{||l|c|c|c|c||}
\hline \hline $\begin{array}{c}\text { Layer ID, } \\
\text { Dim. }(\mathrm{cm})\end{array}$ & $\begin{array}{c}\text { Mean Void } \\
(\%)\end{array}$ & $\begin{array}{c}\text { In Situ Volume } \\
\left(\mathrm{m}^{3}\right)\end{array}$ & Pressure Ratio & $\begin{array}{c}\text { Standard Volume } \\
\left(\mathrm{m}^{3}\right)\end{array}$ \\
\hline$\# 30-140$ & $6.2 \pm 0.6$ & $36 \pm 4$ & $2.17 \pm 0.02$ & $78 \pm 8$ \\
\hline$\# 2 \quad 140-205$ & $4.4 \pm 0.7$ & $12 \pm 2$ & $2.03 \pm 0.02$ & $24 \pm 4$ \\
\hline$\# 1 \quad 205-280$ & $2.2 \pm 0.6$ & $7 \pm 2$ & $1.96 \pm 0.02$ & $13 \pm 4$ \\
\hline Supernatant 280-977 & $0.8 \pm 0.8$ & $22 \pm 24$ & $1.47 \pm 0.01$ & $32 \pm 34$ \\
\hline Crust & N/A & $66 \pm 23$ & 1.0 & $63 \pm 23$ \\
\hline Total Nonconv. & $4.7 \pm 0.5$ & $54 \pm 6$ & $2.13 \pm 0.02$ & $115 \pm 12$ \\
\hline Total Tank & N/A & $142 \pm 36$ & $1.47 \pm 0.10$ & $209 \pm 47$ \\
\hline
\end{tabular}


and instrument error was $1.35 \%$. This means that the standard deviation of a single void measurement is on the order of 1.8\%; however, the deviation of the average in each layer is much less because there are many data points in the average.

The crust gas standard volume is estimated to be $63 \pm 22 \mathrm{~m}^{3}(2,300 \pm 800 \mathrm{SCF})$. Adding this to the $115 \pm 12 \mathrm{~m}^{3}(4,000 \pm 430 \mathrm{SCF})$ in the nonconvective layer and $32 \pm 34 \mathrm{~m}^{3}(1,100 \pm$ $1,200 \mathrm{SCF}$ ) in the convective layer yields a total standard gas volume in $\mathrm{AW}-101$ of $209 \pm 46 \mathrm{~m}^{3}$. at $1 \mathrm{~atm}(7,400 \pm 1,600 \mathrm{SCF})$. Removing the in situ gas in the nonconvective layer reduces the level by $13 \mathrm{~cm}$, making the degassed level $1027 \pm 7 \mathrm{~cm}$ (404 $\pm 3 \mathrm{in})$.

The effective pressure ratio in the nonconvective layer is 2.13 and 1.47 for the entire tank gas content. The computed barometric pressure response or compressibility is $-0.25 \pm 0.08$ $\mathrm{cm} / \mathrm{kPa}$ and the effective pressure for calculating the gas volume from the barometric pressure effect is $1.37 \pm 0.5 \mathrm{~atm}$.

\subsubsection{Gas Release}

Gas releases in AW-101 are typically very slow. Hydrogen release rates and cumulative release fractions calculated from the hydrogen concentration transient for two events are shown in Figures 4.3.10 and 4.3.11. Total release rates, with $30 \%$ hydrogen, are 0.8 and 2.7 scfm, respectively. The May event took 10 hours for $80 \%$ of the total release, and the June event required six hours. The peak release rate occurred 2-3 hours after the start in each case.

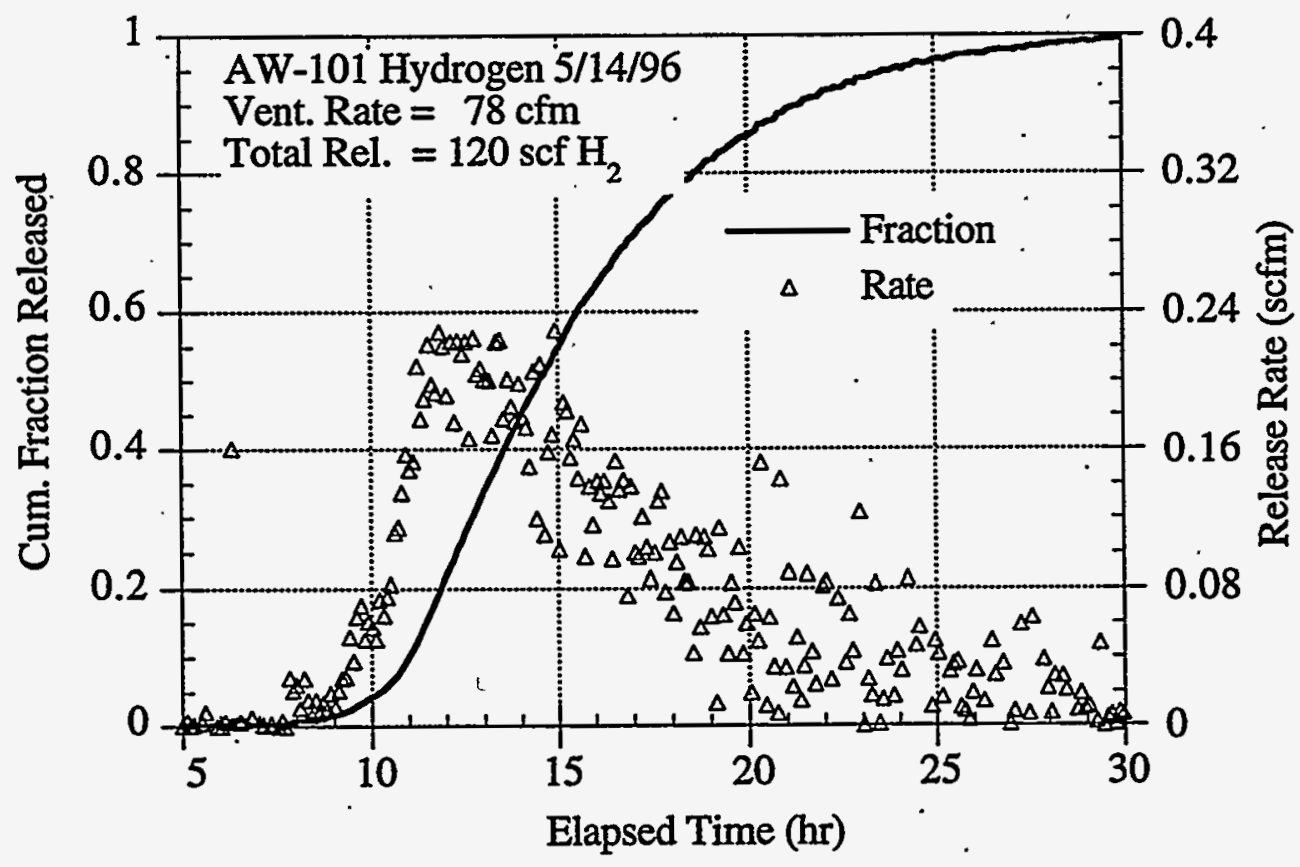

Figure 4.3.10. Gas Release Transient in AW-101 May 14, 1996 


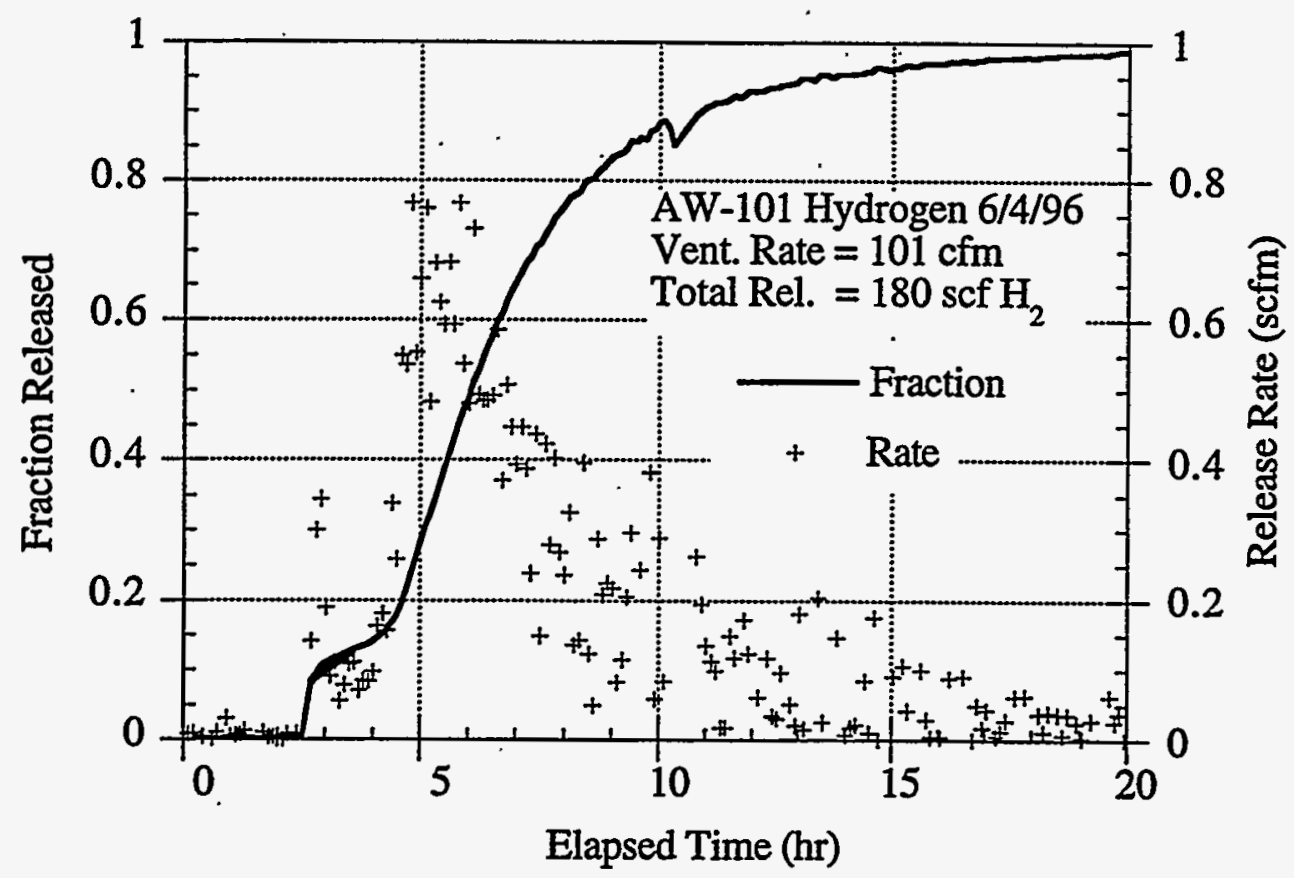

Figure 4.3.11. Hydrogen Release in AW-101 June 4, 1996

It must be emphasized that waste level drops are not completely correlated with gas releases in AW-101. The typical level drops are so small as to challenge the sensitivity of the measurement and, as shown above, some gas releases don't show a level drop at all or show an increase. A much more reliable GRE baseline will be available from gas monitoring data in a few more years. Nevertheless, the GRE history developed from the observed level drops (see Appendix A) is all that we have now, and it yields an expected gas release of $14 \pm 10 \mathrm{~m}^{3}(490 \pm 350$ SCF). The average gas release fraction is $0.16 \pm 0.11$. The maximum release fraction was 0.48 for an event . on September 12, 1988, that released $45 \mathrm{~m}^{3}(1,600 \mathrm{SCF})$. The distribution of historical gas releases is given in Figure 4.3.12 and shows that the large September 1988 release was clearly an outlier from the base population.

The period between GREs varies randomly from about 40 to 400 days, although one period in 1992-93 lasted 750 days. The average is 174, but the standard deviation is 185 days, indicating that $\mathrm{AW}-101$ is unpredictable.

\subsection{AN-103 In-Situ Rheology and Gas Volume}

AN-103 initially received liquid removed from SSTs by salt well pumping with regular transfers out to the 242-A evaporator from 1982-86. In February 1986 the tank was pumped out to a $224-\mathrm{cm}(88-\mathrm{in}$.) heel before being filled to $835 \mathrm{~cm}$ (329 in.) with double-shell slurry feed from the 242-A evaporator. The surface level steadily rose $43 \mathrm{~cm}$ (17 in.) due to gas accumulation by late 1989 and has continued to rise another $7 \mathrm{~cm}$ to the current level of $885 \mathrm{~cm}$. The small 


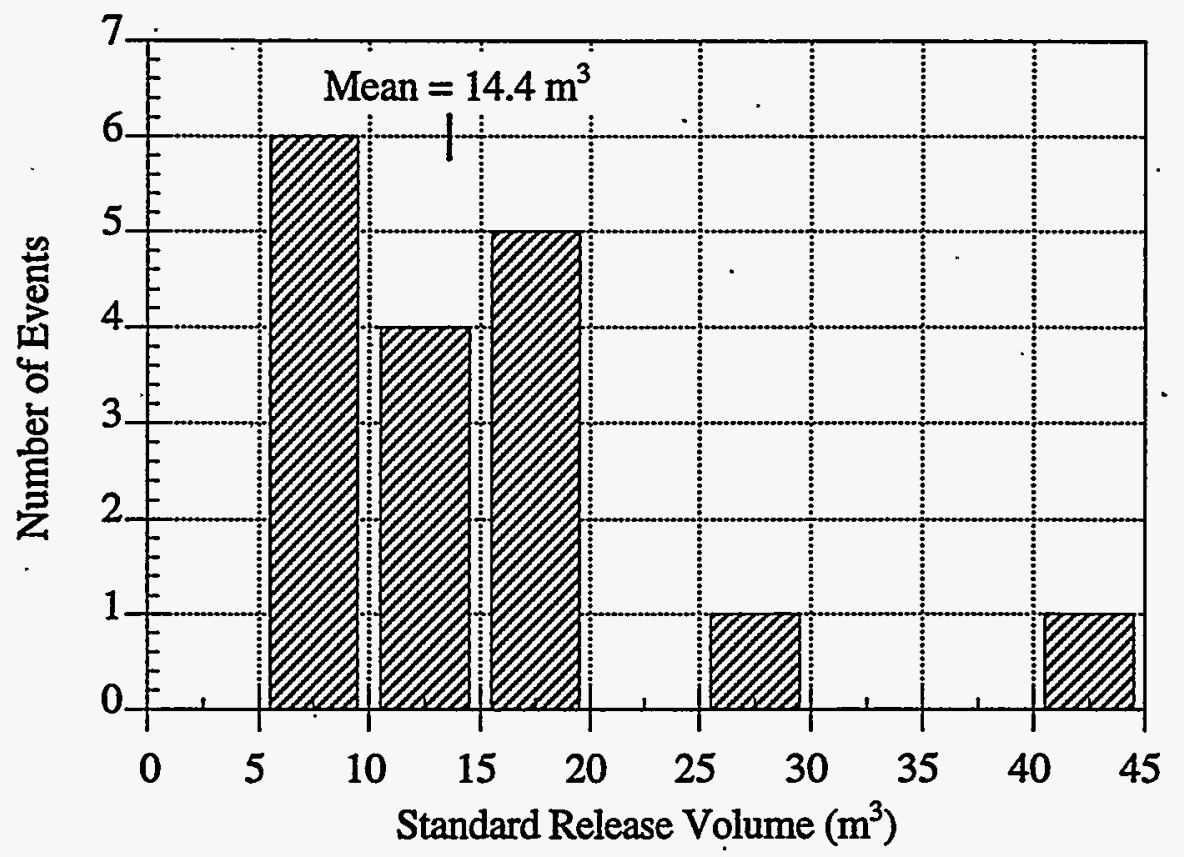

Figure 4.3.12. AW-101 GRE Volume Distribution

sawtooth level fluctuations typical of this tank began in early 1990 with very small GREs about every 100 days. The GRE period has been up to 270 days since November 1993 . AN-103 has a crust nearly. 1 -m thick, second only to that in SY-101, and a nonconvective layer $380 \mathrm{~cm}$ (150 in.) deep.

The waste level is currently about $982 \mathrm{~cm}$ ( $386 \mathrm{in}$.) and consists of a $61 \mathrm{~cm}$ (24 in.) crust at the surface, a convective liquid nonuniform layer of about $500 \mathrm{~cm}(197 \mathrm{in}$.), and a layer of nonconvective material about $375 \mathrm{~cm}$ (148 in.) in depth. The dome space volume is about $2,129 \mathrm{~m}^{3}$ $\left(45,662 \mathrm{ft}^{3}\right)$.

The placement of in-tank instrumentation is shown in Figure 4.4.1. A color video camera, located in riser 5B, was installed in October 1995 to aid instrument installations and to monitor any changes in the waste's crust. Waste surface level is currently measured by a manual tape in riser $1 \mathrm{~A}$ and an Enraf ${ }^{\otimes}$ buoyancy gauge in riser $2 \mathrm{~A}$ on the opposite side of the tank. The Enraf gauge replaced an FIC contact probe in the same riser in August 1995. Tank dome pressure is monitored in riser $10 \mathrm{~A}$

Vertical temperature profiles are measured in two locations. An MIT was installed in riser $15 \mathrm{~A}$ in November 1995 and is currently being read manually. A validation probe was run in $15 \mathrm{~A}$ in August 1996. An older thermocouple tree is mounted in riser 4A; readings from this tree are monitored and recorded with the Tank Monitoring and Control System (TMACS).

An SHMS was installed in this tank in September 1994. Hydrogen concentration in the exhaust gas is measured with two Whittaker cells; one has a range of $0-1 \%$, and the other has a range of $0-10 \%$. The cells are tested and calibrated quarterly. 


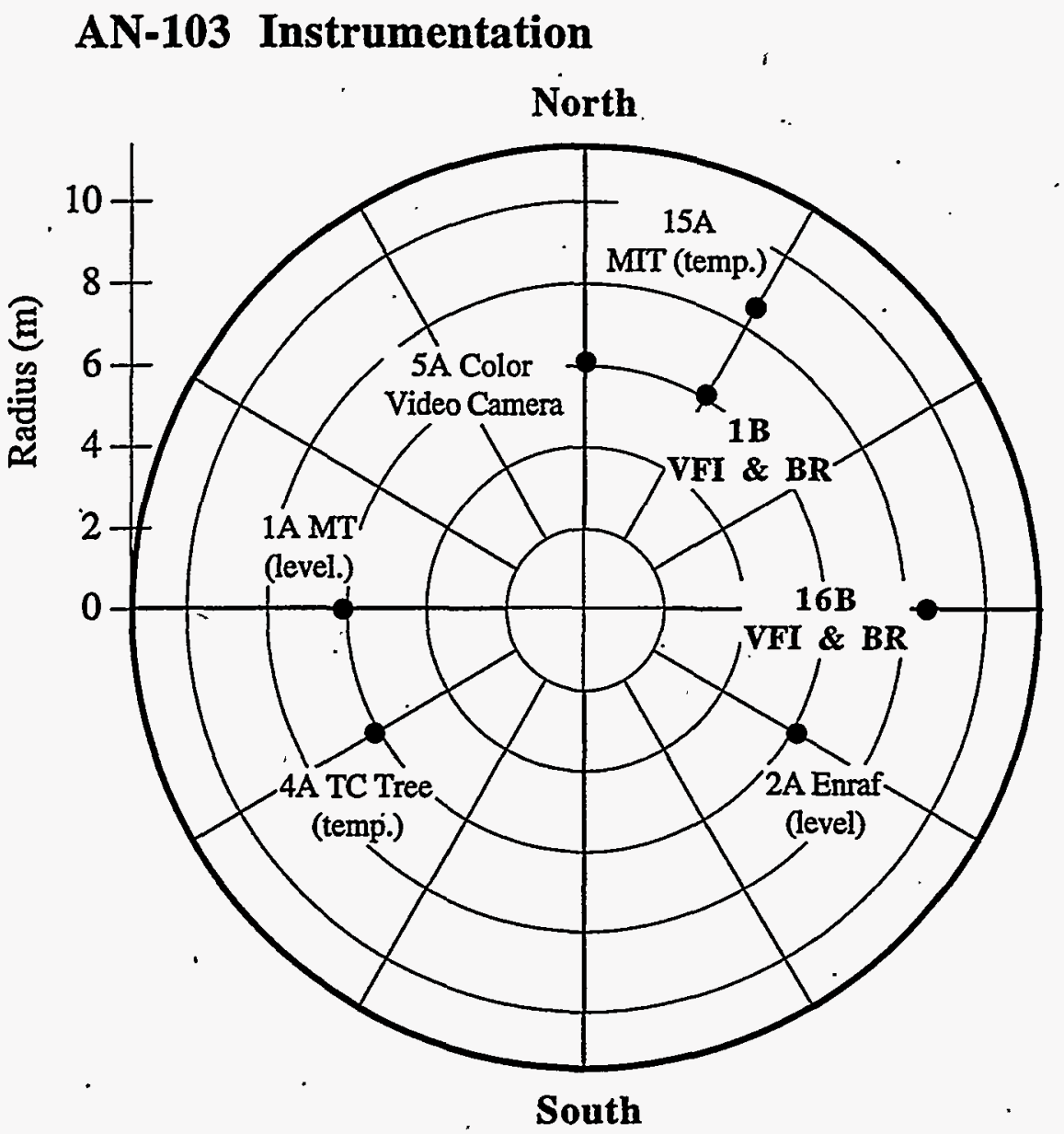

Figure 4.4.1. Tank 241-AN-103 Instrumentation

The ball rheometer was deployed in risers 16B and 1B on May 7 and 9, 1996, respectively. In riser $16 \mathrm{~B}$, the ball went to within about $2 \mathrm{~m}$ (79 in.) of the tank bottom; in riser $1 \mathrm{~B}$, it went to within about $1.5 \mathrm{~m}$ (59 in.) of the bottom. The VFI was operated in riser 16B on May 14, 1996, and in riser 1B on May 16, 1996. Three traverses were accomplished in riser 1B and two in 16B. Void measurements were obtained to within about $43 \mathrm{~cm}$ (17 in.) of the tank bottom in 16B and within $63 \mathrm{~cm}(25 \mathrm{in}$.) in riser 1B. No gas releases were evident on the surface or via the SHMS in any of the tests.

\subsubsection{Waste Configuration}

The temperature profiles shown by the MIT in 15A for June 10,1995, the validation probe on August 28, 1996, and by the thermocouple tree in 4A on May 15, 1996, are shown in Figure 4.4.2. The MIT installation video taken on November 16,1995, suggests that there is a thick crust. The thermocouple tree and the MIT measurements both indicate this crust is $92 \pm 10 \mathrm{~cm}$ thick and covers the entire surface.

The nonconvective layer depth in AN-103 appears to vary somewhat over the tank but is generally more uniform than in the other tanks. The ball rheometer indicated 387 and $375 \mathrm{~cm}$ 


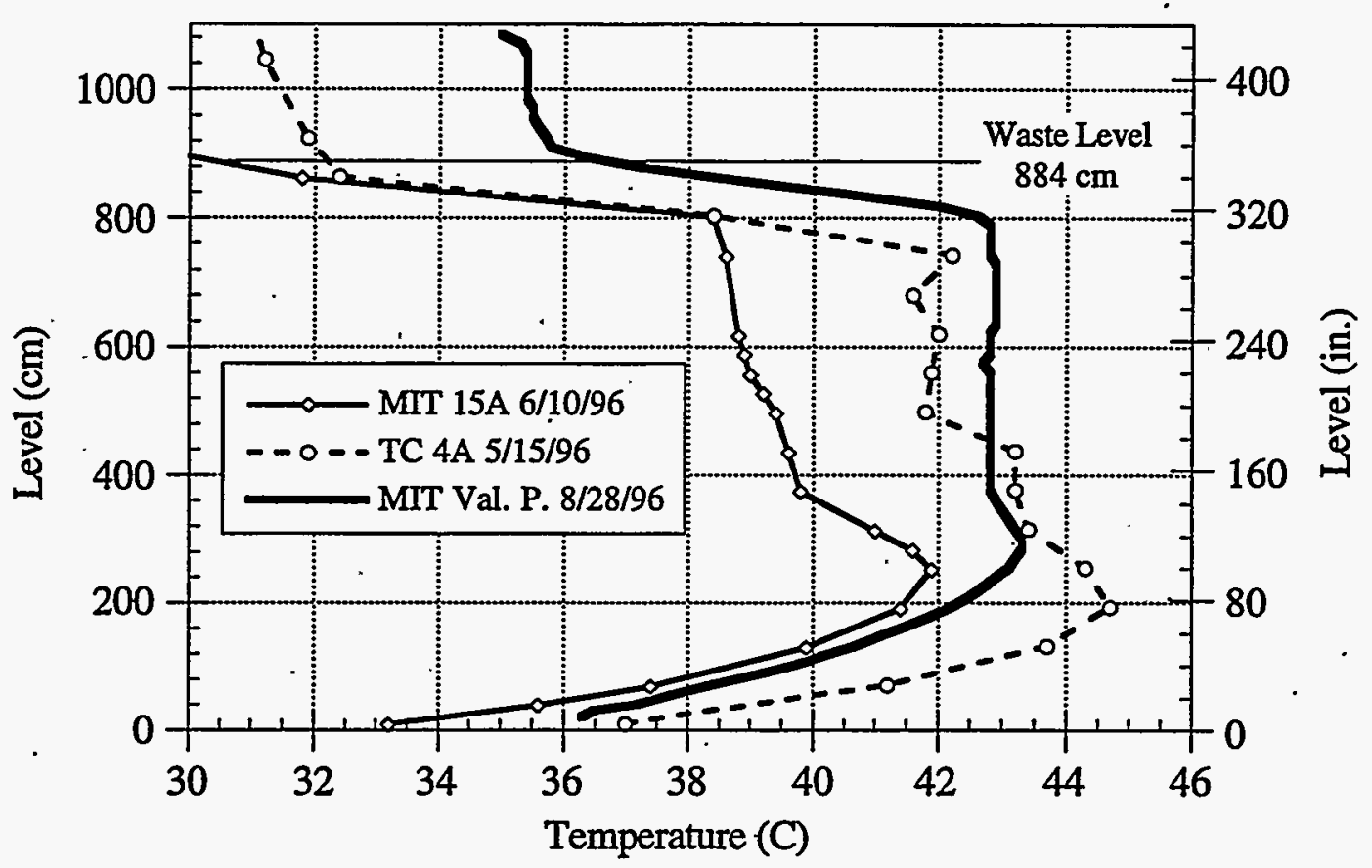

Figure 4.4.2. AN-103 Temperature Profiles

(152 to 148 in.) in risers $16 \mathrm{~B}$ and $1 \mathrm{~B}$, respectively. Temperature profiles from the thermocouple tree and MTT validation probe in risers $4 A$ and $15 \mathrm{~A}$ show $345 \pm 40 \mathrm{~cm}$ and $375 \pm 8 \mathrm{~cm}$, respectively. Table 4.9 summarizes the estimates of nonconvective layer depth derived using the different measurement schemes. The sludge depth is assumed to be the average of the four estimates, $371 \pm 24 \mathrm{~cm}(149 \pm 10 \mathrm{in}$.).

\subsubsection{Rheology and Density}

The viscosity of the supernatant was calculated from the recorded drag force data on the ball and cable at speeds between 50 and $100 \mathrm{~cm} / \mathrm{sec}$ in risers $1 \mathrm{~B}$ and $16 \mathrm{~B}$. The analysis yielded an average supernatant viscosity of $10 \mathrm{cP}$, bounded above by $60 \mathrm{cP}$ and below by $2 \mathrm{cP}$.

Table 4.9. Summary of Sludge Depth Indications

\begin{tabular}{||c|c|c|}
\hline \hline Riser/Date & Depth $(\mathrm{cm})$ & Method of Estimate \\
\hline 4A Tree & $345 \pm 40$ & Temperature profiles \\
15A MIT Val. P. & $375 \pm 8$ & \\
\hline 16B 5/6/1996 & $387 \pm 7$ & Ball rheometer. \\
\hline IB 5/10/1996 & $375 \pm 7$ & Ball rheometer \\
\hline Average & $371 \pm 24$ & \\
\hline
\end{tabular}


Figure 4.4.3 shows upper bound on the yield stress as a function of elevation for the first pass of the ball through the nonconvective layer in each riser. At all the elevations from which data could be obtained, the yield stress in riser $16 \mathrm{~B}$ is slightly higher than that in riser $1 \mathrm{~B}$. The apparent viscosities were also higher in riser 16B than in riser 1B. Figure 4.4.4 shows the apparent viscosities in $1 \mathrm{~B}$ as a function of elevation for several values of the strain rate for the first and fourth (last) passes.

The density determined for the convective layer from risers $1 \mathrm{~B}$ and $16 \mathrm{~B}$ data is $1.53 \mathrm{~g} / \mathrm{cm}^{3}$. Figure 4.4.5 shows the density measurements obtained by the ball rheometer from both risers as a function of elevation. The density in both risers increases with depth. The nonconvective layer density was assumed to be the same as that reported for the 1988 core sample, $1.80 \pm 0.05 \mathrm{~g} / \mathrm{cm}^{3}$ (Reynolds 1994).

\subsubsection{Void Fraction and Gas Volume}

The void measurements from each traverse in each riser and the averaging layer dimensions are shown in Figure 4.4.6. AN-103 has the-highest void fraction of the six tanks tested. It also shows the least scatter in the void measurements. The data from every traverse also follow a trend of almost linear decreasing void with depth below about $250 \mathrm{~cm}$. This is believed to be a combination of increasing hydrostatic pressure and lower temperature. All this is consistent with the tank's almost nonexistent GRE behavior. The lower layers of the waste might not have been disturbed since the last fill. It may be that $\mathrm{AN}-103$ has some aspects of single-shell tank behavior.

The overall nonconvective layer average void is $12.2 \pm 0.4 \%$. The ANOVA model indicates that the deviation due to riser, $R$, traverse, $T$, and the interaction of traverse and elevation, $\mathrm{TD}$, were all essentially 0 . The deviation due to the interaction of riser and elevation, $\mathrm{RD}$, is

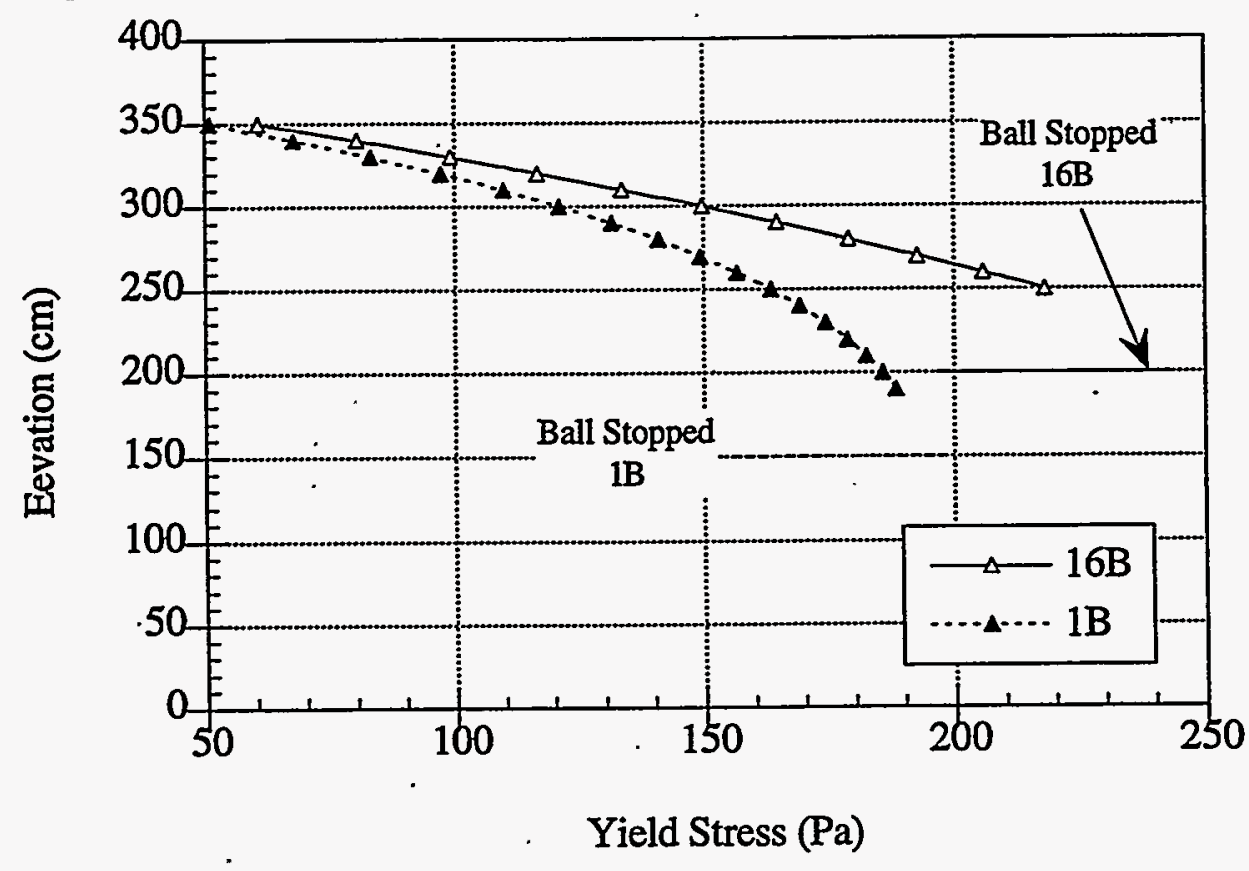

Figure 4.4.3. Upper Bound on the Yield Stress 


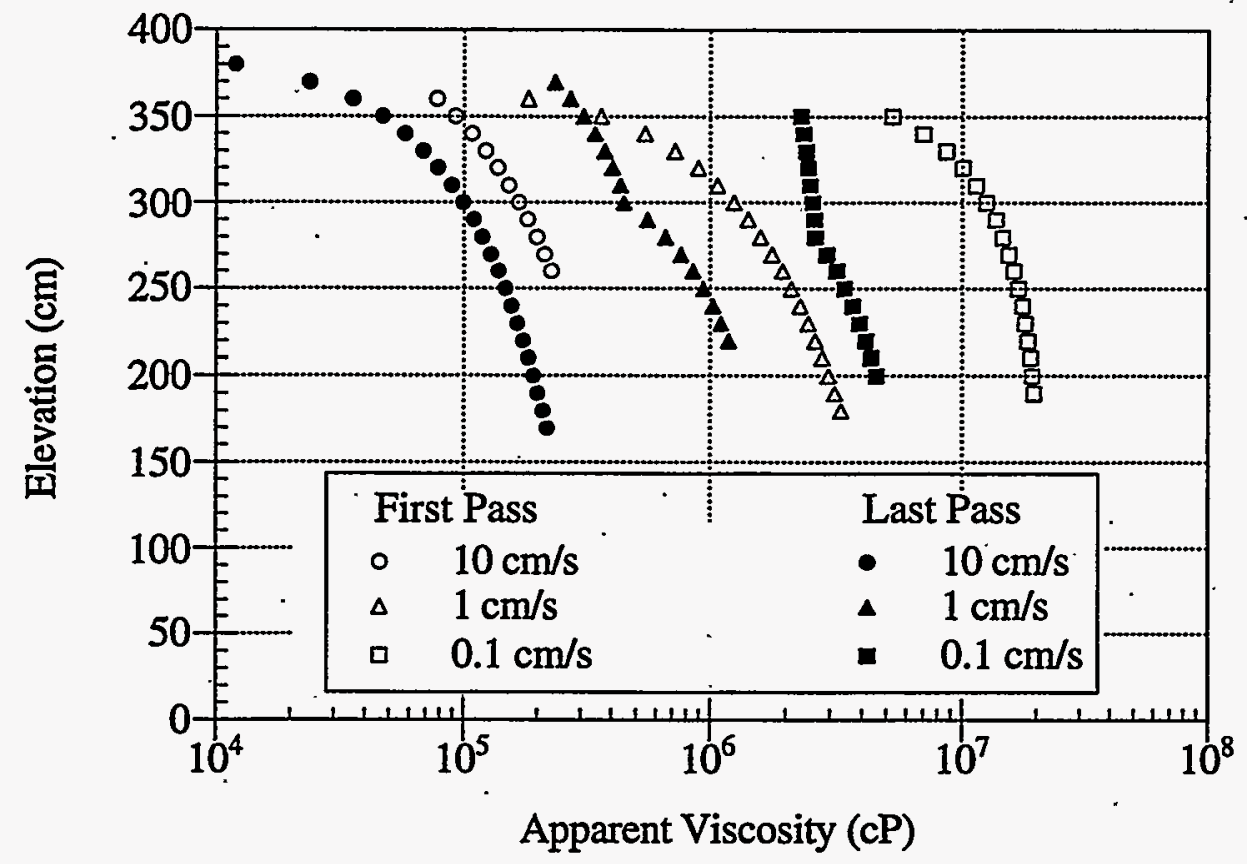

Figure 4.4.4. Apparent Viscosities in Riser 1B

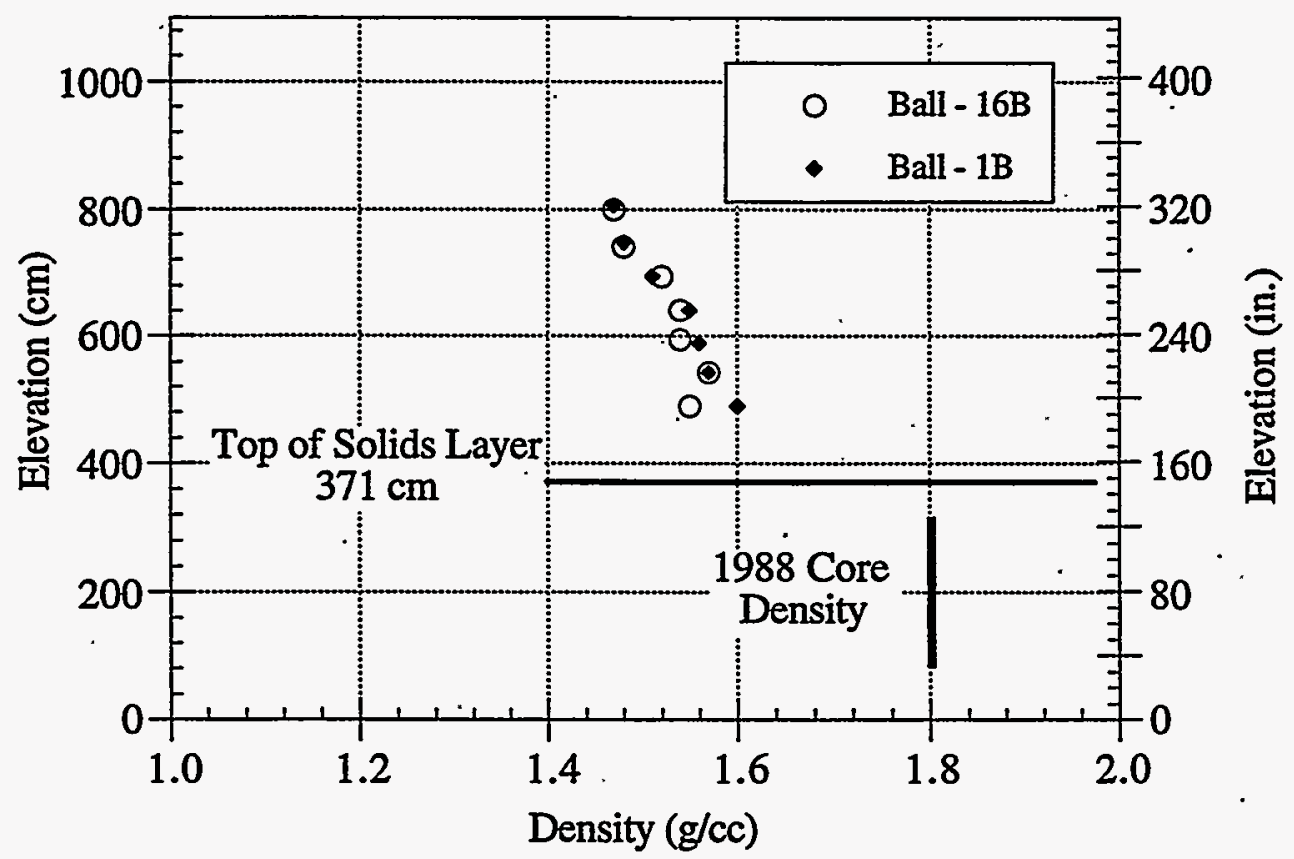

Figure 4.4.5. Density as a Function of Elevation 


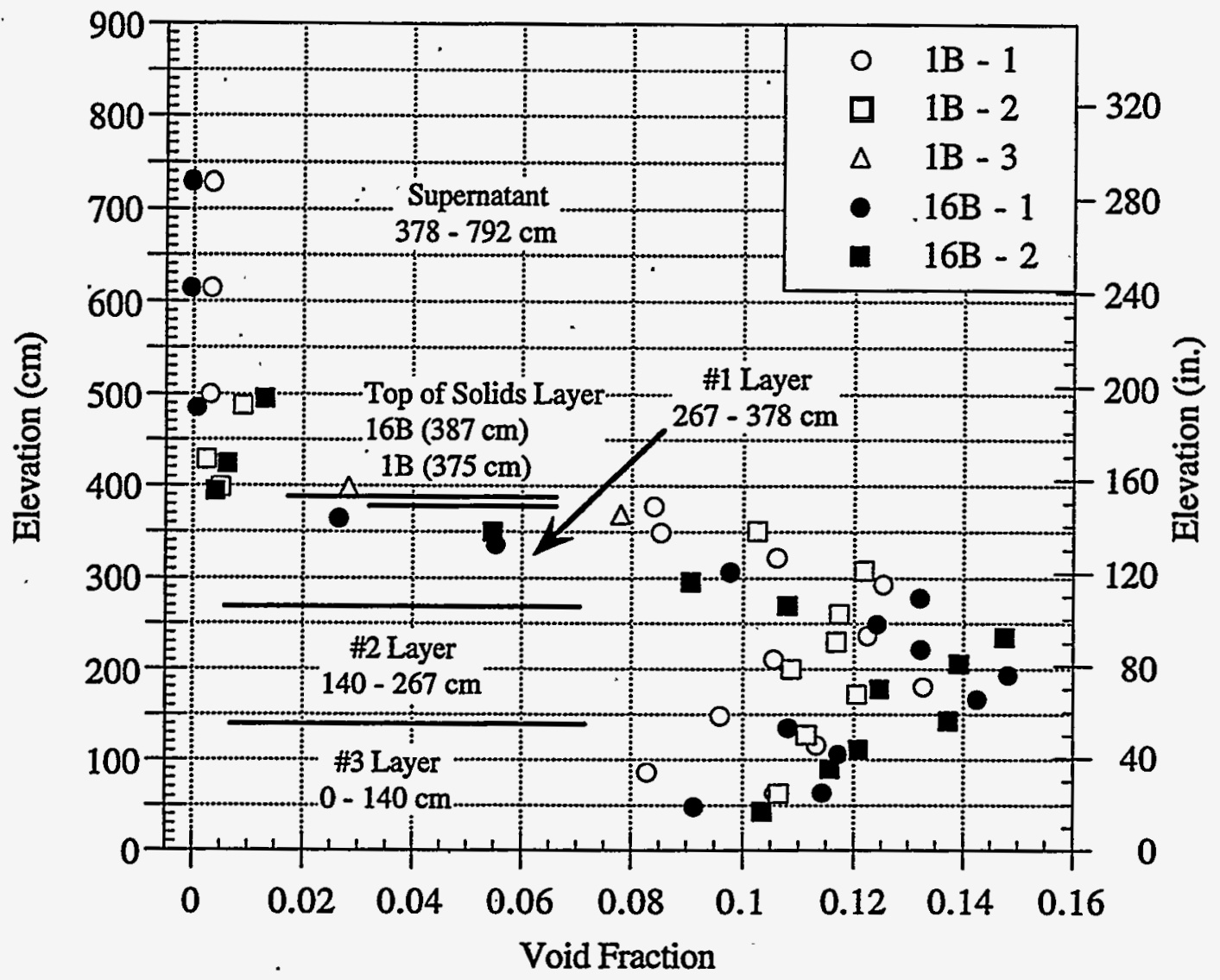

Figure 4.4.6. Void Measurements in AN-103

$0.06 \%$, and the sampling and instrument error was $4.3 \%$. This means that the overall uncertainty of a single void measurement is on the order of $4.3 \%$. However, the deviation of the average in each layer is less than $1 \%$, because there are many data points in the average.

The total standard gas volume in the nonconvective layer is estimated at $363 \pm 12 \mathrm{~m}^{3}$ $(12,800 \pm 300 \mathrm{SCF})$; the estimated gas volume in the convective layer is $10 \pm 15 \mathrm{~m}^{3}$ $(350 \pm 500 \mathrm{SCF})$, and the crust contains an estimated $91 \pm 31 \mathrm{~m}^{3}(3,200 \pm 1,100 \mathrm{SCF})$. This yields a total gas content of $464 \pm 36 \mathrm{~m}^{3}$ at $1 \mathrm{~atm}(16,400 \pm 1,270 \mathrm{SCF})$ in AN-103. These results are summarized in Table 4.10.

The effective pressure ratio in the nonconvective layer is $1.92 \pm 0.02$ and $1.6 \pm 0.08$ for the entire tank gas content. The computed barometric pressure response or compressibility is $-0.46 \pm 0.08 \mathrm{~cm} / \mathrm{kPa}$, and the effective pressure for calculating the gas volume from the barometric response correlation is $1.52 \pm 0.3 \mathrm{~atm}$. 
Table 4.10. Estimates of Mean Void Fraction and Gas Volume

\begin{tabular}{|c|c|c|c|c|}
\hline $\begin{array}{l}\text { Layer ID, } \\
\text { Dim. (cm) }\end{array}$ & $\begin{array}{l}\text { Mean Void } \\
(\%)\end{array}$ & $\begin{array}{c}\text { In-Situ Volume } \\
\left(\mathrm{m}^{3}\right)\end{array}$ & Pressure Ratio & $\begin{array}{c}\text { Standard } \\
\text { Volume }\left(\mathrm{m}^{3}\right)\end{array}$ \\
\hline $\begin{array}{ll}\text { \#3 } & 0-140\end{array}$ & $11.8 \pm 0.7$ & $68 \pm 4$ & $2.09 \pm 0.03$ & $145 \pm 9$ \\
\hline \#2 $140-267$ & $14.1 \pm 0.6$ & $73 \pm 3$ & $1.88 \pm 0.02$ & $138 \pm 6$ \\
\hline $267-378$ & $10.5 \pm 0.6$ & $48 \pm 3$ & $1.70 \pm 0.02$ & $81 \pm 5$ \\
\hline $\begin{array}{l}\text { Supernate } \\
378-792\end{array}$ & $0.5 \pm 0.7$ & $8 \pm 12$ & $1.30 \pm 0.01$ & $10 \pm 15$ \\
\hline Crust & N/A & $94 \pm 32$ & 1.0 & $91 \pm 31$ \\
\hline Tot. Nonconv. & $12.2 \pm 0.4$ & $189 \pm 6$ & $1.92 \pm 0.02$ & $363 \pm 10$ \\
\hline Tot. Tank & $\overline{\mathrm{N} / \mathrm{A}}$ & $291 \pm 34$ & $1.59 \pm 0.08$ & $464 \pm 36$ \\
\hline
\end{tabular}

\subsubsection{Gas Release}

The character of GREs in AN-103 is the mildest of the AN tanks (Reynolds 1994). Surface level drops in the past years are in the 1 to $3 \mathrm{~cm}(0.4$ to $1 \mathrm{in}$.) range. The total level drop typically occurs over several days, although most occurs on the day of the event, and the typical drop is $2 \mathrm{~cm}$ ( $0.8 \mathrm{in}$.) or less. The largest level drops, $2.8 \mathrm{~cm}$ (1.1 in.), occurred in October 1992 and November 1993.

Waste level drops are not good indicators of gas release in AN-103. The typical level drops are so small they challenge the sensitivity of the measurement, and gas monitoring data are the best measures of GREs in this tank. Unfortunately, gas monitoring has only been available since 1994 and is recorded on strip charts. AN-103 GREs are similar in volume to those of AW101 and SY-103. The GRE history developed from the observed level drops (see Appendix A) gives an expected gas release of $14 \pm 5 \mathrm{~m}^{3}(500 \pm 180 \mathrm{SCF})$. But, because of the very large retained gas volume, the average gas release fraction is only $0.04 \pm 0.01$. The maximum release fraction was 0.07 for the event that released $22 \mathrm{~m}^{3}$ (780 SCF) on October 23,1992 . The distribution of historical gas releases is given in Figure 4.4.7.

The period.between GREs varies randomly between about 30 and 300 days. The average period is 129 days with a standard deviation of 117 days; thus AN-103 GREs are not very predictable.

\subsection{AN-104 In Situ Rheology and Gas Volume}

$\mathrm{AN}-104$ and $\mathrm{AN}-105$ were initially used to receive slurry from the 242-A evaporator and return the slurry to the evaporator feed tank for further concentration in converting dilute noncomplexed waste into double-shell slurry feed. The tank was initially filled in several steps between late 1983 and mid-1984. It was then pumped out to a 218-cm (86-in.) heel in October 1984 before receiving double-shell slurry in 1985 to about $866 \mathrm{~cm}$ (341 in.) (Brager 1994). The surface level continued to rise until it reached a level of $870 \mathrm{~cm}$ (342.5 in.) in April 1985; additional slurry was then added, increasing the surface level to $978 \mathrm{~cm}$ (385 in.). 


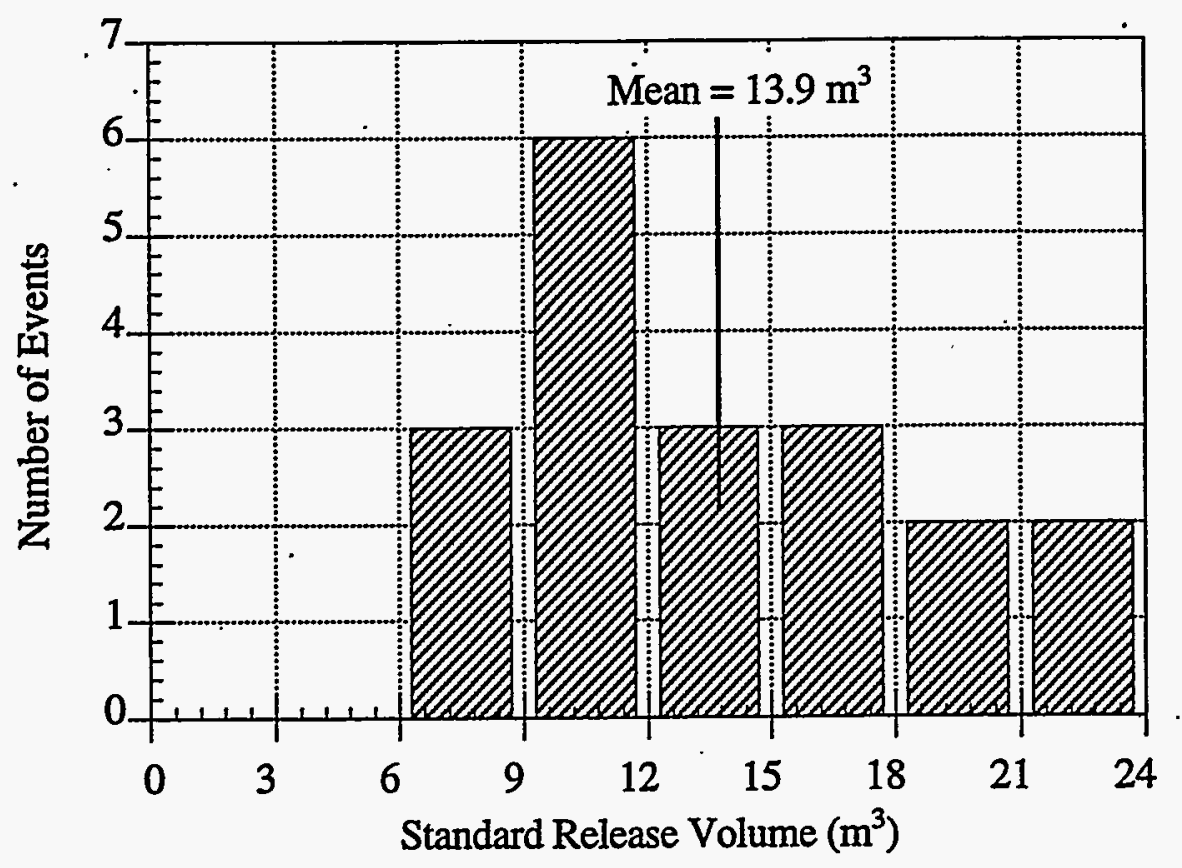

Figure 4.4.7. AN-103 Gas Release Distribution

After its last fill, the waste level grew about $10 \mathrm{~cm}$ (4 in.) before incurring a large initial drop of almost $20 \mathrm{~cm}$ during January and February 1986. The level grew back by early 1988, when one more 20-cm drop occurred over about a month. It is not clear whether there were large gas releases associated with either of these drops. The current behavior, small 3-7 cm drops about every 100 days, began after the last large drop.

The waste level is currently about $979 \mathrm{~cm}$ ( $386 \mathrm{in}$.) and consists of a nonuniform layer of nonconvective material 380-415 cm (150-163 in.) in depth and 577-612 cm (227-241 in.) of supernatant liquid. There is also a thin crust layer about $40 \mathrm{~cm}$ thick. The head space volume in Tank AN-104 is about $1,323 \mathrm{~m}^{3}\left(46,723 \mathrm{ft}^{3}\right)$.

The placement of important in-tank instrumentation is shown in Figure 4.5.1. Waste surface level is currently measured by a manual tape in riser $1 \mathrm{~A}$ and an Enraf ${ }^{\otimes}$ buoyancy gauge in riser $2 \mathrm{~A}$ on the opposite side of the tank. The Enraf gauge replaced FIC contact probe in the same riser in August 1995.

An SHMS was installed in this tank in October 1994. Hydrogen is measured with a gas chromatograph as well as two Whittaker cells. The largest gas release since monitoring began peaked at $0.5 \%$ hydrogen. The baseline hydrogen concentration is about $100 \mathrm{ppm}$ and reached $5000 \mathrm{ppm}$ during the GRE of October 8, 1995.(a)

(a) Memo, NE Wilkins to GD Johnson. April 25, 1996: Tanks 241-AN-103, -104, and -105 Data Review Update. Internal memo 74A10-96-063, Westinghouse Hanford Company, Richland, Washington. 


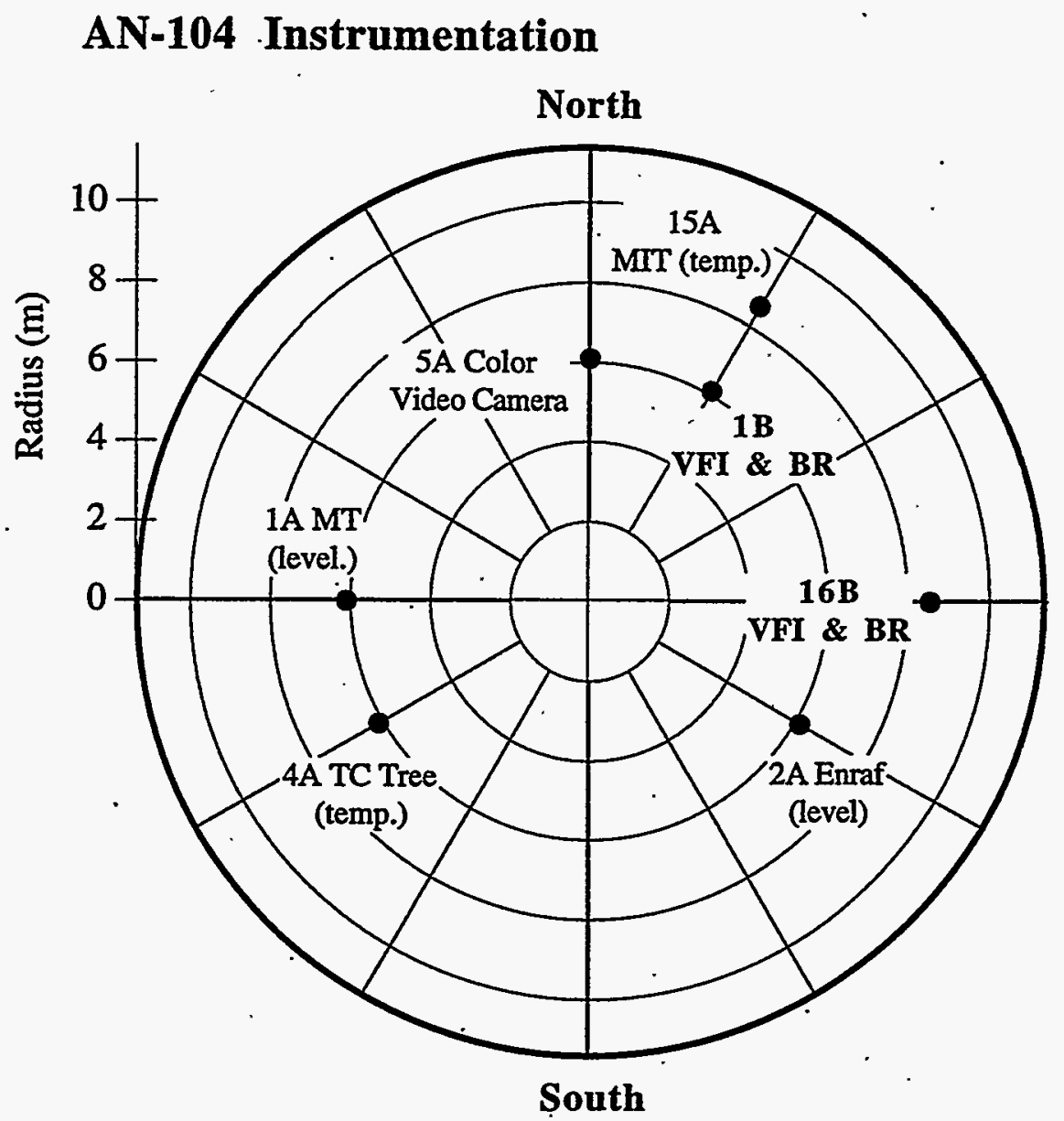

Figure 4.5.1. Tank 241-AN-104 Instrumentation

Temperature profiles are measured with an MIT, which was installed in riser 15A in November 1995, and a thermocouple tree in riser 4A. The MIT is currently being read manually. A validation probe run was performed in the MIT August 27, 1996. The temperature profiles shown by the MIT in 15A for June 10,1996, the validation probe run, and by the thermocouple tree in 4A on April 2, 1996, are shown in Figure 4.5.2.

The VFI was operated in riser 16B on April 2, 1996, and in riser 1B on April 4, 1996. Two traverses were accomplished in riser 1B and three in 16B. Interference with the scaffolding around the riser prevented VFI measurements below about $100 \mathrm{~cm}$ in $16 \mathrm{~B}$ and below about $80 \mathrm{~cm}$ in 1B. Since this test, scaffold height checks were made part of the pre-test review. The ball rheometer was deployed in riser 16B on March 27, 1996, and in riser 1B on April 1,1996. The ball sank to within about $65 \mathrm{~cm}$ ( $25 \mathrm{in}$.) of tank bottom in 16B and sank all the way to the tank bottom in 1B. 


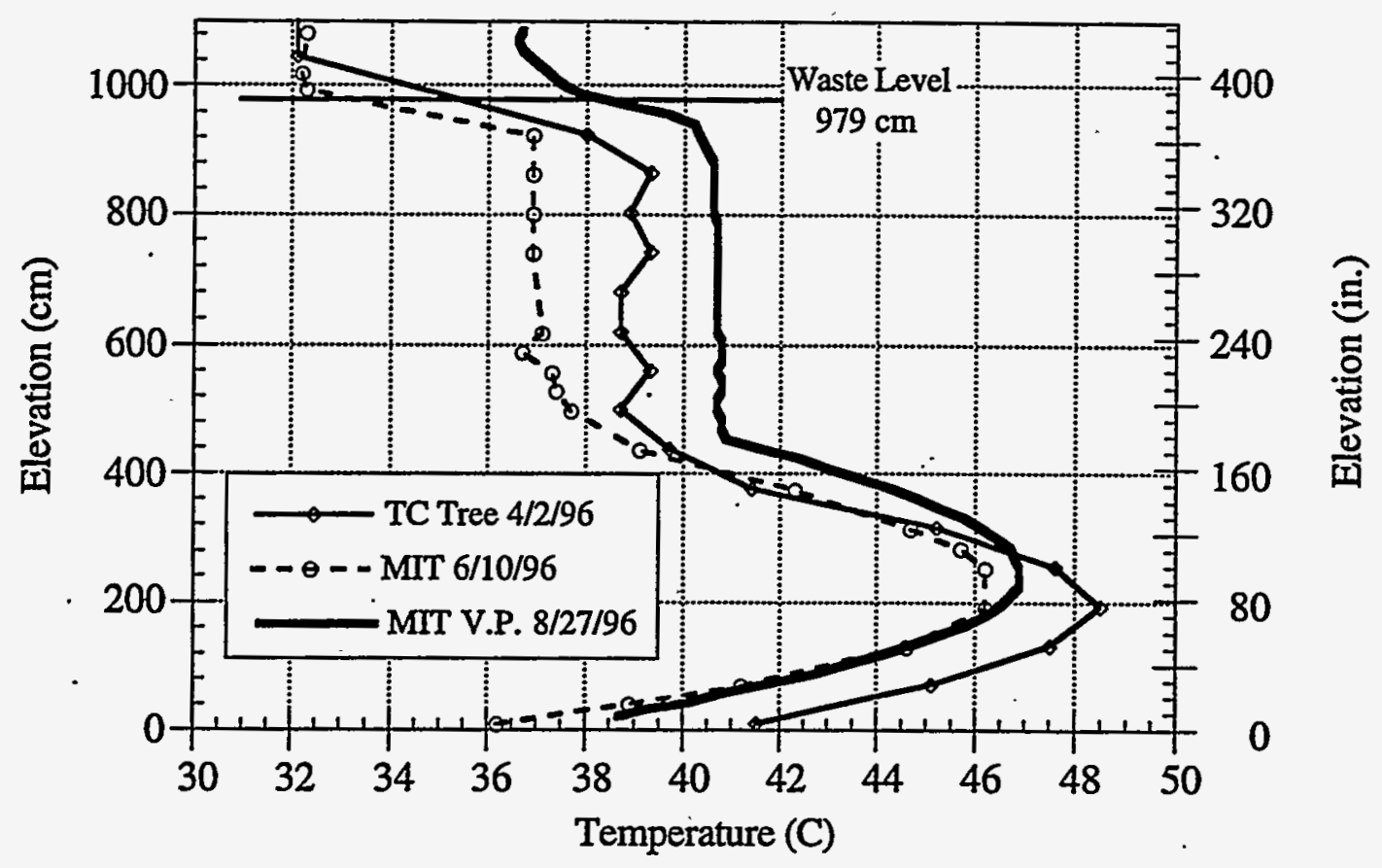

Figure 4.5.2. AN-104 Temperature Profiles

\subsubsection{Waste Configuration}

The ball rheometer passed through surface of the waste at $981 \mathrm{~cm}$ (391 in.). The ball found the nonconvective layer boundary at $422 \mathrm{~cm}$ (166 in.) in riser 16B. In riser 1B, which is somewhat closer to the tank center, the boundary was $372 \mathrm{~cm}$ (146 in.) from tank bottom. Though subject to some interpretation, the temperature profiles at the $4 \mathrm{~A}$ and $15 \mathrm{~A}$ validation probes (Figure 4.5.2) indicate the boundary to be 400 and $450 \mathrm{~cm}$, respectively. Table 4.11 summarizes these observations. The tank overall average nonconvective layer height is estimated to be $411 \pm 19 \mathrm{~cm}$ (162 in.) above the tank bottom.

In-tank video shows the shows a crust layer covering the entire waste surface; however, MIT insertion video indicates the crust is very thin. Clear liquid was visible around the ball rheometer and the VFI. The validation probe temperature profile indicates a crust thickness of $40 \pm 10 \mathrm{~cm}$.(16 $\pm 4 \mathrm{in})$. This value is used in gas volume calculations.

\subsubsection{Rheology and Density}

The density in the convective layer determined from ball rheometer force data in riser $16 \mathrm{~B}$ is $1.44 \pm 0.03 \mathrm{~g} / \mathrm{cm}^{3}$. Figure 4.5 .3 shows the density profile of the convective layer in both risers. The density of the nonconvective layer is assumed to be the same as that found in the AN-105 core sample, $1.59 \pm 0.04 \mathrm{~g} / \mathrm{cm}^{3}$. 
Table 4.11. Summary of Solids Depth Indications

\begin{tabular}{|c|c|c|}
\hline Riser/Date & Depth (cm) & Method of Estimate \\
\hline 4A 4/2/96 & $400 \pm 30$ & Thermocouple tree temp. profile \\
15A 6/10/96 & $450 \pm 8$ & MIT val. probe Temp. profile \\
\hline 16B 4/1/1996 & $422 \pm 7$ & Ball rheometer \\
\hline 1B 3/27/1996 & $372 \pm 7$ & Ball rheometer \\
\hline Average & $411 \pm 19$ & \\
\hline
\end{tabular}

The average viscosity of the convective layer was calculated to be $6 \mathrm{cP}$, bounded above by $10 \mathrm{cP}$ and below by $1 \mathrm{cP}$, from the drag force data on the ball and cable at the speed of $50 \mathrm{~cm} / \mathrm{s}$ in risers $1 \mathrm{~B}$ and 16B. At this speed, the standard deviation of the drag on the ball and cable was approximately half the mean. Data at other speeds $(10,30$, and $100 \mathrm{~cm} / \mathrm{s})$ were not analyzed, because the standard deviation of the drag force was about the same as the average value.

Figure 4.5.4 shows upper bounds on the yield stress as a function of elevation for the first pass of the ball through the sludge layer in both risers. Figure 4.5.5 shows the apparent viscosities as a function of elevation for several values of the strain rate measure (ratio of traversing ball velocity and ball diameter) for the first and fourth (last) passes, respectively. The rheological characteristics of the sludge in Tank AN-104 are very similar to those found in Tank AN-105. The material in both tanks exhibits yield-thixotropic behavior.

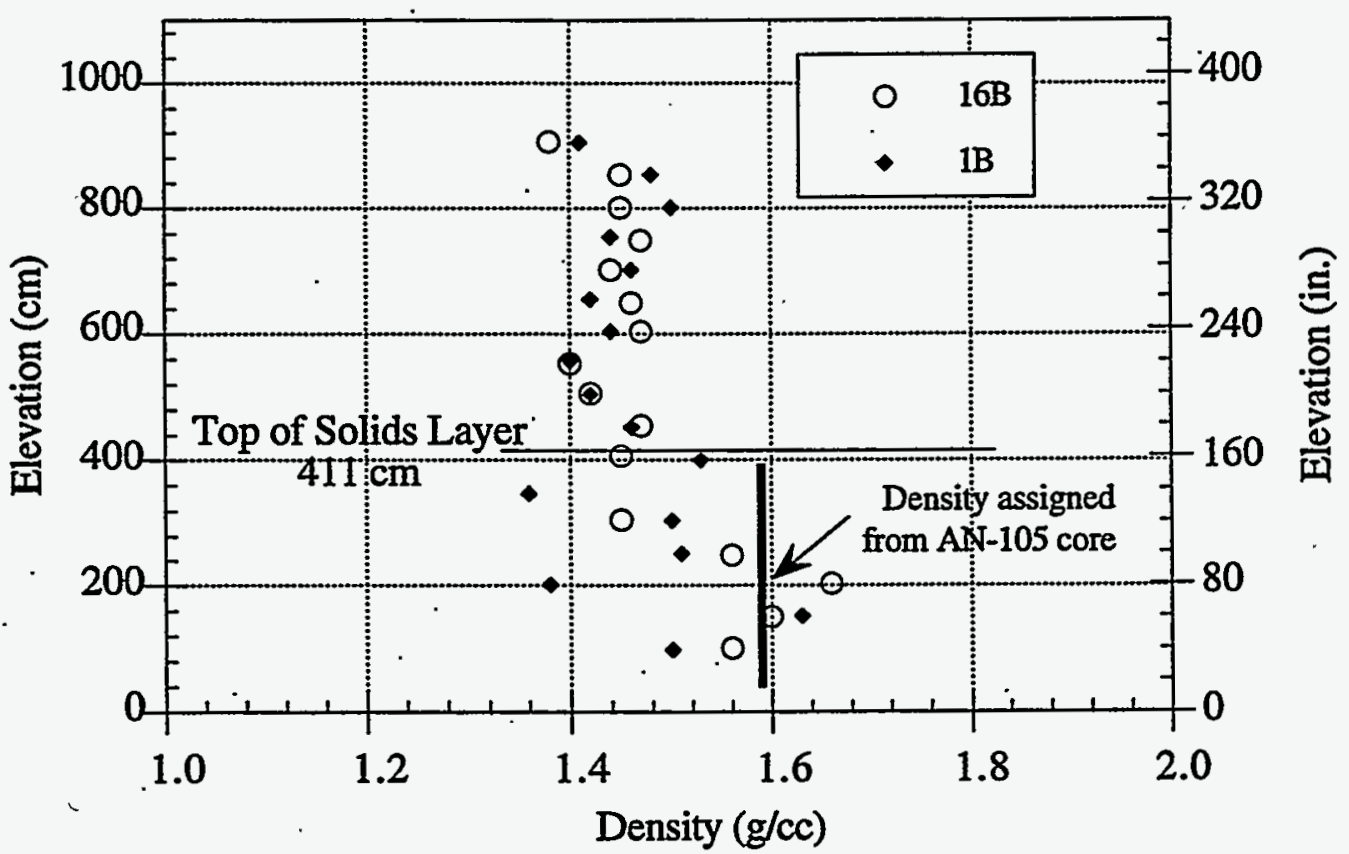

Figure 4.5.3. AN-104 Density Profile 


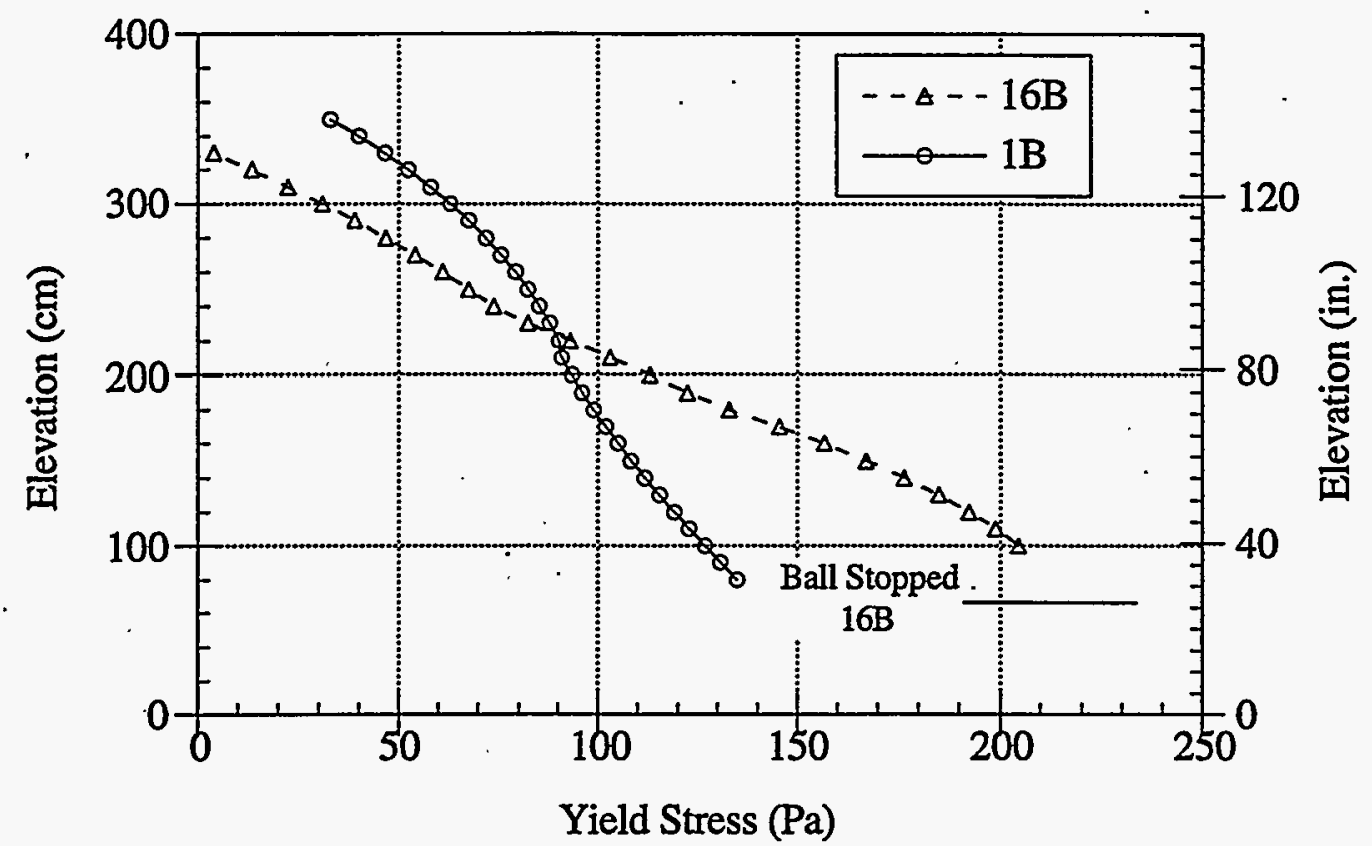

Figure 4.5.4. Upper Bound on the Yield Stress



Figure 4.5.5. Apparent Viscosities at Three Strain Rates 


\subsubsection{Void Fraction and Gas Volume}

The void measurements from each traverse in each riser and the dimensions of the averaging layers are shown in Figure 4.5.6. The average void fraction in the nonconvective layer is $5.9 \pm 0.4 \%$. The measurements in layer $\# 2$ are assumed to represent elevations below $80-100 \mathrm{~cm}$ that could not be reached because of scaffold interference. The deviation due to riser, $R$, traverse, $\mathrm{T}$, and the interaction of traverse and elevation, TD, were essentially zero. The uncertainty due to the interaction of riser and elevation, $\mathrm{RD}$, is $0.32 \%$, and the sampling and instrument error was $1.39 \%$. Thus the standard deviation of a single void measurement is on the order of $1.43 \%$. However, the deviation of the average in each layer is less than $1 \%$, because there are many data points in the average.

The crust gas standard volume is estimated to be $39 \pm 16 \mathrm{~m}^{3}(1,500 \pm 600 \mathrm{SCF})$. Added to the $197 \pm 12 \mathrm{~m}^{3}(6,900 \pm 440 \mathrm{SCF})$ in the nonconvective layer and $11 \pm 17 \mathrm{~m}^{3}(390 \pm 600 \mathrm{SCF})$ in the convective layer, this yields a total standard gas volume in AN-104 of $250 \pm 26 \mathrm{~m}^{3}$ at $1 \mathrm{~atm}$ $(8,700 \pm 900 \mathrm{SCF})$. Removing the in situ gas in the nonconvective layer makes the degassed level $955 \pm 4 \mathrm{~cm}$.

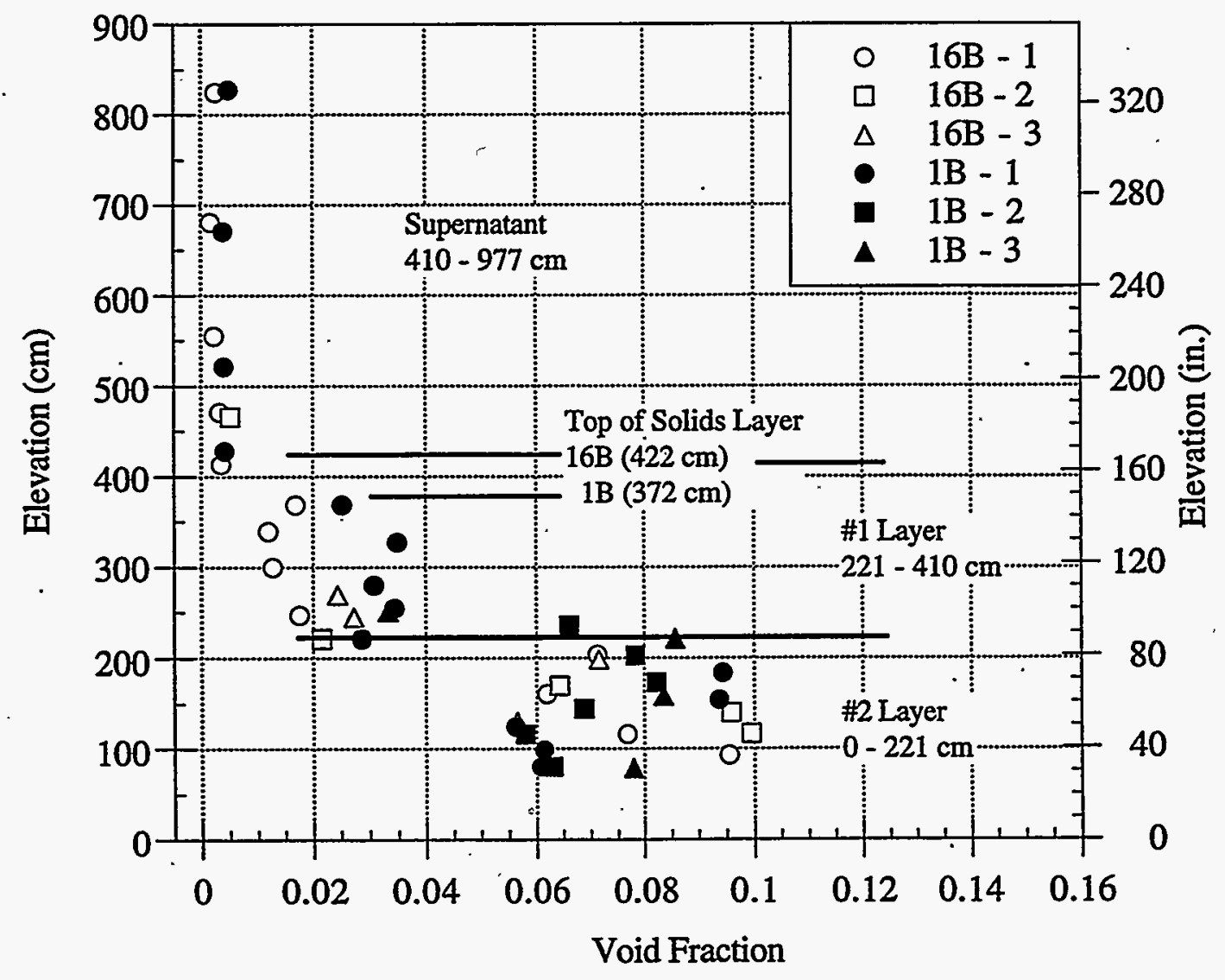

Figure 4.5.6. Void Measurements in $\mathrm{AN}-104$ 
The effective pressure is $1.99 \pm 0.02$ atm in the nonconvective layer and $1.7 \pm 0.1 \mathrm{~atm}$ for the entire tank gas content. The computed barometric pressure response or compressibility is $-0.22 \pm 0.05 \mathrm{~cm} / \mathrm{kPa}$, and the effective pressure for calculating the gas volume from the barometric response correlation is $1.6 \pm 0.4 \mathrm{~atm}$. Table 4.12 summarizes these estimates.

\subsubsection{Gas Release}

Gas releases in $\mathrm{AN}-104$ are quite abrupt, and the higher release rates persist for about two hours. Rates ranged from 6-10 scfm, assuming 50\% hydrogen. The events on May 4, 1996, and October 2, 1995, are shown in Figures 4.5.7 and 4.5.8, respectively. The May 4 GRE had almost no 'tail.' The release essentially ceased after the first two hours. According to the gas chromatograph monitoring the tank, on May 4, 1996, the hydrogen concentration went from $35 \mathrm{ppm}$ to $4850 \mathrm{ppm}$ within ten minutes (the sampling time of the gas chromatograph). The peak reached was $6109 \mathrm{ppm}(0.61 \mathrm{vol \%})$. The concentration was down to $307 \mathrm{ppm}$ by the evening of May 5. ${ }^{\text {(a) }}$

The waste surface level fell $0.81 \mathrm{~cm}(0.32 \mathrm{in}$.) between May 3 and 4 , and it continued to. fall over the next two days, reaching a $1.42 \mathrm{~cm}(0.56 \mathrm{in}$.) total drop on May 6. Temperature profiles at the thermocouple tree in riser $4 \mathrm{~A}$ show a $4^{\circ} \mathrm{C}\left(7.7^{\circ} \mathrm{F}\right)$ drop at the $250 \mathrm{~cm}$ (100-in.) elevation and $5^{\circ} \mathrm{C}\left(8.6^{\circ} \mathrm{F}\right)$ drop at the $315 \mathrm{~cm}$ (124-in.) elevation, which indicates that some waste movement may have occurred near there.

Level drops for GREs in AN-104 typically range from $1.2-4 \mathrm{~cm}(0.5-1.5 \mathrm{in})$ (see Appendix A). Larger drops occurred in 1987-88 just after the initial fill, as mentioned in Section 1. The expected release is $23 \pm 16 \mathrm{~m}^{3}$ ( $\left.800 \pm 550 \mathrm{SCF}\right)$; the average release fraction is $0.10 \pm 0.07$. The maximum release fraction in recent history was 0.16 for the June 18,1992 , event, which released $33.5 \mathrm{~m}^{3}(1,200 \mathrm{SCF})$. A histogram of the GRE volume distribution is given in Figure 4.5.9. Note that the three large events are from the early 1987-88 period and do not represent the present situation.

The GRE period in AN-104 ranges from 30 to 300 days, although this tank appears to have more double events in which two significant GREs occur only a day or two apart. Not counting these; the mean time between GREs over the last five years is about $110 \pm 75$ days.

Table 4.12. Estimates of Mean Void Fraction and Gas Volume

\begin{tabular}{||l|c|c|c|c|}
\hline $\begin{array}{l}\text { Layer ID, } \\
\text { Dimensions (cm) }\end{array}$ & $\begin{array}{c}\text { Mean Void } \\
(\%)\end{array}$ & $\begin{array}{c}\text { In Situ } \\
\text { Volume }\left(\mathrm{m}^{3}\right)\end{array}$ & Pressure Ratio & $\begin{array}{c}\text { Standard } \\
\text { Volume }\left(\mathrm{m}^{3}\right)\end{array}$ \\
\hline$\# 2 \quad 0-221$ & $8.3 \pm 0.5$ & $75 \pm 5$ & $2.04 \pm 0.02$ & $156 \pm 10$ \\
\hline$\# 1 \quad 221-410$ & $3.0 \pm 0.6$ & $24 \pm 4$ & $.1 .80 \pm 0.02$ & $41 \pm 8$ \\
\hline Supernatant 410-977 & $0.4 \pm 0.6$ & $9 \pm 14$ & $1.34 \pm 0.01$ & $11 \pm 17$ \\
\hline Crust & N/A & $41 \pm 17$ & 1.0 & $39 \pm 16$ \\
\hline Total Nonconv. & $5.9 \pm 0.4$ & $99 \pm 6$ & $1.99 \pm 0.02$ & $197 \pm 13$ \\
\hline Total Tank & N/A & $148 \pm 22$ & $1.67 \pm 0.10$ & $247 \pm 26$ \\
\hline
\end{tabular}

(a) Electronic mail message from NE Wilkins, WHC. May 9, 1996. Subject: Gas release in tank 104-AN. 


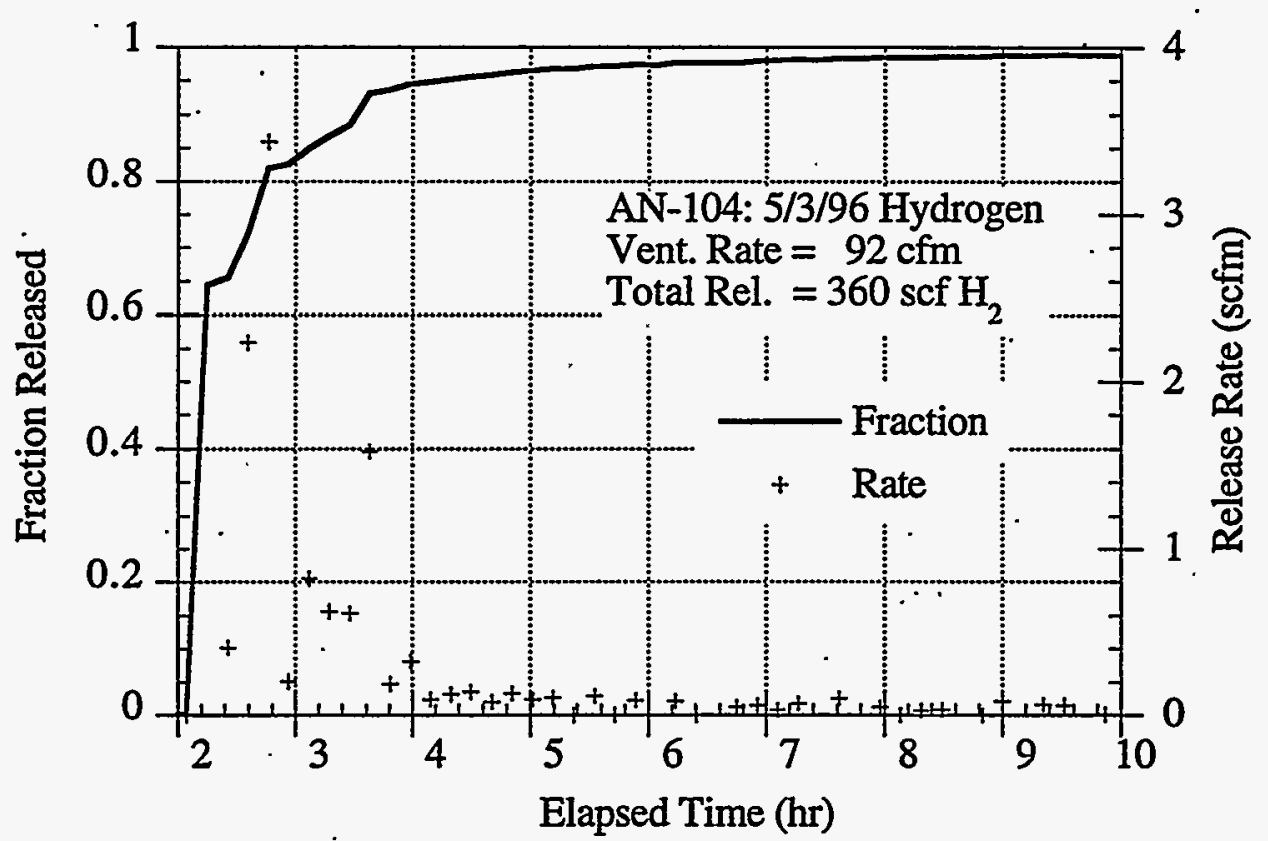

Figure 4.5.7. AN-104 GRE Release Rate May 3, 1996

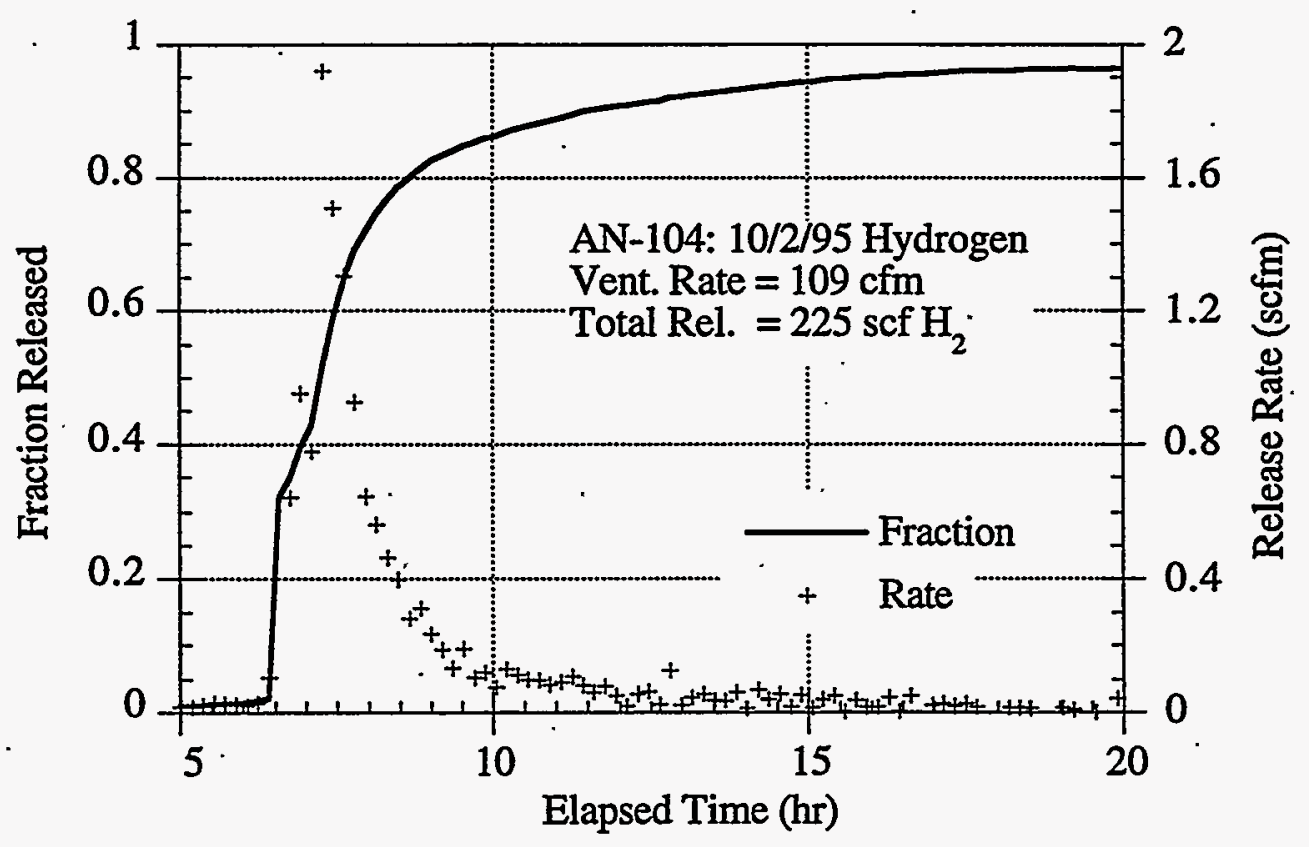

Figure 4.5.8. AN-104 GRE October 2, 1995 


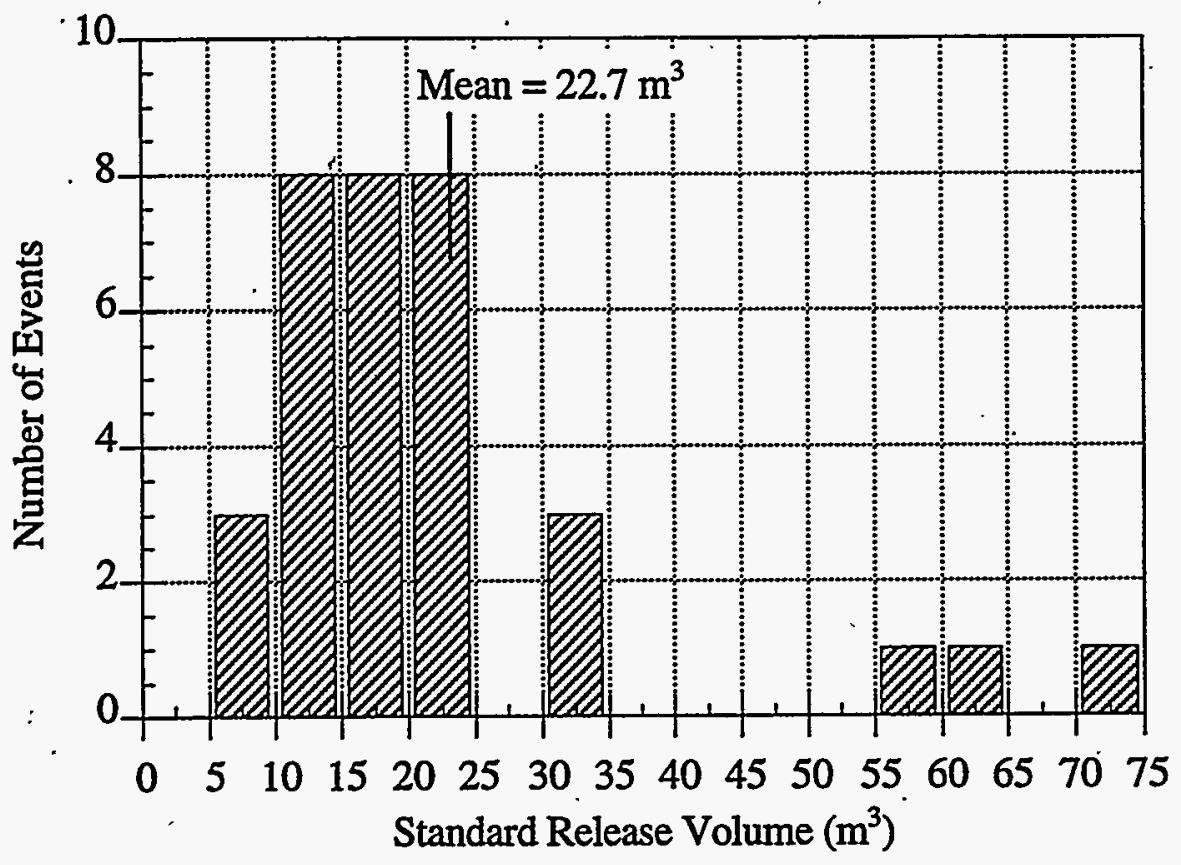

Figure 4.5.9. AN-104 GRE Volume Distribution

\subsection{AN-105 In Situ Rheology and Gas Volume}

AN-105 was initially used to receive slurry from the 242-A evaporator and return it to the evaporator feed tank for further concentration in converting. dilute noncomplexed waste into double-shell slurry feed. AN-105 was pumped to a 81-cm (32-inch) heel in March 1985 and received double-shell slurry feed to the current level of $1036 \mathrm{~cm}(408 \mathrm{in}$.). After the last fill, AN105 's level grew about $15 \mathrm{~cm}$ before a $20-\mathrm{cm}$ drop at the end of 1987. It is not known whether any large rapid gas release was associated with this drop. Following the large initial drop, there were no significant level drops for about 3-1/2 years. The current cycle of 4-7-cm drops ensued in mid-1991. The GRE period in AN-105 has increased to about 270 days since January 1993.

The current waste level is about $1041 \mathrm{~cm}$ (410 in.) and consists of a nonconvective layer $400-460 \mathrm{~cm}(160-180 \mathrm{in}$.) in depth, $580-640 \mathrm{~cm}$ (230-250 in.) of convective liquid, and a noncontinuous floating crust layer that may be up to $30 \mathrm{~cm}(12$ in.) thick. The head space volume in Tank AN-105 is about $1,047 \mathrm{~m}^{3}\left(37,000 \mathrm{ft}^{3}\right)$. The placement of important in-tank instrumentation is shown in Figure 4.6.1.

An SHMS was installed in this tank in. October 1994 that monitors hydrogen with two Whittaker cells. A gas characterization system (GCS) was installed in April 1996. A GCS comprises three instruments: two gas chromatographs $(\mathrm{GC})$ and a Fourier transform infrared spectrometer (FTIR). One GC measures hydrogen, the other measures nitrous oxide and methane. 


\section{AN-105 Instrumentation}

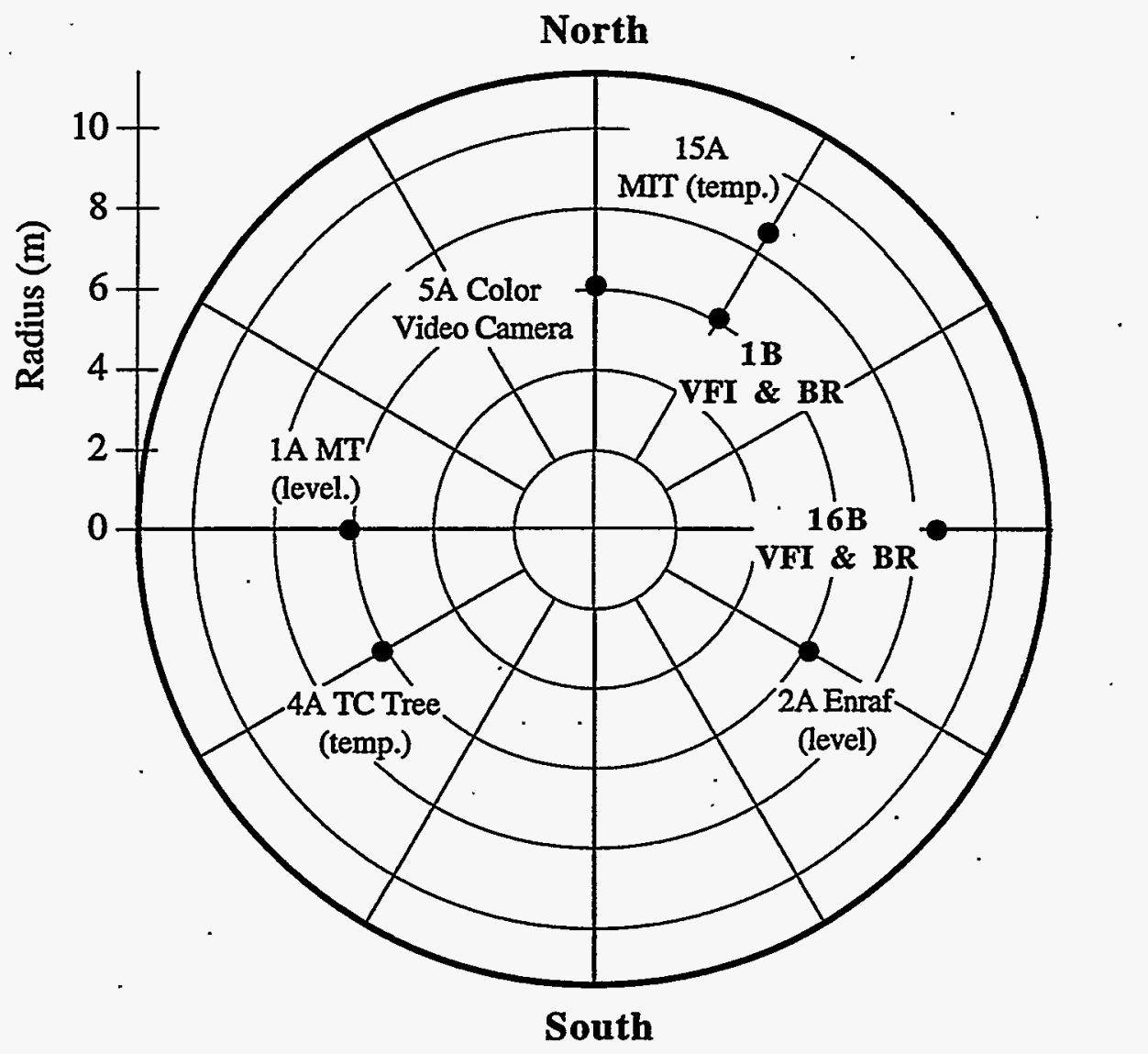

Figure 4.6.1. Tank 241-AN-105 Instrumentation

The FTIR measures ammonia concentrations. The maximum hydrogen concentration measured since the SHMS was installed was $1.6 \%$ on August 21,1995 . Concentration reached $1.5 \%$ on May 30, 1996. Background hydrogen concentration in AN-105 is typically below 100 ppm, nitrous oxide about $20 \mathrm{ppm}$, ammonia at about $10 \mathrm{ppm}$ and methane registers $0 \mathrm{ppm}$.

Waste surface level is currently measured by a manual tape in riser 1A and an Enraf buoyancy gauge in riser $2 \mathrm{~A}$ on the opposite side of the tank. The Enraf gauge replaced a FIC contact probe in the same riser in August 1995.

Vertical temperature profiles are measured with an MIT in riser 15A, installed in October 1995 , and an older thermocouple tree in riser $4 \mathrm{~A}$. The MIT is currently being read manually. A validation probe run was performed August 20,1996 . The temperature profiles shown by the MIT in 15A June 10,1996, the validation probe, and by the thermocouple tree in 4A on December 18, 1995, are shown in Figure 4.6.2.

The ball rheometer and VFI were run in AN-105 in riser 1B on December 15 and 18, 1995, and in 16B on December 20 and 22, 1995, respectively. Two traverses were accomplished with the VFI in riser 1B and three in 16B. The ball sank to within about $110 \mathrm{~cm}$ (43 in.) of the tank 


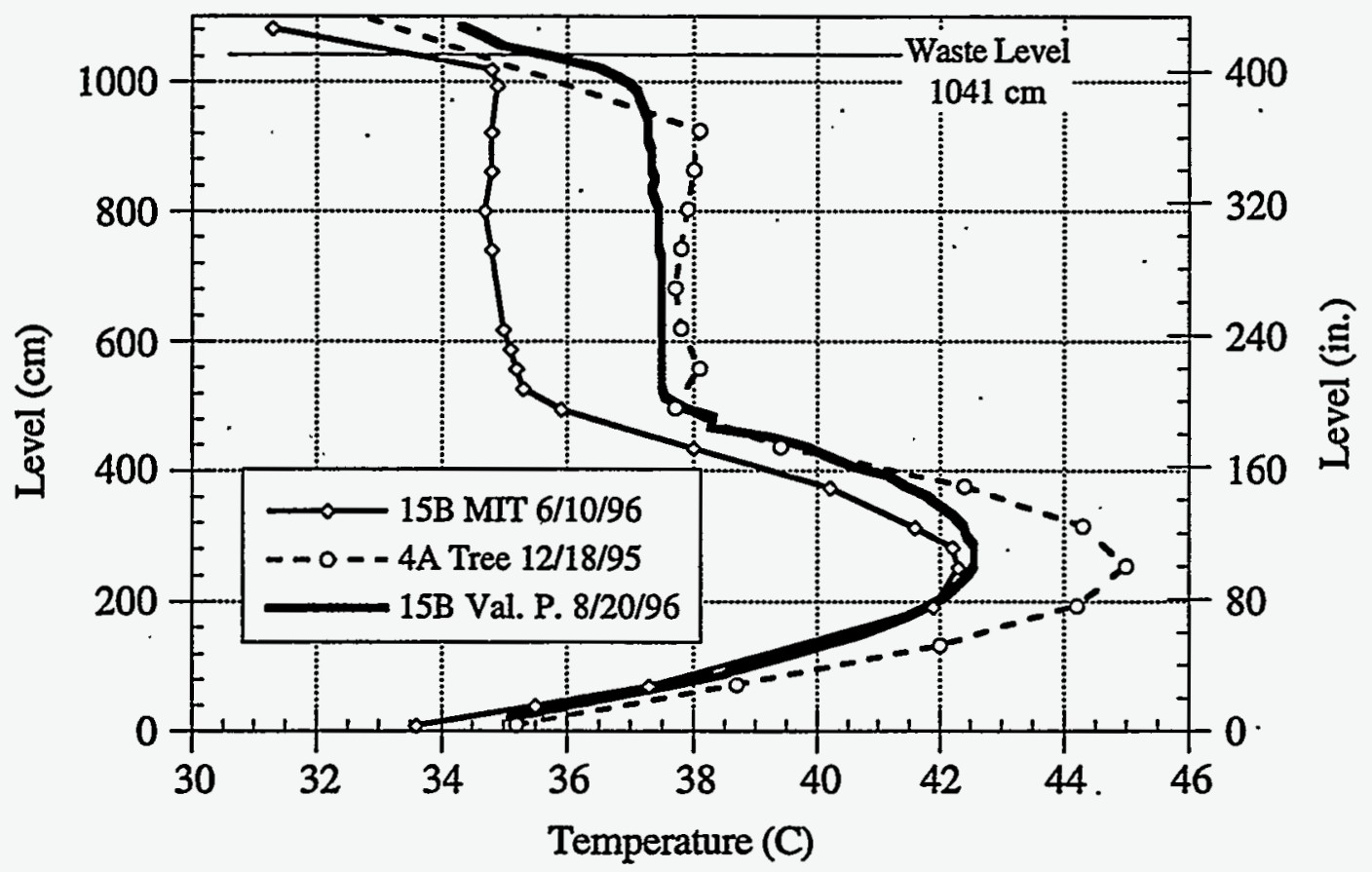

Figure 4.6.2. AN-105 Temperature Profiles

bottom in riser 1B and to within about $20 \mathrm{~cm}$ of the bottom in 16B. No significant gas releases were observed on the waste surface or on the gas monitoring equipment during VFI operation.

No measurements could be taken below about $150 \mathrm{~cm}$ because of interference by a plastic sleeve required for contamination control. The sleeve used in AN-105 was made of thicker material than those encountered in previous tests. Therefore, to estimate the average void fraction and total gas volume, we assumed that void fraction in the unsampled lower $150 \mathrm{~cm}$ of the waste was represented by the available measurements below $215 \mathrm{~cm}$, which is consistent with trends observed in AW-101 and SY-103. A second.VFI deployment is scheduled for September 1996 to measure the void in the lower region.

\subsubsection{Waste Configuration}

The crust thickness in AN-105 is estimated from the MIT validation probe temperature profile in riser 15A as $30 \pm 5 \mathrm{~cm}$ (12 \pm 2 in.). However, video observation of the ball rheometer and VFI passing into the waste indicated that there was essentially no crust present directly under the two risers.

The depth of the nonconvective layer in $\mathrm{AN}-105$ apparently varies somewhat over the tank. The thermocouple tree and the MIT validation probe show the top of the nonconvective layer to be $470 \pm 20 \mathrm{~cm}$ and $500 \pm 8 \mathrm{~cm}$ (185 to 197 in.), respectively. The ball rheometer passed into the nonconvective layer at $453 \pm 9 \mathrm{~cm}$ and $404 \pm 9 \mathrm{~cm}(178-159$ in.) in risers $16 \mathrm{~B}$ and $1 \mathrm{~B}$, respectively. Table 4.13 summarizes these observations. The best estimate from this evidence is a nonconvective layer depth of $457 \pm 14 \mathrm{~cm}(180 \pm 6 \mathrm{in}$; $)$. 
Table 4.13. Summary of Solids Depth Observations

\begin{tabular}{||c|c|c|}
\hline Riser/Date & Depth $(\mathrm{cm})$ & Method of Estimate \\
\hline 4A 9/25/95 & $470 \pm 20$ & Thermocouple tree temp. profile \\
\hline 15A 8/20/96 & $500 \pm 8$ & . MT validation probe temp. profile \\
\hline 16B 12/20/95 & $453 \pm 9$ & Ball rheometer \\
\hline 1B $12 / 15 / 95$ & $404 \pm 9$ & Ball rheometer \\
\hline Average & $457 \pm 14$ & \\
\hline
\end{tabular}

\subsubsection{Rheology and Density}

The average density in the convective layer was found from ball rheometer data to be 1.43 $\pm 0.03 \mathrm{~g} / \mathrm{cm}^{3}$. The density profile is given in Figure 4.6.3. The nonconvective layer density is $1.59 \pm 0.04 \mathrm{~g} / \mathrm{cm}^{3}$ based on the recent core samples. ${ }^{(a)}$

The viscosity of the convective layer was calculated to be $36 \mathrm{cP}$, bounded above by $55 \mathrm{cP}$ and below. by $15 \mathrm{cP}$, from the ball drag force data at speeds of 30 and $50 \mathrm{~cm} / \mathrm{s}$ in risers $1 \mathrm{~B}$ and 16B. Figure 4.6.4 shows upper bounds on the yield strength as a function of elevation.



Figure 4.6.3. AN-105 Density Profile

(a) Personal communication with R. F. Eggers, WHC Characterization Technology, August 14, 1996. 


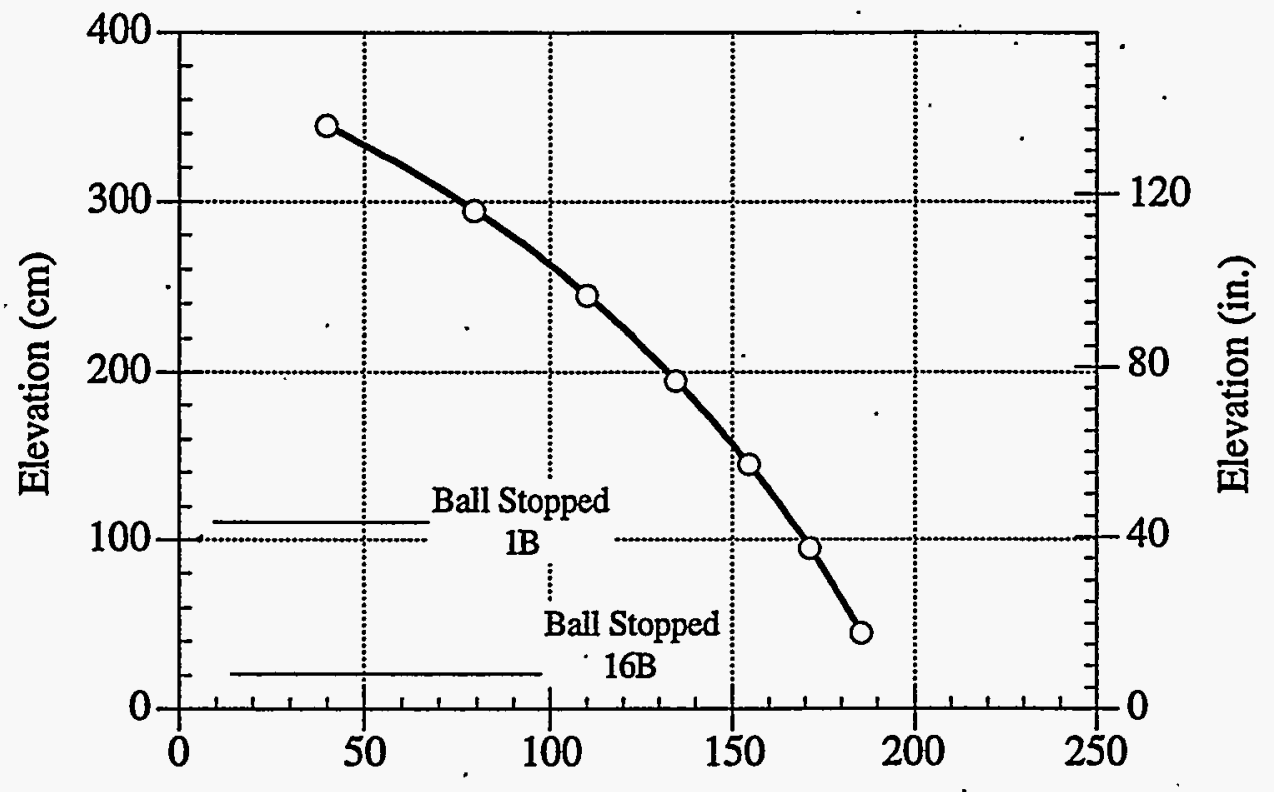

Yield Stress $(\mathrm{Pa})$

Figure 4.6.4. Upper Bound on the Yield Stress

Figure 4.6.5 shows the apparent viscosity at strain rates of $0.01,0.1$ and $1.0 \mathrm{sec}^{-1}$ on the first and last passes. After the ball has traversed through the layer four times, the apparent viscosity decreases considerably.

\subsection{3, Void Fraction and Gas Volume}

The void measurements from each traverse in each riser are shown in Figure 4.6.6. The nonconvective layer was split into three sublayers with boundaries (in $\mathrm{cm}$ ) of $(0,215),(215,330)$, and $(330,450)$, respectively, by a visual interpretation of the void profile. The overall average void is $3.8 \pm 0.6 \%$. Recall that the unsampled lower $150 \mathrm{~cm}$ is assumed to be represented by the void measurements below $215 \mathrm{~cm}$. If the void below $150 \mathrm{~cm}$ is actually higher by $25 \%(6.5 \%$ void instead of $5.2 \%$ ), the total standard gas volume in the nonconvective layer increases by 18 $\mathrm{m}^{3}$, well within the standard deviation of $44 \mathrm{~m}^{3}$.

The ANOVA model of the AN-105 data showed that the deviation due to riser $\mathrm{R}$ is $1.05 \%$, and that due to the interaction of riser and elevation $\mathrm{RD}$ is $0.43 \%$. The deviation due to sampling and instrument error was $1.16 \%$. The deviation due to traverse, $\mathrm{T}$, and the interaction of traverse and elevation, TD, were both essentially zero, meaning that the standard deviation of a single void measurement is on the order of $1.2 \%$. However, the deviation of the average in each layer is less than $1 \%$.

The crust gas standard volume is estimated to be $30 \pm 14 \mathrm{~m}^{3}(1,100 \pm 500 \mathrm{SCF})$. Adding this to the $148 \pm 24 \mathrm{~m}^{3}(5,200 \pm 830 \mathrm{SCF})$ in the nonconvective layer and $7 \pm 26 \mathrm{~m}^{3}(250 \pm 900$ SCF) in the convective layer yields a total standard gas volume in AN-105 of $184 \pm 44 \mathrm{~m}^{3}$ at $1 \mathrm{~atm}$ $(6,500 \pm 1,500 \mathrm{SCF})$. Gas volumes are summarized in Table 4.14. Removing the in situ gas in the nonconvective layer makes the degassed level $1024 \pm 8 \mathrm{~cm}$ (403 $\pm 3 \mathrm{in}$.). 




Figure 4.6.5. Apparent Viscosities on the First and Last Passes

The effective pressure ratio in the nonconvective layer is $2.08 \pm 0.03 \mathrm{~atm}$ and $1.7 \pm 0.13$ atm for the entire tank gas content. The computed barometric pressure response or compressibility is $-0.16 \pm 0.06 \mathrm{~cm} / \mathrm{kPa}$, and the effective pressure for calculating the gas volume from the barometric response correlation. is $1.6 \pm 0.7 \mathrm{~atm}$.

\subsubsection{Gas Release}

The character of GREs in AN-105 shares some of the features of both SY-103 (Shepard et al. 1995) and AW-101. The initial level drop is quite rapid, as is the gas release, although the total level drop typically requires several days. The typical drop is $4 \mathrm{~cm}$ or less. The largest recent level drop, $5.9 \mathrm{~cm}$, occurred November 15, 1991. The maximum one-day drop was $6.1 \mathrm{~cm}$ on August 11, 1986. As mentioned in the introduction to this section, AN-105 experienced a 3-1/2 year hiatus in gas releases between January 1988 and July 1991.

A relatively large release occurred August 1995. The 3.6-cm drop indicates a $33.2 \mathrm{~m}^{3}$ (1170 SCF) total release volume. Recently installed monitoring showed the hydrogen concentration peaked at just over $1.6 \%$. This implies that about $16.8 \mathrm{~m}^{3}$ (592 SCF) of hydrogen was released into the $1066-\mathrm{m}^{3}\left(38,000-\mathrm{ft}^{3}\right)$ dome space, assuming instantaneous mixing without ventilation. The 3.6-cm (1.4-in.) level drop indicates a total release of $30.8 \mathrm{~m}^{3}(1,090 \mathrm{SCF})$ if the gas is held at an effective pressure ratio of 2.08. Dividing the estimated hydrogen release by the total release volume implies that the gas contains about $54 \%$ hydrogen, which is consistent with recent preliminary data from the RGS. ${ }^{(a)}$ No significant temperature changes were observed in the

(a) Personal communication of preliminary data by JM Bates, PNNL, August 1996. 


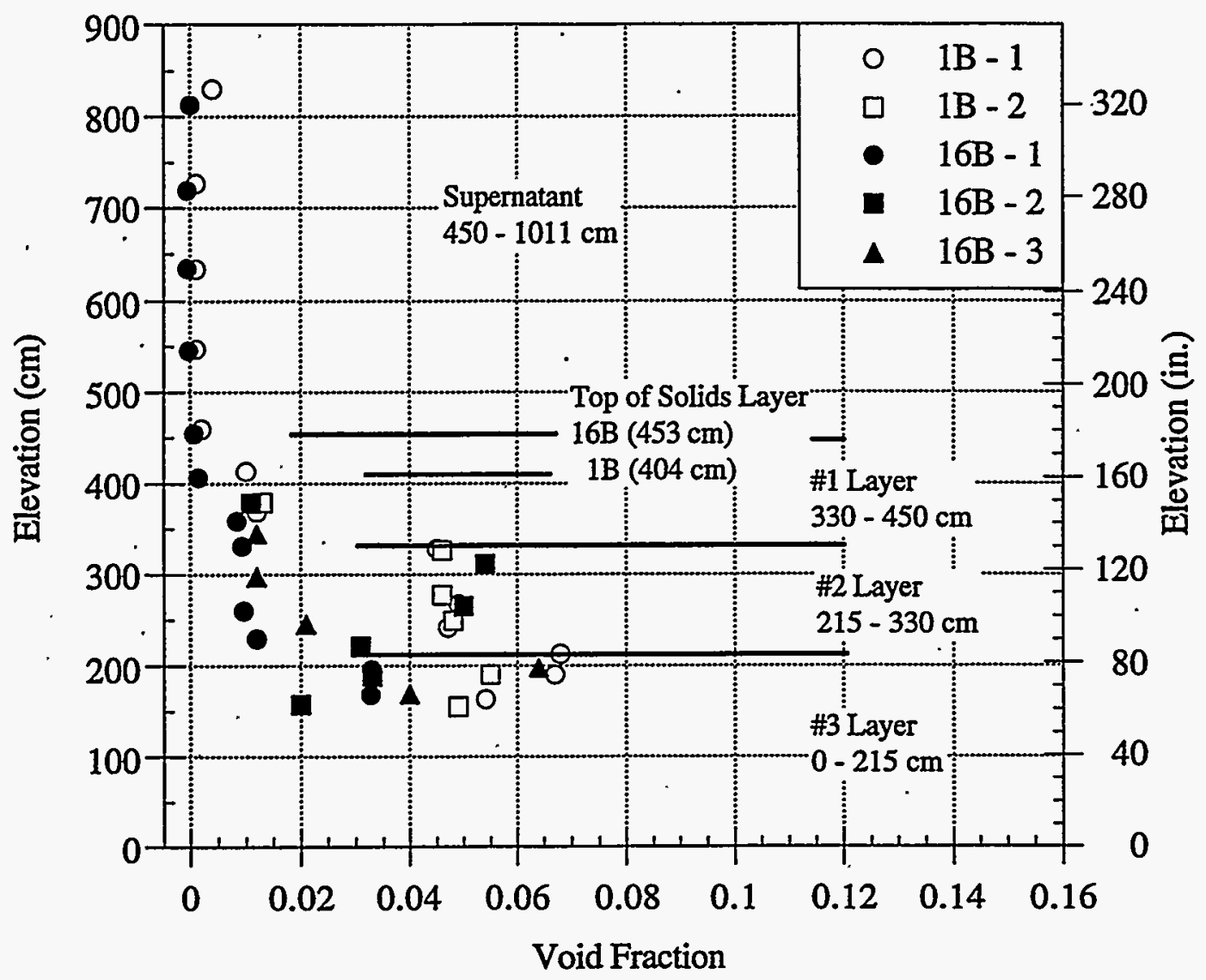

Figure 4.6.6. Void Measurements in $\mathrm{AN}-105$

Table 4.14. Estimates of Void Fraction, Gas Volumes, and Effective Pressure

\begin{tabular}{|c|c|c|c|c|}
\hline $\begin{array}{l}\text { Layer ID, } \\
\text { Dim. (cm) }\end{array}$ & $\begin{array}{c}\text { Mean Void } \\
(\%)\end{array}$ & $\begin{array}{c}\text { In Situ Volume } \\
\left(\mathrm{m}^{3}\right)\end{array}$ & Pressure Ratio & $\begin{array}{c}\text { Standard } \\
\text { Volume }\left(\mathrm{m}^{3}\right)\end{array}$ \\
\hline \#3 $\quad 0-215$ & $5.2 \pm 0.8$ & $46 \pm 7$ & $2.14 \pm 0.02$ & $101 \pm 16$ \\
\hline \#2 $215-330$ & $4.0 \pm 0.8$ & $19 \pm 4$ & $1.93 \pm 0.02$ & $36 \pm 7$ \\
\hline \#1 $330-450$ & $1.2 \pm 0.9$ & $\overline{6 \pm 4}$ & $1.79 \pm 0.02$ & $10 \pm 7$ \\
\hline $\begin{array}{l}\text { Supernate } \\
450-1011\end{array}$ & $0.2 \pm 0.9$ & $5 \pm 20$ & $1.35 \pm 0.01$ & $7 \pm 26$ \\
\hline Crust & N/A & $31 \pm 14$ & 1.0 & $30 \pm 14$ \\
\hline Tot. Nonconv. & $3.8 \pm 0.6$ & $71 \pm 12$ & $2.08 \pm 0.03$ & $148 \pm 24$ \\
\hline Tot. Tank & $\overline{\text { N/A }}$ & $107 \pm 30$ & $1.82 \pm 0.13$ & $\overline{184 \pm 44}$ \\
\hline
\end{tabular}


nonconvective layer as measured by the thermocouple tree in $4 \mathrm{~A}$, but temperatures rose about $1^{\circ} \mathrm{F}$ in the convective layer, indicating that the event was a local one that did not originate in the vicinity of riser $4 A^{(a)}$

Another significant release occurred May 31, 1996, creating a peak hydrogen concentration of $1.3 \%$ with a level drop of $1.7 \mathrm{~cm}$. $^{(b)}$ This release was apparently somewhat more abrupt than the prior one in August 1995. The release rate and cumulative fraction is plotted in Figure 4.6.7. Release rates may have exceeded $20 \mathrm{cfm}$ (assuming $50 \%$ hydrogen) and the major portion of the event was completed in about 1.5 hours. There was relatively little long-term secondary release flow.

A histogram illustrating the GRE history for AN-105 is shown in Figure 4.6.8 (see also Appendix A). The expected release volume is $26 \pm 11 \mathrm{~m}^{3}(920 \pm 390 \mathrm{SCF}$ ) and the maximum release since the $31 / 2$ year hiatus was $50 \mathrm{~m}^{3}$ on November 15,1991 . The average release fraction is $0.16 \pm 0.07$ with a recent maximum of 0.25 on July 6,1992 .



Figure 4.6.7. AN-105 Gas Release, May 30, 1996

(a) WHC Internal memo 74A10-95-058, "Gas Release Event in Tank 241-AN-105." NE Wilkins, August 31, 1995. WHC, Richland, Washington.

(b) Electronic mail message from WB Barton, WHC, May 31, 1996, "AN-105 Gas Release.". 


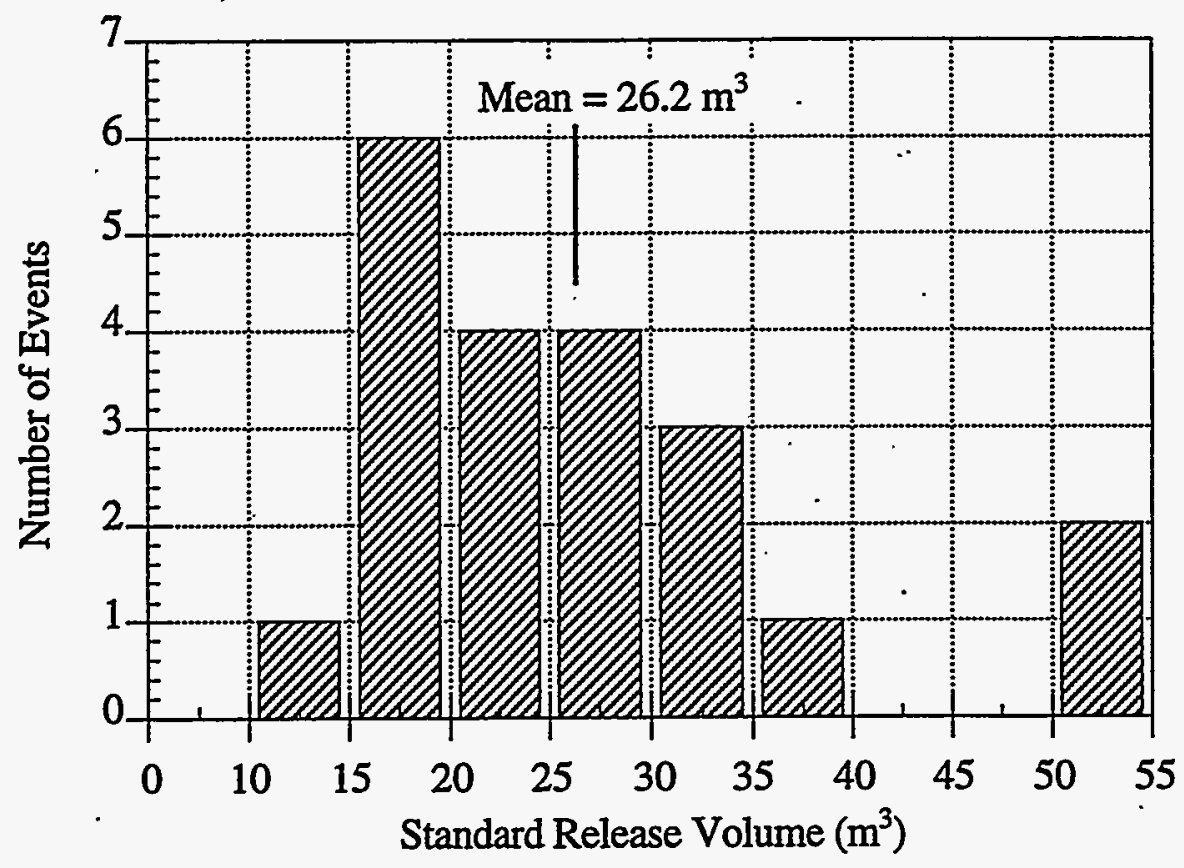

Figure 4.6.8. AN-105 GRE Volume Distribution 


\subsection{Summary and Conclusions}

This section sums up the data developed for each tank discussed in Section 4, comparing the estimated retained gas volumes, assessing the potential consequences of those volumes, and attempting to explain why the different tanks behave.as they do. These subjects make up Sections $5.1,5.2$, and 5.3, respectively. Section 5.4 states the 'bottom line' and gives a recommendation.

\subsection{Gas Volumes}

A summary of all the void fractions, gas volumes, and other quantities relating to gas volume are listed for each of the six tanks in Table 5.1. The first section tallies the input data derived from other sources that directly impact the volume calculation; the second section of the table summarizes the mean void fraction, in situ volume, and effective pressure in the non-. convective layer. The next portion shows quantities that apply to the entire tank, including the compressibility, effective pressure for compressibility (see Section 3.3), and degassed level. The last part of the table summarizes the standard volume (at $1 \mathrm{~atm}$ and $15^{\circ} \mathrm{C}$ ) in each of the three major waste layers and for the entire tank. In all cases, the values are assumed to follow a normal distribution, and uncertainties represent one standard deviation.

Table 5.1. Void Fraction and Volume Summary

\begin{tabular}{|c|c|c|c|c|c|c|}
\hline & 3 & 4 & & & & \\
\hline $\begin{array}{l}\text { Input Data } \\
\text { Waste Level }(\mathrm{cm}) \\
\text { Solids Level }(\mathrm{cm}) \\
\text { Dome Volume }\left(\mathrm{m}^{3}\right) \\
\text { Crust Thickness }(\mathrm{cm}) \\
\text { Conv. Density }\left(\mathrm{kg} / \mathrm{m}^{3}\right) \\
\text { Nonconv. Dens. }\left(\mathrm{kg} / \mathrm{m}^{3}\right)\end{array}$ & $\begin{array}{r}884 \pm 5 \\
378 \pm 29 \\
1712 \pm 20 \\
92 \pm 10 \\
1530 \pm 50 \\
1800 \pm 50 \\
\end{array}$ & $\begin{array}{r}979 \pm 4 \\
410 \pm 25 \\
1323 \pm 18 \\
40 \pm 10 \\
1440 \pm 30 \\
1590 \pm 40 \\
\end{array}$ & $\begin{array}{r}1041 \pm 7 \\
450 \pm 18 \\
1066 \pm 21 \\
30 \pm 10 \\
1430 \pm 30 \\
1590 \pm 40 \\
\end{array}$ & $\begin{array}{r}1040 \\
280 \\
1070 \\
64 \\
1430 \\
1570 \\
\end{array}$ & $\begin{array}{c}1019 \pm 5 \\
\mathrm{n} / \mathrm{a} \\
1159 \pm 22 \\
102 \pm 10 \\
1600 \pm 30 \\
1700 \pm 43 \\
\end{array}$ & $\begin{aligned} & 691 \pm 3 \\
& 345 \pm 23 \\
& 2503 \pm 13 \\
& 20 \pm 10 \\
& 1470 \pm 30 \\
& 1570 \pm 50 \\
&\end{aligned}$ \\
\hline $\begin{array}{l}\text { Nonconvecti } \\
\text { Mean Voi } \\
\text { In-situ Vo } \\
\text { Eff. Press } \\
\end{array}$ & $\begin{array}{c}12.2 \pm 0.4 \\
189 \pm 6 \\
1.92 \pm 0.02\end{array}$ & $\begin{array}{c}5.9 \pm 0.4 \\
99 \pm 6 \\
1.99 \pm 0.02 \\
\end{array}$ & $\begin{array}{c}3.8 \pm 0.6 \\
71 \pm 12 \\
2.08 \pm 0.03 \\
\end{array}$ & $\begin{array}{c}4.7 \pm 0.5 \\
54 \pm 6 \\
2.13 \pm 0.02 \\
\end{array}$ & $\begin{array}{l}\mathrm{n} / \mathrm{a} \\
\mathrm{n} / \mathrm{a} \\
\mathrm{n} / \mathrm{a}\end{array}$ & $\begin{array}{r}6.2 \pm 2.0 \\
88 \pm 28 \\
1.70 \pm 0.03 \\
\end{array}$ \\
\hline $\begin{array}{l}\text { Whole Tank } \\
\text { In-situ Volume }\left(\mathrm{m}^{3}\right) \\
\text { Eff. Pressure Ratio } \\
\text { dL/dP (cm/kPa) } \\
\text { Comp. P-eff. (atm) } \\
\text { Degassed Level (cm) }\end{array}$ & $\begin{aligned} & 291 \pm 34 \\
& 1.59 \pm 0.08 \\
&-0.46 \pm 0.08 \\
& 1.52 \pm 0.32 \\
& .838 \pm 5\end{aligned}$ & $\begin{array}{c}148 \pm 22 \\
1.67 \pm 0.10 \\
-0.22 \pm 0.05 \\
1.60 \pm 0.41 \\
955 \pm 4 \\
\end{array}$ & $\begin{array}{c}107 \pm 30 \\
1.72 \pm 0.13 \\
-0.16 \pm 0.06 \\
1.61 \pm 0.67 \\
1024 \pm 8 \\
\end{array}$ & $\begin{array}{c}142 \pm 36 \\
1.47 \pm 0.10 \\
-0.25 \pm 0.08 \\
1.37 \quad 0.51 \\
1027 \pm 7 \\
\end{array}$ & $\begin{aligned} & 164 \pm 43 \\
& 1.32 \pm 0.11 \\
&-0.32 \pm .0 .10 \\
& 1.23 \pm 0.47 \\
& 1010 \pm 5 \\
&\end{aligned}$ & $\begin{aligned} & 114 \pm 57 \\
& 1.55 \pm 0.10 \\
&-0.18 \pm 0.08 \\
& 1.56 \pm 1.0 \\
& 669 \pm 8 \\
&\end{aligned}$ \\
\hline $\begin{array}{l}\text { Std. Volume }\left(\mathrm{m}^{3}\right) \\
\text { Crust } \\
\text { Convective Layer } \\
\text { Nonconvective Layer } \\
\text { Whole Tank } \\
\end{array}$ & $\begin{array}{r}91 \pm 31 \\
10 \pm 15 \\
363 \pm 12 \\
464 \pm 36 \\
\end{array}$ & $\begin{array}{r}39 \pm 16 \\
11 \pm 17 \\
197 \pm 12 \\
247 \pm 26 \\
\end{array}$ & $\begin{array}{r}30 \pm 14 \\
7 \pm 26 \\
148 \pm 24 \\
184 \pm 44 \\
\end{array}$ & $\begin{array}{r}63 \pm 22 \\
32 \pm 34 \\
115 \pm 12 \\
209 \pm 47 \\
\end{array}$ & $\begin{array}{r}100 \pm 34 \\
33 \pm 31 \\
84 \pm 12 \\
218 \pm 52 \\
\end{array}$ & $\begin{array}{r}20 \pm 12 \\
6 \pm 33 \\
150 \pm 46 \\
176 \pm 79 \\
\end{array}$ \\
\hline
\end{tabular}




\subsubsection{Gas Volume Distribution}

The gas stored in the nonconvective layer is the most important because it initiates rollovers and releases its gas content in the process. Based on the observed behavior of SY-101, relatively little of the gas in the crust is released in a GRE, and, since it is already buoyant, it cannot initiate a rollover. The small gas volume computed for the supernatant layer has a high uncertainty and would exist as tiny bubbles that would not be released during a rollover.

It is clear from Table 5.1 that $\mathrm{AN}-103$ has the largest total gas volume and the largest nonconvective layer volume. In fact, AN-103 stores almost as much gas as SY-101 did prior to mixing. SY-101 rates second in total gas content because of the large volume still held in its crust. But very little gas is left in what remains of its nonconvective layer. AN-104 has about a third more nonconvective layer gas volume than AN-105, whose volume equals that of SY-103. AW101 has the smallest nonconvective layer volume (besides SY-101).

The gas volumes actually vary over time, because all of these tanks accumulate gas and periodically release it between (SY-101 releases 1.4 to $2.8 \mathrm{~m}^{3}$ of gas each mixer pump run). The gas volume at any time can be estimated from the current waste level and the degassed level (see Section 3.4). Therefore, the probability distribution of gas volume can be computed directly from the waste level history, assuming the past behavior is representative of the current state. The cumulative probability distributions of retained gas volume in the nonconvective layer of each tank, including all the uncertainties, are shown in Figure 5.1.

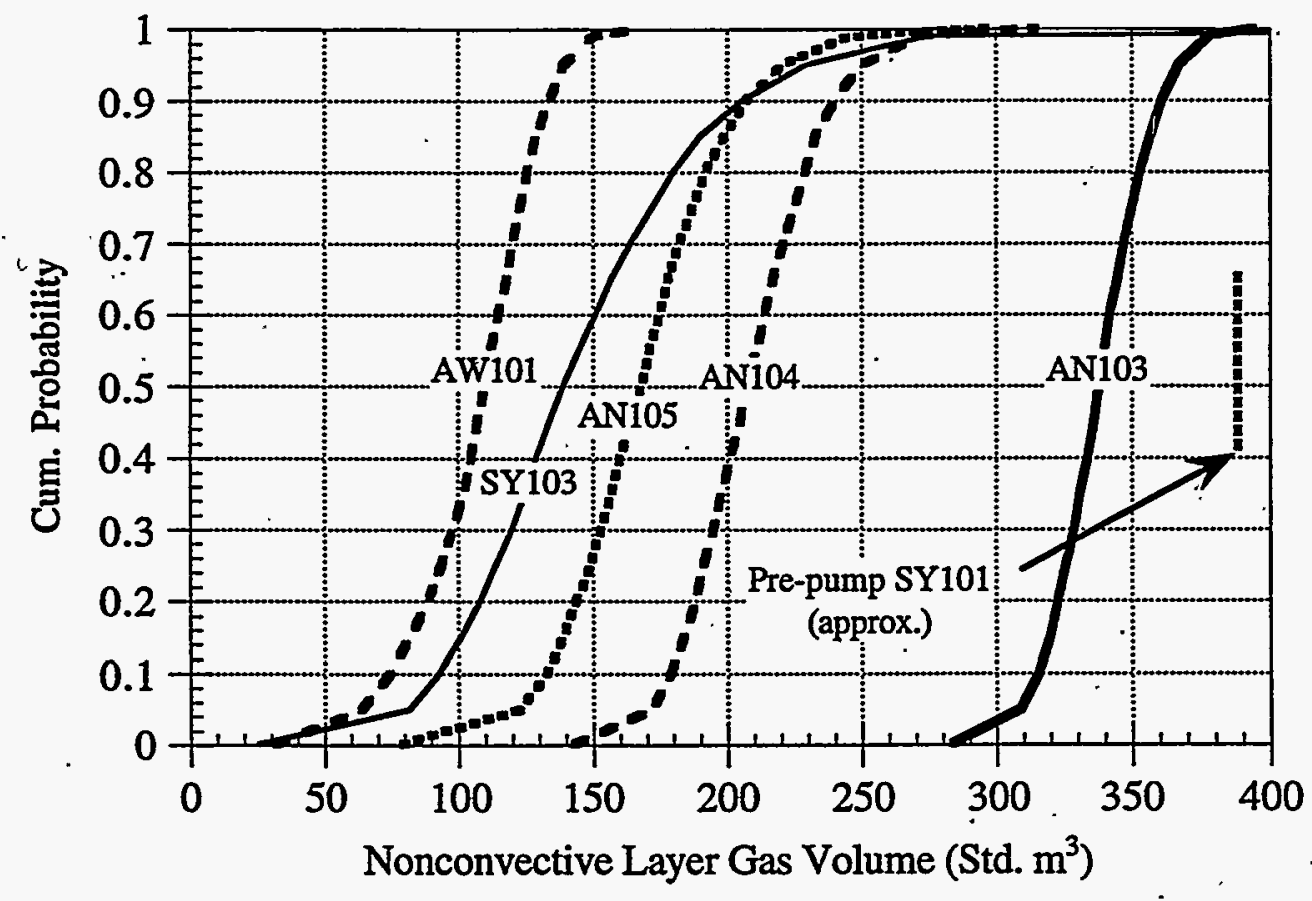

Figure 5.1. Expected Stored Gas Volume by Tank 


\subsubsection{Comparison with Barometric Pressure Effect Method}

The VFI provides an accurate assay of the void fraction profile in the liquid and nonconvective layers but cannot penetrate the crust; this very significant gas volume can only be imperfectly estimated. Also, the VFI is only operated under two risers per tank and therefore potentially misses major maldistributions in gas content. However, all the gas in the tank, regardless of location or distribution, responds to changes in barometric pressure-so the barometric pressure effect (BPE) method is potentially able to measure the total gas content.

The BPE method, however, is subject to the assumption that waste level responds uniformly to pressure changes over the entire tank. It is also believed that the barometric pressure change must exceed the waste yield strength before the waste level responds correctly. Thus the BPE calculation tends to underestimate gas volume with small barometric pressure variation or strong waste. The effective pressure of the retained gas also must be known to compute its volume accurately.

The BPE method and VFI measurements are synergistic; the VFI data provide a very accurate effective pressure for the BPE volume calculation, and the BPE volume calculation provides a check as to whether the local VFI measurements might have missed a large amount of gas, particularly in the crust. Table 5.2 shows the volume, compressibility, and effective pressure for barometric response computed from the VFI measurements along with the compressibility derived directly from waste level response and the total gas volume computed from this and the effective pressure. ${ }^{(a)}$

In all cases, the two gas volume calculations overlap within one standard deviation. The largest relative differences are in AW-101 and SY-103. The discrepancy may be due to a horizontally nonuniform void distribution that the VFI missed. In SY-103 there is a large uncertainty in both the BPE and VFI calculations. The VFI data are uncertain because of the large difference in void between the two risers. The uncertainty is high in the BPE calculation because the time period when the response was calculated had no large barometric pressure swings.

Table 5.2. Barometric Response Comparison

\begin{tabular}{|c|c|c|c|c|c|c|}
\hline & AN & AN-104 & AN-105 & AW-101 & SY-101 & SY -103 \\
\hline$\sqrt{\mathbf{F I}}$ & & & & $142 \pm 36$ & \pm 43 & $114 \pm 57$ \\
\hline ist. & & & .06 & $-0.25 \pm 0.08$ & .10 & $-0.18 \pm 1.22$ \\
\hline ffe & & & 1.67 & $\begin{array}{ll}1.37 & 0.51\end{array}$ & .47 & $1.56 \pm 1.0$ \\
\hline Meas. dL & -0.52 & -0.2 & 0.02 & $-0.18 \pm 0.04$ & -0.3 & $-0.14 \pm 0.04$ \\
\hline $\begin{array}{l}\text { BPE In Situ Vol. } \\
\text { VFI - BPE }\left(\mathrm{m}^{3}\right)\end{array}$ & $\begin{array}{c}328 \pm 70 \\
-36\end{array}$ & $\frac{133 \pm 43}{15}$ & $\begin{array}{c}94 \pm 39 \\
13\end{array}$ & $\begin{array}{c}102 \pm 44 \\
40\end{array}$ & $\frac{154 \pm 69}{11} 69$ & $91 \pm 63$ \\
\hline
\end{tabular}

(a) Reid, HC, ME Brewster, TR Shippert, and PD Whitney. 1996. Comparison of Retained Gas Estimates from Void Fraction Instrument Measurements and Correlations Between Level and Pressure in Several Hanford Double Shell Waste Tanks. Letter report TWSMIT:081996, Pacific Northwest National Laboratory, Richland, Washington. 


\subsection{Potential Consequences of Stored Gas Volume}

The question remaining after the retained gas volumes and their uncertainties are computed and compared is, "So what?". That is, what does a reasonably accurate estimate of stored gas volume tell us about the potential hazards of a tank?

The standard method for assessing the hazard due to a flammable gas burn has been to estimate the percent of the LFL caused by the gas release assuming a fully mixed dome. This measure is not directly connected to any consequence other than the probability of a burn and is not an accurate indicator of the flammable gas hazard apart from a full risk calculation. For DSTs a gas release of a significantly larger volume than that required to achieve LFL is necessary to produce structural failure of the tank (not including failure of the HEPA filters). In fact, the burn probability in a release that just reaches LFL is zero, because the time period of flammability is zero. The mixture will immediately drop below LFL by ventilation. On the other hand, because of stratification, a significant volume may exceed LFL during a release even though the head space would not be flammable if fully mixed.

The peak headspace pressure resulting from a postulated deflagration is a better quantitative measure of the potential safety consequences of a tank's stored gas volume. If the peak pressure from burning all or a given fraction of the stored gas would not exceed the maximum allowable. pressure within an acceptable confidence interval, there is no major hazard from any potential gas release of lower magnitude.

A probabilistic model provides the best method for determining and comparing the potential consequences of gas releases. A bounding deterministic calculation, in which all inputs are conservative or bounding point values, compounds the conservatism of each step in the calculation so that the end result often passes beyond believability (Johnson 1996). Another flaw of a bounding calculation is that the actual degree of conservatism is never known. Though it may demonstrate a condition is 'safe,' it can't answer 'how safe,' or 'how much safer' than some other condition.

The procedure for estimating the burn pressure described in Section 3.4 uses the best estimates available for the required input and the associated uncertainty, including the uncertainty in the gas volume itself, its composition, and the variation in the gas volume with time. It follows the method used by LANL to compute the maximum allowable release in SY-103 for the recent USQ closure submittal. $^{(\mathrm{a})}$

Gas compositions are the best current estimates available. Preliminary RGS data are used for gas compositions in $\mathrm{AN}-105^{(\mathrm{b})}$ and $\mathrm{AW}-101,{ }^{(\mathrm{c})}$ although they are still under review. The SY101 compositions are derived from the 'best estimates' of the release gas composition taken from Appendix B of the mixer pump safety assessment (Sullivan 1995). AN-104 compositions are assumed equal to those in AN-105 because their wastes are similar. The compositions in AN-103 are also assumed equal to those in $\mathrm{AN}-105$, although about a fourth of its waste is dissimilar (see Sections 4.4 and 4.6). SY-103 compositions are assumed equal to SY-101 as per the USQ closure analysis.

(a) Pasamehmetoglu, KO. 1996. Maximum Allowable Gas Release Volume Predictions. Letter report TSA-10-96-329, Los Alamos National Laboratory, Los Alamos, New Mexico.

(b) Preliminary RGS data supplied by JM Bates, PNNL, August 1996.

(c) Shekarriz, A, DR Rector, MA Chieda, M White and JM Bates. 1996. Retained Gas Sampler Measurement Results for Hanford Waste Tank 241-AW-101. Letter report TWSMIT:071996, Pacific Northwest National Laboratory, Richland, Washington. 
We derive the fraction of dissolved gas release fraction for SY-101 by comparing the best estimate of the ammonia concentration of 0.06 in the waste gas (Palmer et al. 1996) with the best estimate of 0.11 in the release gas (Sullivan 1995). Solving Eq. (3.4.7) for $F_{\text {SOL }}$ and applying these values yields $\mathrm{F}_{\mathrm{SOL}}=0.06$. A value of about 0.03 can be calculated from the estimates of diffusive ammonia release during SY-101 Event I and the August 27, 1993, release. ${ }^{(2)}$ Hodgson et al. (1996) use 0.22 , which they acknowledge to be very conservative, for all tanks.

The ammonia evaporation rate, and hence the dissolved gas release fraction, is roughly proportional to the dissolved ammonia concentration in the liquid. The dissolved ammonia concentrations in SY-101 and SY-103 are approximately equal so both are assigned the same release fraction of 0.06 . AW-101, however, has from one-sixth to one-fortieth the ammonia of SY-101 and is therefore assigned a dissolved gas release fraction of 0.01 . We have no direct measurement of the dissolved ammonia concentrations in the AN tanks but preliminary RGS results indicate they may be relatively high. Hence we also assign AN-103, AN-104, and AN-105 each a dissolved gas release fraction of 0.06 .

The concentration of each gas component and the dissolved gas release fraction are input as distributions. For reference, the distributions of the gas composition used in the Monte Carlo simulation are given in Table 5.3. If point values were used instead of distributions, the distribution is referred to as "constant," and the value of that constant is entered in the table. Otherwise, distributions of two types were used, beta or lognormal.

The probability density of the beta distribution is defined as .

$$
\operatorname{Beta}(r, s)=C x^{r-1}(1-x)^{s-1}, 0<\mathrm{x}<1 .
$$

where $\mathrm{r}$ and $\mathrm{s}$ are the distribution parameters. The constant, $\mathrm{C}$, is chosen for normalization of the density to 1 . The Lognormal distribution is a normal distribution for the logarithm of the argument. The parameters are the mean and standard deviations of the normal distribution. Thus the density is given by

$$
\log N(\mu, \sigma)=C \frac{1}{x} e^{-(\ln x-\mu)^{2} / 2 \sigma^{2}}, x>0
$$

The constant, $C$, is chosen to normalize the density to 1 . For comparison purposes, the values of the gas composition distributions corresponding to the 5,50 , and 95 percentile values are given in Table 5.4. For computational purposes, the full distributions given in Table 5.3 should be used rather than specific numerical values.

Plots of the estimated peak burn pressure versus fraction of retained gas released are shown for each tank in Figures 5.2 through 5.9. These plots are intended to portray a tank's 'hazard signature.' Three curves are shown: the median (50th percentile), or best estimate burn pressure; the 95th percentile; and the 99th percentile. The values are developed directly from the simulations. Five thousand simulations were performed, so the pressure at the 95th percentile was greater than that predicted in $4750(95 \%)$ of the 5000 results. This also means that the probability of a pressure less than the 95 th percentile value is 0.95 , or that the pressure is less than the 95th percentile value at a $95 \%$ confidence limit.

(a) Diffusive release was estimated in Calculation of Ammonia Release by Diffusion from Waste Surface of Tank 241-SY-101, by BJ Palmer, 1995. Letter report PNLMIT:012595, Pacific Northwest National Laboratory, Richland, Washington. 
Table 5.3. Waste Gas Composition Distributions

\begin{tabular}{|c|c|c|c|c|c|c|}
\hline & $\mathbf{A N - 1 0 3}$ & $\overline{A N-104}$ & AN-105 & $\overline{A W-101}$ & SY-101 & SY-103 \\
\hline $\mathbf{H}_{2}$ & $\begin{array}{c}\text { Lognormal } \\
-0.625 \\
0.125\end{array}$ & $\begin{array}{c}\text { Lognormal } \\
-0.625 \\
0.125\end{array}$ & $\begin{array}{c}\text { Lognormal } \\
-0.625 \\
0.125 \\
\end{array}$ & $\begin{array}{l}\text { Beta } \\
3 \\
8\end{array}$ & $\begin{array}{c}\text { Lognormal } \\
-1.187 \\
0.128\end{array}$ & $\begin{array}{c}\text { Lognormal } \\
-1.187 \\
0.128\end{array}$ \\
\hline $\mathbf{N}_{2} \mathrm{O}$ & $\begin{array}{c}\text { Lognormal } \\
-2.02 \\
0.26\end{array}$ & $\begin{array}{c}\text { Lognormal } \\
-2.02 \\
0.26\end{array}$ & $\begin{array}{c}\text { Lognormal } \\
-2.02 \\
0.26\end{array}$ & $\begin{array}{c}\text { Lognormal } \\
-2.75 \\
0.25\end{array}$ & $\begin{array}{c}\text { Lognormal } \\
-1.351 \\
0.13\end{array}$ & $\begin{array}{c}\text { Lognormal } \\
-1.351 \\
0.13\end{array}$ \\
\hline $\mathrm{CH}_{4}$ & $\begin{array}{c}\text { Lognormal } \\
-5.13 \\
0.165\end{array}$ & $\begin{array}{c}\text { Lognormal } \\
-5.13 \\
0.165\end{array}$ & $\begin{array}{c}\text { Lognormal } \\
-5.13 \\
0.165\end{array}$ & $\begin{array}{c}\text { Lognormal } \\
-4.29 \\
0.125\end{array}$ & $\begin{array}{l}\text { Constant } \\
0.0034\end{array}$ & $\begin{array}{c}\text { Constant } \\
0.0034\end{array}$ \\
\hline CO & $\begin{array}{c}\text { Lognormal } \\
-4.95 \\
0.4\end{array}$ & $\begin{array}{c}\text { Lognormal } \\
-4.95 \\
0.4\end{array}$ & $\begin{array}{c}\text { Lognormal } \\
-4.95 \\
0.4\end{array}$ & $\begin{array}{c}\text { Lognormal } \\
-4.83 \\
0.15\end{array}$ & $\begin{array}{c}\text { Constant } \\
0.0027\end{array}$ & $\begin{array}{c}\text { Constant } \\
0.0027\end{array}$ \\
\hline $\mathrm{NH}_{4}$ & $\begin{array}{c}\text { Lognormal } \\
-2.95 \\
0.55\end{array}$ & $\begin{array}{c}\text { Lognormal } \\
-2.95 \\
0.55\end{array}$ & $\begin{array}{c}\text { Lognormal } \\
-2.95 \\
0.55 \\
\end{array}$ & $\begin{array}{c}\text { Constant } \\
0.001\end{array}$ & $\begin{array}{c}\text { Lognormal } \\
-2.813 \\
0.48\end{array}$ & $\begin{array}{c}\text { Lognormal } \\
-2.813 \\
0.48\end{array}$ \\
\hline $\mathbf{F}_{\text {SOL }}$ & $\begin{array}{c}\text { Lognormal } \\
-2.813 \\
0.42\end{array}$ & $\begin{array}{c}\text { Lognormal } \\
-2.813 \\
0.42 \\
\end{array}$ & \begin{tabular}{|c|} 
Lognormal \\
-2.813 \\
0.42 \\
\end{tabular} & $\begin{array}{c}\text { Lognormal } \\
-4.608 \\
0.844 \\
\end{array}$ & $\begin{array}{c}\text { Lognormal } \\
-2.813 \\
0.42 \\
\end{array}$ & $\begin{array}{c}\text { Lognormal } \\
-2.813 \\
0.42 \\
\end{array}$ \\
\hline
\end{tabular}

Table 5.4. Waste Gas Composition Comparison

\begin{tabular}{|c|c|c|c|c|c|c|c|}
\hline & Percentile & AN-103 & AN-104 & AN-105 & AW-101 & SY-101 & SY-103 \\
\hline \multirow{2}{*}{$\mathbf{H}_{\mathbf{2}}$} & 5 & 0.436 & 0.436 & 0.436 & 0.087 & 0.247 & 0.247 \\
& 50 & 0.535 & 0.535 & 0.535 & 0.259 & 0.305 & 0.305 \\
& 95 & 0.657 & 0.657 & 0.657 & 0.507 & 0.377 & 0.377 \\
\hline \multirow{2}{*}{$\mathbf{N}_{\mathbf{2}} \mathbf{O}$} & 5 & 0.086 & 0.086 & 0.086 & 0.042 & 0.209 & 0.209 \\
& 50 & 0.133 & 0.133 & 0.133 & 0.064 & 0.259 & 0.259 \\
& 95 & 0.203 & 0.203 & 0.203 & 0.096 & 0.321 & 0.321 \\
\hline & 5 & 0.005 & 0.005 & 0.005 & 0.011 & & \\
$\mathbf{C H}_{\mathbf{4}}$ & 50 & 0.006 & 0.006 & 0.006 & 0.14 & 0.0034 & 0.0034 \\
& 95 & 0.008 & 0.008 & 0.008 & 0.017 & & \\
\hline \multirow{2}{*}{$\mathbf{C O}$} & 5 & 0.004 & 0.004 & 0.004 & 0.006 & & \\
& 50 & 0.007 & 0.007 & 0.007 & 0.008 & 0.0027 & 0.0027 \\
& 95 & 0.014 & 0.014 & 0.014 & 0.010 & & \\
\hline \multirow{2}{*}{$\mathbf{N H}_{\mathbf{3}}$} & 5 & 0.021 & 0.021 & 0.021 & & 0.027 & 0.027 \\
& 50 & 0.052 & 0.052 & 0.052 & 0.001 & 0.060 & 0.060 \\
& 95 & 0.129 & 0.129 & 0.129 & & 0.133 & 0.133 \\
\hline \multirow{2}{*}{$\mathbf{F}_{\text {SOL }}$} & 5 & 0.03 & 0.03 & 0.03 & 0.0025 & 0.03 & 0.03 \\
& 95 & 0.06 & 0.06 & 0.06 & 0.010 & 0.06 & 0.06 \\
& 95 & 0.12 & 0.12 & 0.12 & 0.040 & 0.12 & 0.12 \\
\hline
\end{tabular}


The hazard signatures compare the predicted peak pressures with the limiting dome pressure difference of $3.08 \mathrm{~atm}(312 \mathrm{kPa}, 45.3 \mathrm{psig})$. This pressure was determined in the SY101 mixer pump safety assessment (Sullivan 1995) to maintain confinement of radioactive waste within the primary liner. Though the analysis predicts extensive concrete cracking and rebar yielding throughout the dome structure at this pressure, gross structural deformations are prevented. The peak dome apex velocity is also predicted to be under the limiting value at which the overlying soil would separate and re-impact the dome, potentially causing it to collapse.

The solid and dashed vertical lines on each 'hazard signature' represent the mean and maximum release fraction observed in the tank's GRE history (see Appendix A). This shows the range of potential consequences resulting from what the tank has been known to do. Higher release fractions might result from a severe seismic event, for example.

The release fraction required to bring the entire mixed head space to the LFL is also shown on each hazard signature by the vertical line marked 'LFL." The mixture LFL is computed via LeChatalier's linear combination rule based on the 50th percentile values for the concentrations given in Table 5.4, including the additional ammonia assumed to evaporate from exposed surface during a GRE, $\mathrm{F}_{\mathrm{SoL}}$, as described in Section 3.4. The fraction of waste gas (including evaporated ammonia) in the head space at LFL, $F_{L F}$, is computed by

$$
\mathrm{F}_{\mathrm{LFL}}=\left(1+\mathrm{F}_{\mathrm{SOL}}\right)\left[\frac{\left[\mathrm{H}_{2}\right]}{\mathrm{LFL}_{\mathrm{H}_{2}}}+\frac{\left[\mathrm{CH}_{4}\right]}{\mathrm{LFL}_{\mathrm{CH}_{4}}}+\frac{[\mathrm{CO}]}{\mathrm{LFL}_{\mathrm{CO}}}+\frac{\left[\mathrm{NH}_{3}\right]+\mathrm{F}_{\mathrm{SOL}}}{\mathrm{LFL}_{\mathrm{NH}_{3}}}\right]^{-1}
$$

The release fraction required to bring the entire head space to LFL is then estimated by

$$
R_{L F L}=\frac{F_{L F L} \cdot V_{H S}}{\hat{V}_{N C}}
$$

where $\mathrm{V}_{\mathrm{HS}}$ is the head space volume, and the standard gas volume in the nonconvective layer, $\hat{\mathrm{V}}_{\mathrm{NC}}$, is determined from Eq. (3.3.8).

The LFL and release fractions required to achieve it are summarized in Table 5.5. As stated at the beginning of this section, the mixed headspace LFL is an artificial quantity that assumes instantaneous mixing and ignores ventilation. Releases smaller than those predicted by Eq. (5.4) will almost certainly exceed the LFL in a portion of the head space. Recall that the burn calculations assume the entire release is burned without dilution in the head space.

The peak burn pressure predictions are not risk calculations in the true sense because there is no frequency in view. We make no attempt to compute flammability times or to assess spark frequency; however, the results are valid input to a full risk calculation and serve to compare the safety state of the six tanks studied. It is possible to assign an approximate frequency to the spectrum of release fractions to put the results in the proper perspective. The mean release fraction from the GRE history will have a frequency on the order of 1-2/year, and the maximum release fraction will occur at about 0.1 year (one in ten years). A $50 \%$ release fraction might be anticipated in a 100-year earthquake so would have a frequency of 0.01 (unless $50 \%$ is already covered by historic releases, as it is in SY-101). The frequency of releases larger than about 75\% is more problematic, because they have never been observed and no feasible mechanism predicts them. A $100 \%$ release is technically impossible. 
Table 5.5. Release Fractions to Achieve LFL

\begin{tabular}{|c|c|c|c|c|c|c|}
\hline & AN-103 & AN-104 & AN-105 & AW-101 & SY-101 ${ }^{(\mathrm{a})}$ & SY-103 \\
\hline Mixture Conc. at LFL & 0.073 & 0.073 & 0.073 & 0.140 & 0.122 & 0.122 \\
\hline Headspace Vol. $\left(\mathrm{m}^{3}\right)$ & 1712 & 1323 & 1066 & 1070 & 1066 & 2503 \\
\hline Release Vol. for LFL $\left(\mathrm{m}^{3}\right)$ & 124 & 96 & 77 & 150 & $\overline{130}$ & 306 \\
\hline Retained Gas Vol. $\left(\mathrm{m}^{3}\right)$ & 363 & 197 & $\overline{148}$ & 115 & 393 & 150 \\
\hline Rel. Fraction for LFL & 0.34 & 0.49 & 0.52 & 1.30 & 0.33 & 2.04 \\
\hline
\end{tabular}

The hazard signature estimated for SY-101 prior to mixer pump installation is given in Figure 5.2. Since the gas volume was measured with a waste configuration different than what existed when the tank was 'burping,' this signature should only be taken as an example for comparisons with the other tanks. The best estimate peak burn pressure is predicted to exceed the $3.08 \mathrm{~atm}$ maximum at the maximum historical release. Releases cannot be much larger than the median to remain below the maximum pressure at a $99 \%$ confidence limit. Even the expected release exceeds the LFL. It is clear that this tank presented a significant hazard.

In contrast, consider the signatures of SY-103 and AW-101 in Figures 5.3 and 5.4. SY103 has such a large headspace that, even for a $100 \%$ release, the peak burn pressure would remain well below the $3.08 \mathrm{~atm}$ limit at $99 \%$ confidence, and the fully mixed headspace would remain well below the LFL. This conclusion was also reached in the SY-103 USQ closure analysis discussed earlier. AW-101 has less than half the head space volume as SY-103 and stores $30 \%$ less gas. Thus it also cannot exceed the maximum allowable pressure or reach the LFL, even if all the gas in the nonconvective layer were released. Both of these tanks are clear candidates for removal from the FGWL and USQ.

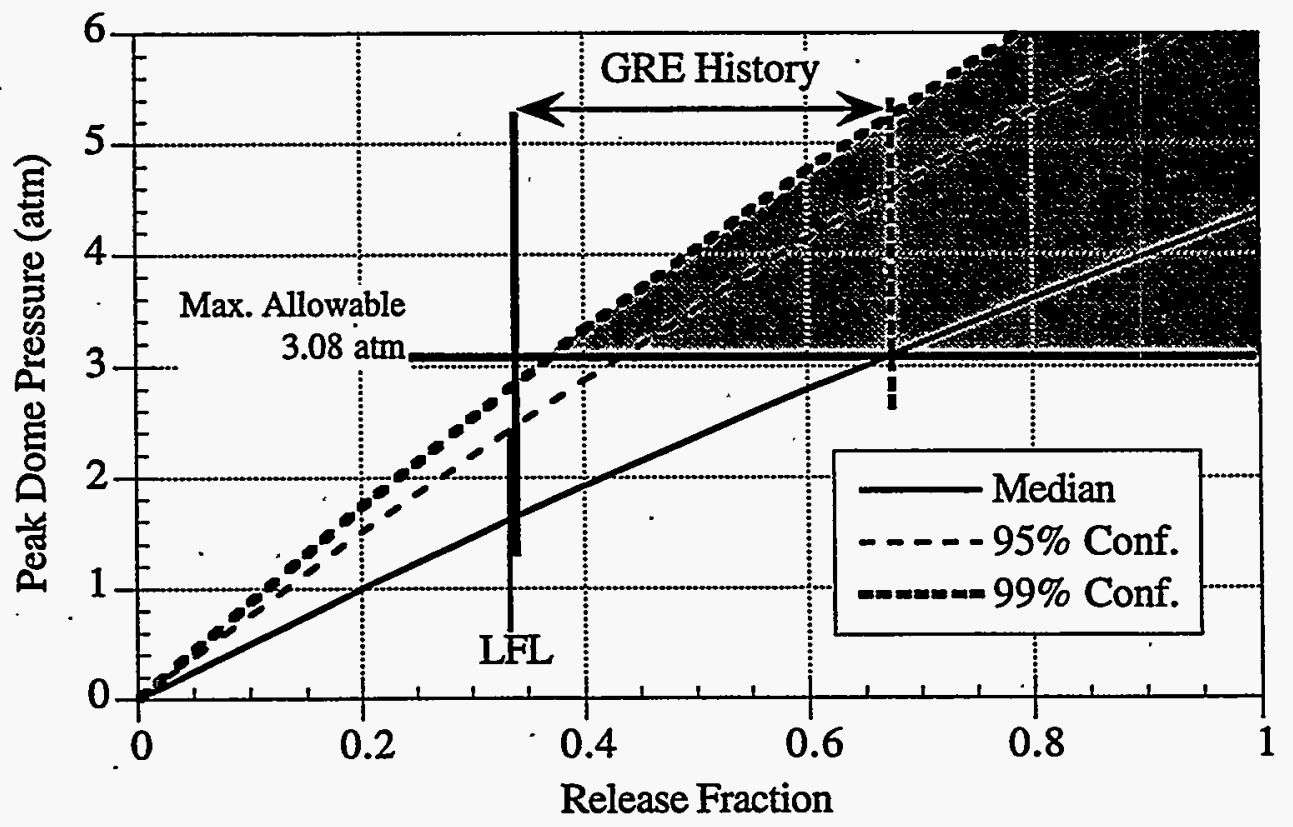

Figure 5.2. Peak Burn Pressure in SY-101 


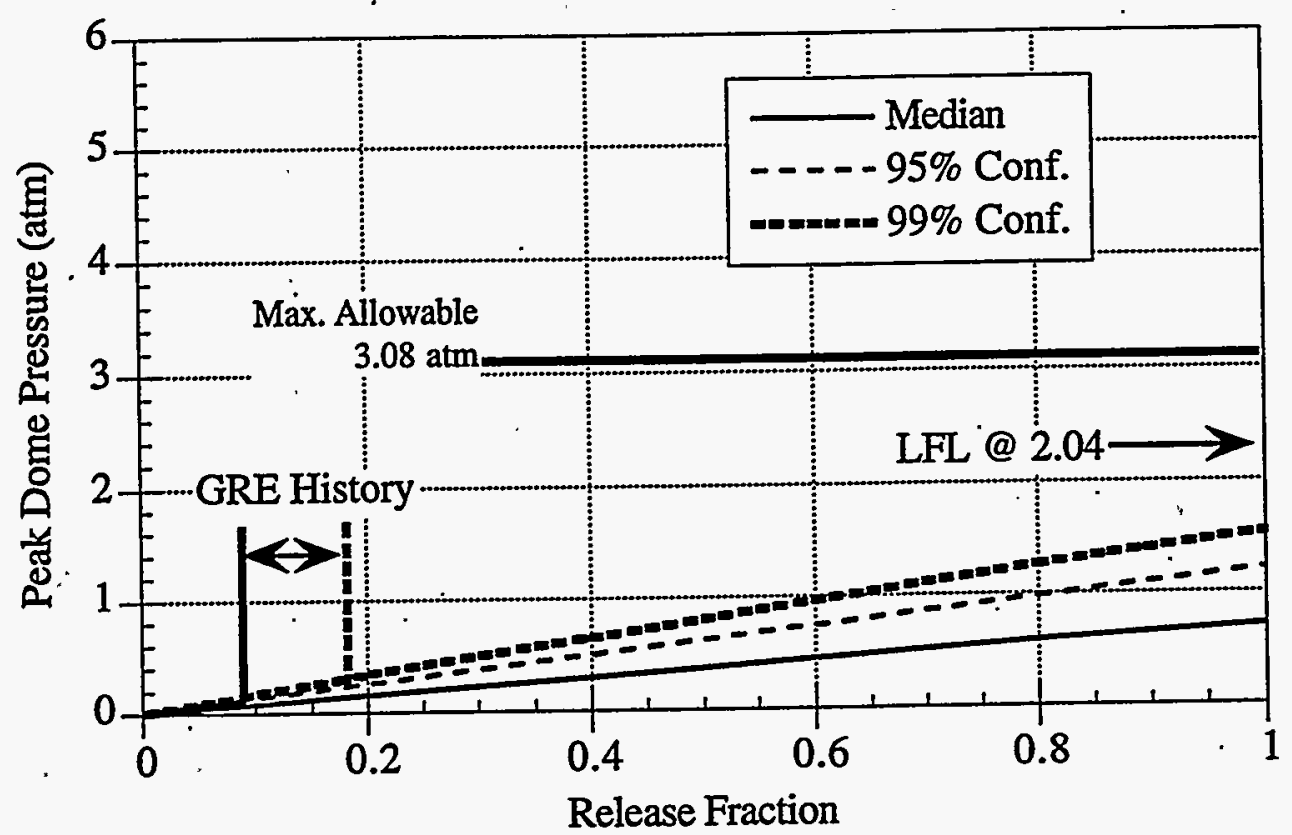

Figure 5.3. Peak Burn Pressure in SY-103

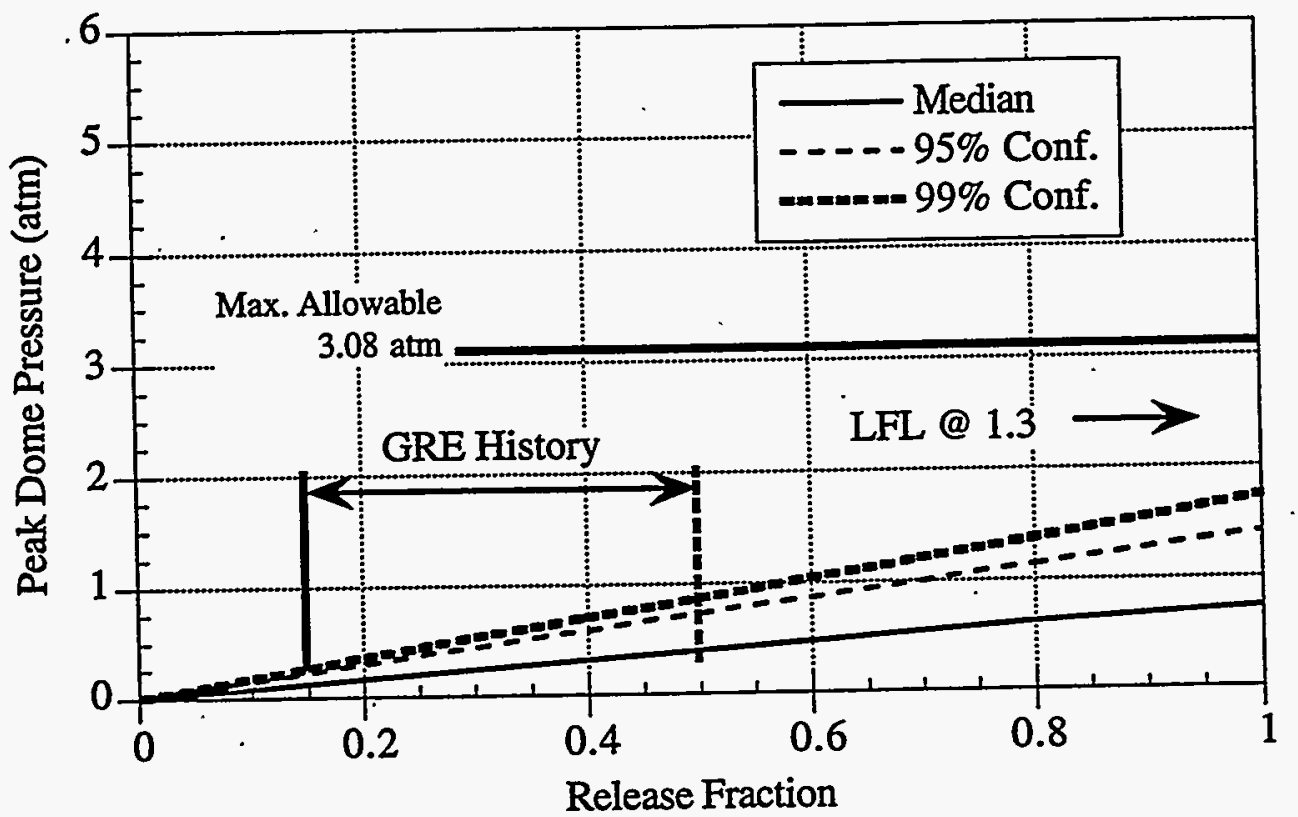

Figure 5.4. Peak Burn Pressure in AW-101 
The three AN tanks do not show such a clear distinction. AN-103 is the most hazardous but is still far less so than SY-101. The hazard signatures for AN-103, AN-104, and AN-105 are shown in Figures 5.5, 5.6, and 5.7, respectively. None of them has ever released enough gas in historical GREs to even approach the maximum allowable pressure or the LFL. In AN-103, the best estimate of peak burn pressure just reaches the maximum allowable pressure in a $100 \%$ release and will remain below it in a $70 \%$ release at $99 \%$ confidence. The best estimates of peak pressure in AN-104 and AN-105 are well below the maximum allowable pressure and remain below it at $99 \%$ confidence for a $85 \%$ release in $\mathrm{AN}-104$ and a $75 \%$ release in AN-105. The release fractions required to achieve LFL in the mixed head space are $34 \%, 49 \%$, and $52 \%$ in AN-103, AN-104, and $\mathrm{AN}-105$, respectively.

The dominant sources of uncertainty in the peak pressure calculation vary from tank to tank. In SY-101 the waste level, which defines the stored gas volume available, dominates strongly. It was input as a normal distribution with average and standard deviations derived from the historical level readings just before each GRE, which vary considerably. In the other tanks, the level is input as an empirical distribution created simply by binning all the waste level readings, ignoring how the readings relate to GREs. The only other tank whose largest uncertainty was due to level is $\mathrm{AN}-104$. The dominant uncertainty for the $\mathrm{AN}-103$ and $\mathrm{AW}-101$ calculations was in the hydrogen concentration. The nonconvective layer void fraction uncertainty dominated in AN-105 and SY-103. The void fraction uncertainty is high in AN-105 because no measurements were made below about $150 \mathrm{~cm}$, and in SY-103 it is simply due to the wide scatter in the measurements.

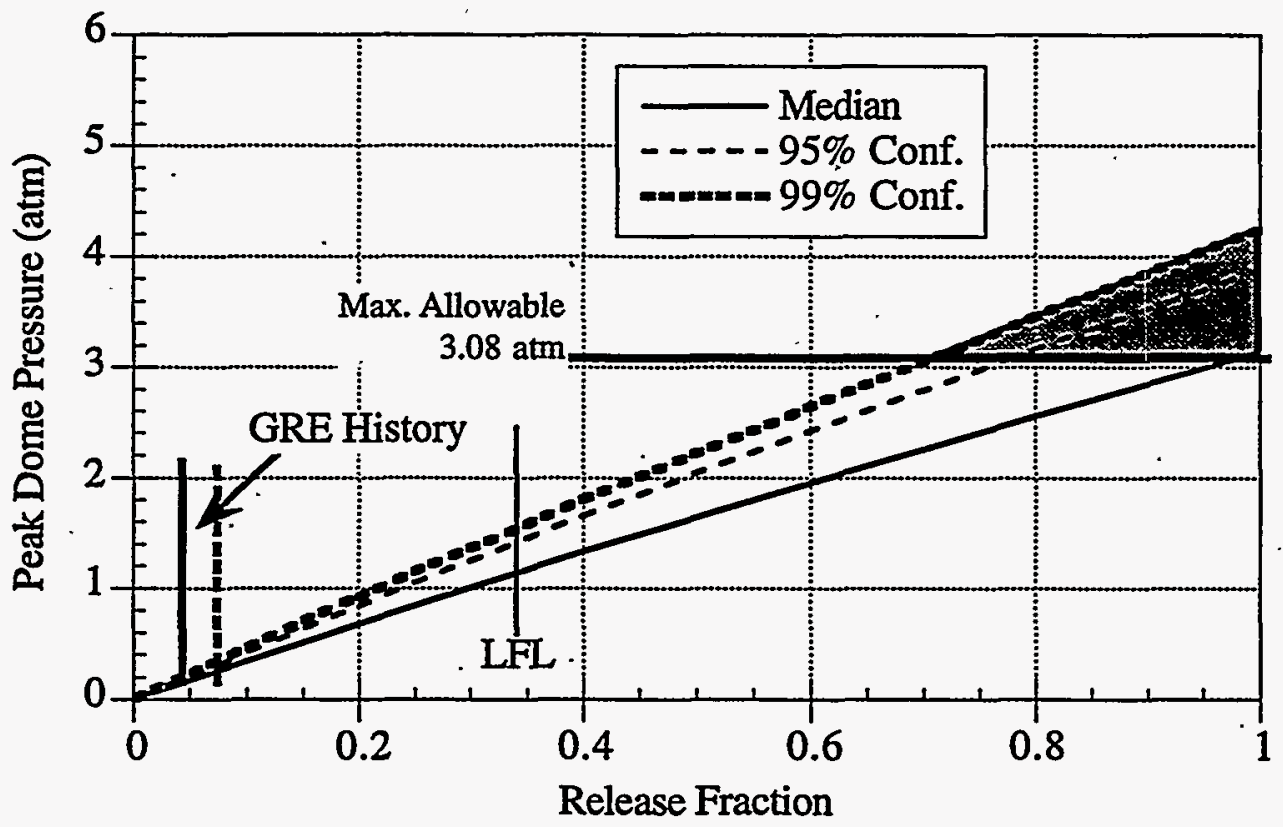

Figure 5.5. Peak Burn Pressure in AN-103 


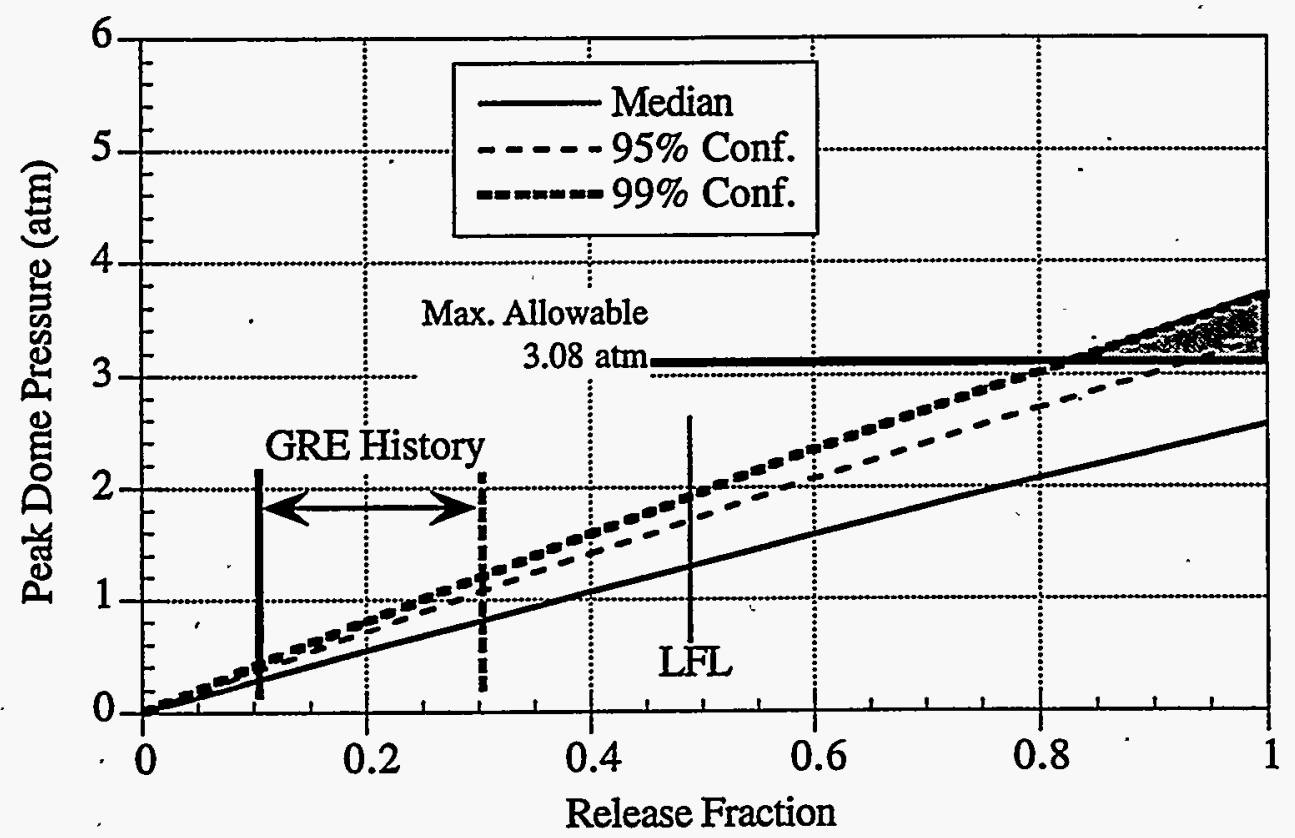

Figure 5.6. Peak Burn Pressure in AN-104



Figure 5.7. Peak Burn Pressure in AN-105 


\subsection{Rheology and Waste Configuration}

In the two preceding sections we presented the results of the gas volume calculations and attempted to describe the implications and answer the "so what?" question. The last question that eventually must be answered is, "Why?". Why was the GRE behavior of SY-101 so much more severe than in the other tanks? Why does AN-103 store so much gas with hardly detectable GREs? Generally, how can we explain the gas retention and release behavior of each tank? As yet there is no satisfactory answers to these questions, but there are a few clues in the rheology and the physical condition of the waste.

The waste yield stress affects the way bubbles grow and how much is stored (Gauglitz et al. 1996). The apparent viscosity should also have some effect on the dynamics of a GRE. However, the apparent viscosity profiles presented in Section 4 are all very similar (note that first pass apparent viscosity for SY-103 was obtained at $3 \mathrm{~cm} / \mathrm{s}$ ). There are as many variations among risers in a tank as there are among different tanks. Except for AN-103, the estimated yield stress profiles are equivalent within their uncertainty. The yield strength profiles are shown in Figure 5.8.

Waste density is another indicator of GRE behavior. The ratio of supernatant to nonconvective layer densities determines the void fraction at neutral buoyancy where a rollover is possible. Density profiles of the convective layer and the nonconvective layer density are shown for all tanks. in Figure 5.9 (SY-101 values are pre-mixer pump recommendations of Reynolds 1993). SY-101 and AN-103 have higher convective layer densities and much higher nonconvective layer densities than the others.

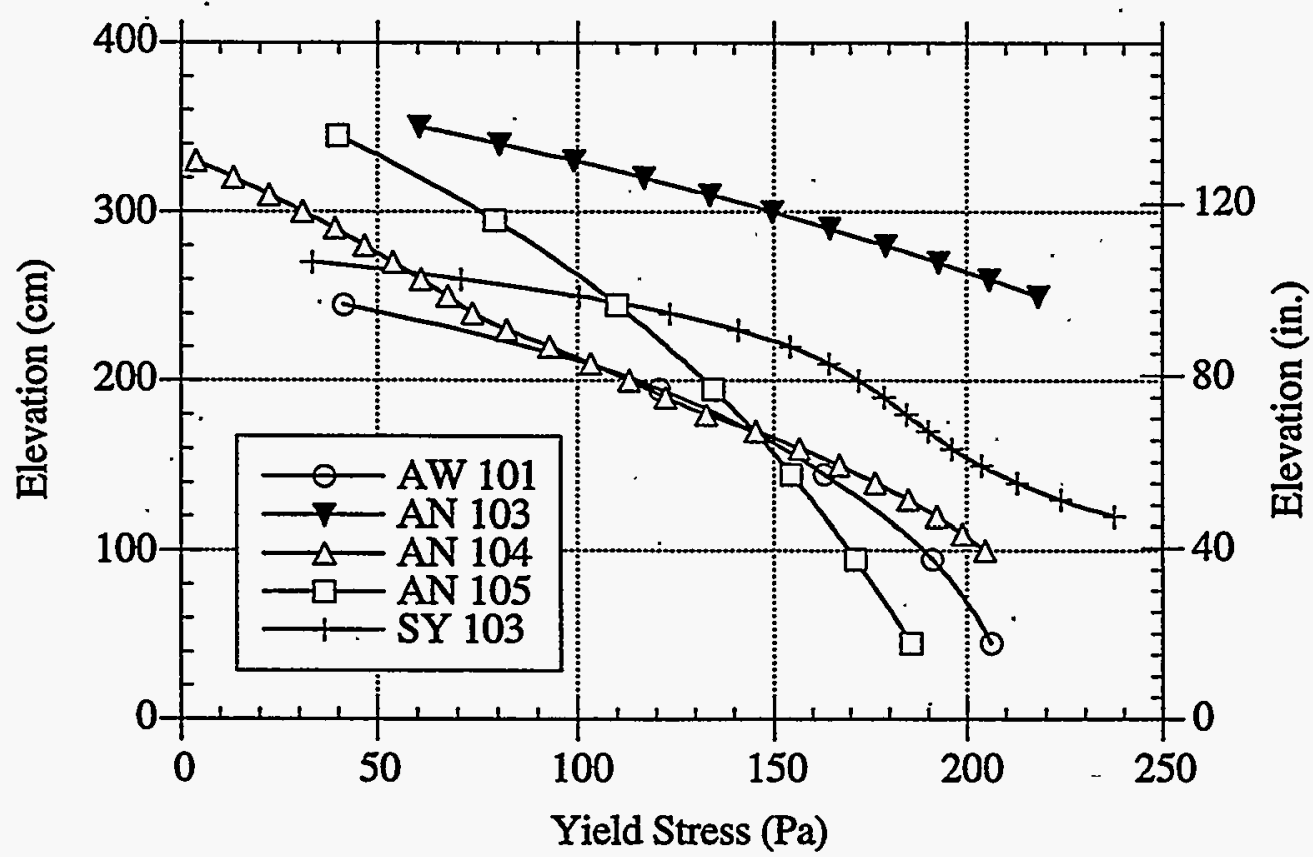

Figure 5.8. Yield Stress for Five Tanks 


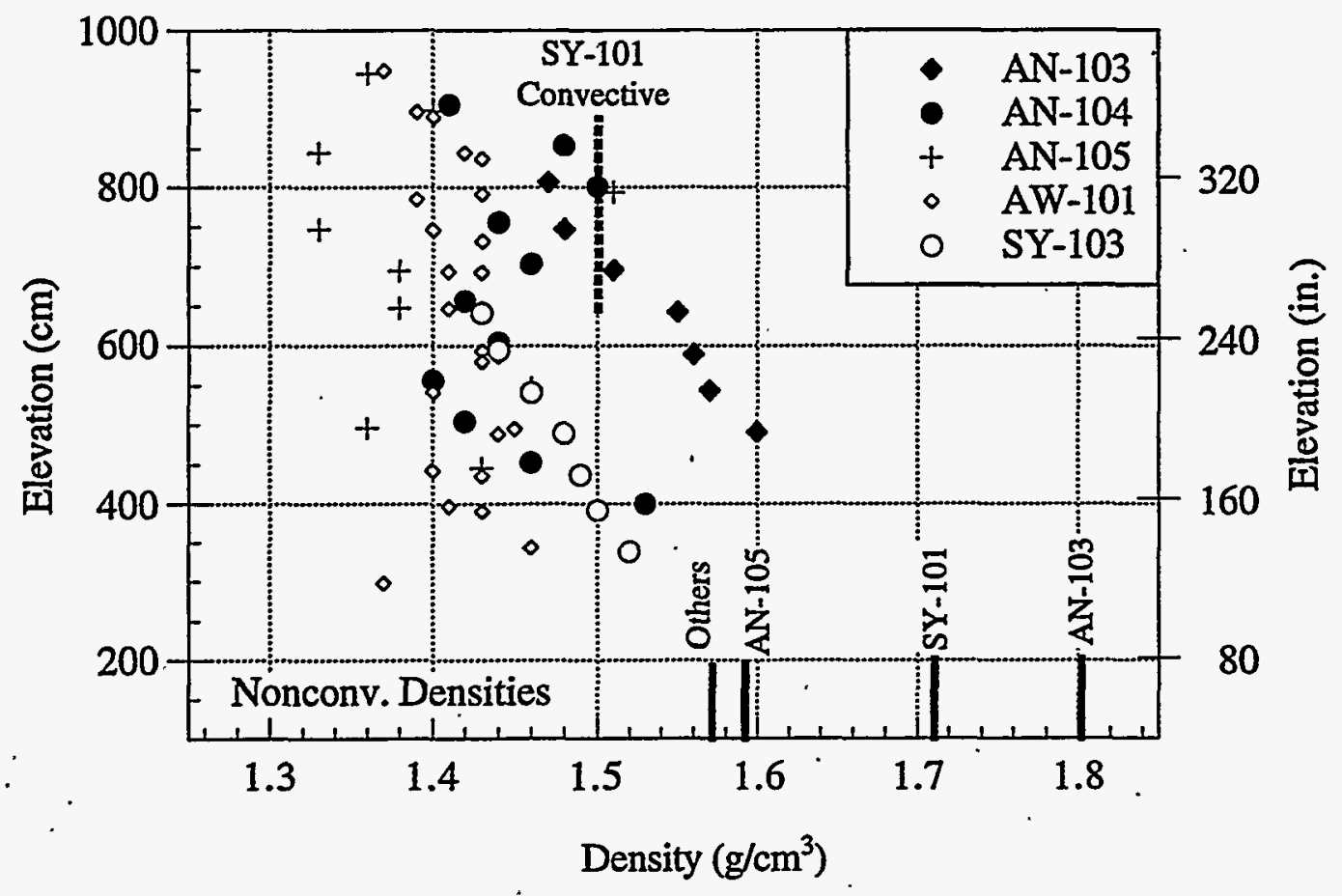

Figure 5.9. Density Profile Comparison

Though interesting, density does not appear to be a very good indicator of GRE behavior or gas retention. Based on density alone, one would expect SY-101 and AN-103 to behave similarly, yet their GRE history is at opposite ends of the spectrum. The neutral buoyancy void fractions for the six tanks are listed in descending order in Table 5.6 along with the mean and maximum of their measured void fractions. While AN-103 has both the highest neutral buoyancy void and measured void fraction, the other tanks appear to follow the opposite trend (recall that the VFI made no measurements in the lower $150 \mathrm{~cm}$ of AN-105). Also the local maximum void tends to trend exactly opposite to the neutral buoyancy for the last four tanks. Neither historical GREs nor their frequency appears to correlate with neutral buoyancy.

The waste temperature profiles are compared in Figure 5.10. The waste temperatures are similar, except that SY-103 is much cooler. The SY-103, AN-104, and AN-105 profiles show the pronounced parabolic bulge typical of a DST nonconvective layer. The profile of AN-103 is remarkable for the absence of a 'knee.' The uniform convective layer profile joins the parabolic nonconvective layer profile near its peak. AW-101 shows a similar weak knee. AN-104 and AN105 tend to release almost twice as much gas per event as AW-101 and AN-103 and do so more abruptly. SY-103 releases are small like the latter two tanks but abrupt like the former. However, the size of release probably depends more on nonconvective layer depth and abruptness on the crust thickness than either does on the shape of the temperature profile. Also, the crust thickness could explain the temperature profiles based on heat transfer arguments. 
Table 5.6. Neutral Buoyancy Void Fractions Compared with VFI Measurements

\begin{tabular}{|c|c|c|c|}
\hline & Neutral Buoyancy & \multicolumn{2}{|c|}{ Measured Void Fraction } \\
\hline Tank & Void Fraction & Mean & Max. \\
\hline AN-103 & 0.15 & 0.12 & 0.15 \\
\hline SY-101. & $0.12^{\text {(a) }}$ & N/A & N/A \\
\hline AN-105 & 0.10 & 0.04 & 0.07 \\
\hline AN-104 & 0.09 & 0.06 & 0.10 \\
\hline AW-101 & 0.09 & 0.05 & 0.09 \\
\hline SY-103 & 0.06 & 0.06 & 0.13 \\
\hline
\end{tabular}

(a) Reynold's (1993) recommended density for centrifuged supernatant of $1.50 \mathrm{~g} / \mathrm{cm}^{3}$ is used here. If the centrifuged solids value is also used, the neutral buoyancy point is 0.16 .

One other possible source of information is the appearance of the actual waste from the core sample extrusions. The extrusion photos in Appendix B reveal some interesting differences and similarities in core segments from a 1988 core from AN-103, a 1996 core from AN-105, a 1996 core from AW-101, and 1986 and 1994 cores from SY-103. The figures in Appendix B were created by scanning color-corrected still photographs, except for the 1994 core from SY-103, which was constructed from video taken through the hot-cell window. The texture of the waste in this case appeared best in black and white.

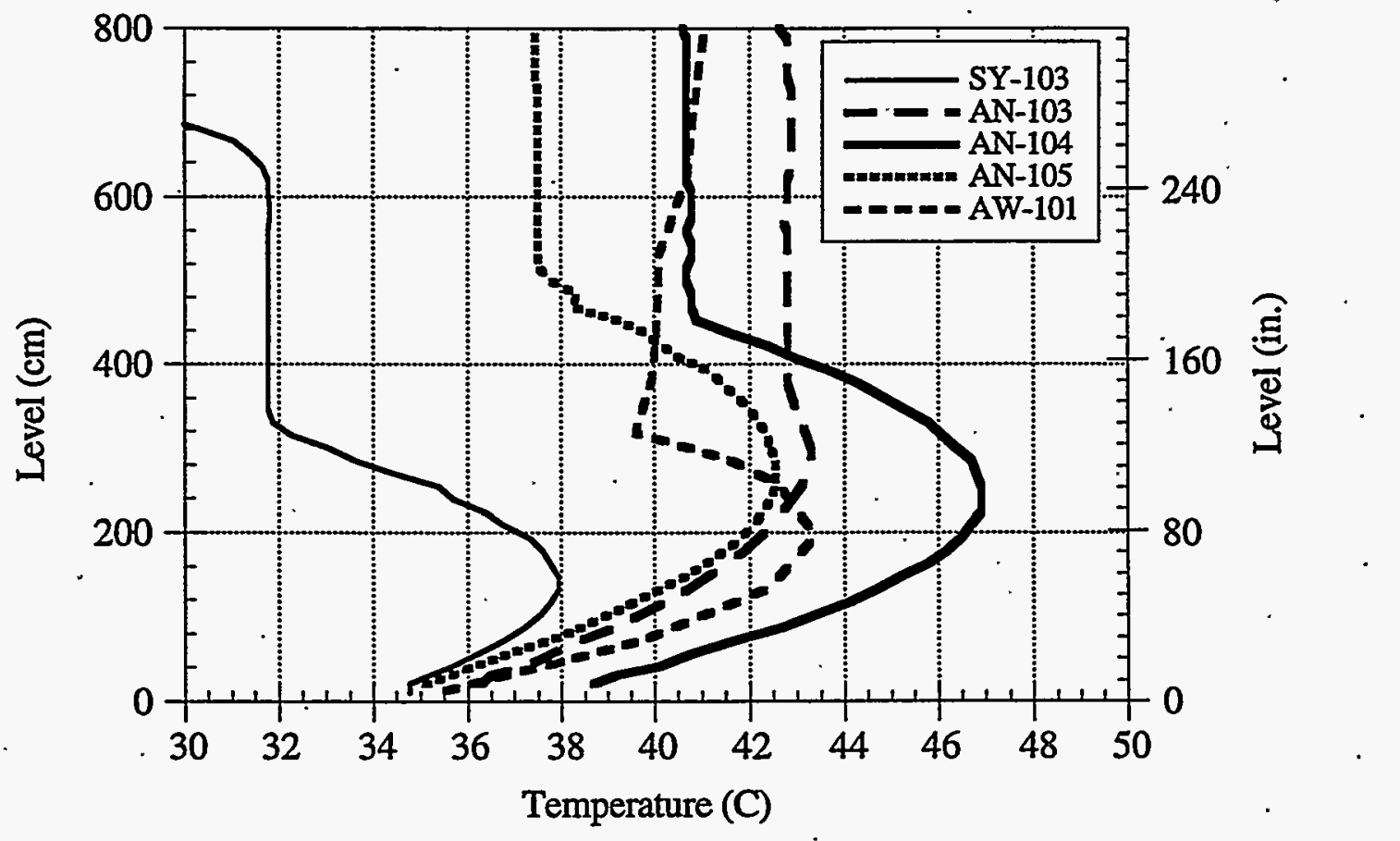

Figure 5.10. Temperature Profiles for Five Tanks 
All nonconvective layer segments (except the 1986 SY-103 core) show 'pock marks' that are evidence of retained gas. This is especially clear in segment 13 of AN-103, segment 18 of AN105 and segment 12 of the 1994 SY-103 core. All the recent cores tend to show a dryer, stiffer looking waste in the region of peak void fraction with more fluid material at the top and the bottom. This trend appears most obvious in AN-103 and AN-105. The peak void was measured at about $200-250 \mathrm{~cm}$ in AN-103, $200 \mathrm{~cm}$ in AN-105, $100 \mathrm{~cm}$ in AW-101, and 150-200 cm in SY-103.

The tanks that show definite 'rollover' behavior appear to have softer, wetter looking waste with wider variation in appearance. a dryer appearance may result from lower liquid content, larger particles allowing liquid to separate in the extrusion tray, or both. Compare AN-103 and AW-101 segments with those of AN-105 and, to some extent, the 1994 SY-103 core. AN-105, the best 'burper' has a more fluid waste than AN-103, which hardly burps at all: The strongest evidence is the difference between the 1986 and 1994 cores from SY-103. This tank has exhibited rollovers only after the last fill in 1988 . It was not doing so in 1986 when the very dry, stiff waste was sampled.

The extrusion photos reveals another interesting feature. The sample from the crust layer in AW-101 appears soft and virtually indistinguishable from the upper nonconvective material. SY103 (both 1994 and 1986) and AN-105 are similar, though very little crust was captured. This indicates that the crust layer and the upper portion of the nonconvective layer are made of the same waste. This is consistent with the theory that the crust is formed by small bubbles lifting attached particles to the waste surface.

Estey and Guthrie (1996) suggested that DST gas retention and release behavior are well described and discriminated by plotting the barometric response slope, $\mathrm{dL} / \mathrm{dP}$, against the product of solids depth (includes both crust and nonconvective layers) and liquid specific gravity. A version of this plot is shown as Figure 5.11. Estey and Guthrie's original data are plotted with the

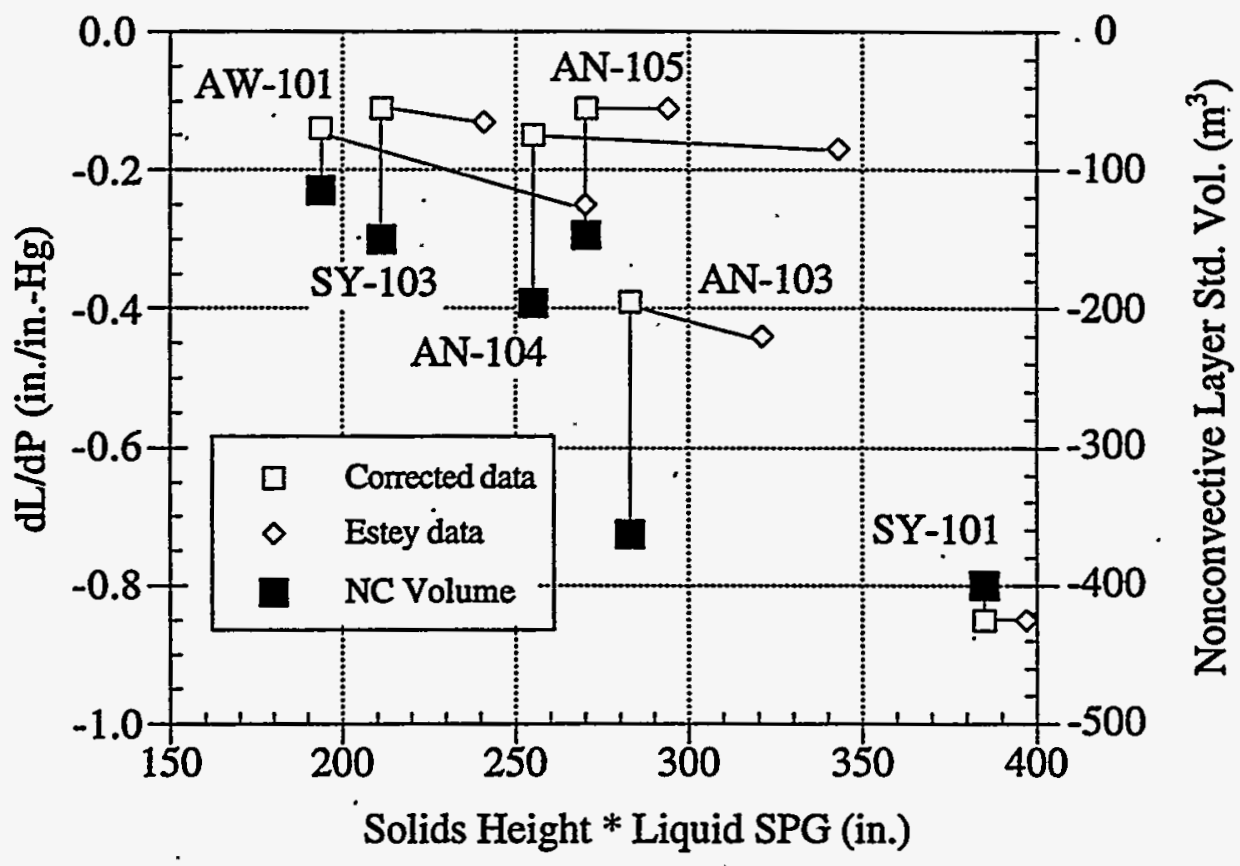

Figure 5.11. DL/dP Versus Depth 
small open symbol, and the new data derived from the liquid specific gravity and nonconvective layer depth from the ball rheometer, with the revised crust thickness and new dL/dP values, are plotted in large, solid squares. The large solid squares plot the same parameter against the standard gas volume in the nonconvective layer, which is a more basic quantity than $\mathrm{dL} / \mathrm{dP}$. The new data appear to sort the tanks better by potential hazard by grouping AN-104 with AN-105, and AW-101 with SY-103. AN-103 is closer to the other AN-tanks than to SY-101, which remains entirely unique. Using the nonconvective layer volume appears to improve the grouping aesthetically, but not substantially.

Gas retention behavior appears to be reasonably well correlated by the product of solids height and liquid specific gravity, and gas release behavior is also roughly sorted. AN-103 appears to be misplaced if one considers the observed GRE behavior; however, it may be that the correlation is predicting large GREs in the future. Recall that AN-105 experienced a 3-1/2 year period of slow level growth without GREs in a pattern very similar to the one AN-103 is following.

\subsection{The Bottom Line}

The data obtained with the ball rheometer and VFI have allowed us to physically characterize waste in the six flammable gas DSTs relatively well. When this information is combined with results from the retained gas sampler, core extrusion photos, and some of the laboratory analyses, we have all the data required to quantify the flammable gas hazard and assess its consequences and risk. However, a full understanding of all the processes that make up the gas retention and release personalities of the individual tanks and explaining them to everyone's satisfaction will require further study.

By any measure, the flammable gas hazard of the pre-pump GREs in SY-101 was clearly in a completely different class than the any of the other DSTs on the flammable gas watch list. It was actually possible for a large burp in SY-101 to fail the tank dome, if the gas were ignited. In contrast, AN-103, AN-104, and AN-105 present only a potential hazard-an improbably large fraction of their retained gas would need to be released to damage the dome. AW-101 and SY-103 store such a small volume of gas relative to their head space that a $100 \%$ release does not approach the maximum allowable pressure at $99 \%$ confidence or even exceed the LFL. These two tanks are good candidates for removal from the FGWL and USQ list.

Another important conclusion is that there is no important difference in the waste configuration of the tanks. The temperature profiles of all six tanks (including SY-101 before mixing) show a definite convective layer. This is consistent with the absence of gas measured by the VFI and with the low viscosity and absence of yield stress derived from the ball rheometer. Likewise, all the tanks exhibit a definite nonconvective layer of similar properties, consistent. with all measurements and observations. This is confirmed by available core samples from SY-103, AW-101, AN-105, and AN-103 (see Appendix B). The crust is the only feature that differs widely among the tanks. The most important differences appear to be in the dimensions of the waste layers and the total waste volume.

The waste temperatures (except for SY-103), yield stress, and apparent viscosity are also very similar. The only significant difference in properties is a high waste density in $\mathrm{AN}-103$ and SY-101 compared with the other tanks. There is, as yet, no explanation for the differences in void fraction and gas volume. But there are subtle differences in waste appearance that may correlate with GRE behavior. The tanks with wettest waste appear to exhibit the strongest, most abrupt rollovers (e.g. AN-105, SY-103); those with dryer, stiffer waste either do not show GRE behavior or have slower, smaller ones (e.g., AN-103, AW-101, SY-103 before 1988). We are hopeful that extrusion photos from AN-104 and new ones from AN-103 cores will confirm this observation. 
Summing up all the information available leaves many questions unanswered, but some speculations are possible. AW-101's GRE behavior may be gentle simply by virtue of its shallow nonconvective layer. The dense, plastic crust is apparently a fairly effective barrier to gas release as evidenced by its long, slow releases preceded by a level rise.

The high solids density in $\mathrm{AN}-103$ may force the void fraction so high that gas percolates out before accumulating to the point of neutral buoyancy. Hence the this tank's small releases may not be buoyancy-driven partial rollovers but percolation relief events similar to what may be happening in some SSTs. Similar effects may be occurring in AW-101 if the more crystalline appearance of its waste indicates larger particles that favor formation of dendritic bubbles. On the other hand, AN-104 and AN-105 waste may be sufficiently weak, with fine particles and a low solids density, that bubbles remain spherical and true rollovers can occur.

To help resolve the issue, we recommend that a few DSTs that do not retain a significant amount of gas or periodically release it be sampled with the available instruments. This will provide an important comparison baseline for tanks that do not present a flammable gas hazard. AN-107 is already tentatively scheduled for VFI testing in FY 1997; we also recommend that AW104 be tested with the ball rheometer, VFI, and RGS, if possible.

A revision of this report should be planned for the second quarter of FY 1997 to include results from the repeat VFI and ball rheometer tests in AN-105 and any additional tanks, as recommended above. RGS data will also be available from tanks AN-103, AN-104, and AN-105 by that time for comparison with VFI results and to supply better waste gas composition data. Surface level fluctuations do not adequately correlate with gas releases from several tanks, notably $\mathrm{AN}-103$ and $\mathrm{AW}-101$. The GRE histories of several tanks can be re-evaluated using gas monitoring data; this additional information will provide a much more complete summary of flam- mable gas DSTs than is available now. 


\subsection{References}

Antoniak, ZI. 1993. Historical Trends in Tank 241-SY-101 Waste Temperatures and Levels. PNL-8880, Pacific Northwest Laboratory, Richland, Washington.

Atapattu, DD, RP Chhabra, and PHT Uhlherr. 1995. Creeping sphere motion in HerschelBulkley fluids: flow field and drag. J. Non-Newtonian Fluid Mechanics. 59, 245-265.

Allemann, RT, TM Burke, DA Reynolds and DE Simpson. 1993. Assessment of Gas Accumulation and Retention - Tank 241-SY-101. WHC-EP-0576, Westinghouse Hanford Company, Richland, Washington.

Allemann, RT, ZI Antoniak, WD Chvala, LE Efferding, JG Fadeff, JR Friley, WB Gregory, JD Hudson, JJ Irwin, NW Kirch, TE Michener, FE Panisko, CW Stewart, BM Wise. 1994. Mitigation of Tank 241-SY-101 by Pump Mixing: Results of Testing Phases A and B. PNL9423, Pacific Northwest Laboratory, Richland, Washington.

Babad, H, GD Johnson, DA Reynolds, and DM Strachan. 1992. Understanding of Cyclic Venting Phenomena in Hanford Site High-Level Waste Tanks: The Evaluation of Tank 241-SY101. WHC-SA-1364-FP, Westinghouse Hanford Company, Richland, Washington.

Brager, HR. 1994. Summary of Information on Flammable Gas Watch List Tanks. WHC-EP0711, Westinghouse Hanford Company, Richland, Washington.

Bredt, PR, and JM Tingey. 1996. The Effect of Dilution on the Gas Retention Behavior of Tank 241-SY-103 Waste. PNNL-10893, Pacific Northwest National Laboratory, Richland, Washington.

Brewster, ME, NB Gallagher, JD Hudson, and CW Stewart. 1995. The Behavior, Quantity, and Location of Undissolved Gas in Tank 241-SY-101. PNL-10681, Pacific Northwest Laboratory, Richland, Washington.

Cannon, NS, and RC Knight. 1996. Retained Gas Sampler System Acceptance Test Report. WHC-SD-WM-ATR-137, Rev. 1, Westinghouse Hanford Company, Richland, Washington.

Carlslaw, HS, and JC Jaeger. 1973. Conduction of Heat in Solids. Oxford University Press, London.

Chhabra, RP. 1993. Bubbles, Drops, and Particles in Non-Newtonian Fluids. CRC Press, Boca Raton, Florida.

Estey, SD, and MD Guthrie. 1996. An Analysis of Parameters Describing Gas Retention/Release Behavior in Double Shell Tank Waste. WHC-SD-WM-TI-755, Rev. 0, Westinghouse Hanford Company, Richland, Washington.

Gauglitz, PA, SD Rassat, PR Bredt, JH Konynenbelt, JM Tingey, and DP Mendoza. 1996. Mechanisms of Gas Bubble Retention and Release: Results for Hanford Waste Tanks 241-S-102 and 241-SY-103 and Single-Shell Tank Simulants. PNNL-11298, Pacific Northwest National Laboratory, Richland, Washington. 
Hartley, SA, KM Remund, BC Simpson, RD Cromar, and CM Anderson. 1995. Statistical Supplement to the Tank Characterization Reference Guide, WHC-SD-WM-TI-648, Rev 0, Westinghouse Hanford Company, Richland, Washington.

Herting, DL, DB Bechtold, BE Hey, BD Keele, L Jensen, and TL Welsh. 1992. Laboratory Characterization of Samples Taken in December 1991 (Window E) from Hanford Waste Tank 241SY-101. WHC-SD-WM-DTR-026, Westinghouse Hanford Company, Richland, Washington.

Hodgson, KM, RP anantamula, SA Barker, KD Fowler, JD Hopkins, JA Lechelt, and DA Reynolds. 1996. Evaluation of Hanford Tanks for Trapped Gas. WHC-SD-WM-ER-536, Rev. 1, Westinghouse Hanford Company, Richland, Washington.

Hopkins, JD. 1995. Methodology for Flammable Gas Evaluations. WHC-SD-WM-TI-724, Rev. 0, Westinghouse Hanford Company, Richland, Washington.

Johnson, G.D. 1996. Evaluation of Recommendation for Addition of Tanks to the Flammable Gas Watch List. WHC-SD-WM-ER-594, Rev. 0, Westinghouse Hanford Company, Richland, Washington.

Keenan, JH and J Kaye. 1965. Gas Tables. John Wiley \& Sons, New York.

Khan, A R and J F Richardson. 1987. The Resistance to Motion of a Solid Sphere in a Fluid. Chem. Eng. Commun., 62, 135.

Macosko, CW. 1994. Rheology Principles, Measurements, and Applications. VCH Püblishers, Inc., New York.

Moran, MJ, and HN Shapiro. 1988. Fundamentals of Engineering Thermodynamics. John Wiley and Sons, Toronto.

Palmer, BJ, CM Anderson, G Chen, JM Cuta, TA Ferryman, and G Terrones. 1996. Evaluation of the Potential for Significant Ammonia Releases from Hanford Waste Tanks. PNNL-11237, Pacific Northwest National Laboratory, Richland, Washington.

Reynolds, DA. 1993: Tank 101-SY Window E Core Sample: Interpretation of Results. WHCEP-0628, Westinghouse Hanford Company, Richland, Washington.

Reynolds, DA. 1994. Evaluation of 241 AN Tank Farm Flammable Gas Behavior. WHC-EP0717, Westinghouse Hanford Company, Richland, Washington.

SAS Institute, Inc. 1992. SAS Technical Report P.229, SAS/STAT Software: Changes and Enhancements, Release 6.07. Cary, North Carolina.

Shepard, CL, CW Stewart, JM Alzheimer, G Terrones, G Chen, and NE Wilkins. 1995. In Situ Determination of Rheological Properties and Void Fraction: Hanford Waste Tank 241-SY-103. PNL-10865, Pacific Northwest Laboratory, Richland, Washington.

Skelland, AHP. 1967. Non-Newtonian Flow and Heat Transfer. John Wiley \& Sons, New York.

Stewart, CW, JD Hudson, JR Friley, FE Panisko, ZI Antoniak, JJ Irwin, JG Fadeff, LE Efferding, TE Michener, NW Kirch, DA Reynolds. 1994. Mitigation of Tank 241-SY-101 by Pump Mixing: Results of Full-Scale Testing. PNL-9959, Pacific Northwest Laboratory, Richland, Washington. 
Stewart, CW, CL Shepard, JM Alzheimer, TI Stokes, and G Terrones. 1995. In Situ

Determination of Rheological Properties and Void Fraction in Hanford Waste Tank 241-SY-101. PNL-10682, Pacific Northwest Laboratory, Richland, Washington.

Sullivan, HL. 1995. A Safety Assessment for Proposed Pump Mixing Operations to Mitigate Episodic Gas Releases in Tank 241-SY-101: Hanford Site, Richland, Washington. LA-UR-923196 Rev. 14, Los Alamos National Laboratory, Los Alamos, New Mexico.

Whitney, PD. 1995. Screening the Hanford Tanks for Trapped Gas. PNL-10821, Pacific Northwest Laboratory, Richland, Washington.

Wilkins, NE. 1995. Tank 241-SY-103 Core Sample: Interpretation of Results. WHC-SD-WMTI-712. Westinghouse Hanford Company, Richland, Washington. 


\section{Appendix A}

Gas Release Histories 


\section{Appendix A}

\section{Gas Release Histories}

This appendix describes the historical gas releases in the six tanks studied in this report as observed in the waste level history. A gas release is indicated by a sharp drop of over at least 0.75 $\mathrm{cm}$, which is essentially the limit of detection, or a sharp rise immediately followed by a sudden drop. The release volume is computed based on the total level drop over the first 24 hours following the initial drop. Even though the level may continue to drop for several days, the total gas release correlates best with the first day's drop. Each subsection to follow contains a plot of the waste level history and a table listing each GRE with the level before and after, gas release, release fraction and time since the last event.

Detecting gas release by level changes is very unsatisfactory in tanks where the gas releases are small. This is particularly true of AW-101 and AN-103. In AW-101, comparing gas monitoring data to level drops reveals that many GREs occur without a level drop. Many show a level rise followed by a slow drop that would not normally identify a release. Since gas monitoring equipment has been installed in many tanks since 1994, it will soon be possible to redefine these tanks' GRE statistics with actual gas release data. 


\section{A.1 SY-101 Gas Release History}

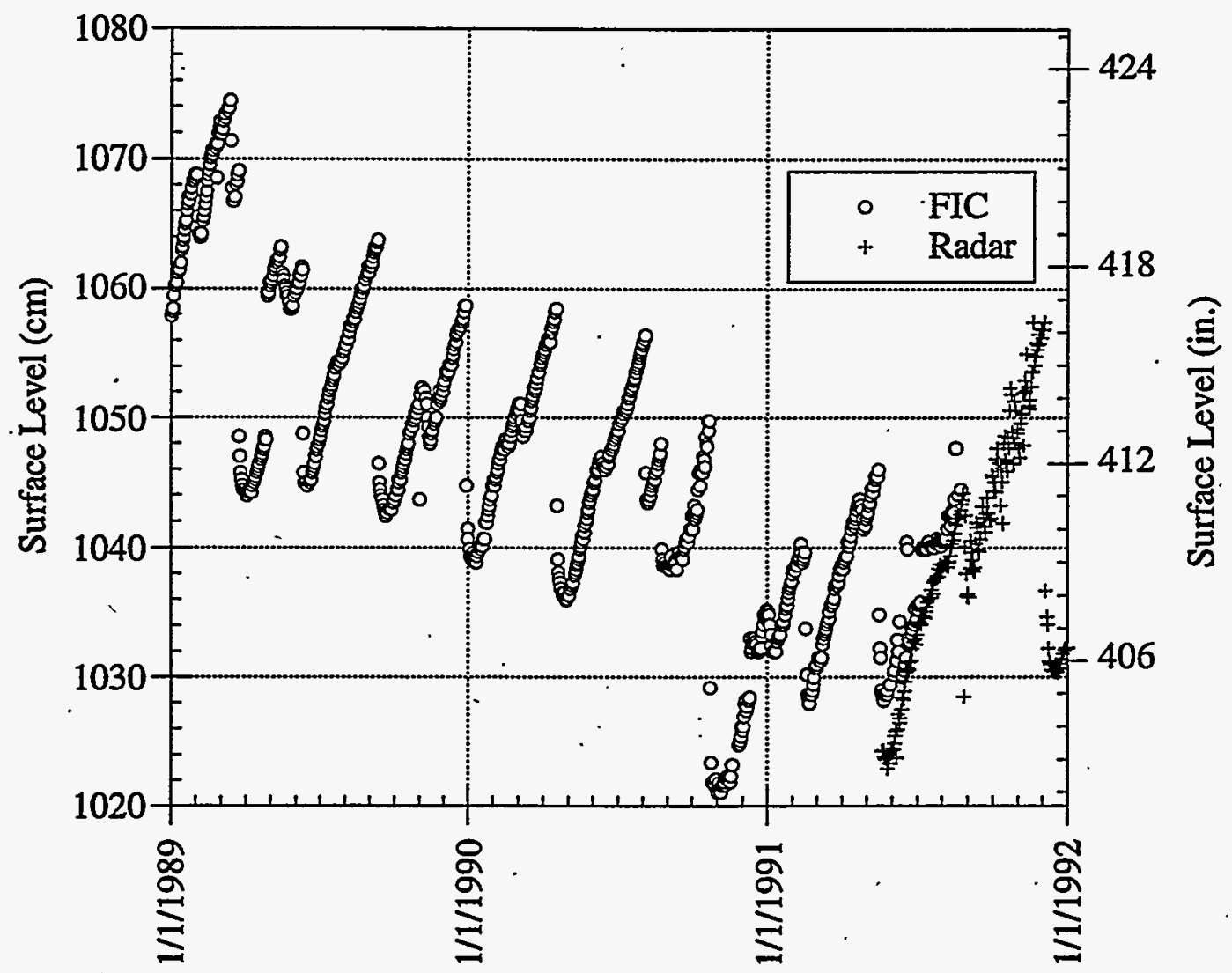

Figure A.1. SY-101 Waste Level History: January 1989 to January 1992 
Table A.1. SY-101 GRE History

\begin{tabular}{|c|c|c|c|c|c|c|c|c|}
\hline \multirow[b]{2}{*}{ Event } & \multirow[b]{2}{*}{ Date } & \multicolumn{3}{|c|}{ Level $(\mathrm{cm})$} & \multicolumn{3}{|c|}{ Standard Volume $\left(\mathrm{m}^{3}\right)$} & \multirow{2}{*}{$\begin{array}{l}\text { Period } \\
\text { (days) }\end{array}$} \\
\hline & & Before & After & Drop & Release & Before & Fraction & \\
\hline & $03 / 25 / 89$ & 1074.9 & 1054.3 & 20.6 & 186.3 & 586.4 & 0.318 & 0 \\
\hline & $06 / 10 / 89$ & 1062.7 & 1050.0 & 12.7 & 115.0 & 476.3 & 0.242 & 77 \\
\hline & $09 / 12 / 89$ & 1063.5 & 1046.2 & 17.3 & 156.2 & 483.1 & 0.323 & 94 \\
\hline & $12 / 30 / 89$ & 1057.9 & 1044.7 & 13.2 & 119.3 & 432.7 & 0.276 & 109 \\
\hline & $04 / 19 / 90$ & 1057.9 & 1038.9 & 19.0 & 171.7 & 432.7 & 0.397 & 110 \\
\hline & $08 / 05 / 90$ & 1056.6 & 1048.0 & 8.6 & 78.0 & 421.2 & 0.185 & 108 \\
\hline A & $10 / 24 / 90$ & 1050.3 & 1036.1 & 14.2 & 128.1 & 363.9 & 0.352 & 80 \\
\hline B & $02 / 16 / 91$ & 1039.1 & 1033.3 & 5.8 & 52.5 & 262.9 & 0.200 & 115 \\
\hline C & $05 / 16 / 91$ & 1046.5 & 1037.9 & 8.6 & 77.5 & 329.5 & 0.235 & 89 \\
\hline D & $08 / 27 / 91$ & 1049.0 & 1035.1 & 14.0 & 126.2 & 352.4 & 0.358 & 103 \\
\hline $\mathrm{E}$ & $12 / 04 / 91$ & 1057.4 & 1036.7 & 20.7 & 187.0 & 428.1 & 0.437 & 99 \\
\hline$\vec{F}$ & $04 / 20 / 92$ & 1051.6 & 1044.5 & 7.1 & 63.8 & 375.3 & 0.170 & 138 \\
\hline G & $09 / 03 / 92$ & 1043.6 & 1021.1 & 22.5 & 203.2 & 303.4 & 0.670 & 136 \\
\hline $\mathrm{H}$ & $02 / 02 / 93$ & 1044.7 & 1029.0 & 15.7 & 141.8 & 313.4 & 0.452 & 152 \\
\hline & $06 / 26 / 93$ & 1048.5 & 1030.9 & 17.6 & 159.1 & 347.8 & 0.457 & 144 \\
\hline & & & Avg. & $\begin{array}{l}14.5 \\
52\end{array}$ & $\begin{array}{l}131.0 \\
47.3\end{array}$ & $\begin{array}{l}393.9 \\
83.6\end{array}$ & $\begin{array}{l}0.338 \\
0.133\end{array}$ & $\begin{array}{c}104 \\
37\end{array}$ \\
\hline
\end{tabular}




\section{A.2 SY-103 Gas Release History}

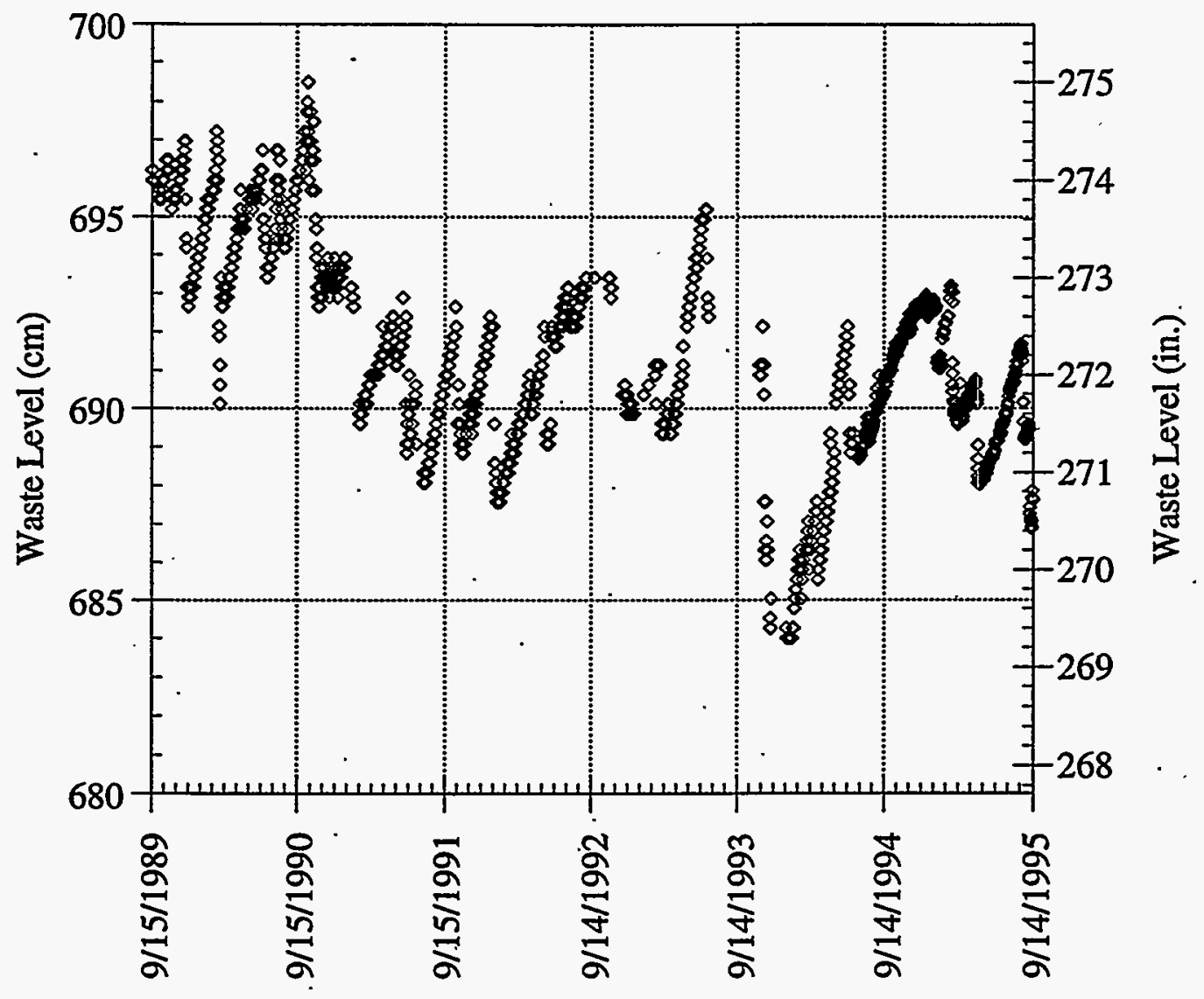

Figure A.2. SY-103 Waste Level History: October 1989 to October 1995 
Table A.2. Summary of GREs in SY-103

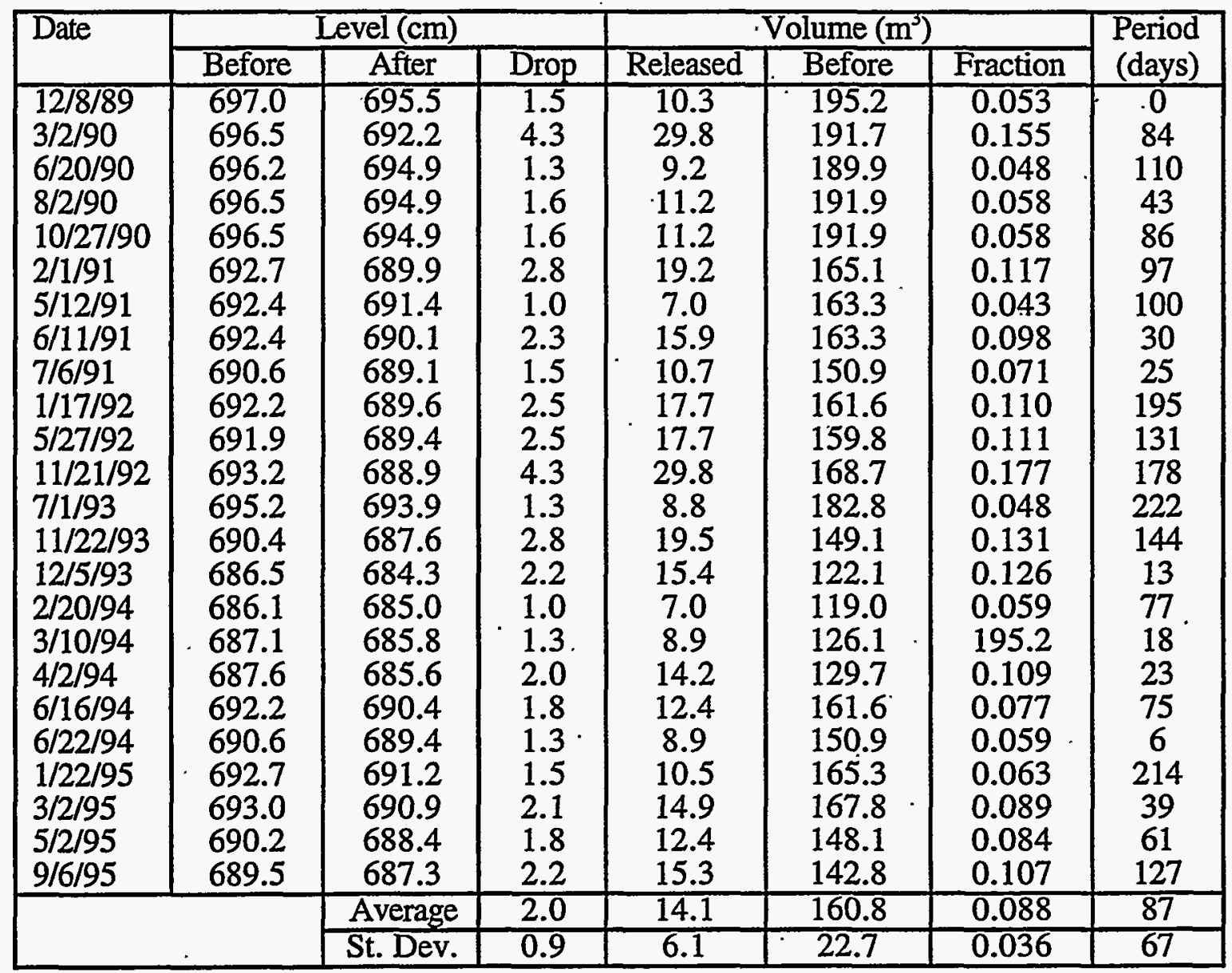




\section{A.3 AW-101 Gas Release History}



Figure A.3. Waste Level History (MT and FIC), 1986-1995 
Table A.3. AW-101 GRE History

\begin{tabular}{|c|c|c|c|c|c|c|c|}
\hline \multirow[t]{2}{*}{ Date } & \multicolumn{3}{|c|}{ Level (cm) } & \multicolumn{3}{|c|}{ Standard Volume $\left(\mathrm{m}^{3}\right)$} & \multirow{2}{*}{$\begin{array}{l}\text { Period } \\
\text { (days) }\end{array}$} \\
\hline & Before & After. & Drop & Released & Before & Fraction & \\
\hline $11 / 17 / 86$ & 1036.32 & 1034.5 & 1.8 & 15.9 & $\overline{81.5}$ & 0.195 & 0 \\
\hline $4 / 20 / 87$ & 1037.6 & 1034.5 & 3.1 & 27.1 & 92.7 & 0.292 & 154 \\
\hline $8 / 3 / 87$ & 1036.1 & 1034.8 & 1.3 & 11.4 & 79.6 & 0.143 & 105 \\
\hline $9 / 7 / 87$ & 1036.1 & 1034.3 & 1.8 & 15.7 & 79.6 & 0.198 & 35 \\
\hline $9 / 12 / 88$ & 1037.6 & 1032.5 & 5.1 & 44.6 & 92.7 & 0.481 & 371 \\
\hline $1 / 9 / 89$ & 1035.3 & 1033.8 & 1.5 & 13.1 & 72.6 & 0.181 & 119 \\
\hline $3 / 20 / 89$ & 1035.1 & 1034.3 & 0.8 & 7.0 & 70.8 & 0.099 & 70 \\
\hline $8 / 4 / 89$ & 1037.1 & 1036.3 & 0.8 & 7.0 & 88.3 & 0.079 & 137 \\
\hline $1 / 17 / 90$ & 1038.8 & 1036.6 & 2.3 & 19.8 & 103.7 & 0.191 & 166 \\
\hline $2 / 28 / 90$ & 1035.3 & 1034.0 & 1.3 & 11.4 & 72.6 & 0.157 & 42 \\
\hline $5 / 3 / 91$ & 1035.1 & 1033.3 & 1.8 & 15.7 & 70.8 & 0.222 & 429 \\
\hline $9 / 10 / 91$ & 1038.9 & 1038.1 & 0.8 & 7.0 & 104.0 & 0.067 & 130 \\
\hline $11 / 3 / 91$ & 1039.4 & 1038.6 & 0.8 & 7.0 & 108.4 & 0.065 & 54 \\
\hline $3 / 21 / 92$ & 1039.4 & 1037.3 & 2.1 & 18.4 & 108.4 & 0.169 & 139 \\
\hline $4 / 10 / 94$ & 1038.6 & 1037.8 & 0.8 & 7.0 & 101.4 & 0.069 & 750 \\
\hline $10 / 4 / 94$ & 1040.4 & 1039.0 & 1.4 & 12.2 & 117.2 & 0.104 & 177 \\
\hline $12 / 22 / 94$ & 1038.4 & 1037.8 & 0.6 & 5.2 & 99.7 & 0.053 & 79 \\
\hline & & Average & 1.7 & 14.4 & 90.8 & 0.163 & 174 \\
\hline & & St. Dev. & 1.1 & 9.7 & 15.1 & 0.106 & $\overline{185}$ \\
\hline
\end{tabular}




\section{A.4 AN-103 Gas Release History}

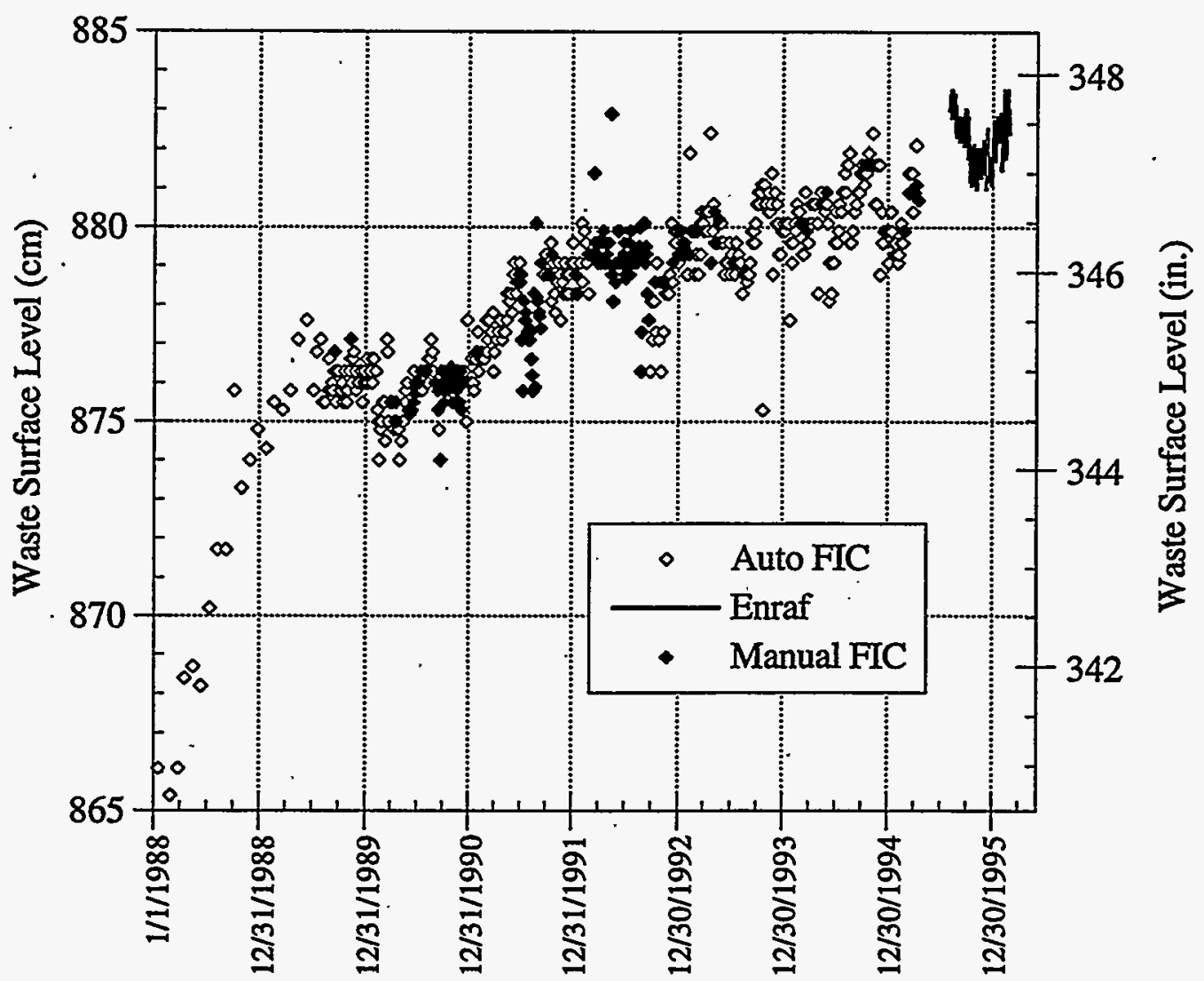

Figure A.4. AN-103 Waste Level History: January 1988 to January 1996 
Table A.4. AN-103 GRE History

\begin{tabular}{|c|c|c|c|c|c|c|c|}
\hline \multirow[t]{2}{*}{ Date } & \multicolumn{3}{|c|}{ Level (cm) } & \multicolumn{3}{|c|}{ Standard Volume $\left(\mathrm{m}^{3}\right)$} & \multirow{2}{*}{$\begin{array}{l}\text { Period } \\
\text { (days) }\end{array}$} \\
\hline & Before & After & $\overline{\text { Drop }}$ & Released & Before & Fraction & \\
\hline $6 / 1 / 89$ & 877.1 & 876.0 & 1.1 & 8.7 & 308.1 & 0.028 & $\mathbf{0}$ \\
\hline $8 / 4 / 89$ & 877.3 & 876.3 & 1.0 & 7.9 & 309.7 & 0.025 & 64 \\
\hline $2 / 11 / 90$ & 876.3 & 874.8 & 1.5 & 11.8 & 301.8 & 0.039 & 191 \\
\hline $2 / 18 / 90$ & 875.0 & 874.0 & 1.0 & 7.9 & 291.6 & 0.027 & 7 \\
\hline $9 / 26 / 90$ & 878.6 & 877.1 & 1.5 & 11.8 & 319.9 & 0.037 & 220 \\
\hline 7/6/91 & 878.8 & 877.1 & 1.7 & 13.4 & 321.5 & 0.042 & 283 \\
\hline $8 / 24 / 91$ & 878.3 & 875.9 & 2.4 & 18.9 & 317.6 & 0.060 & 49 \\
\hline 9/14/91 & 880.4 & 879.1 & 1.3 & 10.2 & 334.1 & 0.031 & 21 \\
\hline $8 / 25 / 92$ & 878.8 & 876.3 & 2.5 & 19.7 & 321.5 & 0.061 & 346 \\
\hline $9 / 25 / 92$ & 878.3 & 876.3 & 2.0 & 15.8 & 317.6 & 0.050 & 31 \\
\hline $10 / 23 / 92$ & 879.1 & 876.3 & 2.8 & 22.1 & 323.9 & 0.068 & 28 \\
\hline $11 / 23 / 92$ & 879.6 & 878.1 & 1.5 & 11.8 & 327.8 & 0.036 & 31 \\
\hline $2 / 10 / 93$ & 881.6 & 880.1 & 1.5 & 11.8 & 343.6 & 0.034 & 79 \\
\hline $11 / 15 / 93$ & 880.4 & 878.3 & 2.1 & 16.5 & 334.1 & 0.050 & 278 \\
\hline $11 / 23 / 93$ & 881.4 & 878.6 & 2.8 & 22.1 & 342.0 & 0.065 & 8 \\
\hline $8 / 20 / 94$ & 882.1 & 879.9 & 2.2 & 17.3 & 347.5 & 0.050 & 270 \\
\hline $12 / 4 / 94$ & 880.6 & 878.8 & 1.8 & 14.2 & 335.7 & 0.042 & 106 \\
\hline $8 / 17 / 95$ & 882.9 & 881.7 & 1.2 & 9.5 & 353.8 & 0.027 & 256 \\
\hline $2 / 10 / 96$ & 883.5 & 881.8 & 1.7 & 13.4 & 358.6 & 0.037 & 177 \\
\hline & & Average & 1.8 & 13.9 & 326.9 & 0.043 & 129 \\
\hline & & St. Dev. & 0.6 & 4.5 & 17.7 & 0.013 & 117 \\
\hline
\end{tabular}




\section{A.5 AN-104 Gas Release History}

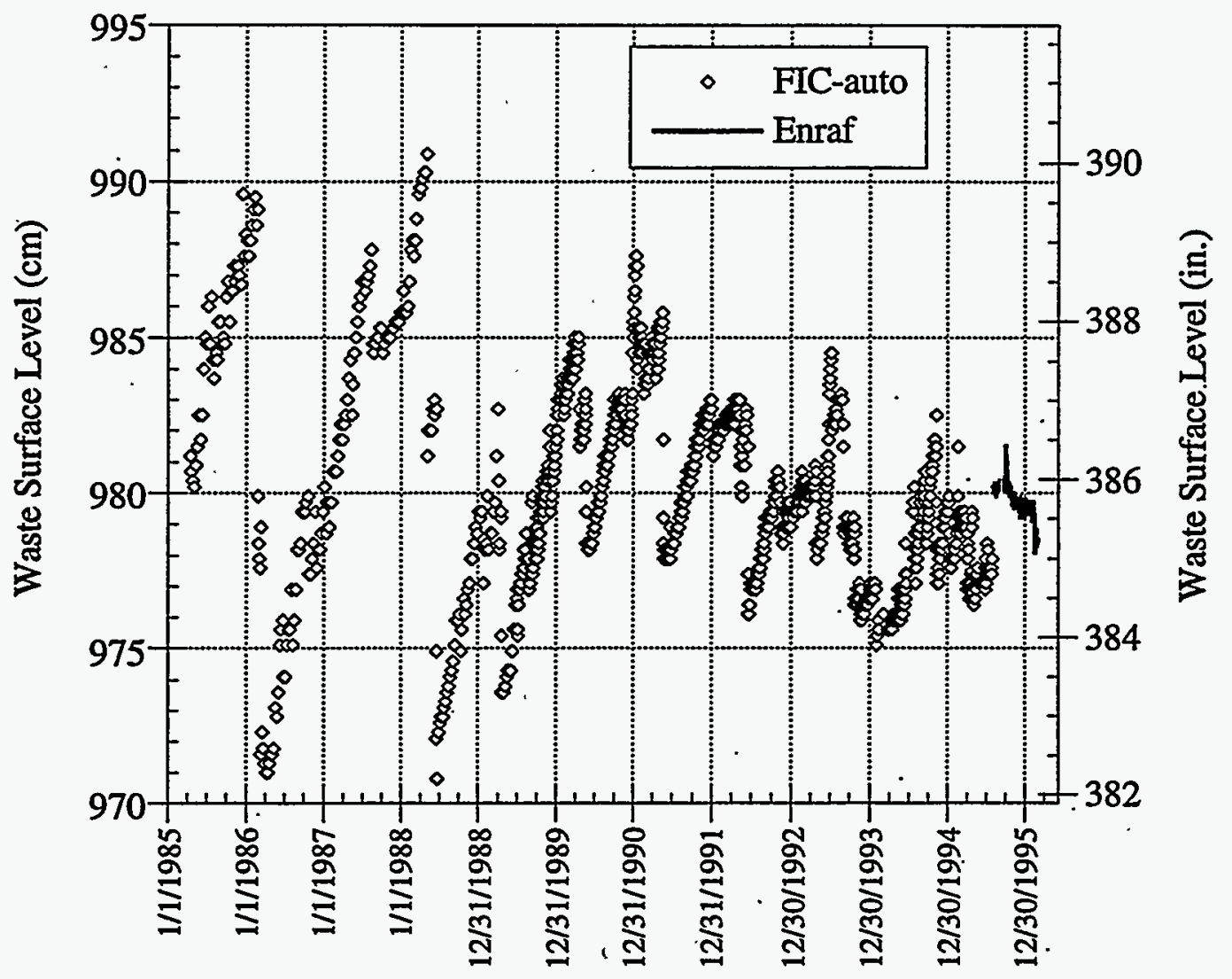

Figure A.5. AN-104 Waste Level History: January 1985 to January 1996 
Table A.5. AN-104 GRE History

\begin{tabular}{|l|c|c|c|c|c|c|c|}
\hline \multirow{2}{*}{ Date } & \multicolumn{3}{|c|}{ Level (cm) } & \multicolumn{3}{c|}{ Standard Volume (m) } & Period \\
\cline { 2 - 7 } & Before & After & Drop & Released & Before & Fraction & (days) \\
\hline $2 / 27 / 86$ & 989.1 & 979.9 & 9.2 & 75.1 & 278.5 & 0.270 & 0 \\
$3 / 13 / 86$ & 978.9 & 971.6 & 7.3 & 59.6 & 195.2 & 0.305 & 14 \\
$10 / 27 / 86$ & 979.9 & 977.4 & 2.5 & 20.4 & 203.4 & 0.100 & 228 \\
$8 / 17 / 87$ & 987.8 & 984.8 & 3.0 & 24.5 & 267.9 & 0.091 & 294 \\
$6 / 17 / 88$ & 982.7 & 974.9 & 7.8 & 63.7 & 226.2 & 0.282 & 305 \\
$4 / 19 / 89$ & 979.4 & 975.4 & 4.0 & 32.7 & 199.3 & 0.164 & 306 \\
$11 / 1 / 89$ & 980.4 & 979.2 & 1.2 & 9.8 & 207.5 & 0.047 & 196 \\
$12 / 4 / 89$ & 982.0 & 979.7 & 2.3 & 18.8 & 220.5 & 0.085 & 33 \\
$1 / 31 / 90$ & 983.7 & 982.5 & 1.2 & 9.8 & 234.4 & 0.042 & 58 \\
$4 / 16 / 90$ & 985.0 & 982.7 & 2.3 & 18.8 & 245.0 & 0.077 & 75 \\
$5 / 20 / 90$ & 982.7 & 980.2 & 2.5 & 20.4 & 226.2 & 0.090 & 34 \\
$1 / 18 / 91$ & 987.3 & 984.3 & 3.0 & 24.5 & 263.8 & 0.093 & 243 \\
$2 / 17 / 91$ & 984.8 & 983.2 & 1.6 & 13.1 & 243.4 & 0.054 & 30 \\
$5 / 20 / 91$ & 985.8 & 981.7 & 4.1 & 33.5 & 251.6 & 0.133 & 92 \\
$5 / 21 / 91$ & 981.7 & 979.2 & 2.5 & 20.4 & 218.1 & 0.094 & 1 \\
$1 / 3 / 92$ & 983.0 & 981.7 & 1.3 & 10.6 & 228.7 & 0.046 & 227 \\
$5 / 12 / 92$ & 983.0 & 981.2 & 1.8 & 14.7 & 228.7 & 0.064 & 130 \\
$6 / 18 / 92$ & 981.5 & 977.4 & 4.1 & 33.5 & 216.4 & 0.155 & 37 \\
$4 / 27 / 93$ & 979.9 & 977.9 & 2.0 & 16.3 & 203.4 & 0.080 & 313 \\
$7 / 9 / 93$ & 984.5 & 982.0 & 2.5 & 20.4 & 240.9 & 0.085 & 73 \\
$8 / 31 / 93$ & 981.5 & 978.9 & 2.6 & 21.2 & 216.4 & 0.098 & 53 \\
$10 / 24 / 93$ & 978.9 & 976.6 & 2.3 & 18.8 & 195.2 & 0.096 & 54 \\
$2 / 1 / 94$ & 976.9 & 975.5 & 1.4 & 11.4 & 178.9 & 0.064 & 100 \\
$7 / 25 / 94$ & 980.2 & 977.9 & 2.3 & 18.8 & 205.8 & 0.091 & 174. \\
$9 / 19 / 94$ & 980.7 & 978.4 & 2.3 & 18.8 & 209.9 & 0.089 & 56 \\
$11 / 7 / 94$ & 982.5 & 979.7 & 2.8 & 22.9 & 224.6 & 0.102 & 49 \\
$11 / 9 / 94$ & 979.7 & 978.2 & 1.5 & 12.3 & 201.7 & 0.061 & 2 \\
$2 / 17 / 95$ & 981.5 & 979.9 & 1.6 & 13.1 & 216.4 & 0.060 & 100 \\
$3 / 31 / 95$ & 979.2 & 976.9 & 2.3 & 18.8 & 197.7 & 0.095 & 42 \\
$10 / 2 / 95$ & 981.5 & 979.2 & 2.3 & 18.8 & 216.4 & 0.087 & 185 \\
$10 / 8 / 95$ & 981 & 979.6 & 1.4 & 11.4 & 212.4 & 0.054 & 6 \\
$2 / 14 / 96$ & 979.3 & 978.1 & 1.2 & 9.8 & 198.5 & 0.049 & 129 \\
$5 / 4 / 96$ & 978.7 & 977.2 & 1.5 & 12.3 & 193.6 & 0.063 & 80 \\
\hline & & Average & 2.8 & 22.7 & 220.2 & 0.102 & 113 \\
\cline { 3 - 7 } & St. Dev. & 1.9 & 15.5 & 23.2 & 0.065 & 100 \\
\hline
\end{tabular}




\section{A.6 AN-105 Gas Release History}

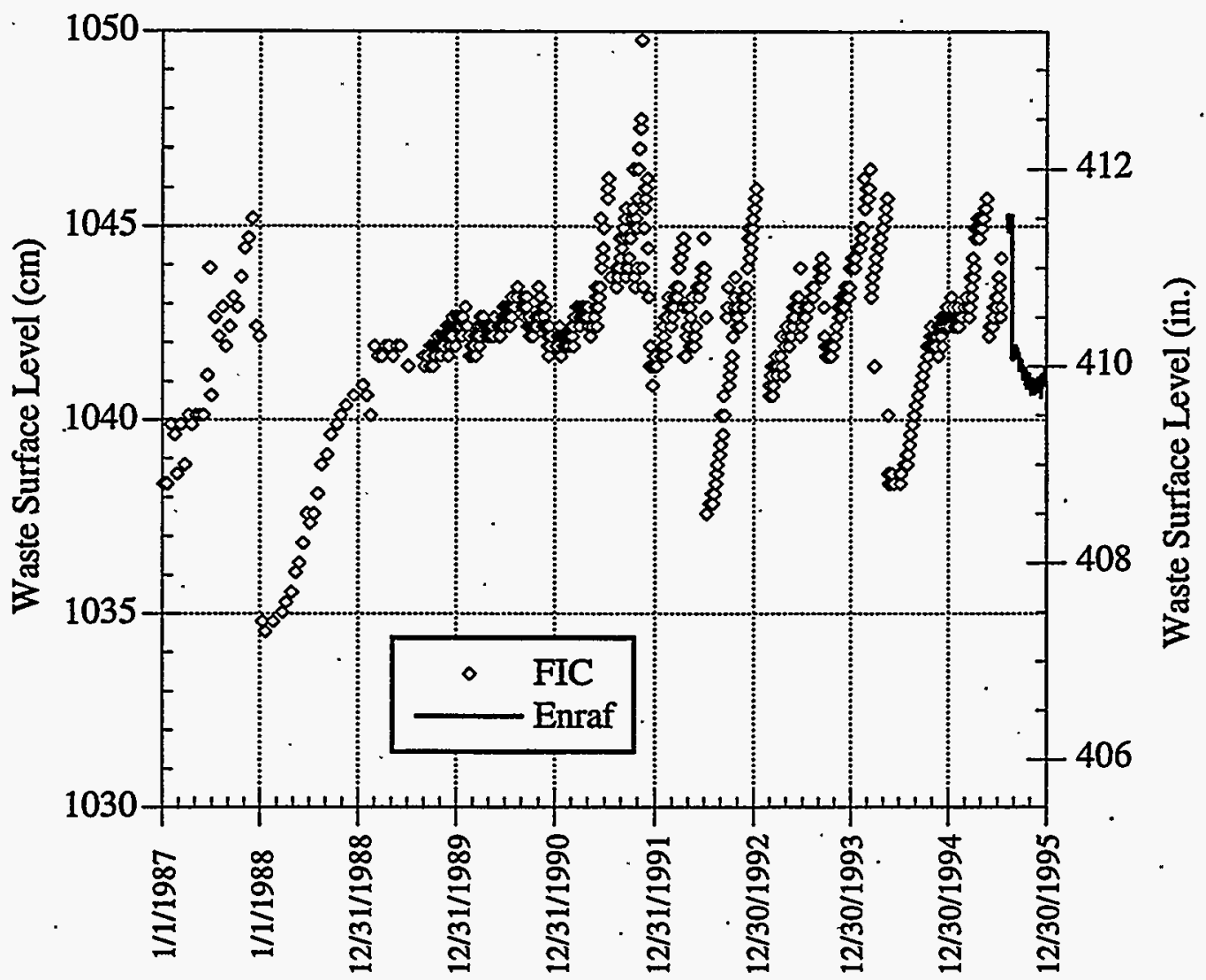

Figure A.6. AN-105 Waste Level History: January 1987 to January 1996 
Table A.6. AN-105 GRE History

\begin{tabular}{|c|c|c|c|c|c|c|c|}
\hline \multirow[b]{2}{*}{ Date } & \multicolumn{3}{|c|}{ Level $(\mathrm{cm})$} & \multicolumn{3}{|c|}{ Standard Volume $\left(\mathrm{m}^{3}\right)$} & \multirow{2}{*}{$\begin{array}{l}\text { Period } \\
\text { (days) }\end{array}$} \\
\hline & Before & After & Drop & Released & Before & Fraction & \\
\hline $5 / 20 / 85$ & 1036.8 & 1034.5 & 2.3 & 19.6 & 109.3 & 0.180 & \\
\hline $12 / 2 / 85$ & 1036.8 & 1033.8 & 3.0 & 25.6 & 109.3 & 0.234 & 196 \\
\hline $8 / 11 / 86$ & 1041.9 & 1035.8 & 6.1 & 52.1 & 152.8 & 0.341 & 252 \\
\hline $1 / 5 / 87$ & 1040.9 & 1038.4 & 2.5 & 21.3 & 144.3 & 0.148 & 147 \\
\hline $2 / 24 / 87$ & 1041.1 & 1038.6 & 2.5 & 21.3 & 146.0 & 0.146 & 50 \\
\hline $8 / 17 / 87$ & 1042.9 & 1041.1 & 1.8 & 15.4 & 161.3 & 0.095 & 174 \\
\hline $12 / 7 / 87$ & 1045.2 & 1041.9 & 3.3 & 28.2 & 181.0 & 0.156 & 112 \\
\hline $1 / 4 / 88$ & 1042.2 & 1038.4 & 3.8 & 32.4 & 155.4 & 0.209 & 28 \\
\hline $1 / 8 / 88$ & 1038.4 & 1034.8 & 3.6 & 30.8 & 122.9 & 0.250 & 4 \\
\hline 7/19/91 & 1047.2 & 1043.7 & 3.5 & 29.9 & 198.1 & 0.151 & 1288 \\
\hline $9 / 17 / 91$ & 1045.5 & 1043.7 & 1.8 & 15.4 & 183.5 & 0.084 & 60 \\
\hline $11 / 15 / 91$ & 1049.8 & 1043.9 & 5.9 & 50.4 & 220.3 & 0.229 & 59 \\
\hline $12 / 6 / 91$ & 1046.2 & 1044.4 & 1.8 & 15.4 & 189.5 & 0.081 & 21 \\
\hline $4 / 14 / 92$ & 1044.7 & 1042.9 & 1.8 & 15.4 & 176.7 & 0.087 & 130 \\
\hline $7 / 6 / 92$ & 1042.7 & 1038.1 & 4.6 & 39.3 & 159.6 & 0.246 & 83 \\
\hline $9 / 27 / 92$ & 1043.4 & 1040.9 & 2.5 & 21.3 & 165.6 & 0.129 & 83 \\
\hline $1 / 23 / 93$ & 1046.0 & 1043.7 & 2.3 & 19.6 & 187.8 & 0.105 & 118 \\
\hline $9 / 19 / 93$ & 1046.0 & 1042.9 & 3.1 & 26.5 & 187.8 & 0.141 & 239 \\
\hline $5 / 17 / 94$ & 1045.7 & 1042.9 & 2.8 & 24.1 & 185.4 & 0.130 & 240 \\
\hline $8 / 24 / 95$ & 1045.2 & 1041.6 & 3.6 & 30.8 & 181.1 & 0.170 & 464 \\
\hline $5 / 31 / 96$ & 1044.8 & 1043.1 & 1.7 & 14.7 & 177.6 & 0.083 & 281 \\
\hline & & Average & 3.1 & 26.2 & 166.4 & 0.162 & 162 \\
\hline & & & 1.3 & 10.7 & $\overline{28.6}$ & 0.069 & 132 \\
\hline
\end{tabular}




\section{Appendix B}

\section{Core Extrusion Photographs}


AN-103 Core, Extruded 1988.

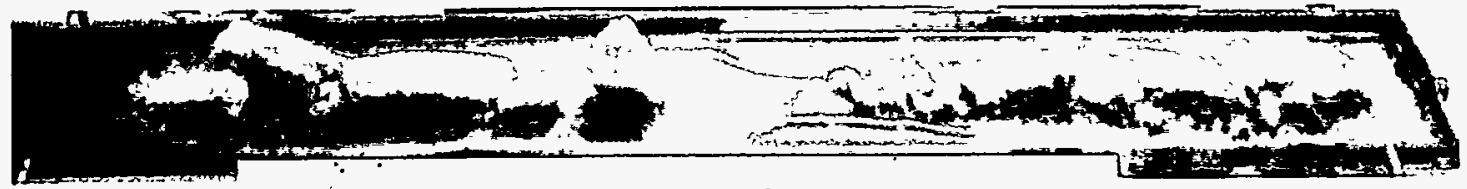

Segment 11 elevation $338-386 \mathrm{~cm}$ (133-152 inches)

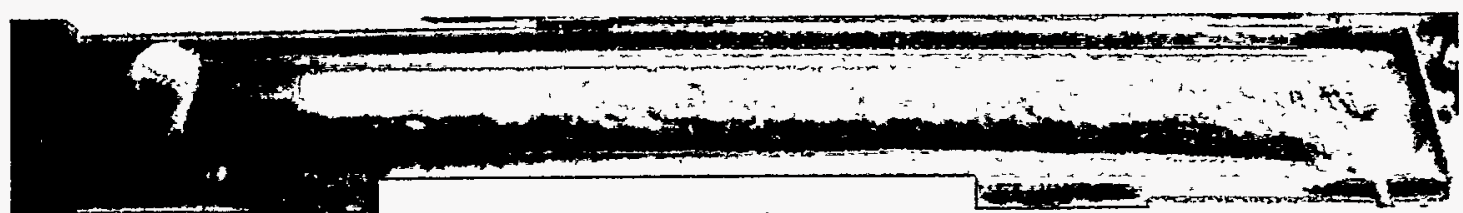

Segment 12 elevation $290-338 \mathrm{~cm}$ (114-133 inches)



Segment 13 elevation $241-290 \mathrm{~cm}$ (95-114 inches)

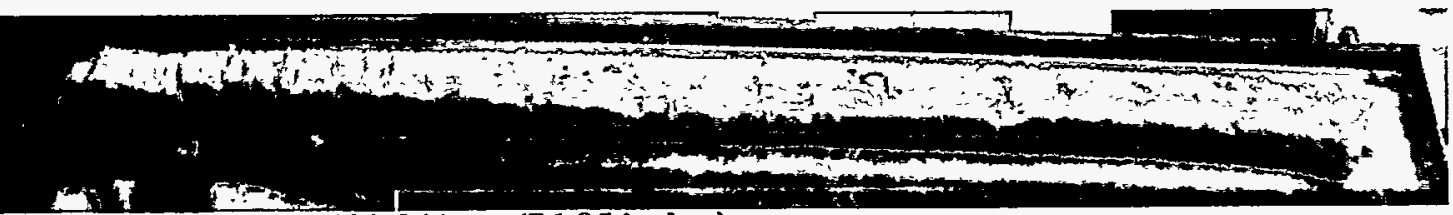

Segment 14 elevation 193-241 cm (76-95 inches)

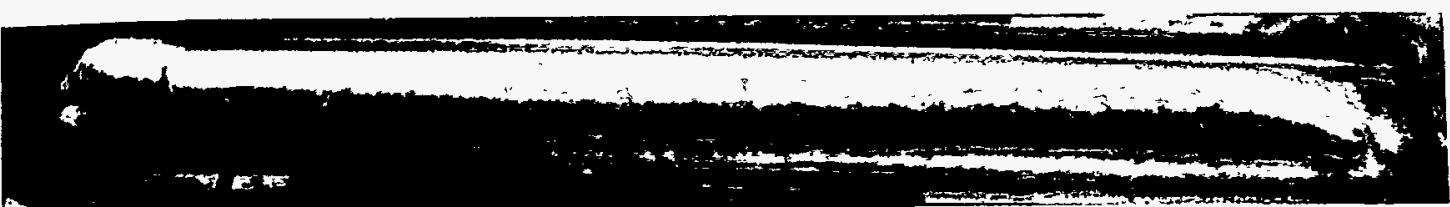

Segment 15 elevation $145-193 \mathrm{~cm}$ (57-76 inches)

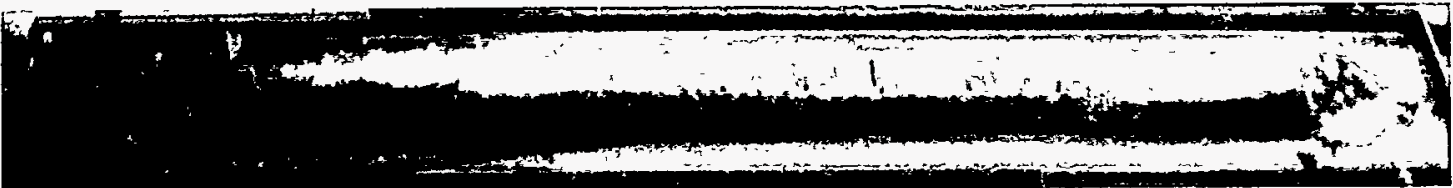

Segment 16 elevation $96-145 \mathrm{~cm}$ (38-57 inches)



Segment 18 elevation $0-48 \mathrm{~cm}(0-19$ inches)

Figure B.1. Core samples from AN-103

B.1 


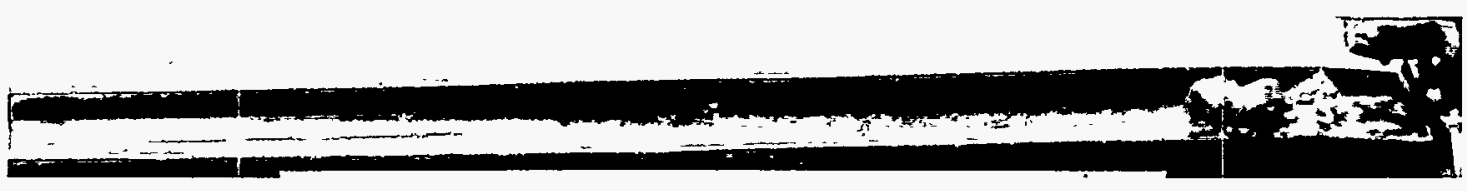

Segment 1 elevation 1013-1041 cm (399-410 inches).

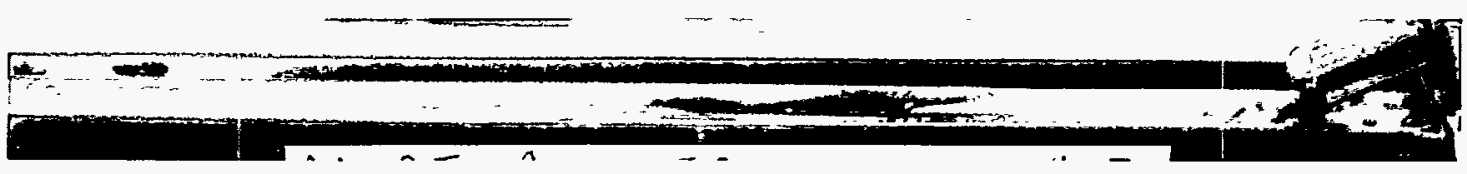

Segment 5 elevation $820-869 \mathrm{~cm}$ (323-342 inches).

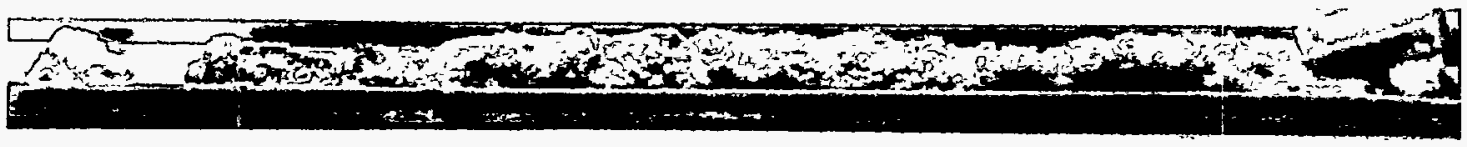

Segment 16 elevation $290-338 \mathrm{~cm}$ (114-133 inches).

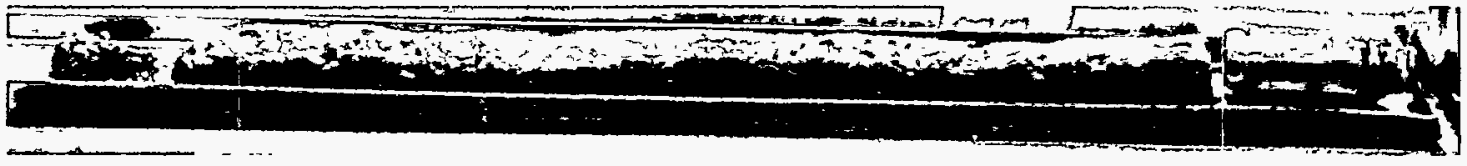

Segment 18 elevation 193-241 cm (76-95 inches).

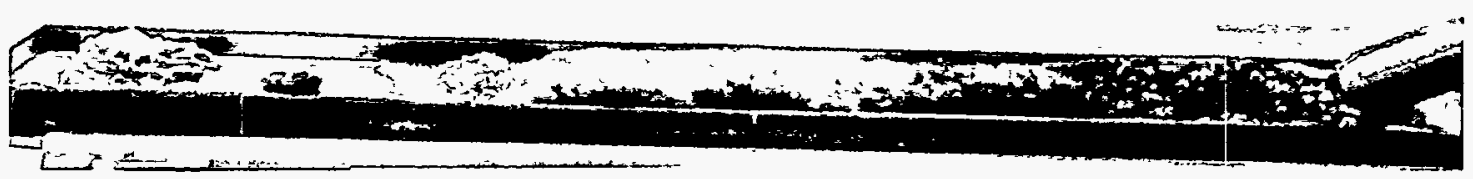

Segment 20 elevation $96-145 \mathrm{~cm}$ (38-57 inches).



Segment 22 elevation $0-48 \mathrm{~cm}$ (0-19 inches).

Figure B.2. Core samples from AN-105. 
AW-101, Core 132, Extruded April 1996.

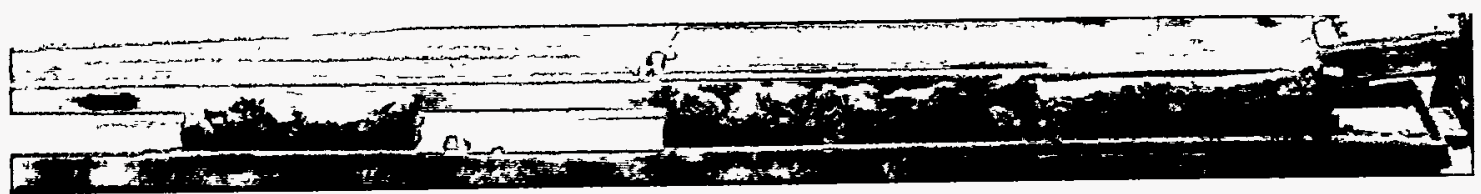

Segment 1 elevation 1013-1040 cm (399-409 inches).

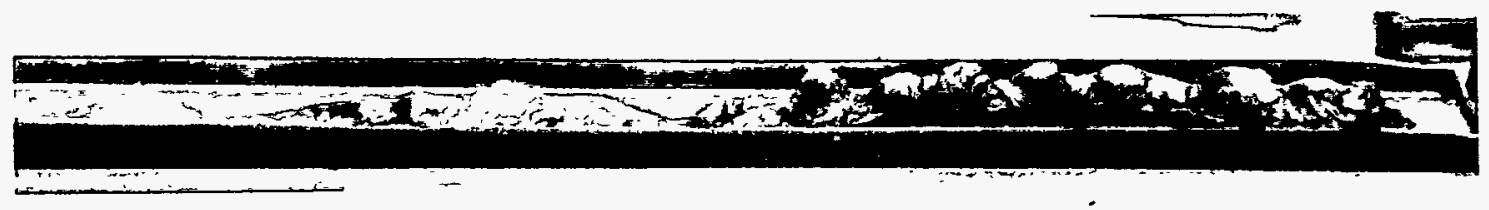

Segment 2 elevation 965-1013 cm (380-399 inches).

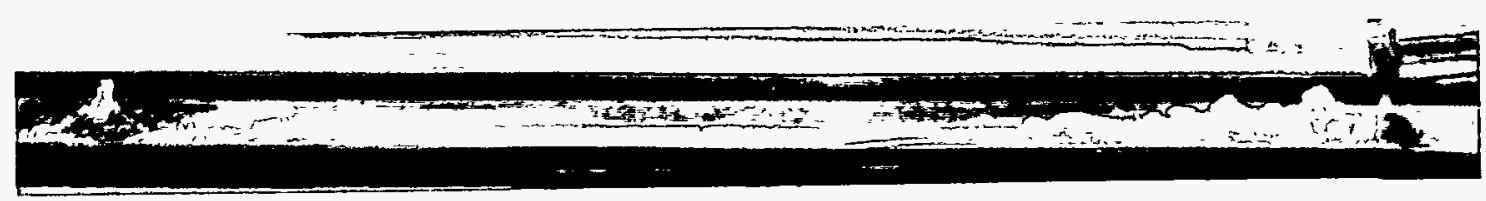

Segment 16 elevation $290-338 \mathrm{~cm}$ (114-133 inches).

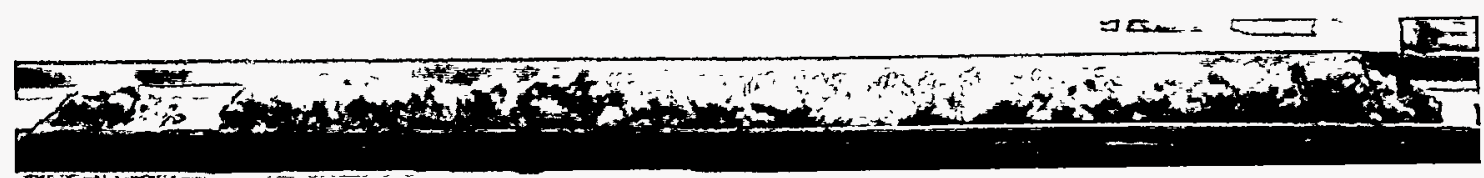

Segment 18 elevation 193-241 cm (76-95 inches).

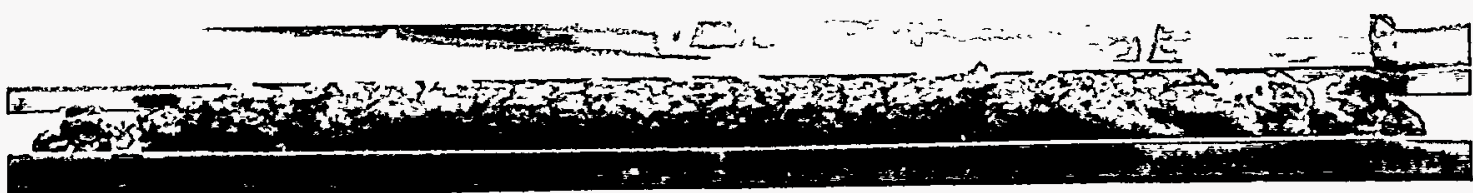

Segment 20 elevation 96-145 cm (38-57 inches).

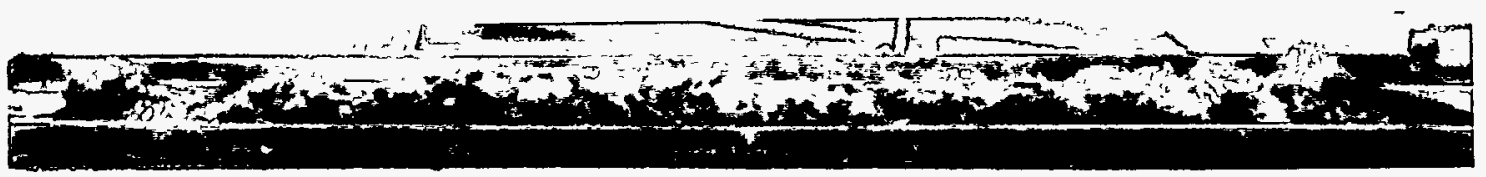

Segment 22 elevation $0-48 \mathrm{~cm}$ (0-19 inches).

Figure B.3. Core samples from AW-101. 
SY-103, Core 1, Extruded 1986.

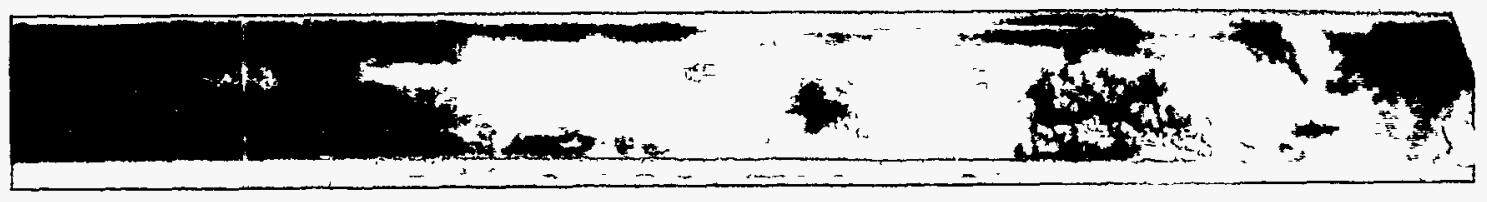

Segment 2 elevation 531-579 cm (209-228 inches).

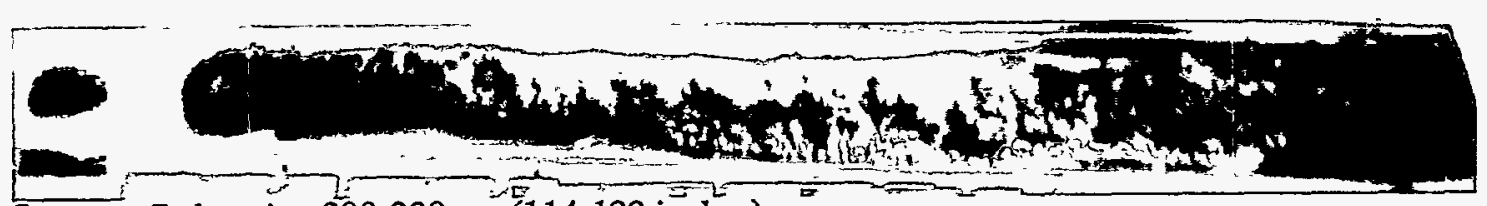

Segment 7 elevation 290-338 cm (114-133 inches).



Segment 10 elevation $145-193 \mathrm{~cm}$ (57-76 inches).

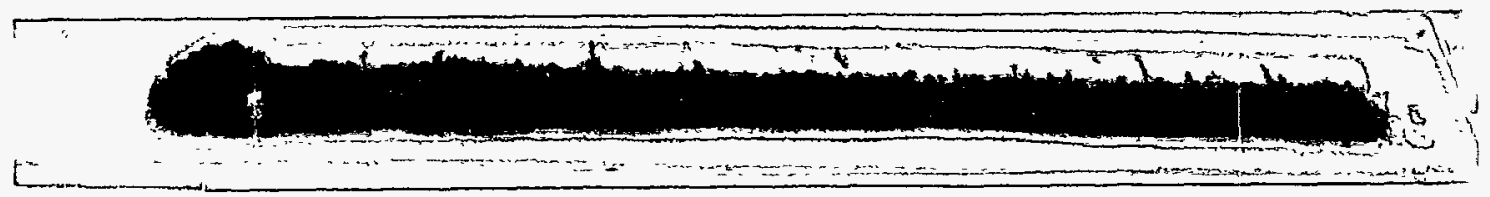

Segment 12 elevation $48-96 \mathrm{~cm}$ (19-38 inches).

Figure B.4. Core samples from SY-103. 
SY-103, Core 62, Extruded September 1994.

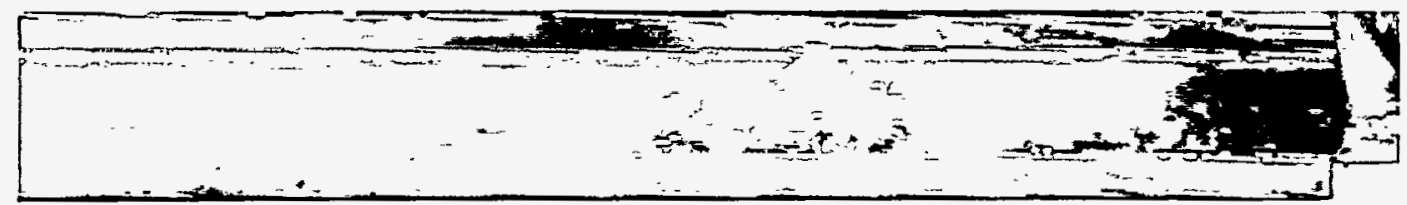

Segment 4 elevation $531-579 \mathrm{~cm}$ (209-228 inches).



Segment 9 elevation 290-338 cm (114-133 inches).



Segment 10 elevation $241-289 \mathrm{~cm}$ (95-114 inches).



Segment 11 elevation 193-241 cm (76-95 inches).

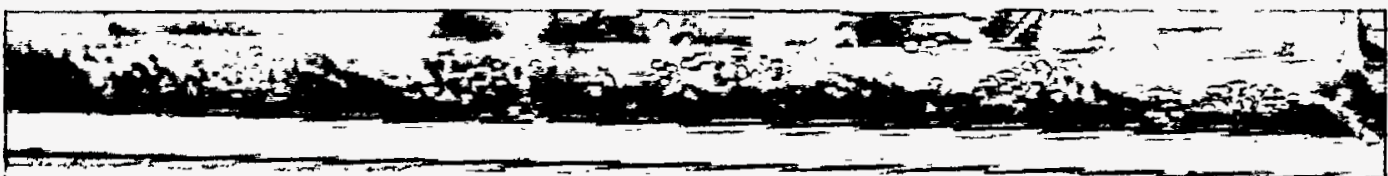

Segment 12 elevation $145-193 \mathrm{~cm}$ (57-76 inches).

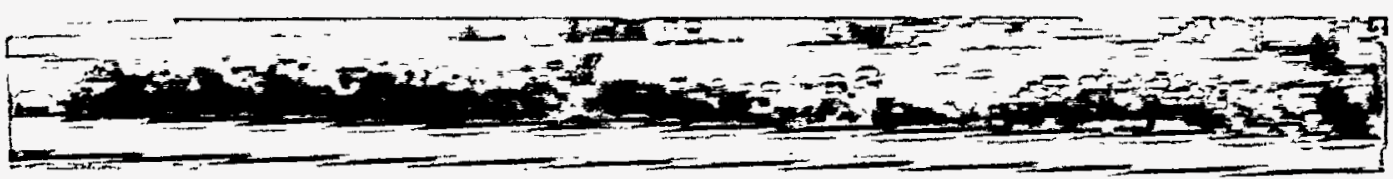

Segment 13 elevation $96-145 \mathrm{~cm}$ (38-57 inches).

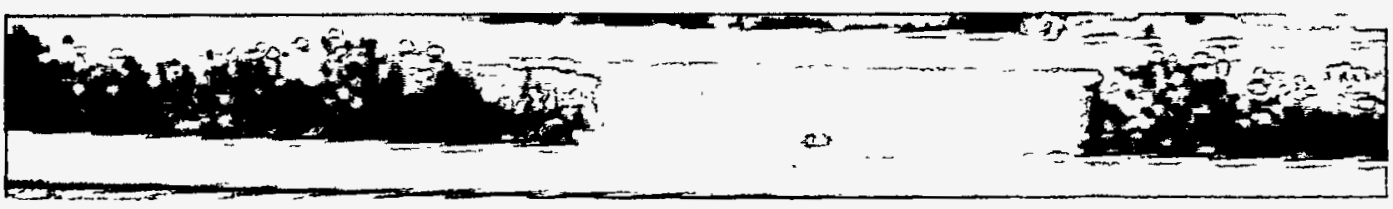

Segment 14 elevation $48-96 \mathrm{~cm}$ (19-38 inches).

Figure B.5. Core Samples from SY-103, Core 62. 


\section{Distribution}

No. of

Copies

Offsite

2 DOE Office of Scientific and

Technical Information

C. S. Abrams

1987 Virginia

Idaho Falls, ID 83404

D. Campbell

102 Windham Road

Oak Ridge, TN 37830

Charles W. Forsberg

Oak Ridge National Laboratory

P.O. Box 2008, MS-6495

Oak Ridge, TN 37831-6495

Argonne National Laboratory

Billy C. Hudson

P.O. Box 271

Lindsborg, KS 67456

M. S. Kazimi

Massachusetts Institute

of Technology

Department of Nuclear Engineering

77 Massachusetts Avenue

Cambridge, MA 02139

J. Louis Kovach

P.O. Box 29151

70000 Huntley Road

Columbus, OH 43229

Thomas S. Kress

102-B Newridge Road

Oak Ridge, TN 37830

Thomas E. Larson

2711 Walnut St.

Los Alamos, NM 87545

3 Los Alamos National Laboratory

P.O. Box 1663

Los Alamos, NM 87545

Attn: W. L. Kubic, K557

K. Pasamehmetoglu, K555

C. Unal, K575
No. of

Copies

D. Pepson

U.S. Department of Energy

Trevion II Building, EM-35

Washington, D.C. 20585-0002

Scott E. Slezak

806 Hermosa NE

Albuquerque, NM 87110

Dana A. Powers

Sandia National Laboratory

Nuclear Facilities Safety Department

MS-0744

Albuquerque, NM 87185-0744

J. Tseng

U.S. Department of Energy

Trevion II Building, EM-35

Washington, D.C. 20585-0002

\section{Onsite}

15 DOE Richland Operations Office

M. H. Campbell

S7-73

J. M. Gray (10)

S7-54

C. A. Groendyke

S7-54

J. C. Peschong

S7-53

G. W. Rosenwald

S7-54

D. L. Vieth

S7-54

47 Westinghouse Hanford Company
S. A. Barker
R2-11
W. B: Barton
R2-11
R. E. Bauer
L6-37
C. J. Benar
R2-12
R. J. Cash
S7-14
G. L. Dunford
A2-34
S. J. Eberlein
R2-12
R. F. Eggers
R2-12
D. L. Herting
T6-09
K. M. Hodgson
R2-11
J. R. Jewett
T6-09
G. D. Johnson (10)
N. W. Kirch
S7-15
J. R. Kristofzki.
R2-11
D. C. Larsen
T6-06
R1-51

Distr.1 
No. of Copies

J. A. Lechelt

R2-11

J: W. Lentsch (10)

S7-15

R. M. Marusich

H4-65

R. E. Mendoza

R1-51

D. M. Ogden

D. A. Reynolds

HO-34

G. R. Sawtelle

R2-11

A3-37

E. R. Siciliano

HO-31

T. I. Stokes

H5-09

L. M. Stock

S7-14

J. E. Van Beek

R3-27

R. J. Van Vleet

H4-63

J. R. White

H5-09

N. E. Wilkins

R2-11

$48 \quad$ Pacific Northwest National

Laboratory

J. M. Alzheimer

K5-22

Z. I. Antoniak

J. M. Bates

$\mathrm{K} 7-15$

S. Q. Bennett

P. R. Bredt

K7-15

K7-90

P7-25

M. E. Brewster
No. of

Copies

J. W. Brothers (5)

K5-22

G. Chen

K5-12

P. A. Gauglitz

R. H. Gallucci

W. B. Gregory

P7-41

K8-07

K7-22.

L. A. Klevgard

L. A. Mahoney

K5-16

K7-15

P. A. Meyer

T. E. Michener

K7-15

$\mathrm{K} 7-15$

F. E. Panisko

P8-34

L. R. Pederson

K2-44

L. M. Peurrung

M. R. Powell

P7 -41

K. P. Recknagle .

P7-19

K7-15

D. R. Rector

K7-15

H. C. Reid

K7-15

P. A. Scott

P7-43

A. Shekarriz

K7-15

C. L. Shepard

K5-25

C. W. Stewart (10)

K7-15

G. Terrones

J. M. Tingey

P. D. Whitney

K7-15

P7-25

K5-12

Information Release (5) K6-06 